Florida International University

FIU Digital Commons

FIU Electronic Theses and Dissertations

University Graduate School

3-12-2009

\title{
Variables Affecting the Collection and Preservation of Human Scent Components through Instrumental and Biological Evaluations
}

Davia Tamar Hudson

Florida International University, dhuds001@fiu.edu

DOI: $10.25148 /$ etd.FI10022521

Follow this and additional works at: https://digitalcommons.fiu.edu/etd

\section{Recommended Citation}

Hudson, Davia Tamar, "Variables Affecting the Collection and Preservation of Human Scent Components through Instrumental and Biological Evaluations" (2009). FIU Electronic Theses and Dissertations. 201.

https://digitalcommons.fiu.edu/etd/201

This work is brought to you for free and open access by the University Graduate School at FIU Digital Commons. It has been accepted for inclusion in FIU Electronic Theses and Dissertations by an authorized administrator of FIU Digital Commons. For more information, please contact dcc@fiu.edu. 


\section{FLORIDA INTERNATIONAL UNIVERSITY}

Miami, Florida

\section{VARIABLES AFFECTING THE COLLECTION AND PRESERVATION OF HUMAN SCENT COMPONENTS THROUGH INSTRUMENTAL AND BIOLOGICAL \\ EVALUATIONS}

A dissertation submitted in partial fulfillment of the

requirements for the degree of

DOCTOR OF PHILOSOPHY

in

CHEMISTRY

by

Davia Tamar Hudson

2009 


\section{To: Dean Kenneth Furton}

College of Arts and Sciences

This dissertation, written by Davia Tamar Hudson, and entitled Variables Affecting the Collection and Preservation of Human Scent Components through Instrumental and Biological Evaluations, having been approved in respect to style and intellectual content, is referred to you for judgment.

We have read this dissertation and recommend that it be approved.

$\begin{array}{r}\hline \text { Jose Almirall } \\ \hline \text { Bruce McCord } \\ \hline \text { DeEtta Mills } \\ \hline \text { Watson Lees }\end{array}$

Kenneth Furton, Major Professor

Date of Defense: March 12, 2009

The dissertation of Davia Tamar Hudson is approved.

\begin{tabular}{r} 
Dean Kenneth Furton \\
College of Arts and Sciences \\
\hline Dean George Walker \\
University Graduate School
\end{tabular}

Florida International University, 2009 
(C) Copyright 2009 by Davia Tamar Hudson

All rights reserved. 


\section{DEDICATION}

I dedicate this dissertation to my mother, Yvonne Pallard and my husband, Howard Holness. Without their support, patience, encouragement and most of all their love, the completion of this work would not have been possible. I also dedicate this work to the memory of my grandmother, Francella Pallard, who passed away before it was completed. 


\section{ACKNOWLEDGMENTS}

I wish to thank my committee members who were more than generous with their expertise and time. I would like to say special thanks to my major professor, Dr Kenneth Furton, for his patience with me throughout this entire process. Thanks to Dr Jose Almirall, Dr Bruce McCord, Dr DeEtta Mills and Dr Watson Lees for serving on my committee. I would also like to thank Dr Adee Schoon, for her commitment to this project, and Marc Rutzerveld of the Netherlands National Police Agency for the financial support that was provided.

I would also like to thank my family members, who provided endless support throughout this process, especially my uncles, Terrence and Clifton Pallard, my aunts, Charmaine, Len and Elaine Pallard, my cousin Novadeen Pallard and my grandfather Rufus Pallard. I would also like to thank my in-laws especially Roy and Edith Stultz who were most accommodating when I relocated to Florida to pursue this degree. I would also like to thank my many friends and church family from Jamaica who were always encouraging me to do my best, especially Davina and Mirando Lal, Kelly Lawson, Kennisha Robinson and Kayanne McCook. 


\begin{abstract}
OF THE DISSERTATION
VARIABLES AFFECTING THE COLLECTION AND PRESERVATION OF HUMAN SCENT COMPONENTS THROUGH INSTRUMENTAL AND BIOLOGICAL
\end{abstract}

EVALUATIONS

by

Davia Tamar Hudson

Florida International University, 2009

Miami, Florida

Professor Kenneth Furton, Major Professor

In certain European countries and the United States of America, canines have been successfully used in human scent identification. There is however, limited scientific knowledge on the composition of human scent and the detection mechanism that produces an alert from canines. This lack of information has resulted in successful legal challenges to human scent evidence in the courts of law.

The main objective of this research was to utilize science to validate the current practices of using human scent evidence in criminal cases. The goals of this study were to utilize Headspace Solid Phase Micro Extraction Gas Chromatography Mass Spectrometry (HSSPME-GC/MS) to determine the optimum collection and storage conditions for human scent samples, to investigate whether the amount of DNA deposited upon contact with an object affects the alerts produced by human scent identification canines, and to create a prototype pseudo human scent which could be used for training purposes.

Hand odor samples which were collected on different sorbent materials and exposed to various environmental conditions showed that human scent samples should be stored 
without prolonged exposure to UVA/UVB light to allow minimal changes to the overall scent profile. Various methods of collecting human scent from objects were also investigated and it was determined that passive collection methods yields ten times more VOCs by mass than active collection methods.

Through the use of polymerase chain reaction (PCR) no correlation was found between the amount of DNA that was deposited upon contact with an object and the alerts that were produced by human scent identification canines. Preliminary studies conducted to create a prototype pseudo human scent showed that it is possible to produce fractions of a human scent sample which can be presented to the canines to determine whether specific fractions or the entire sample is needed to produce alerts by the human scent identification canines. 


\section{TABLE OF CONTENTS}

CHAPTER

PAGE

1. INTRODUCTION. 1

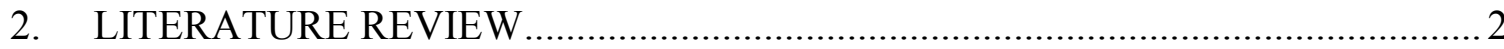

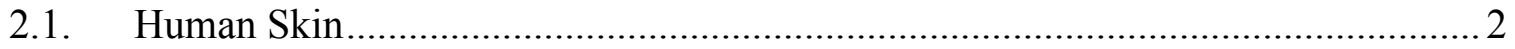

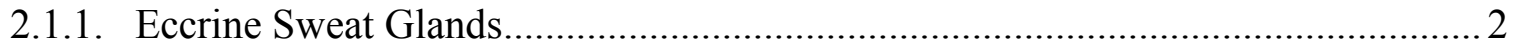

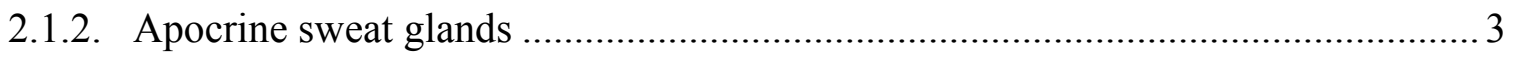

2.1.3. Sebaceous glands................................................................................... 3

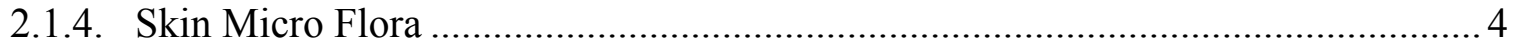

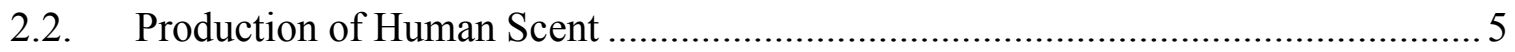

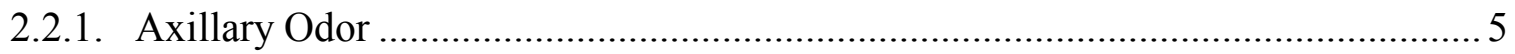

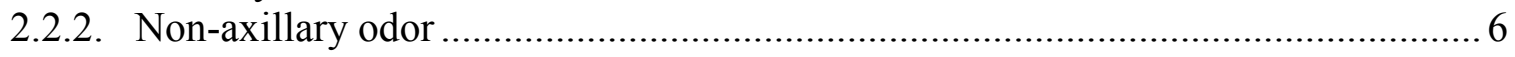

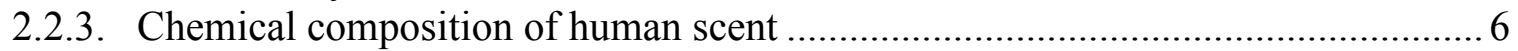

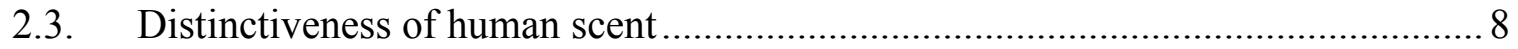

2.3.1. Human scent and the major histocompatibility complex (MHC) ……………..... 8

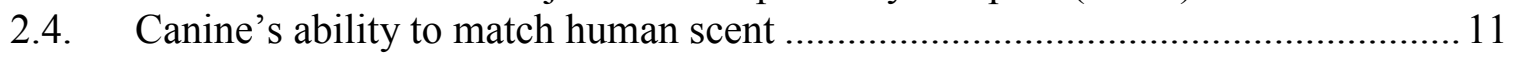

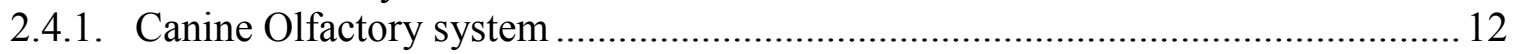

2.5. Canines used for human scent identification.................................................... 14

2.5.1. Human scent identification canines.............................................................. 14

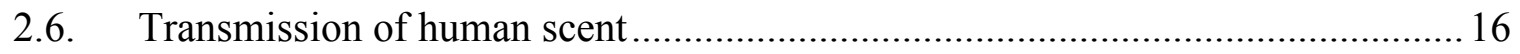

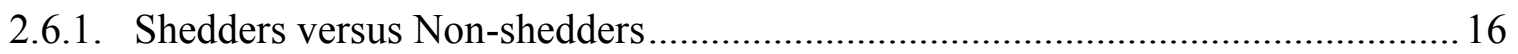

2.7. Collection of human scent evidence............................................................... 18

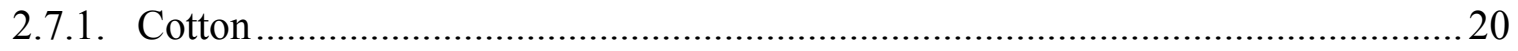

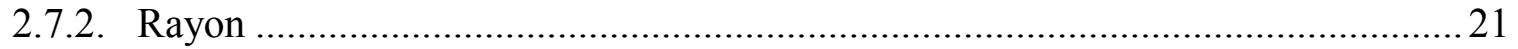

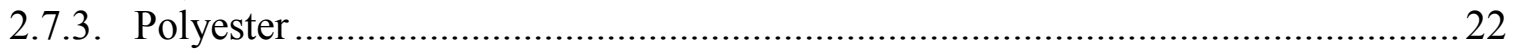

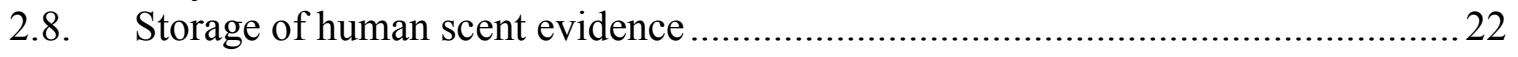

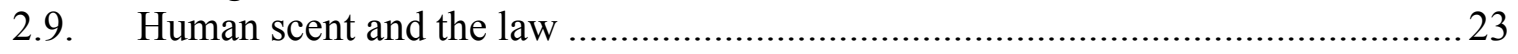

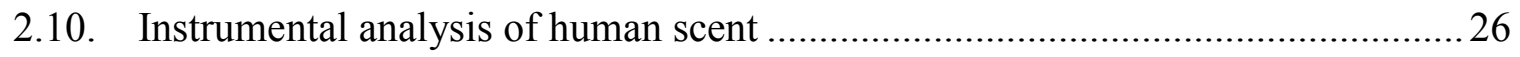

2.10.1. Solid Phase Micro Extraction (SPME) .......................................................... 26

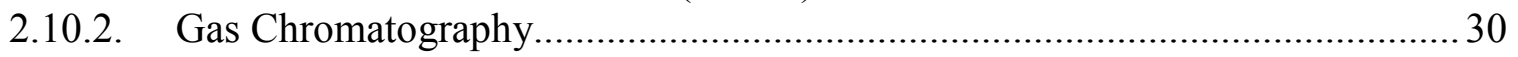

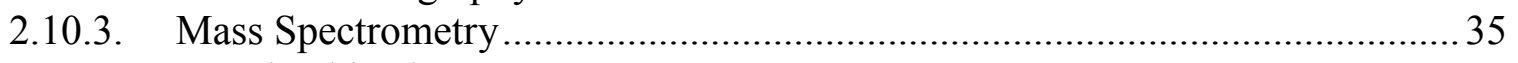

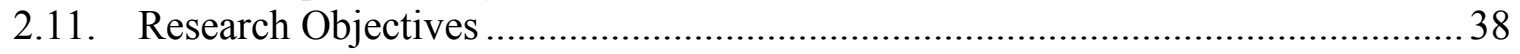

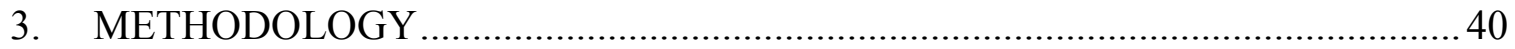

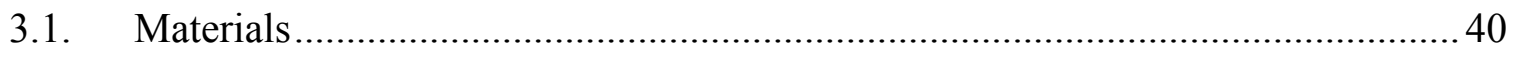

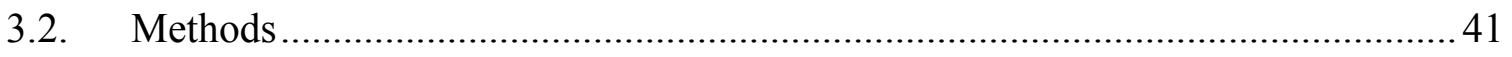

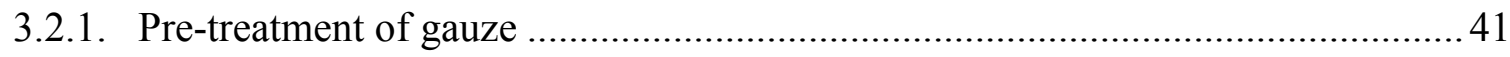

3.2.2. Direct hand sampling procedure ……………............................................. 42

3.2.3. SPME-GC/MS procedure ................................................................................ 42

3.2.4. Development of a Selected Ion Monitoring Method (SIM) ................................. 43

3.2.5. Instrumental and biological evaluation of the effect of storage conditions on 


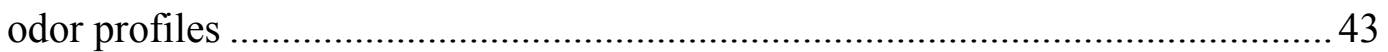

3.2.6. Trapping and releasing capabilities of different sorbent materials ...................... 47

3.2.7. Collection of human scent from objects......................................................... 48

3.2.8. Stainless steel bar hand sampling procedure...................................................52

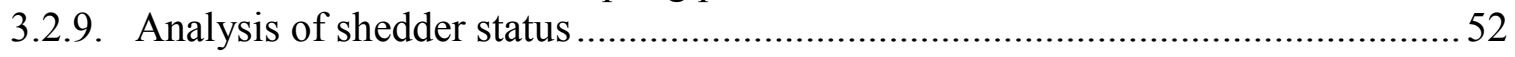

3.2.10. Creation of Prototype Pseudo Human Scent ................................................... 55

3.2.11. Discriminating between VOCs in hand odor samples from twins using

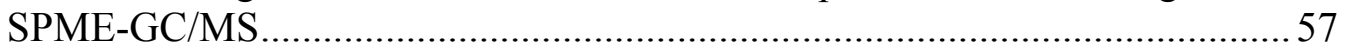

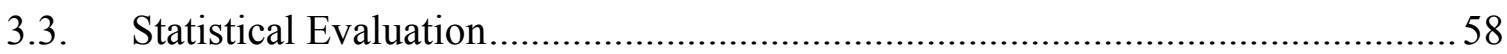

3.3.1. Three Dimensional Covariance Mapping …………….....................................58

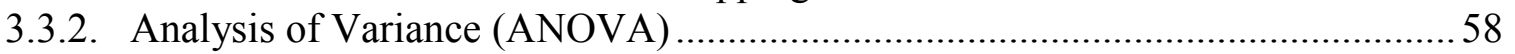

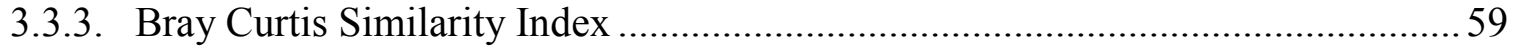

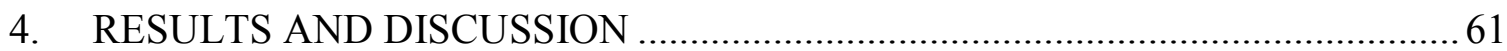

4.1. Optimization of collection and analysis methods for human scent samples..........61

4.1.1. Optimization of a full scan GC/MS method.......................................................64 64

4.1.2. Development of a selected ion monitoring (SIM) GC/MS method .......................68

4.1.3. Optimization of hand odor sample collection method ........................................ 78

4.2. Evaluation of the effect of different storage conditions on odor profiles .............79

4.2.1. Instrumental Evaluations using SPME-GC/MS ............................................... 79

4.2.2. Biological evaluations using human scent identification canines ....................... 102

4.3. Trapping and releasing capabilities of sorbent materials ................................... 105

4.4. Identification of the best procedure to follow in collecting human traces from

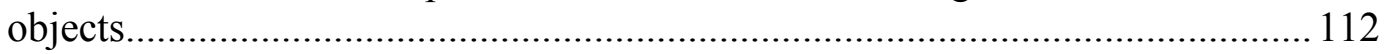

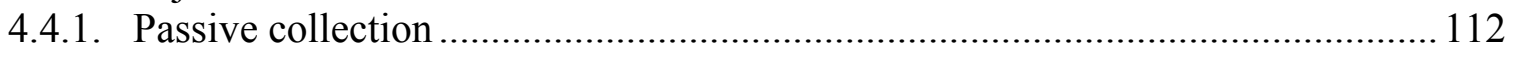

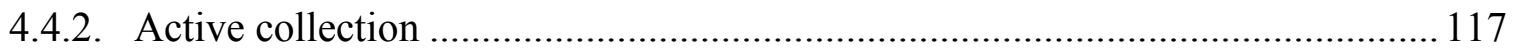

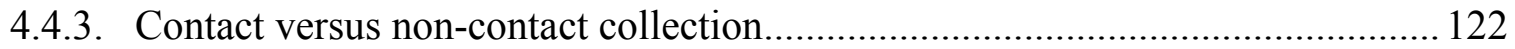

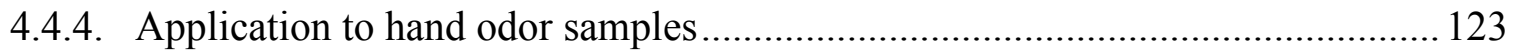

4.4.5. Headspace extractions using Activated Charcoal Strips (ACS).......................... 133

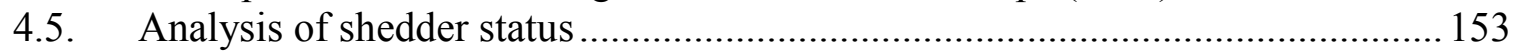

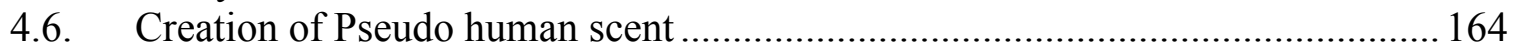

4.7. Discriminating between the hand odor of monozygotic and dizygotic twins

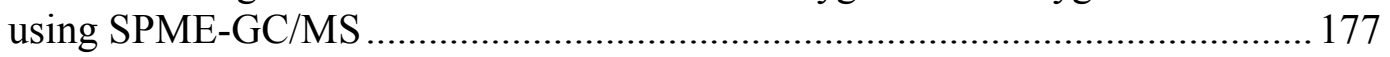

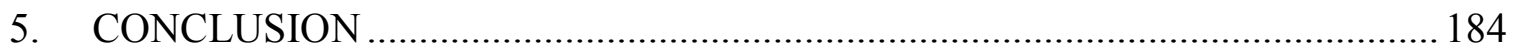

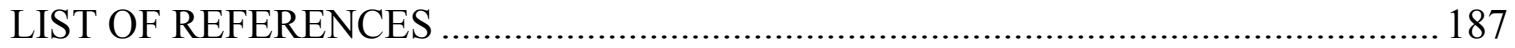

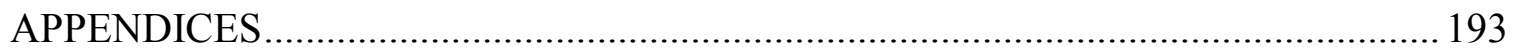

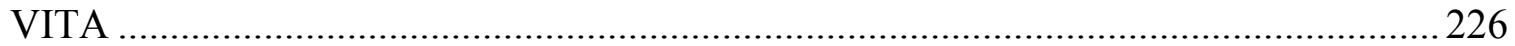




\section{LIST OF TABLES}

TABLE

PAGE

Table 1: Examples of stationary phases used for capillary columns............................. 34

Table 2: Weather conditions for the duration of the human scent identification lineup ... 47

Table 3: Samples collected from subjects for shedder/non-shedder analyses .................53

Table 4: Number of telogen shed hairs obtained from eleven individuals...................... 54

Table 5: List of compounds previously reported as human scent compounds and their frequency of occurrence in a population study

Table 6: Properties of the compounds used for optimization of the GC/MS procedure for optimal separation of human scent samples

Table 7: Retention times and qualifying ions of standard compounds used to develop GC/MS SIM method

Table 8: Limits of detection and quantitation of Agilent 6890/5973 GC/MS using full scan and SIM methods

Table 9: Comparison between slopes of calibration curves for human scent compounds analyzed in full scan and SIM mode.

Table 10: Calculated similarity, S, between hand odor samples collected from the above male subject on Dukal brand gauze and stored at room temperature over a 7 week period (multiple headspace extractions)

Table 11: Calculated similarity, $\mathrm{S}$, between hand odor samples collected from the above male subject on Dukal brand gauze and stored at $-80{ }^{0} \mathrm{C}$ over a 7 week period (multiple headspace extractions).

Table 12: Calculated similarity, S, between hand odor samples collected from the above male subject on Dukal brand gauze and stored in the dark over a 7 week period (multiple headspace extractions).

Table 13: Calculated similarity, S, between hand odor samples collected from the above male subject on Dukal brand gauze and stored in the presence of UVA/UVB light over a 7 week period (multiple headspace extractions).

Table 14: Calculated similarity, S, between hand odor samples collected on different sorbent materials and stored at room temperature over a 7 week period (week 0 vs. 
weeks $0,1,3,5$ and 7 )

Table 15: Calculated similarity, S, between hand odor samples collected on different sorbent materials and stored at room temperature over a 7 week period (week 7 vs. weeks $7,5,3,1$ and 0 ).

Table 16: Calculated similarity, S, between hand odor samples collected on different sorbent materials and stored at -80 degrees Celsius over a 7 week period (week 0 vs. weeks $0,1,3,5$ and 7 )

Table 17: Calculated similarity, S, between hand odor samples collected on different sorbent materials and stored at -80 degrees Celsius over a 7 week period (week 7 vs. weeks $7,5,3,1$ and 0$)$.

Table 18: Calculated similarity, S, between hand odor samples collected on different sorbent materials and stored in the dark over a 7 week period (week 0 vs. weeks 0,1 , 3,5 and 7).

Table 19: Calculated similarity, S, between hand odor samples collected on different sorbent materials and stored in the dark over a 7 week period (week 7 vs. weeks 7, 5, $3,1$ and 0$)$......

Table 20: Calculated similarity, S, between hand odor samples collected on different sorbent materials and stored in the presence of UVA/UVB Light over a 7 week period (week 0 vs. weeks $0,1,3,5$ and 7)

Table 21: Calculated similarity, S, between hand odor samples collected on different sorbent materials and stored in the presence of UVA/UVB Light over a 7 week period (week 7 vs. weeks 7, 5, 3, 1 and 0 )

Table 22: Preliminary canine trials matching fresh hand odor samples (week zero) to aged hand odor samples (week five and week seven).

Table 23: Canine trials matching fresh (week 0 ) hand odor samples to aged hand odor samples which were stored at room temperature

Table 24: Canine trials matching fresh (week 0 ) hand odor samples to aged hand odor samples which were stored at $-80{ }^{\circ} \mathrm{C}$

Table 25: Canine trials matching fresh (week 0) hand odor samples to aged hand odor samples which were stored in the dark.

Table 26: Canine trials matching fresh (week 0) hand odor samples to aged hand odor samples which were stored in the presence of UVA/UVB light. 
Table 27: Properties of different sorbent materials

Table 28: Recovery of human scent VOCs from the headspace of a $500 \mathrm{ml}$ glass jar containing spiked stainless steel bars via 21 hour headspace SPME followed by GC/MS

Table 29: Comparison between mass of VOCs transferred from scented bars to gauze to SPME fiber and LOD of 6890/5973 GC/MSD

Table 30: Table showing the number of human scent compounds extracted in 0.5 hour from the headspace of a $10 \mathrm{ml}$ glass vial using ACS

Table 31: Table showing the number of human scent compounds extracted in 1 hour from the headspace of a $10 \mathrm{ml}$ glass vial using ACS

Table 32: Table showing the number of human scent compounds extracted in 3 hours from the headspace of a $10 \mathrm{ml}$ glass vial using ACS

Table 33: Table showing the number of human scent compounds extracted in 6 hours from the headspace of a $10 \mathrm{ml}$ glass vial using ACS

Table 34: Table showing the number of human scent compounds extracted in 12 hours from the headspace of a $10 \mathrm{ml}$ glass vial using ACS

Table 35: Table showing the number of human scent compounds extracted in 24 hours from the headspace of a $10 \mathrm{ml}$ glass vial using ACS 145

Table 36: Table showing the number of human scent compounds extracted from the headspace of a $10 \mathrm{ml}$ glass vial using a 21 hour SPME extraction. 


\section{LIST OF FIGURES}

FIGURE

PAGE

Figure 1: Human Scent Identification Line up...................................................... 15

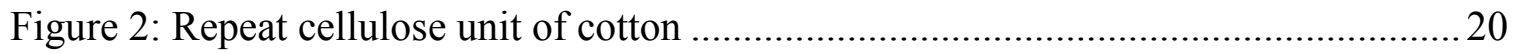

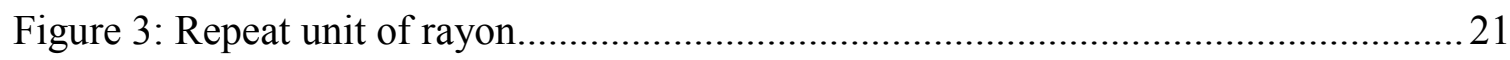

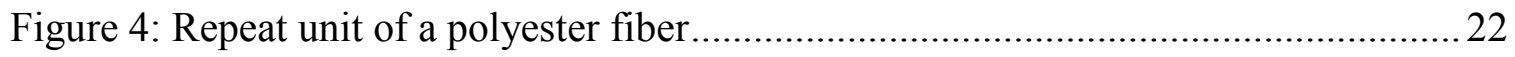

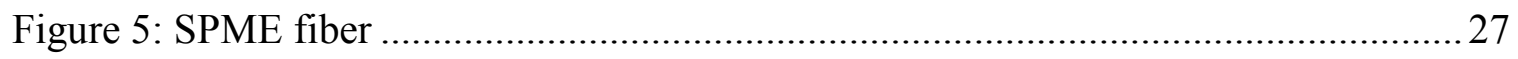

Figure 6: Schematic representation of different types of SPME extractions ................... 28

Figure 7: Block diagram of a gas chromatograph ............................................... 31

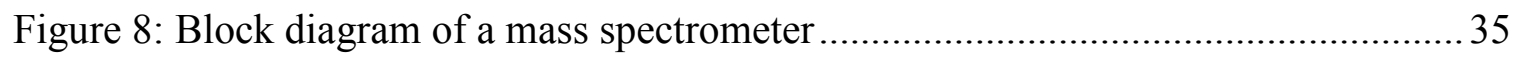

Figure 9: Containers for storage of hand odor samples in the dark and in the presence

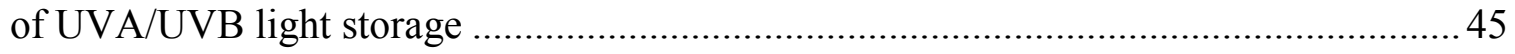

Figure 10: Passive collection of VOCs from objects (a) Contact (b) Non-contact.......... 49

Figure 11: Schematic representation of STU-100 showing metal plate and cardboard

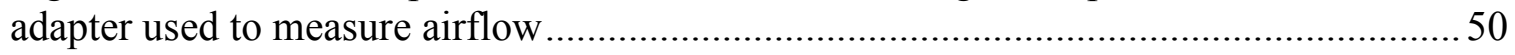

Figure 12: Active collection of VOCs from objects (a) Contact (b) Non-contact ............51

Figure 13: Picture showing collection of human scent compound fractions using a GC/FID.

Figure 14: Examples of different temperature ramps evaluated to obtain optimum

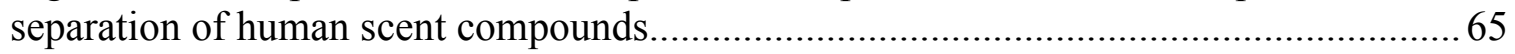

Figure 15: Abundances obtained for standard human scent compounds analyzed using mass spectrometer scan ranges of 45-550 and 39-300.

Figure 16: Ratio of standard human scent compounds analyzed using mass spectrometer scan ranges of 45-550 and 39-300

Figure 17: Chromatogram showing VOCs present in hand odor sample collected on Dukal brand gauze and analyzed via SPME-GC/MS using a full scan method 75 
Figure 18: Chromatogram showing VOCs present in hand odor sample collected on Dukal brand gauze and analyzed via SPME-GC/MS using a SIM method 76

Figure 19: Common VOCs present in hand odor sample collected from a male subject and analyzed by SPME-GC/MS in full scan mode.

Figure 20: Common VOCs present in hand odor sample collected from a male subject and analyzed by SPME-GC/MS in SIM mode.

Figure 21: Comparison between common Volatile organic compounds present in hand odor samples collected from a female subject outdoors and indoors. 79

Figure 22: Comparison between common VOCs present in hand odor samples collected on Dukal gauze from a male subject and stored at room temperature over seven weeks (multiple headspace extractions)

Figure 23: Comparison between common VOCs present in hand odor samples collected on Dukal gauze from a male subject and stored at $-80{ }^{\circ} \mathrm{C}$ over seven weeks (multiple headspace extractions)

Figure 24: Comparison between common VOCs present in hand odor samples collected on Dukal gauze from a male subject and stored in the dark over seven weeks (multiple headspace extractions)

Figure 25: Comparison between common VOCs present in hand odor samples collected on Dukal gauze from a male subject and stored in the UVA/UVB light over seven weeks (multiple headspace extractions).

Figure 26: Comparison between common VOCs present in hand odor samples collected on Dukal gauze from a female subject and stored in different types of $10 \mathrm{ml}$ vials at room temperature over seven weeks (multiple headspace extractions). 85

Figure 27: Comparison between common VOCs present in hand odor samples collected on Dukal gauze from a female subject and stored in $4{ }^{0} \mathrm{C}$ over seven weeks.... 86

Figure 28: Graph showing effects of multiple headspace extractions from the same vial.

Figure 29: Arrhenius plot showing multiple headspace extractions from the same vial .. 87

Figure 30: Comparison between common VOCs present in hand odor samples collected on Dukal gauze from a male subject and stored at room temperature (single headspace extractions).

Figure 31: Comparison between common VOCs present in hand odor samples 
collected on Dukal gauze from a male subject and stored at $-80{ }^{0} \mathrm{C}$ (single headspace extractions)

Figure 32: Comparison between common VOCs present in hand odor samples collected on Dukal gauze from a male subject and stored in the dark (single headspace extractions).

Figure 33: Comparison between common VOCs present in hand odor samples collected on Dukal gauze from a male subject and stored in the presence of UVA/UVB light (single headspace extractions)

Figure 34: Comparison between common VOCs present in hand odor samples collected on Kings Cotton from a female subject and stored in at room temperature (single headspace extractions).

Figure 35: Comparison between common VOCs present in hand odor samples collected on Kings Cotton from a female subject and stored at $-80{ }^{0} \mathrm{C}$ (single headspace extractions)

Figure 36: Comparison between common VOCs present in hand odor samples collected on Kings Cotton from a female subject and stored in the dark (single headspace extractions).

Figure 37: Comparison between common VOCs present in hand odor samples collected on Kings Cotton from a female subject and stored in the presence of UVA/UVB light (single headspace extractions)

Figure 38: Comparison between common VOCs present in hand odor samples collected on Johnson \& Johnson Gauze from a female subject and stored at room temperature (single headspace extractions).....

Figure 39: Comparison between common VOCs present in hand odor samples collected on Johnson \& Johnson Gauze from a female subject and stored at $-80{ }^{\circ} \mathrm{C}$ (single headspace extractions).

Figure 40: Comparison between common VOCs present in hand odor samples collected on Johnson \& Johnson Gauze from a female subject and stored in the dark (single headspace extractions).

Figure 41: Comparison between common VOCs present in hand odor samples collected on Johnson \& Johnson Gauze from a female subject and stored in the presence of UVA/UVB light (single headspace extractions).

Figure 42: VOCs present in hand odor samples collected from a male subject on different sorbent materials. 
Figure 43: VOCs present in hand odor samples collected from a female subject on different sorbent materials.

Figure 44: SEM Images of (a) Dukal brand gauze (b) Johnson and Johnson brand gauze (cotton blend) (c) Kings Cotton (Resolution x25)

Figure 45: Average mass of VOCs recovered from positive control and sorbent materials

Figure 46: Average mass of functional groups recovered from each sorbent material... 110

Figure 47: Volatile Organic Compounds collected on Dukal Brand Gauze from objects via a passive contact collection method.

Figure 48: Volatile Organic Compounds collected on Dukal Brand Gauze from objects using a passive non- contact collection method

Figure 49: Volatile Organic Compounds collected on Kings Cotton from objects via a passive contact collection method

Figure 50: Volatile Organic Compounds collected on Kings Cotton from objects via a passive non-contact collection method

Figure 51: Volatile Organic Compounds collected on Johnson \& Johnson brand gauze from objects via a passive contact collection method

Figure 52: Volatile Organic Compounds collected on Johnson \& Johnson brand gauze from objects via a passive non-contact collection method.

Figure 53: Flow rates of STU-100 with and without sorbent materials

Figure 54: Volatile Organic Compounds collected on Dukal brand gauze from objects using an active contact collection method.

Figure 55: Volatile Organic Compounds collected on Dukal brand gauze from objects using an active non-contact collection method

Figure 56: Volatile Organic Compounds collected on Kings Cotton from objects using an active contact collection method

Figure 57: Volatile Organic Compounds collected on Kings Cotton from objects using an active non-contact collection method

Figure 58: Volatile Organic Compounds collected on Johnson and Johnson brand 
gauze from objects using an active contact collection method

Figure 59: Volatile Organic Compounds collected on Johnson and Johnson brand gauze from objects using an active contact collection method

Figure 60: Comparison between maximum mass of human scent VOCs recovered on the three different sorbent materials using passive collection methods

Figure 61: Comparison between maximum mass of human scent VOCs recovered on the three different sorbent materials using active collection methods

Figure 62: Common VOCs present in hand odor samples collected on Dukal brand gauze from a male subject using the direct hand odor collection method

Figure 63: Common VOCs present in hand odor samples collected on from scented stainless steel bars onto Dukal brand gauze from a male subject using the passive hand odor collection method.

Figure 64: Common VOCs present in hand odor samples collected from a scented stainless steel bar onto Dukal brand gauze from a male subject using the active hand odor collection method

Figure 65: Common VOCs present in hand odor samples collected on Kings Cotton from a male subject using the direct hand odor collection method.

Figure 66: Common VOCs present in hand odor samples collected on from scented stainless steel bars onto Kings Cotton from a male subject using the passive hand odor collection method

Figure 67: Common VOCs present in hand odor samples collected from a scented stainless steel bar onto Kings Cotton from a male subject using the active hand odor collection method

Figure 68: Common VOCs present in hand odor samples collected on Johnson and Johnson Brand Gauze from a male subject using the direct hand odor collection method

Figure 69: Common VOCs present in hand odor samples collected from scented stainless steel bars onto Johnson and Johnson Brand Gauze from a male subject using the passive hand odor collection method

Figure 70: Common VOCs present in hand odor samples collected from a scented stainless steel bar onto Johnson and Johnson Brand Gauze from a male subject using the active hand odor collection method. 
Figure 71: Graph showing optimum SPME extraction time for human scent VOCs

from the headspace of a $500 \mathrm{ml}$ glass jar

Figure 72: Chromatogram of blank Activated Charcoal Strip which was eluted with carbon disulfide and analyzed by GC/MS.

Figure 73: Chromatograms obtained for 0.5 hour ACS extraction of human scent VOCs present in the headspace of a $10 \mathrm{ml}$ glass vial analyzed using GC/MS

Figure 74: Chromatograms obtained for 1 hour ACS extraction of human scent VOCs present in the headspace of a $10 \mathrm{ml}$ glass vial analyzed using GC/MS 150

Figure 75: Chromatograms obtained for 3 hour ACS extraction of human scent VOCs present in the headspace of a $10 \mathrm{ml}$ glass vial analyzed using GC/MS

Figure 76: Chromatograms obtained for 6 hour ACS extraction of human scent VOCs present in the headspace of a $10 \mathrm{ml}$ glass vial analyzed using GC/MS .

Figure 77: Chromatograms obtained for 12 hour ACS extraction of human scent VOCs present in the headspace of a $10 \mathrm{ml}$ glass vial analyzed using GC/MS .

Figure 78: Chromatograms obtained for 24 hour ACS extraction of human scent VOCs present in the headspace of a $10 \mathrm{ml}$ glass vial analyzed using GC/MS .

Figure 79: Chromatograms obtained for 21 hour headspace SPME of human scent VOCs present in the headspace of a $10 \mathrm{ml}$ glass vial analyzed using GC/MS .

Figure 80: Mass of human DNA recovered from washed and unwashed hands

Figure 81: Average mass of nuclear DNA present in hand odor samples collected from individuals who are easily identified by canines and individuals who are difficult for canines to identify.

Figure 82: Nuclear DNA present in telogen shed head hair from the persons easily identified and the persons difficult for canines to identify

Figure 83: Average mass of microbial DNA present in hand odor samples collected from individuals who are easily identified by canines and individuals who are difficult for canines to identify.....

Figure 84: Multi-dimensional scaling plot of Bray Curtis Similarity indices between microbial communities present in hand odor samples of individuals who are easily identified by canines and individuals who are difficult for canines to identify ...

Figure 85: Ratio of VOCs present in hand odor samples collected from a female 
subject and subjected to air transportation

Figure 86: VOCs present in the hand odor samples collected from individuals who are easily identified by canines and individuals who are difficult for canines to identify

Figure 87: Recurring VOCs present in the hand odor samples collected from individuals who are easily identified by canines and individuals who are difficult for canines to identify

Figure 88: Average masses of VOCs present in hand odor samples collected from individuals who are easily identified by canines and individuals who are difficult for canines to identify

Figure 89: Correlation between average mass of VOCs and the average mass of nuclear DNA present in hand odor samples.

Figure 90: Correlation between average mass of VOCs and the average mass of microbial DNA present in hand odor samples

Figure 91: Correlation between average mass of nuclear DNA and the average mass of microbial DNA present in hand odor samples

Figure 92: Overlaid chromatograms showing fractioned samples of a standard compound mixture obtained using a GC/MS connected to an ODP 165

Figure 93: Chromatogram showing the separation of human scent compounds using the $5890 \mathrm{GC} / \mathrm{FID}$

Figure 94: Schematic showing collection of fractions using the GC/FID

Figure 95: Overlaid chromatograms showing fractioned samples of a standard compound mixture obtained using a GC/FID followed by SPME-GC/MS analysis

Figure 96: Parts removed from FID to facilitate maximum trapping of VOCs onto gauze for fractionation 168

Figure 97: Overlaid chromatograms showing fractioned samples of a standard compound mixture obtained using a GC/FID (FID disassembled) followed by SPME-GC/MS analysis.... 169

Figure 98: Chromatogram showing human scent VOCs detected by GC/FID after injection by headspace sampler (initial trial) 
Figure 99: Chromatogram showing human scent VOCs detected by GC/FID after injection by headspace sampler (headspace sampler oven temperature increased) 171

Figure 100: Chromatogram showing human scent VOCs detected by GC/FID after injection by headspace sampler $(20 \mathrm{ml}$ glass vials replaced by $10 \mathrm{ml}$ glass vials $)$

Figure 101: Chromatogram showing human scent VOCs detected by GC/FID after injection by headspace sampler (purge off)

Figure 102: Comparison between area counts obtained when VOCs were introduced into GC/FID using a headspace sampler and SPME.

Figure 103: Fractions collected on Dukal brand gauze from single SPME injection onto GC/FID followed by SPME-GC/MS ....

Figure 104: Fractions collected on Dukal brand gauze from triple SPME injection onto GC/FID followed by SPME-GC/MS

Figure 105: Hand odor sample collected from a female subject, fractioned using GC/FID and collected on Dukal brand gauze followed by SPME-GC/MS analysis

Figure 106: Hand odor sample collected from a male subject, fractioned using GC/FID and collected on Johnson and Johnson brand gauze followed by SPME-GC/MS analysis

Figure 107: Hand odor sample collected from a female subject, fractioned using GC/FID and collected on Johnson and Johnson brand gauze followed by SPMEGC/MS analysis. 176

Figure 108: VOCs present in hand odor samples collected from a DZ boy and girl twin.

Figure 109: Dendrogram showing Bray Curtis Similarity between VOCs present in hand odor samples collected from a DZ boy and girl twin ....

Figure 110: VOCs present in hand odor samples collected from DZ twin girls

Figure 111: Dendrogram showing Bray Curtis Similarity between VOCs present in hand odor samples collected from DZ twin girls

Figure 112: VOCs present in hand odor samples collected from DZ twin boys

Figure 113: Dendrogram showing Bray Curtis Similarity between VOCs present in hand odor samples collected from DZ twin boys 180 
Figure 114: VOCs present in hand odor samples collected from MZ twin girls 181

Figure 115: Dendrogram showing Bray Curtis Similarity between VOCs present in hand odor samples collected from MZ twin girls

Figure 116: VOCs present in hand odor samples collected from MZ twin boys...... 182

Figure 117: Dendrogram showing Bray Curtis Similarity between VOCs present in hand odor samples collected from MZ twin boys

Figure 118: VOCs present in hand odor samples collected from MZ twin boys

Figure 119: Dendrogram showing Bray Curtis Similarity between VOCs present in hand odor samples collected from MZ twin boys

Figure 120: Calibration curve for Octane

Figure 121: Calibration curve for Furfural.

Figure 122: Calibration curve for 2-Furanmethanol 194

Figure 123: Calibration curve for Nonane

Figure 124: Calibration curve for Heptanal

Figure 125: Calibration curve for Propanedioic acid dimethyl ester 195

Figure 126: Calibration curve for Benzaldehyde .................................................... 196

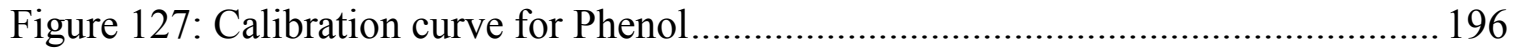

Figure 128: Calibration curve for 6-Methyl-5-hepten-2-one 197

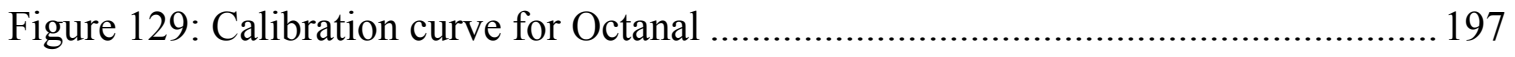

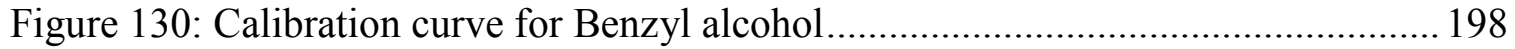

Figure 131: Calibration curve for 2-Octenal (E) ................................................. 198

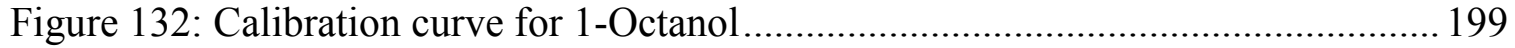

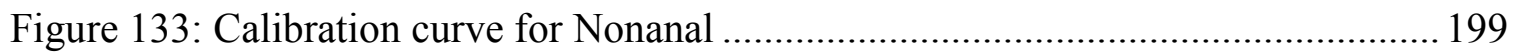

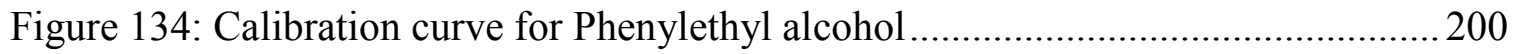


Figure 135: Calibration curve for Octanoic acid methyl ester 200

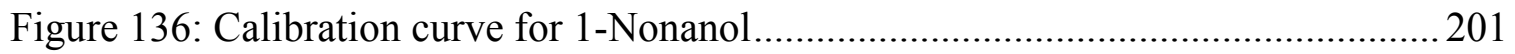

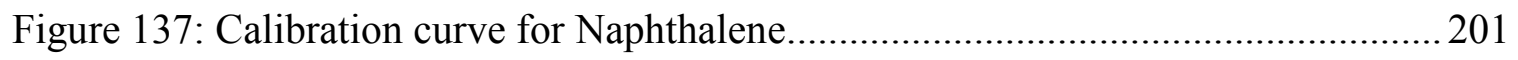

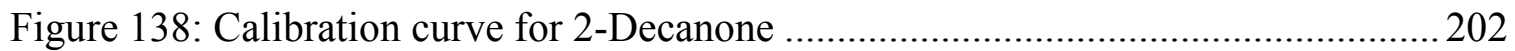

Figure 139: Calibration curve for Dodecane ...............................................................202

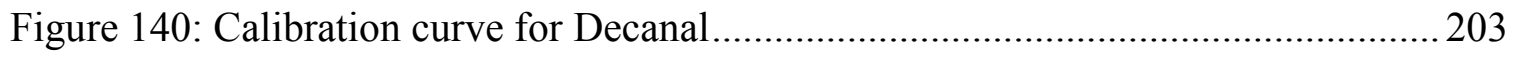

Figure 141: Calibration curve for Hexanedioic acid dimethy ester ................................2203

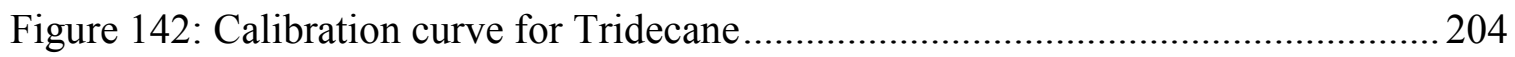

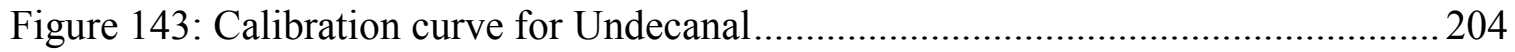

Figure 144: Calibration curve for n-Decanoic acid.......................................................2205

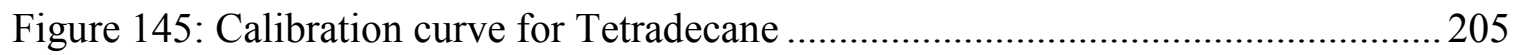

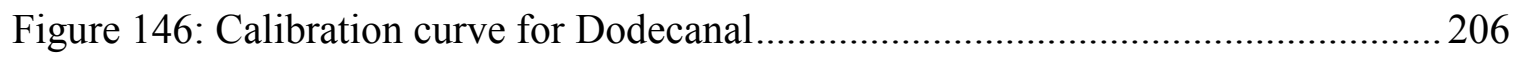

Figure 147: Calibration curve for 6, 10-Dimethyl-5, 9-undecadien-2-one ......................2206

Figure 148: Calibration curve for Pentadecane ................................................................ 207

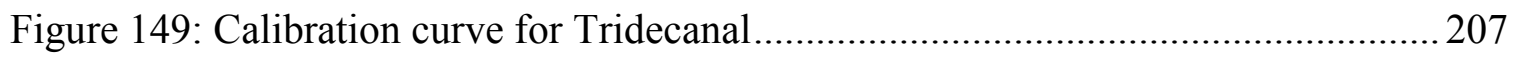

Figure 150: Calibration curve for Dodecanoic acid methyl ester ...................................2.208

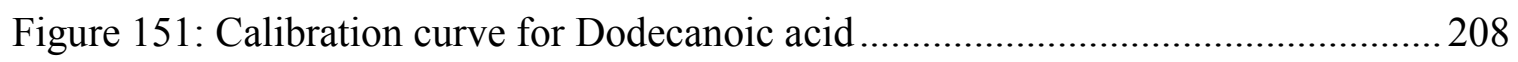

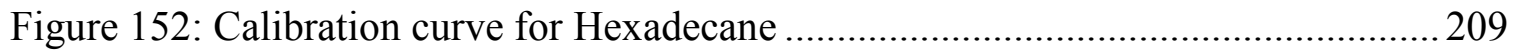

Figure 153: Calibration curve for Heptadecane …………………................................... 209

Figure 154: Calibration curve for Methyl tetradecanoate ……………........................2. 210

Figure 155: Calibration curve for Pentadecanoic acid ................................................2. 210

Figure 156: Calibration curve for Hexadecanoic acid methyl ester................................211 


\section{INTRODUCTION}

For over one hundred years, canines have been successfully used in human scent identification in certain European countries. In the United States, however, human scent identification has only recently gained acceptance. There is still limited scientific knowledge pertaining to the composition of human odor and the detection mechanisms that result in an alert from canines. Because of this lack of information, human scent evidence has been successfully challenged in the court of law.

Human scent identification is an identification based on canines matching human scent collected from a crime scene to scent collected from the hands of a possible suspect in what is known as a scent identification line-up. Scent identification line-ups are possible as persons have distinctive odors and also because canines have the ability to discriminate human scent.

There is currently no standardized or optimized method for the collection and storage of human scent evidence across the various law enforcement agencies. The main objective of this research was to utilize science to validate the current practice of using human scent evidence in court. Solid phase micro extraction gas chromatography mass spectrometry (SPME-GC/MS) was utilized to extract, separate and identify the volatile components of human scent, aiding in the determination of the changes that human scent undergoes when subjected to various methods of collection and preservation. This research not only included laboratory testing but also field testing for the improved performance of canines that are used for human scent identification. 


\section{LITERATURE REVIEW}

\subsection{Human Skin}

The human skin is a complex organ which is said to extend to approximately $2 \mathrm{~m}^{2}$ in area, is approximately $2.5 \mathrm{~mm}$ thick and has an average density of $1.1 \mathrm{~g} / \mathrm{cm}^{3}$. It serves many functions including; providing a physical permeable barrier, protection from infectious diseases, thermoregulation, sensation, ultraviolet (UV) protection, wound repair and regeneration, and outward physical appearance $(3,4)$. It is comprised of three (3) major layers which mediate these various functions; the epidermis, dermis and hypodermis.

The epidermis is a stratified non-vascularized layer with a thickness between 75 and 150 $\mu \mathrm{m}$ which acts as a physical barrier. It consists of four major "strata" which are primarily keratin producing cells. These cells progressively differentiate from the basal cells attached to the epidermal basement membrane, to the terminally differentiated stratum corneum which forms the outermost layer of the epidermis $(3,4)$. The dermis and the hypodermis maintain the structural integrity of the skin. The dermis can be between $2-4$ $\mathrm{mm}$ in thickness. It is an integrated network which incorporates the vascular, neural and lymphatic systems and its many accessory appendages which include the excretory and secretory glands (Eccrine, Apocrine and Sebaceous glands) (3, 4).

\subsubsection{Eccrine Sweat Glands}

The skin is made up of 3-4 million eccrine glands which produce a watery perspiration that serves to cool the body and maintain its core temperature at $37.5{ }^{\circ} \mathrm{C}$. These glands

are most abundant on the soles of the feet $\left(620 / \mathrm{cm}^{2}\right)$ and least abundant on the back 
$\left(64 / \mathrm{cm}^{2}\right)(3)$. Eccrine glands first appear in the 3.5 month old fetus on the surfaces of the hands and feet, in the fifth month they appear in the axillary skin and then a few weeks later elsewhere in the body (3). Eccrine sweat is a clear, odor free, colorless fluid that is predominantly water $(99.0-99.5 \%)$. The remainder consists of electrolytes such as sodium chloride $(\mathrm{NaCl})$, potassium $\left(\mathrm{K}^{+}\right)$and hydrogen carbonate $\left(\mathrm{HCO}_{3}{ }^{-}\right)$and other simple molecules such as lactate, urea, ammonia and calcium (4). Research as shown that the $\mathrm{NaCl}$ content of eccrine sweat is increased in individuals with cystic fibrosis and so has been used in the diagnosis of this disease (3).

\subsubsection{Apocrine sweat glands}

Apocrine glands are mainly confined to the regions of the axillae and perenium and become active only after puberty (3). Secretions from apocrine glands are thick and viscous with a milky consistency. This is the result of the high levels of fatty acids such as cholesterol, squalene, triglycerides, and androgens. When first secreted, it is odorless but it is believed that upon decomposition on the skin's surface by bacteria, it becomes odiferous $(3,4)$.

\subsubsection{Sebaceous glands}

Sebaceous glands are associated with hair follicles and are found all over the body except for the palms of the hands and the soles of the feet which have no hair follicles (4). Sebaceous glands develop in the thirteenth to sixteenth week of gestation in a fetus. There is on average about 100 sebaceous glands per square centimeter on the human body. On specific areas however, such as the middle of the chest, the back, face and scalp, this amount increases to almost 1000 (6). 
Sebaceous glands secrete an oily substance called sebum which is discharged when there is a complete breakdown of the gland and the products leaving contains squalene, cholesterol, cholesterol esters, wax esters and triglycerides. The composition of sebum varies from species to species; in humans, the lipid content consists of about $25 \%$ wax monoesters, $41 \%$ triglycerides, $16 \%$ free fatty acids, and $12 \%$ squalene (7). The lipids present in the sebaceous glands provide substrate for growth and metabolism of skin micro-organisms (7). The products of the sebaceous glands are distributed all over the body through movement and as a result, can be found in the palms and also on the feet (8).

\subsubsection{Skin Micro Flora}

The mixture of organisms which are found at any anatomical site is often referred to as the normal flora (9). The composition of the normal flora depends upon various factors including; genetics, age, sex, stress, nutrition and diet of the individual. Normal flora typically consists of a few eukaryotic fungi and protists, some methanogenic Archaea but bacteria are the most numerous and obvious microbial components of the normal flora (9). The micro flora of the skin is composed of bacteria such as micrococcadae, staphylococci, corynebacterium acnes, pityrosporum ovale, pityrosporum acnes, pityrosporum granulosum and propionibacteria (8).

The density and composition of the micro flora of the skin vary with anatomical locale. High densities of bacterial cells are found in high moisture content areas such as the axilla, groin and areas between the toes while the bacterial population at other sites is fairly low. The number of bacteria living on the human body of an average healthy adult 
is said to outnumber human cells 10:1 (10). A preliminary study conducted at New York University identified 182 bacterial species living on the skin. Subsequent studies have shown that the number of different species living on the skin could approach 500. It was discovered that approximately 10 species predominate which accounts for approximately $50 \%$ of the total population. Based on these findings, it was assumed that everyone could have a unique bacterial signature (10).

\subsection{Production of Human Scent}

The most common depiction of the creation of human odor is that of bacterial action on skin rafts in combination with glandular secretions of the skin, genetic differences, and diet. The human skin emits a wide variety of volatile metabolites some of which are odorous. Most of the research that has been conducted regarding the production of human odor has focused primarily on axillary odor as this is the main source of human body odor $(11,12)$.

\subsubsection{Axillary Odor}

It has been generally accepted that axillary odor is attributable to microbial biotransformation of odorless secretions into volatile odiferous compounds (11). Axillary odor has been shown to arise from a combination of glandular secretions particularly apocrine secretions and a stable population of micro-organisms. Studies conducted by Shelley et al. showed a lack of odor in pure apocrine sweat when it initially appears on the skin's surface (12). Over time, however, a foul odor develops which increases in intensity (12). In a series of experiments conducted by Shelley et al. it was determined that bacterial action was necessary for the production of odor from apocrine sweat (12). 
The main group of micro-organisms which are found in the human axillae are; staphylococci, aerobic corneforms, propionibacteria, micrococci and malassezia spp (13). The population densities of these microbial colonies can vary from $5 \times 10^{0}$ to $3 \times 10^{7}$ colony forming units per $\mathrm{cm}^{2}$. The aerobic bacteria Corynebacterium spp. and some Stapyllococcus spp. have been shown to carry out the biochemical conversions of proteins, lipids and steroids which are necessary for the generation of malodor (14). Short chain volatile fatty acids (VFAs) (C2-C5) and 16-androstene steroids are among the compounds suspected of causing malodor in the axillae (15).

\subsubsection{Non-axillary odor}

Non-axillary skin also produces VOCs which could possibly possess different biological origins than axillary odor. A number of researchers have examined non-axillary skin for VOCs to determine potential mosquito attractants and chemical markers to determine personal traits such as age and gender $(18,19,20)$. There has also recently been research conducted using non-axillary odor to discriminate between individuals as it is not as readily influenced by hormonal changes as axillary odor.

\subsubsection{Chemical composition of human scent}

Preliminary studies which were conducted suggested that the main chemical composition of axillary odor was due to four main odiferous steroids; $5 \alpha$-androst-16-en-3-one,

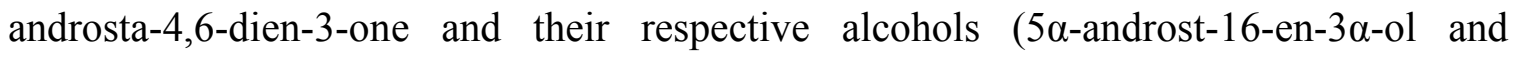
androsta-4,16-dien-3 $\alpha$-ol $)(13,15)$. Further studies conducted by Zeng et al. showed that the presence of $\mathrm{C} 6$ to $\mathrm{C} 11$ straight chain, branched and unsaturated acids are major contributors to axillary odor $(21,22)$. 
An extensive analysis of human skin emanations using gas chromatography mass spectrometry (GC/MS) was conducted to determine the volatile compounds which were potentially attracting mosquitoes. Samples were collected on glass beads which were held by the subjects followed by GC/MS analysis. Chromatograms were obtained that contained as many as 346 discernable peaks, 303 of which were identified. The compounds which were identified were from several different classes including; acids, alcohols, esters, aldehydes, aliphatics, aromatics, ketones, amides, amines and heterocycles (19).

Ostrovskaya et al. also conducted experiments that analyzed the headspace above nonaxillary skin using solid phase micro extraction gas chromatography mass spectrometry (SPME-GC/MS) (23). This study was not very extensive and their preliminary results showed that the odor above the skin consisted of several classes of compounds which included short chain aldehydes, long chain hydrocarbons and branched ketones (23). More recent studies conducted by Curran et al. dealt with the analysis of hand odor samples. Hand odor samples were chosen as this is the portion of the body which generally comes in contact with objects at a crime scene. Solid phase micro extraction gas chromatography mass spectrometry (SPME-GC/MS) was used to analyze the headspace (the gaseous constituents of a closed space above a liquid or a solid sample) of hand odor samples which were collected on sorbent materials and it was determined that the headspace consisted of various classes of compounds which were classified into seven groups; acids, alcohols, aldehydes, hydrocarbons, esters, ketones and nitrogen containing compounds. This study also showed that there was a sufficient degree of variability between a sixty subject population to allow for discrimination between the 
subjects (24). Other authors who have performed analysis of human scent VOCS have speculated that it is this compositional variability which provides trained dogs the ability to discriminate between individuals.

\subsection{Distinctiveness of human scent}

An individual's odor can be altered due to a number of different factors such as menstrual cycle in women, emotional state, health and possibly age. Despite these changes however, each individual may retain his or her own scent (26). Specific terms were "coined" by a research group at Florida International University to describe human scent. The primary odor of an individual is said to be comprised of constituents that are stable over time regardless of diet or environmental conditions; secondary odor is influenced by diet and environmental factors while the tertiary odor contains elements which are due to exogenous sources such as lotions, soaps or perfumes (27).

It may possibly be the presence of this primary odor which allows canines, when presented with human scent to recognize and discriminate between individuals with a certain degree of accuracy. Extensive studies are currently being undertaken by a number of research groups to determine if an individual's odor is influenced by genetics thus providing a consistent distinctive odor for individuals.

\subsubsection{Human scent and the major histocompatibility complex (MHC)}

If human scent is to be as individual as a fingerprint, then the VOCs that make up the scent have to be controlled by highly polymorphic genes. The major histocompatibility complex (MHC) is the most polymorphic set of alleles in the human genome (29). It is a matching system that is utilized by the immune system to distinguish between self and 
non-self, thus regulating the recognition of infectious diseases. Studies have shown that each species has only a very small number of MHC loci that are used for cell recognition. There are, however, a large number of alleles at each of these loci which provide many different combinations that result in no two individuals being identical in their MHC genotype except for identical twins (29). Investigations involving house mice and humans have indicated that the MHC genes influence not only mating preferences but also body odor (30). Several theories have been proposed to explain the influence of MHC genes on odor and these theories are discussed below (31).

\section{The MHC model hypothesis}

It has been suggested that the MHC molecules or fragments of the molecules produce odor when they occur in human sweat. However researchers have stated that this is highly unlikely as $\mathrm{MHC}$ molecules are proteins which are non-volatile and MHC determined odors are volatile (31).

\section{The peptide hypothesis}

This hypothesis states that the MHC molecules bind to allele specific subsets of peptides and the volatile metabolites provide the odorants. This hypothesis suggests that the MHC molecules are functioning as odor carriers and peptides are the precursors of the odorants (31).

\section{The micro flora hypothesis}

Another theory has been purported that the MHC genes control odor by influencing an individual's specific population of microbial flora which produces odor (31). 


\section{The peptide-micro flora hypothesis}

Two of the most convincing mechanisms were combined suggesting a fourth hypothesis: the MHC molecules influence odor by binding to specific subsets of peptides and these are transported to some microbe-harboring glands where their metabolites are made volatile by the micro flora which is present. This is said to be one of the most compelling hypotheses as it provides a mechanism through which an individual's odor can be influenced by the peptide binding properties of the MHC molecules. It also takes into account the role of the body's micro flora in the production of odor (31).

Research has shown that $\mathrm{MHC}$ molecules occur in urine and sweat and since they are polymorphic, they may contribute to the distinctive odor profiles of individuals. These MHC proteins which have been found in sweat and urine are large non-volatile proteins so it is unlikely that they provide the odorants. Studies which have been conducted using laboratory mice have shown that it is possible for these proteins to be metabolized and made volatile by microbes (32).

Most of the acids, alcohols and aldehydes found in skin secretions are believed to have originated from interactions between sebaceous gland secretions and cutaneous bacteria (7). Anaerobic bacteria that reside in the sebaceous gland ducts use lipases to liberate long chain acids from triglycerides. These triglycerides are then metabolized by aerobic bacteria into saturated and unsaturated acids, aldehydes and alcohols (7). Savelav et al. studied the interaction between human leukocyte antigen peptide (human MHC) and dermal microflora and their influence on 3-methylbutanal, a human axillary odor (33). Axillary odor was collected from eighteen subjects and analyzed for the presence of 3methylbutanal using SPME-GC/MS. An in vitro study was conducted to determine if 3- 
methylbutanal could be formed from the interaction between human leukocyte antigen peptides and dermal micro flora. The results of their studies show that different HLA peptides can alter the production of VOCs and also that individuals possess differences in microbial populations that influences the production of VOCs (33). The findings of this study agree with the hypothesis that genes and micro flora may influence formation of odor and the distinctiveness of VOCs produced.

\subsection{Canine's ability to match human scent}

Canines have a very sensitive olfactory system giving them the ability to detect low concentrations of odors (34). Due to their olfactory keenness, canines have been trained to detect and identify many different odor signatures including drugs, explosives, accelerants, cadavers and humans (34). Studies involving human scent have been conducted from as early as 1887 when George J. Romanes observed the ability of canines to discriminate between human body odors and background odors. He was able to determine that individual odors can be determined at great distances and under various environmental stresses and also that canines are not deterred by external influences such as fragrances.

Even though canines have the ability to distinguish between scents from different persons, research has shown that they have difficulties discriminating between identical twins (35). Research conducted by Kalmus showed that canines could discriminate between the odors of identical twins in a tracking task but failed to produce a correct match in an odor retrieval test (scent identification line up). Another study conducted by Hepper addressed the issue of genetic makeup and human odor using scent- 
discriminating canines and scent collected from three sets of twins (34). The test subjects included fraternal twin baby boys on the same diet, identical twin baby boys on the same diet, and identical adult twins on different diets. Dogs were able to correctly identify the fraternal baby twins on identical diets and the identical adult twins on different diets, 89 and 83.5 percent respectively. The dogs were able to correctly identify the identical twins on the same diet only 49 percent, which is no better than chance. This study showed that dogs could discriminate twins if they differed in genetic relatedness or environmental factors, but not in twin pairs which were identical in both factors $(43,46)$.

Finally, a study conducted by Harvey et al. showed that canines were not able to distinguish between the scent of one identical twin and a handkerchief scented by the other twin after it was laid out in a scent lineup comprising handkerchiefs scented by a number of different persons. The canines were however able to differentiate between odors of twins if environmental cues were different (35). Evidence from these twin studies suggests that odor is influenced by genetics as canines can readily distinguish between fraternal twins but are only able to differentiate between identical twins that are exposed to different environmental influences.

\subsubsection{Canine Olfactory system}

There are two types of epithelium inside the nose of mammals: the respiratory epithelium and the olfactory epithelium (8). The respiratory epithelium which functions to filter air entering the body possesses small hairs and is coated with mucus. The olfactory epithelium is found deep in the nasal cavity and is comprised of three types of cells:

olfactory sensory neurons, basal cells which are immature olfactory sensory neurons and 
support cells. The olfactory epithelium varies in size across different types of animals and as a result, animals can be divided into two groups; "macrosmates" are described as animals that possess excellent odor perception while "microsmates" are described as animals with poor odor perception. A German Shepherd Dog has an olfactory epithelium that is $150-170 \mathrm{~cm}^{2}$ while humans have an olfactory epithelium of approximately $5 \mathrm{~cm}^{2}$. As a result of the difference in the size of the olfactory epithelium between human and dog, it is believed that for some odors, dogs are 10,000 times more sensitive than humans $(8)$.

The olfactory epithelium is covered with mucus, in which there are small hairs known as cilia and it is on these hairs that the olfactory receptors are located. It is believed that odor molecules make their way through the mucus layer and then to the odor receptors on the surface of the cilia (47). Odor molecules reach the canine's olfactory epithelium through active sniffing during which time, the inhalation/exhalation frequency rises to 140-200 times per minute (8).

Of the five special senses, olfaction is the most complex molecular mechanism, as it comprises hundreds of receptor proteins enabling it to detect and discriminate thousands of odorants. Water soluble binding proteins attach to hydrophobic sites allowing them to be transported through the mucus layer to receptor sites on the surface of the cilia. The odor receptors are members of the G-protein coupled receptor family (47). Studies have shown that a single odorant can activate multiple olfactory receptors and multiple odorants can activate a single olfactory receptor. This observation has resulted in olfaction being perceived as a combinatorial effect. 


\subsection{Canines used for human scent identification}

Three types of dogs are used in human scent procedures; tracking dogs, trailing dogs and scent identification dogs (48). Tracking dogs are trained to locate the scent of a person without receiving an initial scent whereas trailing dogs are given an initial scent to follow until the scent's end (48). Scent identification dogs are given a scent which is collected from the scene of a crime and instructed to match this to a scent sample collected from a possible suspect, thus establishing an association between a suspect and an object or location.

\subsubsection{Human scent identification canines}

For over one hundred years, canines have been successfully used in human scent identification in certain European countries primarily Poland, Hungary and the Netherlands. In the United States, the use of human scent discriminating canines has become more extensive since the 1980's even though it has been acknowledged since the beginning of the $20^{\text {th }}$ century.

The method for conducting human scent identification lineups was pioneered by the Dutch law enforcement agency. Firstly, the scent is collected at the crime scene and secured in an airtight container. Once a suspect has been apprehended, a scent lineup is prepared using six stainless steel bars secured in a line on the floor. One of the bars is scented by the suspect and the five others scented by persons known as decoys (bars are scented by allowing individuals to hold them in their palms for a specified time period). The canine is then presented with the evidence from the crime scene and instructed to 
locate a matching scent in the lineup. If the canine produces a positive match, he is rewarded with the stainless steel bar as a toy (Figure 1).

Measures are put in place as controls to ensure that there is no bias when the human scent identification is being conducted. These include: a) the suspect and the decoys are the same sex and the same race and (b) a second lineup is performed in which the suspect's scent is excluded to eliminate the possibility that the canine is strongly attracted to the scent of the suspect (48).

Figure 1: Human Scent Identification Line up

(a) Scent presented to the canine (b) Canine attempting to match scent in lineup (c) Canine producing an alert (d) Canine rewarded (Pictures courtesy of the Netherlands National Police)

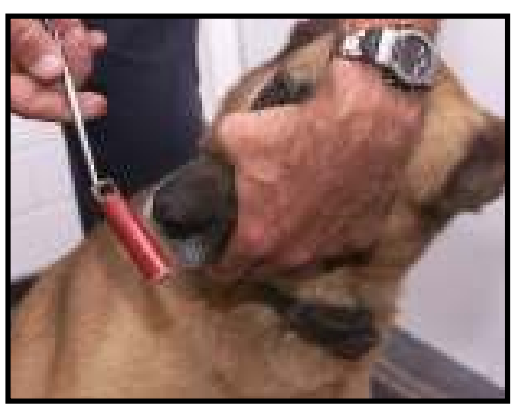

(a)

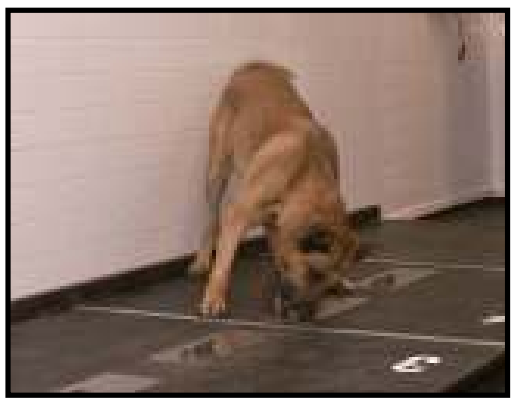

(c)

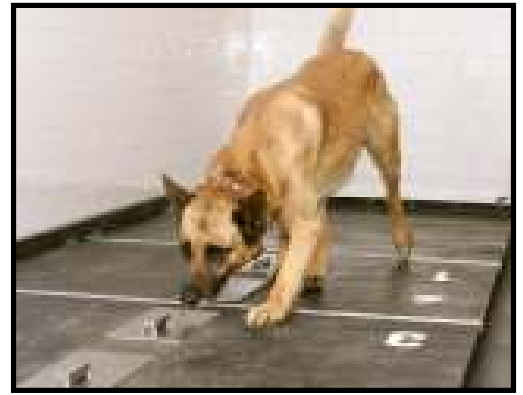

(b)

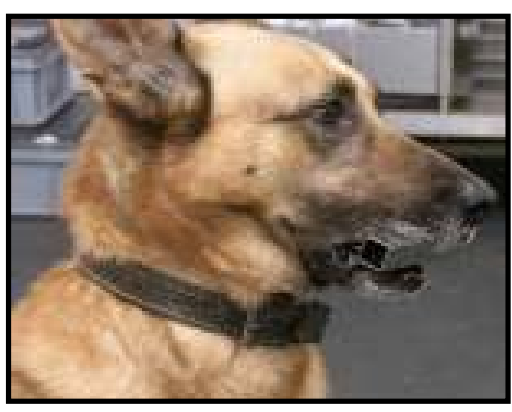

(d) 


\subsection{Transmission of human scent}

The stratum corneum of the skin's epidermis is constantly replenished as the cells gradually flatten, shrink and lay loosely against each other (8). These dead skin cells known as "rafts" are shed constantly at a rate of $0.5-1.00 \mathrm{~g}$ of dead skin cells (rafts) per day (8). The rafts which are shed by the epidermis are on average 14 microns in size and weigh approximately 0.07 micrograms. Each raft carries on up to four microbes on average. The rafts that flake off from the epidermis are usually invisible except when the individual suffers from a skin disease such as psoriasis (8).

It is believed that the rafts' microbial passengers feed on its nutrients thereby producing a cloud of by-products around each raft. This cloud of by-products will be continuously emitted as long as the nutrients persist. It was originally thought that these rafts just fell from an individual but recent research conducted by $\mathrm{H}$. Lewis has shown a current of air next to the skin's surface (1). It is believed that this air carries the rafts along and disperses them into the atmosphere. The dispersal distance depends upon the velocity of the wind and the velocity with which the individual is moving. The velocities will also affect the density (rafts per area) of the particles that are deposited (1).

\subsubsection{Shedders versus Non-shedders}

Dead skin cells can be transferred from an individual to touched items as these dead epidermal cells are sloughed off from the surface of the skin resulting in trace amounts of DNA being left behind on these objects. The amount of DNA which is left behind after an individual comes in contact with an object has been studied by a number of research groups. This has been made possible by the advent of short tandem repeats (STRs) which 
provides greater discrimination than restriction fragment length polymorphism (RFLP) and also uses smaller amounts of samples. The smaller sample size requirement also provides increased probabilities of obtaining DNA profiles from degraded DNA samples. In the mid 1990's, through the use of STRs in conjunction with polymerase chain reactions (PCR), between 1- 20 ng of purified DNA could be used for a full profile development (49).

Skin cells obtained from handled objects have been targeted as potential sources of DNA at crime scenes. Some examples of cases in which handled objects were analyzed for trace amounts of DNA by the Royal Canadian Mounted Police Forensic Laboratory include the nose and earpiece of glasses dropped at a crime scene, handles of plastic shopping bags, screw drivers, knives and a variety of weapons (49).

Lowe et al. conducted a number of experiments to determine if there were differences in the amount of DNA deposited on an item after being in contact with individuals (50). In their experiments, eight subjects were instructed to wash their hands and then hold sterile $50 \mathrm{ml}$ plastic tubes for ten seconds. Various time intervals after washing were investigated to determine the effects of time since washing on the amount of DNA that was deposited on the tubes. All tubes were swabbed both before and after sampling. Replicates were performed over a five day period. The results obtained by this group showed that there are differences between individuals as a result of their tendencies to deposit DNA on an item during handling. They were able to define a "good shedder" as an individual who leaves behind a full DNA profile immediately after hand washing, while a "poor shedder" was defined as an individual that leaves behind a full profile only when their hands have not been washed for a period of six hours (50). 
Another study conducted by Phipps et al. also investigated the tendencies of individuals to transfer DNA to handled objects (51). Their methodology was adapted from Lowe et al. Their results demonstrated that there are variables that affect the amount of DNA that was deposited on handled objects. These include not just time since washing but also the hand that was used to hold the object. This group also discovered that no one individual sheds a consistent amount of DNA over time, as they observed a lot of variation both within individuals and between individuals (51).

Human scent is said to be produced by bacterial action on dead skin cells and it has been determined that there are variations in the amount of skin cells that are deposited by individuals. This raises the question as to whether the amount of skin cells which are deposited by individuals affects the amount of odor that produced hence affecting alerts which are produced by canines. This has yet to be determined by any research group.

\subsection{Collection of human scent evidence}

Individuals deposit varying amounts of skin rafts when they come in contact with objects and this makes it possible for a scent sample to be collected. Collected human scent evidence is of importance to law enforcement because this form of trace evidence can be evaluated through the use of specially trained canines to determine if there is an association between evidence and a suspect. Human scent samples for canine use are usually collected utilizing either a direct collection procedure or an indirect collection procedure. The direct collection method involves presenting the canine with an article of evidence, whereas the indirect method involves the use of a sorbent material to collect the scent from the article of evidence. Indirect collection of scent evidence can be done in 
one of three ways: wiping the sorbent material across the article of evidence, placing the sorbent material in close contact with the evidentiary material for a specific period of time or by using a scent transfer unit which is a portable vacuum that uses airflow through a sorbent material to capture volatiles above an article of evidence. The canine is then presented with the scented sorbent material (54).

The sorbent material that is employed is dependent on the protocol of the specific country, although cotton based sorbents are usually used (8). The Netherlands utilizes a non-sterile cotton sorbent known as Kings Cotton, in Poland cotton "scent tampons" which are manufactured solely for the needs of the police are used, while in Hungary, human scent in collected using an "odor collecting cloth" the composition of which is not specified. In the United States, the Federal Bureau of Investigations (FBI) uses a sterile Johnson and Johnson gauze pad.

Each of these different agencies are currently utilizing materials which are not all necessarily cotton based and so may vary in their trapping and releasing capabilities of the VOCs being captured in a human scent sample. This may not pose a problem for canines but may do so for the numerous laboratories that are currently performing instrumental analyses in an effort to use science to validate the use of human scent in criminal cases. To provide a better understanding of the trapping and releasing capabilities of different materials, the chemical compositions of a number of different materials will be reviewed. 


\subsubsection{Cotton}

There are many varieties of cotton plants which are grown commercially in different parts of the world under various growing conditions such as rainfall, humidity, sunlight and nutrients. As a result, there are many different grades and qualities of cotton which produce varying physical properties and characteristics $(55,56)$. Cotton is cellulosic in nature and is chemically described as (1,4-B-D-anhydroglucopyranose) (Figure 2). Cotton fiber is approximately 94 percent cellulose prior to undergoing chemical treatments with the remaining six percent consisting of protein, pectin materials, mineral substances, wax and small amounts of organic acids, sugars and pigments. Non-cellulosic materials are removed by scouring and bleaching processes resulting in a fiber that is approximately 99 percent cellulose. The cellulose molecule is subject to acidic hydrolysis at the $\beta$-glucosidic linkage resulting in chain scission $(57,58)$. The three hydroxyl groups on each of the glucose moieties in the polymer chain are also subject to oxidation. Cotton fibers burn readily, is hydrophilic and swells readily in water. Cotton is also readily attacked by certain fungi and bacteria. Ultra violet (UV) light also causes oxidation resulting in the formation of oxycelluloses $(57,58)$.

Figure 2: Repeat cellulose unit of cotton

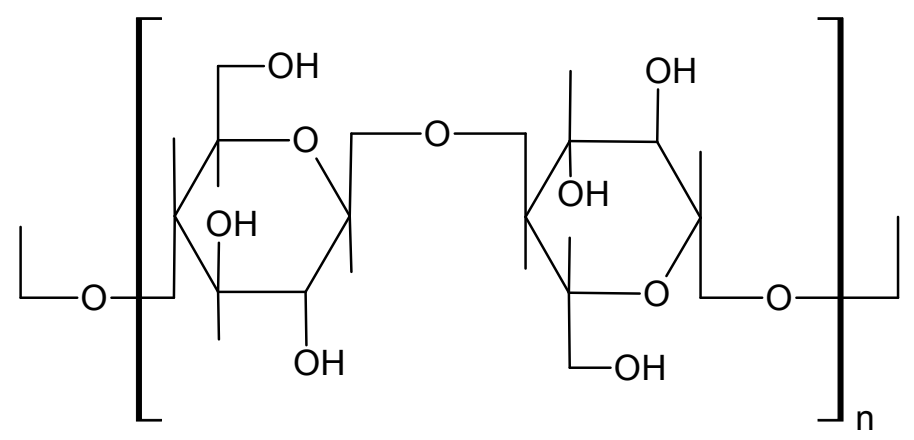




\subsubsection{Rayon}

Rayon is a man-made fiber prepared by dissolution of natural fibrous materials such as cotton or cotton derivatives (Figure 3). The solution is then extruded through small orifices into an aqueous bath where a fiber is produced by coagulation or into air where the solvent is evaporated to produce filaments. This process is referred to as spinning or extrusion (57). A suitable solvent is necessary for the regeneration of one fibrous material from another. Today, the most common way in which rayon is produced commercially is by dissolving cellulose in dilute alkali after it has been treated with caustic soda and carbon disulphide (57). The cellulose is then re-precipitated by extrusion into solutions of dilute acids (55). Chemical properties are similar to those of cotton as both fibers are cellulosic in nature. In the presence of mineral acids, rayon hydrolyzes and disintegrates while in the presence of oxidizing agents, carbonyl and carboxyl groups increase resulting in losses in fiber strength.

Figure 3: Repeat unit of rayon

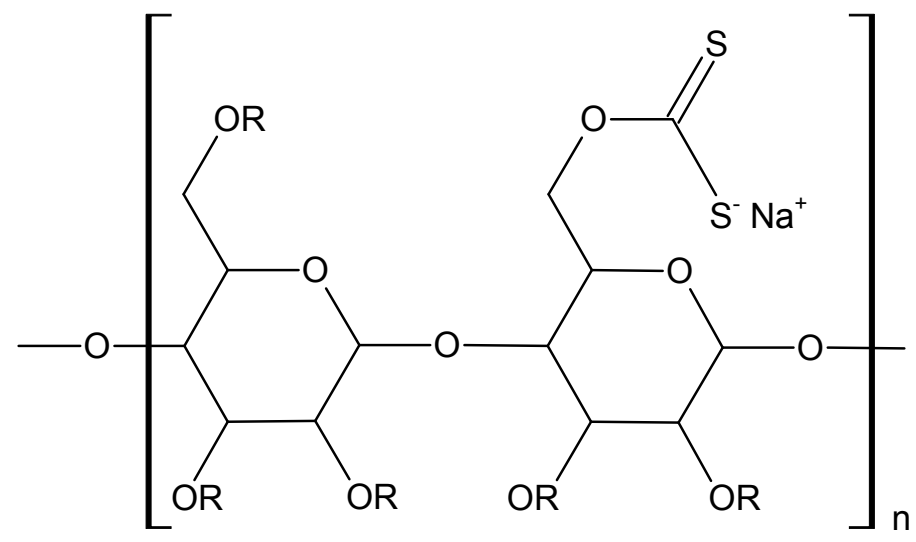




\subsubsection{Polyester}

Polyester is a manufactured fiber made up of long chain synthetic polymers composed of at least $85 \%$ by weight of an ester of dihydric alcohol and terephthalic acid. The most common polyester is polyethylene terephthalate (PET) (Figure 4) (59). Polyester is manufactured by a two step procedure; ester interchange of dimethyl terephtalate with glycol or esterification of terephthalic acid with glycol followed by a condensation step in which excess glycol is removed (59). Polyester fibers generally have good resistance to alkalis, acids and organic solvents. Polyester is also hydrophobic and oleophilic in nature. The hydrophobic nature provides water repelling properties and permits rapid drying while the oleophilic nature allows it to absorb non-polar compounds easily but makes removal difficult (59).

Figure 4: Repeat unit of a polyester fiber

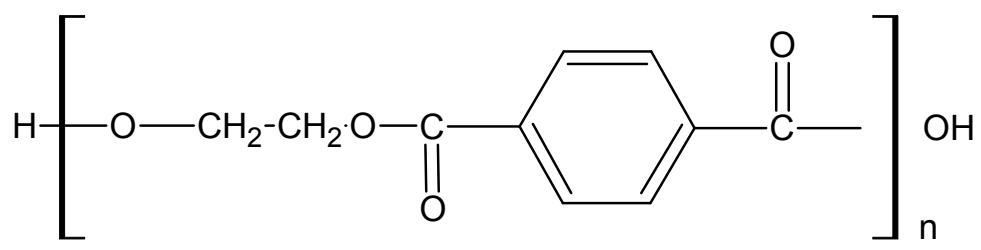

As various materials are subjected to different chemical treatments, they will possess different functional groups which will affect the trapping and releasing capabilities of volatiles compounds at ambient temperature.

\subsection{Storage of human scent evidence}

A suspect is often not immediately identified requiring the collected scent evidence to be stored. There are however, no standardized storage protocols across the various law enforcement agencies. In Western European countries, human scent samples are being 
stored in rooms which are at a constant temperature and are exposed to little or no daylight (8). In Asia, China has recently reported the development of a "scent bank" where scent samples collected on various sorbents are stored at $-18{ }^{0} \mathrm{C}(60,61)$. If there are no set protocols to collect or store human scent evidence, then such evidence will always be constantly challenged in the courts of law and the evidence possibly excluded.

\subsection{Human scent and the law}

In the United States, before any item can be considered as evidence, a proper legal foundation has to be established. The procedural rules for scientific and expert evidence are governed by federal and state statutes, the Federal rules of evidence and case law are applied through the cases of Frye v. United States and Daubert v. Merrel Dow Pharmaceuticals, Inc (62).

\section{Frye v. United States}

This standard comes from the case; Frye vs. United States in 1923 regarding the admissibility of polygraph evidence into court. The Frye standard is now a legal precedent in the United States concerning the admissibility of scientific examinations or experiments in legal proceedings. In order to meet the Frye standard, the scientific evidence presented to the court has to be generally accepted by the scientific community. General acceptance is defined as the following:

"Just when a scientific principle or discovery crosses the line between the experimental and the demonstrative stages is difficult to define. Somewhere in this twilight zone the evidential force of the principle must be recognized and while courts will go a long way in admitting expert testimony deduced from a well recognized scientific principle or discovery, the thing from which the deduction is made must be sufficiently established to have gained general acceptance in the particular field in which it belongs (62)." 
Daubert v. Merrel Dow Pharmaceuticals, Inc

In the Daubert v. Merrel Dow Pharmaceuticals Inc case, the United States Supreme Court announced that the Federal Rules of Evidence supersede the Frye standard for admission of scientific evidence (62). Admission of scientific evidence at the federal court level depends on factors other than general acceptance by the scientific community as stated by the Frye standard. These factors include; whether the theory has been tested, whether it has been subjected to peer review and publication, its error rate, whether there are standards for its operation and whether it has widespread acceptance in the scientific community. The Daubert decision also made the judges "gatekeepers" determining whether the proffered evidence is scientifically valid and relevant to the case at hand.

Therefore, for evidence to be accepted in a United States court of law it must satisfy the Frye, Daubert or Federal Rules of Evidence depending on if it is a federal offence, the crime committed and the state in which the case is being tried. Despite the implementation of these standards, there is still an area of criminal investigation that is accepted by numerous courts with little or no underlying scientific evidence validating its use. This area is the use of human scent canines used to identify persons or follow their scent trails in the environment. The scent identification line up is one of the most controversial types of dog scent evidence presented in courts of law (63). Scent identification lineups represent a relatively new evidentiary tool in the United States. Due to the variability with which scent evidence is collected, stored and analyzed across different agencies, such evidence comes under much scrutiny. The introduction of human scent evidence has been challenged in court due to the limited scientific research in this field. 
In a 2003 U.S. Court of Appeal hearing, People of the State of California v. Jeffrey Dewyane Mitchell, the prosecution introduced evidence that the scent of a defendant was identified by a police dog in a scent identification lineup. The scent identification lineup was performed using scent collected with the scent transfer unit from expended shell casings found at the crime scene. The introduction of this evidence was challenged by the defense on the basis that the scent transfer unit was a novel device requiring a Kelly-Frye analysis and issues regarding the degradation and contamination of the scent both before and during collection. Based on these challenges, the scent evidence was excluded (64). In yet another court of appeal hearing, People v. Ryan Willis, the Superior Court of Los Angeles County (California) convicted the defendant of first degree murder. The defendant appealed and challenged the admission of dog scent identifications which were used at the trial. The admission of dog scent evidence was challenged on the basis that there was foundational weakness in this evidence as there is no evidence on how long a scent remained on an object or at a location, whether a person's scent is unique and the adequacy of the certification procedures for scent identification. The court ruled that there was no prejudice from the admission of the scent evidence because of the overwhelming presence of other evidence that led to the defendant's guilt (65).

In a recent 2005 U.S. Court Case, People of the State of California v. Benigo Salcido, human scent evidence evaluated by canines was challenged. Some of the issues raised included, the uniqueness of human scent, survivability of human scent and whether canines can be trained to discriminate between scents in a scent identification line-up (66). Numerous testimonies were presented by expert witnesses resulting in the court ruling that human scent evidence can be admissible if: "the person performing the 
technique used the correct scientific procedures, the training and experience of the dog and dog handler prove them to be proficient, and the methods used by the dog handler in the case are reliable (66).”

\subsection{Instrumental analysis of human scent}

The above mentioned cases demonstrate the need for the use of robust scientific procedures to produce reliable, reproducible scent evidence that will be admissible in a United States court of law. As a result of the many legal challenges to which scent evidence has been subjected, numerous research groups are now conducting studies to determine instrumentally, the chemical composition of human scent, the uniqueness of human scent and optimal collection techniques for human scent evidence $(2,24,27)$. This is being done in an attempt to provide a scientific basis for the assumptions previously made that canines can discriminate persons due to individuals possessing unique odors. Most of the analyses being conducted involve the use of an instrumental technique known as solid phase micro extraction gas chromatography mass spectrometry (SPMEGC/MS).

\subsubsection{Solid Phase Micro Extraction (SPME)}

Solid Phase Micro Extraction (SPME) is a relatively new technique which was developed in the 1990's by Professor J. Pawliszyn (67). Solid Phase Micro Extraction has proven to be a highly effective pre-concentration technique that is extremely effective for the analysis of volatiles and semi-volatile components. This technique provides a quick and solvent-less means of isolating analytes in a sample matrix. 
A SPME device is essentially a modified syringe that has a spring loaded plunger and a barrel with a detent. The detent allows the barrel to be held in an extended position during extraction and also during desorption. The barrel also contains a modified 24 gauge stainless steel needle which encloses another length of stainless steel tubing fitted tightly to a short piece of fused silica fiber coated with a sorbent polymer which is stable at high temperatures (SPME fiber). The type and thickness of the SPME fiber that is used is dependent on the polarity and volatility of the analyte to be extracted as different types of sorbents will extract different groups of analytes; non-polar coatings retain non-polar hydro-carbons whereas polar coatings extract polar compounds (67).

\section{Figure 5: SPME fiber}

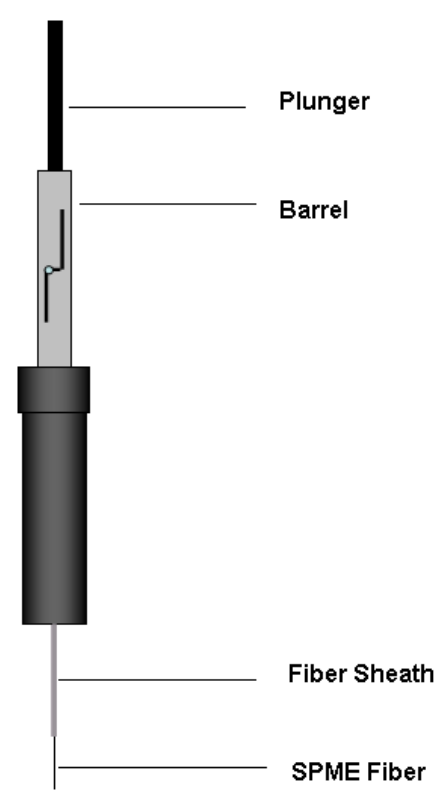

A company known as Supelco is the sole suppliers of commercial fibers. The fibers that are made are usually 1 or $2 \mathrm{~cm}$ long fused silica fibers that have been coated with various polymeric phases. The thickness of the fibers used for the polymeric coating range from 7 
$\mu \mathrm{m}$ to $100 \mu \mathrm{m}$. The thickness of the fiber determines how much analyte is absorbed or adsorbed onto the polymeric phase. The thicker the fiber that is used for the polymeric coating, the higher will be the volume of the analyte extracted but the longer the extraction time. Some of the commercial polymeric phases that are available include;

- Polydimethylsiloxane (PDMS)

- Polydimethylsiloxane/divinylbenzene (PDMS/DVB)

- Polyacrylate (PA)

- Carbowax/divinylbenzene (CW/DVB)

- Polydimethylsiloxane/carboxen (PDMS/CAR)

There are four types of extractions that can be utilized with a SPME fiber; direct extraction, headspace SPME, partial headspace SPME and membrane protected SPME (67).

Figure 6: Schematic representation of different types of SPME extractions

(a) Direct SPME (b) Headspace SPME (c) Partial headspace SPME (d) Membrane SPME

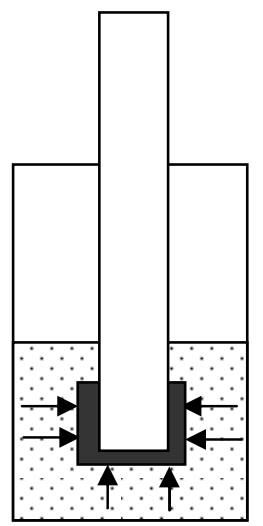

(a)

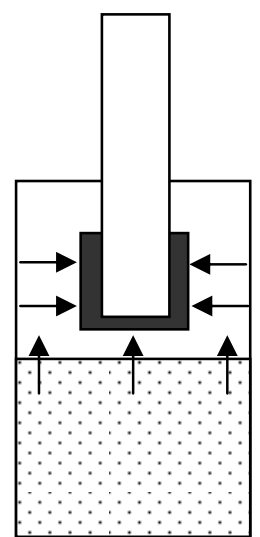

(b)

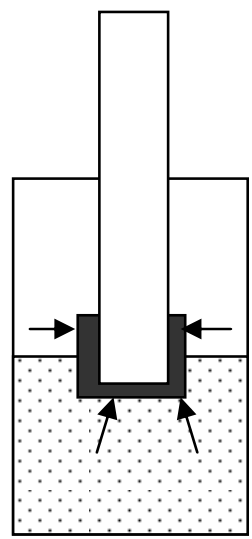

(c)

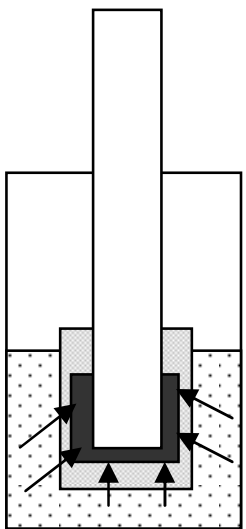

(d)

$\because \quad$ Sample Matrix

Fiber Coating

Membrane 
Solid Phase Micro Extraction is a two step procedure which involves partitioning of the analytes between coating and sample matrix and desorption of the concentrated matrix into an analytical instrument which is usually a gas chromatograph mass spectrometer (GC/MS). The underlying principle of the SPME technique is based on the formation of an equilibrium between the fiber and the sample. In a contained sample, equilibrium forms between the three phases; fiber coating to sample phase, headspace to sample phase and fiber coating to headspace. The equations that govern the equilibrium process between the three phases for headspace sampling include:

$$
\begin{array}{rlr}
K f h=\frac{C f}{C h} & \text { Equation 1 } \\
K h s=\frac{C h}{C s} & \text { Equation 2 } \\
K f s=\frac{C f}{C s} & \text { Equation 3 }
\end{array}
$$

Where: $K f h$ is the partition co-efficient of an analyte between the fiber coating and the headspace phases while $C f$ and $C h$ are the concentrations of the analyte in these phases.

Khs is the partition co-efficient of an analyte between the headspace and aqueous phases and $C h$ and $C s$ are the concentrations of the analyte in these phases.

$K f s$ is the partition co-efficient of an analyte between the fiber coating and aqueous phases and $C f$ and $C s$ are the concentrations of the analyte in these phases (67).

Therefore, the amount of analyte absorbed by the fiber coating in headspace sampling is expressed by the equilibrium conditions equation as:

$$
n f=\frac{K f s V f V s C o}{K f_{s} V f+K h s V h+V s} \quad \text { Equation } 4
$$


The amount of sample that is extracted is independent of where the fiber is placed in the system during the absorption step as long as the volumes of the fiber coating, headspace and sample are kept constant.

\subsubsection{Gas Chromatography}

Gas chromatography was first described in 1952 by James and Martin (68). It is a physical separation technique in which samples are separated by distribution between two phases; one is a stationary phase which can be either a solid or a liquid and the other is mobile phase which is a gas. A solid stationary phase (gas solid chromatography) is essentially a packed column while a liquid stationary phase (gas liquid chromatography) consists of an open tubular column, the walls of which are coated with a liquid. Gas liquid chromatography (GLC) is the more commonly used technique today due to the increased use of open tubular columns. Separation in GC is facilitated by repeated sorption/desorption steps during the movement of analytes by the carrier gas along the stationary phase. The major requirements for separation using GC are that the sample has to be volatile and also thermally stable. Gas chromatography can, therefore, be used for separation of permanent gases, most non-ionized small or medium sized organic molecules (usually up to $\mathrm{C}_{30}$ ) and many organometallic compounds. Gas chromatography, however, cannot be used to separate macromolecules or salts (69). There are cases in which non-volatile compounds can be derivatized converting them into more volatile and stable compounds. The instrumentation for GC consists of a gas control unit, a sample introduction system or injector, a column which is housed in a temperature programmable oven and a detector or transfer line. 
Figure 7: Block diagram of a gas chromatograph

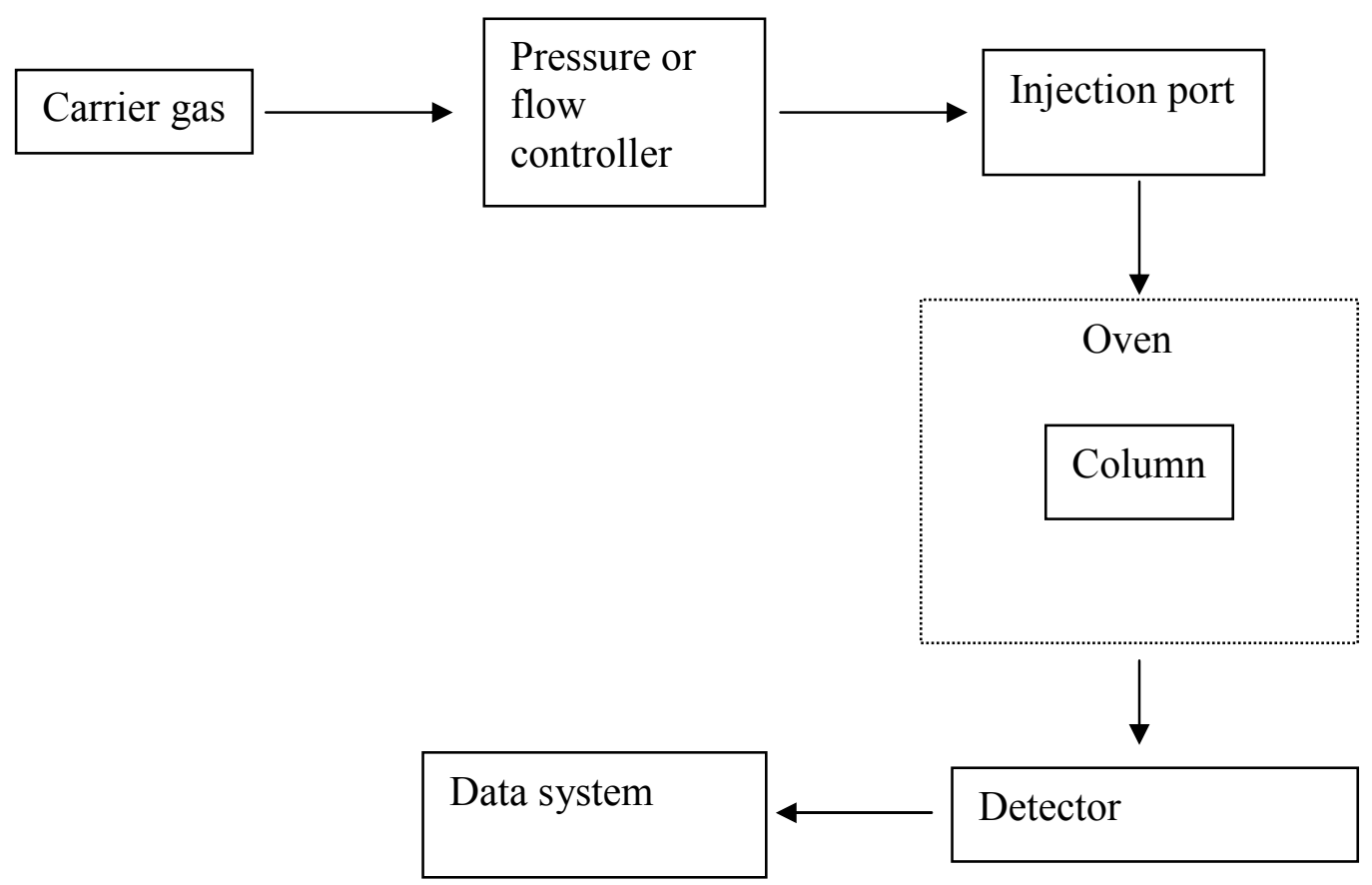

\section{Carrier gas}

The carrier gas used in GC has to be non-reactive towards the analyte, non-flammable and inexpensive. Hydrogen, helium and nitrogen are the most popular carrier gases used in GC with helium being the most frequently used. Nitrogen gives the most efficient separation due to its higher molecular mass and smaller diffusion co-efficient. In order to achieve this efficiency analysis time is increased as the optimum mobile phase velocity for nitrogen is $8-10 \mathrm{cms}^{-1}$. Even though efficiency is slightly reduced using helium instead of nitrogen, analysis time is greatly reduced as helium and hydrogen have optimum mobile phase velocities of $16-20$ and $35-40 \mathrm{cms}^{-1}$ respectively. Hydrogen is highly flammable and may also react with sample components to form hydrogenated artifacts (69). 
The purity of the gas that is used is also very critical as impurities can cause deterioration of the column's stationary phase. A moisture and oxygen trap is usually employed in the carrier gas lines to remove oxygen, water and hydrocarbons $(68,69)$. The traps are made from activated carbon which remove organic impurities or molecular sieves or drierite which remove moisture and oxygen (69). The function of the gas control unit is to maintain the flow rate or pressure control of the carrier gas flow through the injector, column and detector. A constant flow rate has to be maintained in an effort to prevent variations in retention times and also to prevent flow sensitive detectors from becoming non-linear. The carrier gas usually has a pressure below $0.3 \mathrm{MPa}$ and a flow rate of 1 $\mathrm{ml} /$ minute for open tubular columns (68).

\section{Sample introduction}

Sample introduction is a critical and very problematic area in GC. The injector port has to receive and deliver the correct amount of sample to the column so that sample capacity of the column and the linear dynamic range of the detector are not exceeded. The sample also has to be delivered to the top of the column as a narrow band which means it cannot undergo thermal degradation or component discrimination due to differences in volatility. Many different injection techniques are used to ensure that all these requirements are met. Two of the most commonly used injection techniques include split injection and splitless injection. Split injection is believed to be the simplest method of injection and is suitable for many applications. In a split injection system, the injection port is fitted with two valves; one functions as a septum purge allowing a small flow of carrier gas from just below the septum to eliminate any contaminants caused by column bleed while the second valve is used to control the ratio of the gas being vented to the atmosphere and the 
gas flowing onto the column. With split injections, a sample volume as large as $1 \mu 1$ can be injected onto the GC column. The sample is split typically in a ratios ranging from 10:1 to 500:1 with the higher split ratios generally used for columns with small internal diameters $(68,69)$. Split injections do not permit maximum sensitivity and so is not applicable for ultra-trace analyses which require maximum sensitivity nor is it suitable for samples which possess a wide range of boiling points.

In splitless injection mode, sample volumes ranging from 1-5 $\mu 1$ is introduced into the same or a similar device used for split injection where the splitter vent remains closed for time periods between 50 - 120 seconds increasing the residence time in the injector port. This permits lower injection port temperatures for effective sample vaporization. The splitter vent is then opened to purge the remaining sample and solvent from the injector. Splitless injection places a high solvent load on the column and so is recommended for use mainly with bonded columns (69).

\section{Columns}

The column is described as being the heart of the chromatographic system as it determines the selectivity and the efficiency of the separation (69). Currently, open tubular columns are more frequently used and they are made of fused silica with an external polyimide coating. Column lengths can vary from 10-100 $\mathrm{m}$ and the chosen length is dependent on the required analysis. Shorter columns are generally used for fast analyses while the longer columns are used for high resolution analyses. Internal diameters of columns can range from $0.25-0.53 \mathrm{~mm}$ with a phase thickness of $0.1-2$ $\mu \mathrm{m}$. The stationary phases vary in polarity and is chosen based on the nature of the analytes being separated. Polar stationary phases are used for separation of more polar 
compounds while non-polar stationary phases are used for the separation of non-polar compounds. Polar stationary phases are prone to bleeding so the least polar stationary phase is often chosen when separating polar compounds.

Table 1: Examples of stationary phases used for capillary columns

\begin{tabular}{|c|c|c|}
\hline Stationary Phase & Classification & Uses \\
\hline $100 \%$ dimethyl silicone & Non-polar & $\begin{array}{c}\text { Separation of solvents, } \\
\text { petroleum products, } \\
\text { pharmaceuticals }\end{array}$ \\
\hline $\begin{array}{c}95 \% \text { dimethyl silicone } \\
5 \% \text { phenyl silicone }\end{array}$ & Non-polar & $\begin{array}{c}\text { Separation of aromatics, } \\
\text { flavors, aromatic } \\
\text { hydrocarbons }\end{array}$ \\
\hline $\begin{array}{c}86 \% \text { dimethyl silicone } \\
7 \% \text { phenyl silicone } \\
7 \% \text { cyanopropyl }\end{array}$ & Intermediate polarity & $\begin{array}{c}\text { Separation of pesticides, } \\
\text { alcohols }\end{array}$ \\
\hline $\begin{array}{c}50 \% \text { dimethyl silicone } \\
25 \% \text { phenyl silicone } \\
25 \% \text { cyanopropyl }\end{array}$ & Polar & $\begin{array}{c}\text { Separation of triglycerides, } \\
\text { phthalate esters }\end{array}$ \\
\hline $\begin{array}{c}100 \% \text { Cyanopropyl silicone } \\
\text { Polyethylene glycol } 20 \mathrm{M}\end{array}$ & Polar & $\begin{array}{c}\text { Separation of fatty acid } \\
\text { methyl esters, } \\
\text { carbohydrates }\end{array}$ \\
\hline & Polar & $\begin{array}{c}\text { Separation of flavors, fatty } \\
\text { acid methyl esters, acids, } \\
\text { amines }\end{array}$ \\
\hline
\end{tabular}




\subsubsection{Mass Spectrometry}

In mass spectrometry, ions in a gaseous form are separated and identified based on their mass to charge ratio $(\mathrm{m} / \mathrm{z})$. Mass spectrometers are composed of five parts; sample introduction, ionization, mass analysis, ion detection and data handling.

Figure 8: Block diagram of a mass spectrometer

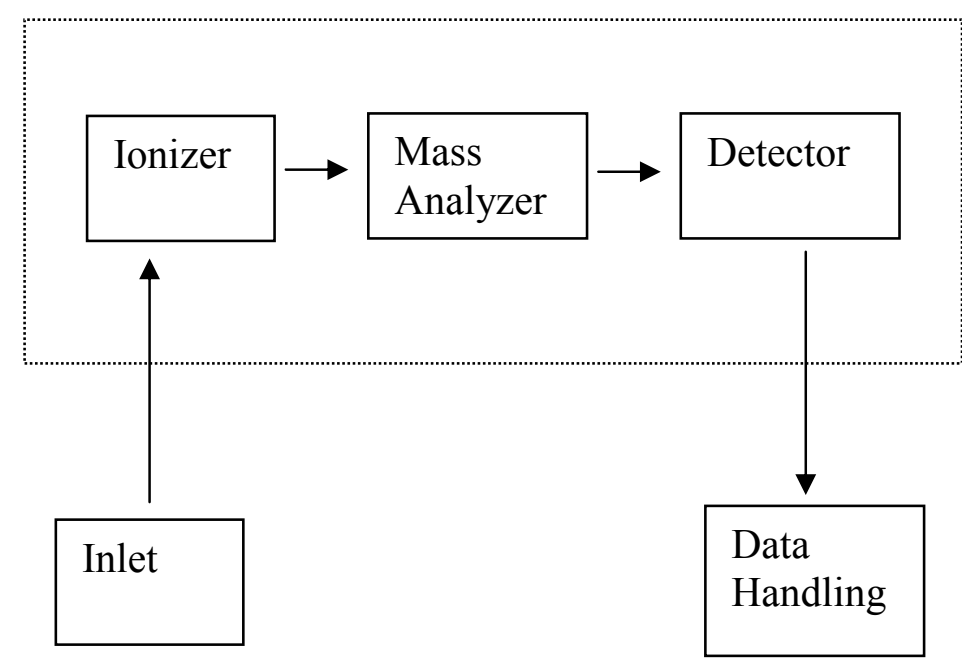

The purpose of the inlet system is to introduce small amounts of sample into the ion source where it is converted into gaseous ions by bombardment with electrons, photons, ions or molecules (70). In GC-MS systems, the sample is introduced into the ionizer directly from the open capillary chromatographic column. In GC-MS systems, ionization, mass analysis and detection are carried out in a high vacuum system $\left(10^{-5}\right.$ to $10^{-7}$ torr) to minimize ion molecule interactions. This high vacuum is maintained by a series of pumps located within the mass spectrometer.

Ionizer

Two of the most common ionization techniques used in mass spectrometry is electron ionization (EI) and chemical ionization (CI). Electron ionization is the older and more 
popular approach for ionizing samples (62). In EI, the gaseous sample is bombarded by electrons which are normally at $70 \mathrm{eV}$. Ionization will only occur when the energy of the incoming electron beam is at least equal to the ionization energy of the sample molecule. As the electron beam is usually set to $70 \mathrm{eV}$ and the ionization potential of most organic molecules lies between 7 and $13 \mathrm{eV}$, then this criterion is easily achieved. When the analyte is bombarded with the electron beam, a radical cation and two electrons are usually produced:

$$
\mathrm{M}+\mathrm{e}^{-} \longrightarrow \mathrm{M}^{+}+2 \mathrm{e}^{-}
$$

The $\mathrm{M}^{+}$. is the molecular ion which corresponds to the molecular mass of the analyte (if the generated ion is singly charged). The excess energy results in bond breakage providing a complex mixture of ions which are present in varying but reproducible proportions. Computer searchable libraries of EI mass spectra have been created enabling the identification of unknown samples (62).

Chemical Ionization (CI) is based on gas-phase chemical reactions and is a softer ionization technique than EI and it also allows the analyst to have some control over the degree of ionization of the sample. This technique is based on ion-molecule reactions between ions from a reagent gas and the analyte. A reagent gas (usually methane, isobutane or ammonia) is introduced into the source and is bombarded with high energy electrons $(100-400$ electron volts). This causes the reagent gas to become ionized producing reagent gas ions. The sample ions upon entering the source become ionized when they interact with the reagent gas ions $(62,68,70)$. 


\section{Mass Analyzer}

The function of the mass analyzer is to separate the ions based on their $\mathrm{m} / \mathrm{z}$ ratio. In the field of forensics, the most common mass analyzers used include quadrupole filter, an ion trap or a magnetic sector.

The quadrupole is the most common type of mass analyzer used and this is due to the lower cost, ruggedness and compact structure. The quadrupole filter is made up of four rods which are symmetrically arranged in a square configuration. One pair of rods receives an $\mathrm{Rf}$ voltage $180{ }^{\circ} \mathrm{C}$ out of phase while the other pair receives an equal but opposite DC potential. Therefore, at any set of $\mathrm{Rf}$ and dc voltage values, only ions which possess specific $\mathrm{m} / \mathrm{z}$ will transverse the length of the open space between the rods. All other ions will strike the rods and be converted to neutral molecules and so get pumped out of the system $(62,70)$.

The ion trap has a small chamber which is configured with a ring electrode centered between two end cap electrodes. There are holes in the top of the end cap for the introduction of ions into the trap while holes in the bottom of the end cap are for the ejection of ions towards the detector. The ion trap features a pulsed technique meaning the sample is not continuously ionized but is ionized for discrete time periods followed by ejection as the ring voltage electrode is increased $(68,70)$.

The magnetic sector uses a magnetic field to separate ions based on their $\mathrm{m} / \mathrm{z}$ values. When the ions are ejected from the source, they go through a field of positive potential acquiring a constant velocity travelling in a circular path. The relationship between $\mathrm{m} / \mathrm{z}$, the magnetic field, $\mathrm{H}$, accelerating voltage, $\mathrm{V}$, and the path radius is: 


$$
m / z=\frac{H^{2} R^{2}}{2 V} \quad \text { Equation } 5
$$

If the values of $\mathrm{H}$ and $\mathrm{V}$ are satisfied for a fixed radius instrument, ions of specific $\mathrm{m} / \mathrm{z}$ values will traverse the magnetic sector to the detector (62).

\section{Detector}

The electron multiplier is usually the detector of choice for routine experiment (70). Electron multipliers have dynodes with $\mathrm{Cu} / \mathrm{Be}$ surfaces which emits electrons when struck by energetic ions or electrons. Electron multipliers can have up to 20 dynodes that can provide a current gain of $10^{7}$. Electron multipliers are very rugged and have the ability to provide high current gains and nanosecond respond time.

\subsection{Research Objectives}

The main objective of this research was to employ scientific methods to validate the current practices of using human scent evidence in court cases. The content of this report focuses on data obtained via instrumental and biological evaluation of human scent samples. The different tasks that were addressed are listed below.

a. Optimization of collection and analysis methods for human scent samples

i. Optimization of a full scan GC/MS method

ii. Development of a selected ion monitoring (SIM) GC/MS method

iii. Optimization of hand odor sample collection method

b. Instrumental and biological evaluation of the effect of different storage conditions on odor profiles

i. Room temperature

ii. $-80{ }^{0} \mathrm{C}$ 
iii. Dark

iv. UVA/UVB Light

c. Trapping and releasing capabilities of different sorbent materials

i. Dukal brand gauze

ii. Kings Cotton

iii. Johnson and Johnson brand gauze

d. Identification of the best procedure to follow in collecting human traces from objects

i. Contact versus non-contact

ii. Passive versus active collection of human scent

e. Analysis of "Shedder Status"

i. Canine evaluations

ii. SPME-GC/MS analysis

iii. DNA analysis using polymerase chain reaction (PCR)

iv. Microbial analysis using polymerase chain reaction (PCR)

f. Creation of prototype pseudo human scents

i. Fractionation of hand odor samples

ii. Instrumental and biological evaluation of fractioned samples

g. Discriminating between VOCs in hand odor samples from twins using SPME-GC/MS 


\section{METHODOLOGY}

\subsection{Materials}

Sorbent materials used for hand odor collection were DUKAL brand, sterile, 2x2 inch, 8ply, gauze pads (DUKAL Corporation, Syosset, NY, USA), Kings Cotton, non-sterile, 2x2 inch sorbent material (Seafarma, NL), Johnson and Johnson brand, sterile, 2x2 inch gauze pads (Johnson and Johnson, Consumer Products Company, China) and Solon cotton tipped applicators (Solon, Maine, USA). The soap used for hand washing was Natural, Clear Olive Oil Soap from Life of the Party (North Brunswick, NJ, USA). Ten $\mathrm{ml}$ glass, clear, screw top vials with PTFE/Silicone septa (SUPELCO, Bellefonte, PA, USA) were used to hold the sorbent materials. The SPME fibers used for the extractions were 50/30 $\mu \mathrm{m}$ divinylbenzene/carboxen/polydimethylsiloxane (SUPELCO, Bellefonte, PA, USA).

The temperature and the humidity of the storage conditions were monitored using Thermochron I-Buttons (MAXIM, Dallas, Texas, USA). Storage containers used were glass aquarium tanks (All Glass Aquarium, Wi, USA) enclosed with aluminum foil (Reynolds Consumer Products Richmond, Va, USA). The light source used was a UVA/UVB reptile light (Energy Savers Unlimited, Ca, USA). The $-80{ }^{\circ} \mathrm{C}$ freezer used was a VWR brand (Revco Scientific Inc., Asheville, NC, USA).

Stainless steel metal bars used for the collection of scent from objects were obtained from the Netherlands National Police Agency. Scent transfer unit (STU-100) which was used for the active collection of scent from objects was obtained from the Federal Bureau of Investigations. $500 \mathrm{ml}$ glass jars used for the passive scent transfer were purchased 
from Industrial Glassware (Millville, NJ, USA). Diffusive Flammable Liquid Extraction (DFLEX) (Cromwell, CT, USA) was used to compare to SPME for headspace analysis of human scent VOCs. Standard compounds were purchased from Sigma Aldrich (Milwaukee, WI, USA).

Human and non-human DNA was extracted from hand odor samples using a QIAamp ${ }^{\circledR}$ DNA Micro Kit (Valencia, Ca, USA). Extracts were analyzed and quantified using a Mini Opticon from Biorad (Hercules, Ca, USA) and an ABI Prism 310 Genetic Analyzer (Applied Biosystems, Foster City, CA, USA) for human and non-human DNA analysis respectively. A detailed list of the reagents and supplies used for the extraction and analysis of DNA from hand odor can be found in appendix B. Human DNA from telogen shed hairs was extracted using a phenol/chloroform method. Extracts were analyzed and quantified using a Corbett Rotor Gene 3000 Real Time PCR Analyzer (Corbett Life Science, CA, USA). A detailed list of the reagents and supplies used for the extraction and analysis of DNA from hair samples can be found in appendix C.

\subsection{Methods}

\subsubsection{Pre-treatment of gauze}

Gauzes were initially pre-cleaned to ensure analytical cleanliness using an ISCO Model 260D Syringe Pump with an SFX 2-10 Supercritical Fluid Extractor. The SFE conditions used included direct spiking of $1000 \mu \mathrm{l}$ of methanol into the $10 \mathrm{ml}$ extractor vessel, 30 minute static extraction followed by a 10 minute dynamic extraction at $1.5 \mathrm{ml} / \mathrm{min}$ and 4500 psi, vessel was maintained at $130{ }^{\circ} \mathrm{C}(24)$. 
The pre-treatment method was modified by spiking the gauze with $1000 \mu 1$ of methanol followed by heating at $105{ }^{0} \mathrm{C}$ for 45 minutes in an Isotemp Oven, Model 655G (Fisher Scientific, Pittsburgh, PA, USA). This method proved to be just as effective as using the SFE treatment; it is also less time consuming and more cost effective.

\subsubsection{Direct hand sampling procedure}

Subjects were required to wash hands and forearms with clear Olive Oil Soap for 30 seconds, rinse with water for 2 minutes, air dry for 4 minutes, then rub the palms of hands over forearms for 5 minutes. Subjects then sampled themselves by holding the pre-treated $2 \times 2$ inch sorbent material between the palms of the hands for 10 minutes. The sample was placed back inside the $10 \mathrm{ml}$ glass vial and sealed by the subjects. This sampling procedure was previously determined to be a viable collection technique to obtain individual human scent profiles from the hands and olive oil based fragrance free soap has been shown previously not to contain any previously reported human scent compounds (24).

\subsubsection{SPME-GC/MS procedure}

The volatile organic compounds from the headspace of the vials containing the gauze were extracted using 50/30 $\mu \mathrm{m}$ DVB/CAR/PDMS fibers. Single headspace extractions of the stored samples were performed at room temperature for 21 hours. The instrumentation used for the separation and analysis of analytes was an Agilent $6890 \mathrm{GC}$ / 5973 MSD with a $0.25 \mathrm{~mm}$ x $30 \mathrm{~m}$ HP-5ms column which had a $0.25 \mu \mathrm{m}$ phase film thickness. Helium carrier gas was maintained at a flow rate of $1.0 \mathrm{ml} / \mathrm{min}$ while the injection port was maintained at $250{ }^{\circ} \mathrm{C}$ in splitless mode. An initial GC oven temperature 
of $40{ }^{\circ} \mathrm{C}$ was held for 5 minutes, followed by a temperature ramp of $10{ }^{\circ} \mathrm{C}$ per minute to a final temperature of $250{ }^{0} \mathrm{C}$ which was held for 2 minutes. The mass spectrometer transfer line was maintained at $280{ }^{\circ} \mathrm{C}$ and the source temperature was $230{ }^{\circ} \mathrm{C}$. Mass spectra were repeatedly scanned from $39-300 \mathrm{~m} / \mathrm{z}$.

\subsubsection{Development of a Selected Ion Monitoring Method (SIM)}

Thirty nine standard compounds previously reported as human scent compounds were procured and analyzed to determine their chemical ion fragments by diluting them in methylene chloride and injecting a $1 \mu 1$ aliquot via an Agilent 7683 auto sampler into the 6890/5973 GC/MSD. The samples were analyzed using the GC/MS method described in section 3.2.3. This information was compiled and a GC/MS method developed to conduct Selected Ion Monitoring (SIM).

3.2.5. Instrumental and biological evaluation of the effect of storage conditions on odor profiles

\section{Instrumental evaluation using SPME-GC/MS}

Five hand odor samples were collected per day from six subjects using the method described in section 2.2.2. Samples were collected from each subject over four consecutive days resulting in a total of 20 samples per subject. Collected hand odor samples were subjected to four different environmental conditions: room temperature, $80{ }^{\circ} \mathrm{C}$ temperatures, dark and UVA/UVB light.

Samples stored at room temperature were allowed to stand in sealed $10 \mathrm{ml}$ vial over a seven week period. These samples were subjected to ten hours of fluorescent lighting of approximately 300-500 lux and 14 hours of darkness. The room temperature was 
controlled to within $\pm 1{ }^{0} \mathrm{C}$ with an average temperature of $20{ }^{\circ} \mathrm{C}$ and an average relative humidity of $56 \pm 6 \%$. Temperature and humidity was monitored constantly throughout the life of the experiment using I-button thermochrons from Maxim Dallas, which were placed alongside the sealed vials.

Samples stored at $-80{ }^{0} \mathrm{C}$ were also sealed in a $10 \mathrm{ml}$ glass vial and temperature maintained at $-80{ }^{\circ} \mathrm{C} \pm 2{ }^{0} \mathrm{C}$. The extreme temperature of the $-80{ }^{\circ} \mathrm{C}$ storage did not allow environmental conditions to be monitored using I-buttons; as a result, temperature readings were obtained as indicated by an external digital display on the unit. Once removed from this condition for analysis, samples were allowed to equilibrate to ambient condition for 1.5 hours before being subjected to a 21 hour SPME extraction.

For the dark storage environment, a glass aquarium was completely enclosed with aluminum foil to prevent the entry of light (Figure 9). The average temperature and relative humidity in this container was $19{ }^{0} \mathrm{C} \pm 4{ }^{0} \mathrm{C}$ and $71 \% \pm 6 \%$ respectively. Again, I-buttons were used to record temperature and humidity throughout the life of the experiment. The container which was constructed for storage of the samples subjected to UVA/UVB light was only partially enclosed with aluminum foil with an opening at the top for the positioning of a UVA/UVB 500 lux light source (Figure 9). The $10 \mathrm{ml}$ glass vials which were used for the storage of the scent samples, offers no protection against the transmission of UV light. The samples stored in this condition were constantly exposed to the UVA/UVB light source for the duration of the storage period. The average temperature and relative humidity in this container was $22{ }^{\circ} \mathrm{C} \pm 2{ }^{0} \mathrm{C}$ and $63 \% \pm 3 \%$ respectively. 
Environmental controls were prepared by storing each of the three sorbent material types used for collection of hand odor samples in all four environmental conditions and monitored over the time period. The materials were all pre-cleaned using the SFE method which was previously discussed. Four of the five samples collected on each sorbent material were stored in each environmental condition and at the specific time period (week one, week three, week five and week seven) one was removed and analyzed using SPME-GC/MS (the fifth sample was used for week zero analysis).

Figure 9: Containers for storage of hand odor samples in the dark and in the presence of UVA/UVB light storage

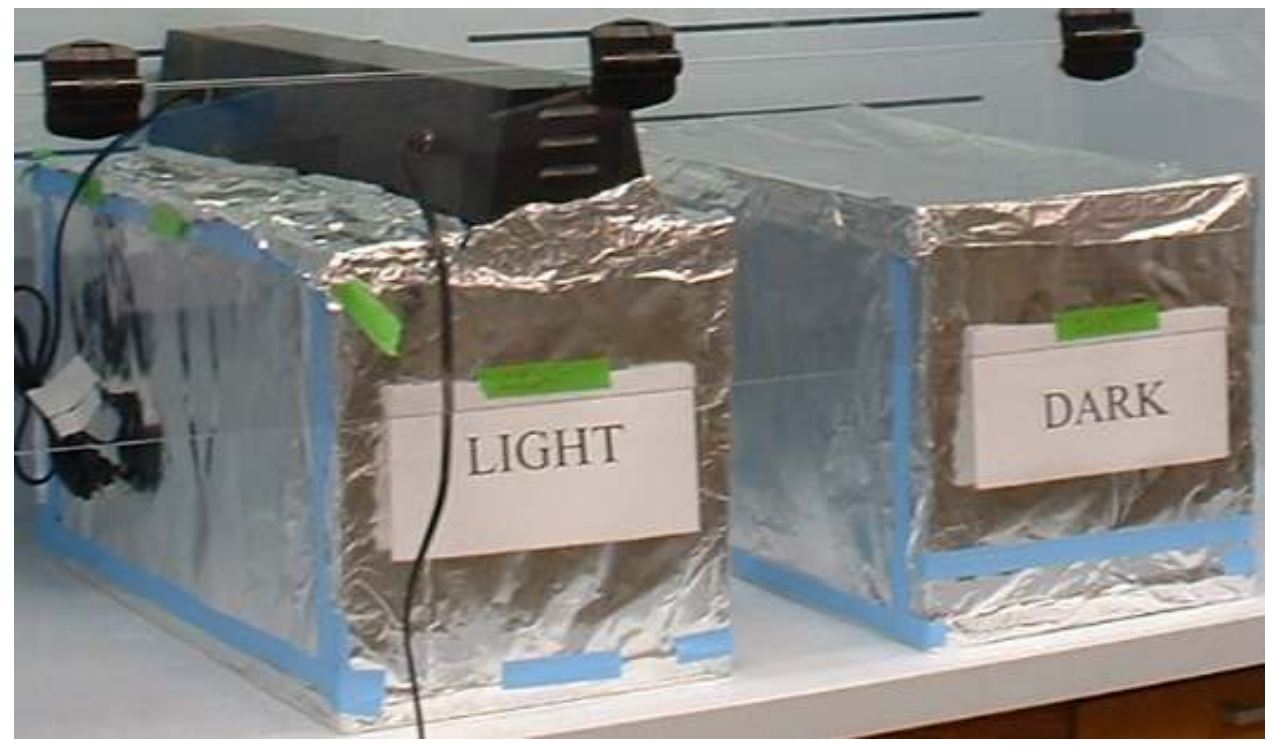

\section{Biological evaluation using human scent identification canines}

A preliminary canine trial was conducted using aged hand odor samples and a human scent identification canine team consisting of Detective Paul Dostie and Buster (Mammoth Lake Police Department, CA, USA). Five plastic containers were laid out in a straight line in a field. The target odor was placed in one of the containers. The target 
odor used was a fresh hand odor sample (week zero) which was collected from a male subject who held a 2x2 inch Dukal brand gauze pad for approximately 2 minutes between the palms of the hands. The canine was then directed to match the target odor to three different aged samples; fresh hand odor sample (week zero), five week old hand odor sample and a seven week old hand odor sample.

A more extensive study was later conducted in which aged hand odor samples stored in four different environmental conditions (room temperature, $-80{ }^{\circ} \mathrm{C}$ temperatures, dark and UVA/UVB light) were presented to a human scent identification canine. Four sets of hand odor samples collected from a male subject were stored in the different environmental conditions for one, two, five and seven week periods.

The canine was presented with the samples in the following order; room temperature, UVA/UVB, dark and $-80{ }^{\circ} \mathrm{C}$. Five plastic containers were laid out in a straight line in a field. The target odor was an aged sample which was placed in one of the containers. The remaining four odors were distracters which were less than one week old. The canine was then allowed to match a fresh hand odor sample collected from the subject to the target odor in the line up.

A positive control was performed at the beginning of the lineup in which the canine was allowed to match a fresh hand odor sample collected from the subject to a fresh hand odor sample placed in the line up (target). An alert was indicated by the canine sitting next to the box containing the target odor at which time the canine was rewarded with rubber ball fired from a Behavior Shaping Device (BSD) hidden within the target box. A negative control was also performed in which the canine was presented with a fresh hand odor sample collected from the subject. The lineup was comprised of all distracters. 
The distracter odors and the fresh odor presented to the canine were changed after eight lineups.

Table 2: Weather conditions for the duration of the human scent identification lineup

\begin{tabular}{|c|c|c|c|c|c|}
\hline Time & Temperature & Humidity & $\begin{array}{c}\text { Wind } \\
\text { Direction }\end{array}$ & Wind Speed & Condition \\
\hline $8 \mathrm{AM}$ & $\begin{array}{c}55^{0} \mathrm{~F} / 12.8 \\
{ }^{0} \mathrm{C}\end{array}$ & $47 \%$ & calm & calm & Clear \\
\hline $9 \mathrm{AM}$ & $\begin{array}{c}66{ }^{0} \mathrm{~F} / 18.9 \\
{ }^{0} \mathrm{C}\end{array}$ & $30 \%$ & calm & calm & Clear \\
\hline $10 \mathrm{AM}$ & $\begin{array}{c}72{ }^{0} \mathrm{~F} / 22.2 \\
{ }^{0} \mathrm{C}\end{array}$ & $20 \%$ & calm & calm & Clear \\
\hline $11 \mathrm{AM}$ & $\begin{array}{c}82{ }^{0} \mathrm{~F} / 27.8 \\
{ }^{0} \mathrm{C}\end{array}$ & $13 \%$ & South & $\begin{array}{l}4.6 \mathrm{mph} / \\
7.4 \mathrm{~km} / \mathrm{hr}\end{array}$ & Clear \\
\hline
\end{tabular}

3.2.6. Trapping and releasing capabilities of different sorbent materials

The results of the storage study revealed that hand odor samples which were collected from one individual on the three different materials resulted in the production of different odor profiles. A study was conducted to determine the differences in trapping and releasing capabilities of different sorbent materials.

Investigations were conducted by spiking the selected sorbent materials with $10 \mu 1$ of a $60 \mathrm{ppm}$ volatile organic compound (VOC) mixture. The VOC mixture was comprised of 
39 compounds previously reported as human scent compounds (Table 5). The materials were immediately sealed in $10 \mathrm{ml}$ glass screw top vials. Positive controls were made by placing $10 \mu \mathrm{l}$ of the VOC mixture directly in $10 \mathrm{ml}$ glass vial (no sorbent material was present). The vials were allowed to equilibrate for 24 hours prior to SPME headspace sampling. Quantitation of the recovered analytes was based on a five-point calibration curve $(5-60 \mathrm{ppm})$. Six replicate samples were analyzed for each material. Comparisons were made between the recovered amounts of VOCs for each of the materials analyzed.

\subsubsection{Collection of human scent from objects}

\section{Contact vs. non-contact (passive collection)}

Stainless steel metal bars were spiked with a standard compound mixture comprised of 40 compounds previously reported as human scent compounds $(10 \mu 1$ of a $60 \mathrm{ppm}$ mixture) (24). Sorbent materials (Dukal, Kings Cotton, Johnson \& Johnson) were exposed to the spiked stainless steel bars for various time periods; 3 hours, 4 hours, 5 hours, 6 hours, 8 hours and 12 hours. Twelve hours was chosen as the maximum time as preliminary experiments conducted showed no significant differences in the amount of compounds collected for time periods greater than twelve hours. Three hours was chosen as the minimum time as this is the time currently being used by the KLPD for passive collection of scent from objects.

For the contact passive collection method, the sorbent material was wrapped around the spiked stainless steel metal bar and both were then wrapped in aluminum foil (adapted from the Netherlands National Police) for the specified time periods (Figure 10). For the non-contact passive collection method, the sorbent material was placed in close, but not 
direct, contact with the spiked stainless steel metal bar for the specified time period. Both the bar and the sorbent material were sealed in a $500 \mathrm{ml}$ glass jar (Figure 10). Once the sorbent materials were exposed to the bars for the specific time periods, they were transferred into $10 \mathrm{ml}$ glass vials using clean stainless steel tweezers and allowed to equilibrate for $24 \mathrm{hrs}$ followed by 21 hour extraction using SPME, then analysis by GC/MS.

Figure 10: Passive collection of VOCs from objects (a) Contact (b) Non-contact

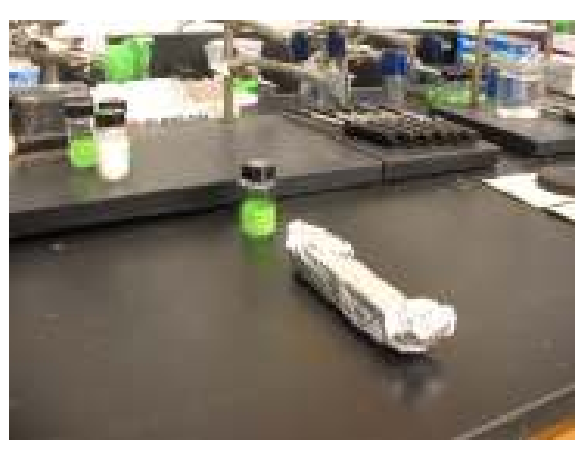

(a)

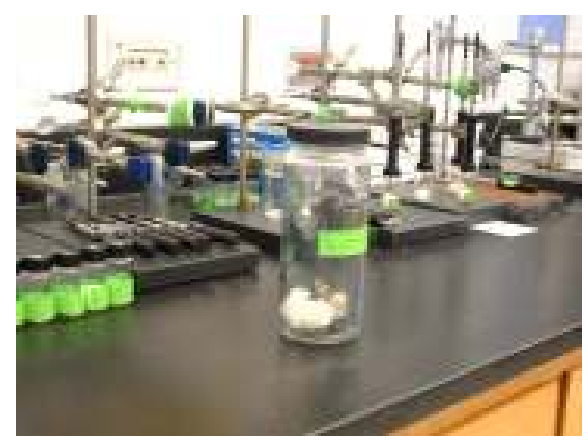

(b)

Contact vs. non-contact (active collection)

For the active collection of human scent from objects, a portable hand held device known as the scent transfer unit (STU-100) was used. The STU-100 has an inlet (hood) which is capable of holding a $12.5 \mathrm{~cm} \times 23.0 \mathrm{~cm}$ sorbent material for the collection of volatiles. As all samples were collected on sorbent materials measuring $2 \times 2$ inches, a metal plate with a circular opening measuring 1.5 inch in diameter was placed on the hood of the STU100 to hold these smaller pieces of materials in place.

The STU-100 has nine speed settings (one - nine) with nine being the lowest and one being the highest. The flow rates at each of the different speeds were calculated with and without sorbent materials. This was done by placing a cardboard adapter directly above 
the opening on the metal plate with an anemometer directly above the adapter. The STU100 was operated at each of the different speeds for ten seconds and the airflow recorded using the anemometer (Figure 11). Once the various flow rates were determined, the collection of scent from spiked bars was conducted.

Figure 11: Schematic representation of STU-100 showing metal plate and cardboard adapter used to measure airflow

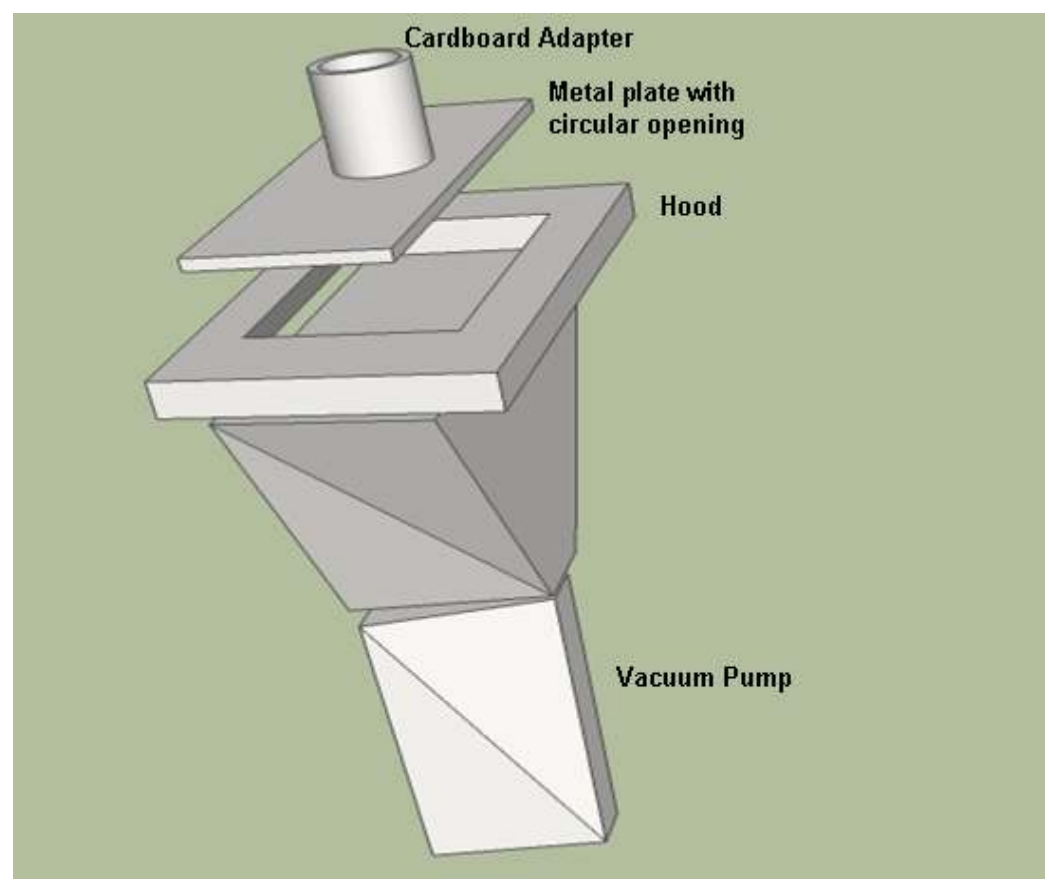

Stainless steel metal bars were spiked with a standard compound mixture comprised of 40 compounds previously reported as human scent compounds $(10 \mu 1$ of a $60 \mathrm{ppm}$ mixture). The scent transfer unit (STU-100) was used to collect the VOCs from the spiked bars onto the sorbent materials (Dukal, Kings Cotton, Johnson \& Johnson) using different speeds (one, three, five, seven, and nine) for one minute time periods. All samples were collected in a human scent collection chamber. The chamber is an enclosure that is equipped with a forced induction device which has removes 
approximately 60 percent of contaminants. This was done to minimize background contamination during sample collection.

For the contact method, the spiked bars were placed directly on the hood of the STU-100 while, for the non-contact method, the hood of the STU-100 was placed approximately one inch away from the spiked bars (Figure 12). The sorbent materials were then transferred into $10 \mathrm{ml}$ glass vials using clean stainless steel tweezers and allowed to equilibrate for 24 hours followed by a 21 hour extraction using SPME, then analysis by GC/MS. The optimum collection procedures were applied to hand odor samples.

Figure 12: Active collection of VOCs from objects (a) Contact (b) Non-contact

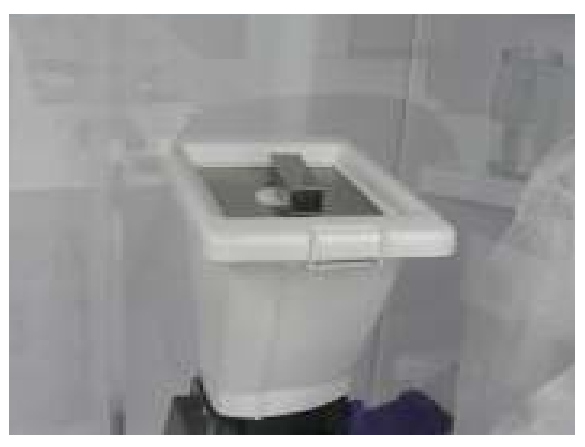

(a)

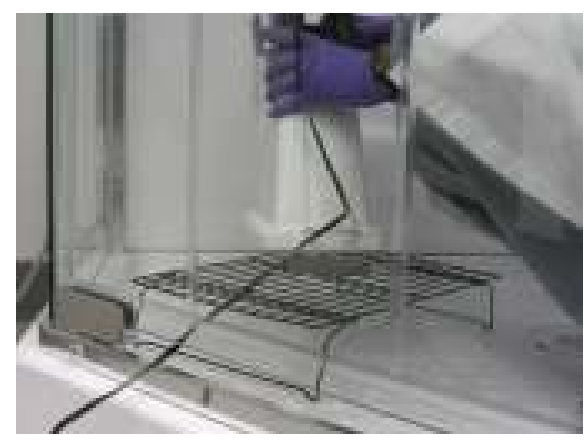

(b)

Activated charcoal strips (ACS) used for extraction of VOCs

A $60 \mathrm{ppm}$ standard solution which was comprised of 39 compounds previously reported as human scent compounds was used to spike pre-cleaned Dukal brand gauzes. The spiked gauzes were sealed in $10 \mathrm{ml}$ glass vials and allowed to equilibrate for 24 hours. Following equilibration, the ACS was suspended in the headspace of the $10 \mathrm{ml}$ glass vial for various time periods; $0.5,1,3,6,12$ and 24 hours. The strips were eluted with $500 \mu 1$ of carbon disulfide $\left(\mathrm{CS}_{2}\right)$ to recover the extracted VOCs from the ACS. A $1 \mu 1$ aliquot was injected via an Agilent 7683 auto sampler into the 6890/5973 GC/MSD. 


\subsubsection{Stainless steel bar hand sampling procedure}

Subjects were required to wash hands and forearms with clear Olive Oil Soap for 30 seconds, rinse with water for 2 minutes, air dry for 4 minutes, then rub the palms of hands over forearms for 5 minutes (24). Subjects then sampled themselves by holding precleaned stainless steel bars between the palms of the hands for 5 minutes, after which the hand in which the bar was being held was switched. The bars were then held for 5 additional minutes. The hand odor was then collected from the bars onto a sorbent material using either the contact/non-contact or passive/active collection method. The sorbent material was then placed back inside the $10 \mathrm{ml}$ glass vial and sealed.

\subsubsection{Analysis of shedder status}

\section{Canine Evaluations}

Human scent identification lineups conducted in the Netherlands using eleven individuals showed that the canines could easily identify six of the individuals but had difficulty identifying the other five individuals. Individuals were classified as "easily identified" and "difficult to identify".

SPME-GC/MS analysis

Hand odor samples were collected on pre-cleaned solon cotton tipped applicators from the eleven individuals in the Netherlands over a one week period (one sample per day until a total of three samples were obtained). Two individuals were unavailable for sampling on the third day (Table 3). Subjects were not required to wash their hands in an effort to facilitate the DNA analyses. Samples were shipped to Florida International University where headspace SPME-GC/MS analyses of the samples were conducted. 
Table 3: Samples collected from subjects for shedder/non-shedder analyses

\begin{tabular}{|c|c|}
\hline Subject ID & Number of samples collected \\
\hline 1 & Three \\
\hline 2 & Three \\
\hline 3 & Three \\
\hline 4 & Three \\
\hline 5 & Three \\
\hline 6 & Two \\
\hline 7 & Three \\
\hline 8 & Three \\
\hline 9 & Three \\
\hline 10 & Two \\
\hline 11 & Three \\
\hline
\end{tabular}

Human and microbial DNA analysis

Once SPME-GC/MS analyses were completed, the human and non-human components were extracted from collected hand odor samples using a QIAamp ${ }^{\circledR}$ DNA Micro Kit. The human DNA obtained was quantified using real-time polymerase chain reaction (PCR) (Mini Opticon, Biorad, Hercules, CA). For the microbial DNA analysis, PCR amplification was performed using fluorescently tagged eubacterial primers. PCR products were loaded on a 310 Genetic Analyzer (Applied Biosystems, Foster City, CA) and electropherograms indicative of the possible contributing microorganisms obtained. Data analysis was based on amplicon length heterogeneity, a technique that exploits the natural length variations of selected bacterial markers. GeneMapper v.3.7 software 
(Applied Biosystems, Foster City, CA) was used to analyze the data. DNA extractions and analyses for the human and non-human DNA from the hand odor samples were performed by the Forensic DNA Profiling Facility at Florida International University. The detailed extraction protocol used can be found in appendix B.

Head hair samples were also collected from the eleven individuals to determine shedder/non-shedder status using the quantities of nuclear DNA present in the hair samples. Hair samples collected had to be telogen shed hair based on a protocol developed by Dr Kerry Opel and Dr Bruce McCord. The numbers of telogen shed hairs obtained from the eleven subjects are shown in Table 4. The detailed extraction protocol can be found in appendix C.

Table 4: Number of telogen shed hairs obtained from eleven individuals

\begin{tabular}{|l|l|}
\hline \multicolumn{1}{|c|}{ Subject ID } & \multicolumn{1}{c|}{ Number of telogen shed hairs } \\
\hline 1 & No telogen shed hairs \\
\hline 2 & No telogen shed hairs \\
\hline 3 & Six \\
\hline 4 & Two \\
\hline 5 & Eight \\
\hline 6 & Four \\
\hline 7 & Four \\
\hline 8 & Two \\
\hline 9 & One \\
\hline 10 & No telogen shed hairs \\
\hline 11 & One \\
\hline
\end{tabular}




\subsubsection{Creation of Prototype Pseudo Human Scent}

\section{Collection of fractions using olfactory detection port (ODP)}

Preliminary fractionation studies were performed using a Gerstel ODP 2 olfactory detection port connected to an Agilent 6890/5973 GC/MS. One microliter of a $100 \mathrm{ppm}$ 40 compound standard mixture was spiked onto the GC column. Twenty percent of this solution was directed to the mass spectrometer with the remaining 80 percent directed to the ODP. The fractions were collected from the ODP at various time periods onto Dukal brand gauze. The various time periods at which the fractions were collected were; $6.00-$ 11.30 minutes (fraction \# 1), 11.41 - 16.55 minutes (fraction \#2), 16.65 - 22.00 minutes (fraction \#3) and $22.34-27.53$ minutes (fraction \#4).

Collection of fractions using a gas chromatograph flame ionization detector (GC/FID)

Subsequent fractionation studies were conducted using a Hewlett Packard GC/FID 5890 series 2, equipped with a Restek DB-5 column with a $0.53 \mathrm{~mm}$ x $30 \mathrm{~m}$ and a $0.5 \mu \mathrm{m}$ phase thickness. By performing liquid injections, $(2 \mu 1$ of a 200 ppm standard human scent compound mixture comprised of 39 compounds) the instrument parameters were optimized to allow separation of the compounds of interest. Helium carrier gas was maintained at a constant pressure of 4 psi. The injection port temperature was maintained at $250{ }^{\circ} \mathrm{C}$ with splitless injections performed. The purge valve was not turned on. An initial GC oven temperature of $40{ }^{\circ} \mathrm{C}$ was held for 5 minutes, followed by a temperature ramp of $10{ }^{\circ} \mathrm{C}$ per minute to a final temperature of $250{ }^{\circ} \mathrm{C}$ which was held for 2 minutes. The detector temperature was set to $250{ }^{\circ} \mathrm{C}$.

Having determined that the compounds of interest could be separated by liquid injection, the next step was to determine optimal separation of VOCs. Using the optimized GC/FID 
method, injection of human scent VOCs were performed using a Hewlett Packard 7694 Headspace Analyzer equipped with a $1 \mathrm{ml}$ sample loop and compared to a 50/30 $\mu \mathrm{m}$ DVB/CAR/PDMS SPME fiber extraction to establish the technique that delivers the greatest mass of VOCs. An optimized headspace analyzer method was developed by spiking Dukal brand gauzes with $2 \mu 1$ of a $200 \mathrm{ppm}$ standard human scent compound mixture comprised of 40 compounds. The spiked gauzes were placed in $10 \mathrm{ml}$ glass vials. The optimized method parameters include a transfer line temperature of $200{ }^{\circ} \mathrm{C}$, an oven temperature of $105{ }^{\circ} \mathrm{C}$ and a sample loop temperature of $120{ }^{\circ} \mathrm{C}$. The $\mathrm{GC}$ cycle time was 34 minutes, the vial equilibration time was 30 minutes, pressurization time was 0.1 minute, loop fill time was 0.3 minutes and injection time was 0.3 minutes. The carrier gas pressure was maintained at $7.7 \mathrm{psi}$ and the vial pressure was maintained at $21 \mathrm{psi}$. This optimized collection technique was compared to the previously developed 21 hour SPME method.

Once the various parameters were optimized, the FID portion of the GC/FID was disconnected to facilitate collection of the various fractions. The GC column was also adjusted to within $3 \mathrm{~cm}$ of the opening of the FID. Fractions were collected by placing an inverted $10 \mathrm{ml}$ glass vial containing a pre-cleaned Dukal brand gauze over the opening of the FID (Figure 13). A negative control was first collected followed by a positive control. For the negative control, no sample was injected while for the positive control, a sample was injected and the entire chromatographic separation (28 minutes) collected onto Dukal brand gauze. The fractions were collected at various time periods which were; $4.00-$ 10.50 minutes (fraction \# 1), $10.50-16.00$ minutes (fraction \#2), $16.00-20.00$ minutes (fraction \#3) and 20.00 - 28.00 minutes (fraction \#4). To increase the mass of VOCs 
being trapped onto the Dukal brand gauze, triplicate SPME injections were performed and the appropriate fractions collected onto one set of Dukal brand gauzes.

Figure 13: Picture showing collection of human scent compound fractions using a GC/FID

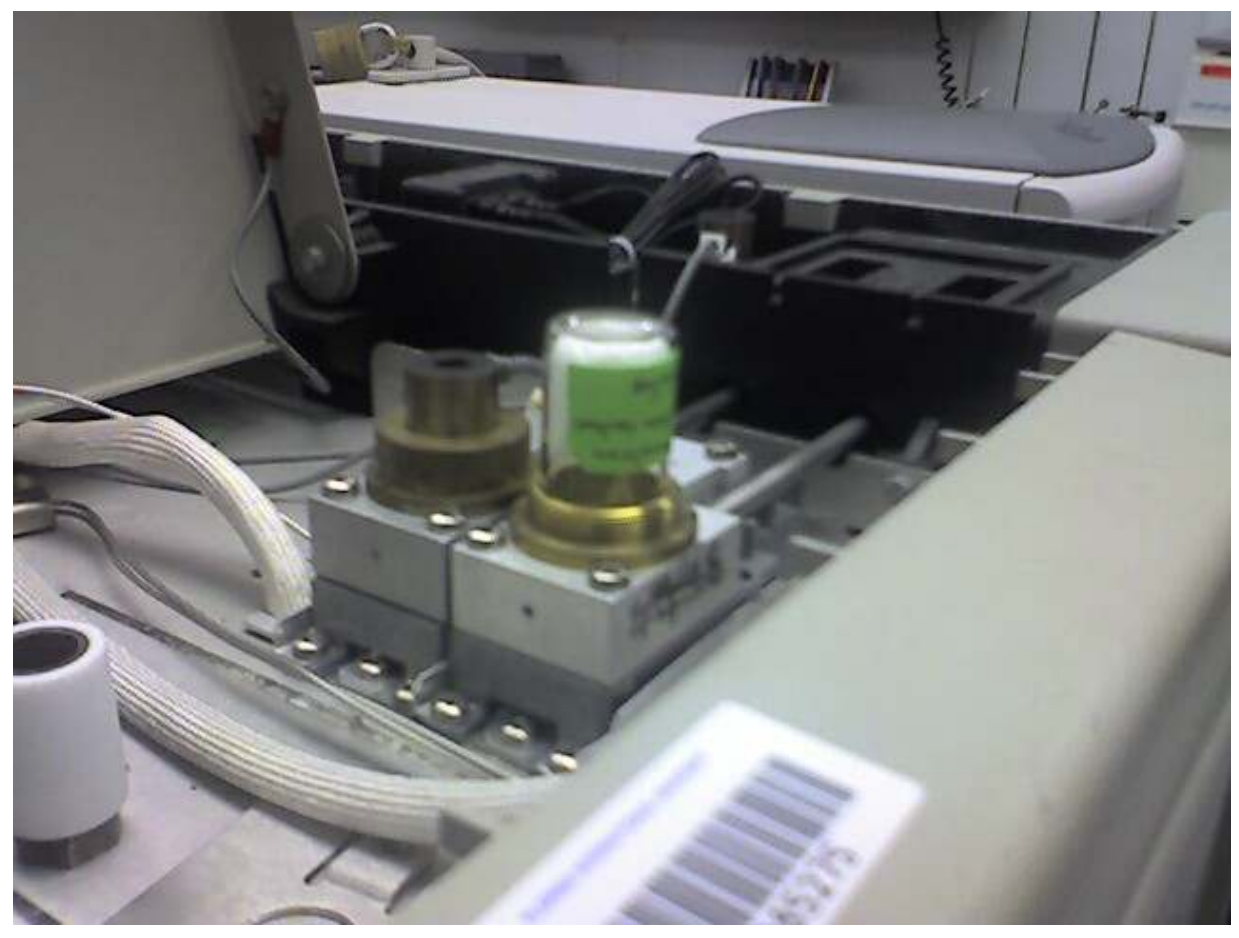

3.2.11. Discriminating between VOCs in hand odor samples from twins using SPME-GC/MS

Duplicate hand odor samples were collected from three sets of cohabitating monozygotic twins and three sets of cohabitating dizygotic twins as described in section 3.2.2. There were two related pairs (siblings) and four non-related pairs. The average age of the twins was 16.2 years. 


\subsection{Statistical Evaluation}

\subsubsection{Three Dimensional Covariance Mapping}

Three dimensional covariance mapping was used for the analysis of the data by using mass spectrometry software to export a data matrix comprised of the individual ion abundances for each mass-to-charge ratio for the mass spectra data from scan 2000-6600 of the chromatographic analysis. The covariance matrix is computed by pre-multiplying the exported matrix by its transpose (the rows of the original sample become columns and vice versa). The computed matrix is normalized and two matrices are compared analytically by calculating a distance, D. D is calculated according to the equation below (71):

$$
D=\frac{\sum_{i} \sum_{j}\left|Z_{N 1}(i j)-Z_{N 2}(i j)\right|}{2} \text { Equation 6 }
$$

$\mathrm{Zn}$ represents the covariance matrix which is the normalized such that the sum of all matrix elements equal one. The maximum value that can be obtained is one and so a similarity index, S, based on D can also be calculated using the equation below:

$$
S=1-D \quad \text { Equation } 7
$$

The similarity index produces values between 0 and $1 ; 1$ demonstrates similarity while a value of 0 shows total dissimilarity.

\subsubsection{Analysis of Variance (ANOVA)}

One way ANOVA was also performed using Microsoft Excel to compare the mean masses recovered from the different sorbent materials. Analysis of variance was used to 
determine if the differences in mean masses between the three sorbents were statistically significant at an alpha value of 0.05 . Within sample variation is given by the equation below:

$$
\frac{\sum\left(x_{i}-\bar{x}\right)^{2}}{n-1} \text { Equation } 8
$$

A Fisher's Least Significant Difference (LSD) post hoc test was used to compare the means if the null hypothesis was rejected using the ANOVA F-test. The least significant difference is given by:

$$
\sqrt[s]{\left(\frac{2}{n}\right)} \times t_{h(n-1)} \quad \text { Equation } 9
$$

Where $\mathrm{s}$ is the within sample estimate and $\mathrm{h}(\mathrm{n}-1)$ is the number of degrees of freedom of this estimate (72).

\subsubsection{Bray Curtis Similarity Index}

Bray Curtis distance sometimes called Sorensen distance is a normalization method commonly used for biological data to compare the similarity of two samples. The Bray Curtis distance gives values between zero and one. A Bray Curtis value of zero represents exact similar coordinates. If both objects are in the zero coordinates, the Bray Curtis distance is undefined. The normalization is done using absolute difference divided by the summation.

$$
S=100\left(1-\frac{\sum_{i}\left|y_{i 1}-y_{i 2}\right|}{\sum_{i} y_{i 1}+\sum_{i} y_{i 2}}\right) \quad \text { Equation } 10
$$


Where $y_{i 1}$ is the peak area for the $i^{\text {th }}$ compound from sample 1 and $\Sigma_{\mathrm{i}}(\ldots)$ denotes the summation over the compounds.

Multi-dimensional scaling plots and hierarchical clusters represented by dendrograms based on the Bray Curtis similarity were constructed using the software PRIMER 6 (Clarke et al. PRIMER-E Ltd, Plymouth, United Kingdom). Multidimensional scaling plots were used to demonstrate the similarity in bacterial communities present in hand odor samples while dendrograms were used to show the similarity between VOCs present in the hand odor samples of twins. 


\section{RESULTS AND DISCUSSION}

4.1. Optimization of collection and analysis methods for human scent samples

Thirty nine standard compounds were purchased from Sigma Aldrich to be used for the optimization of the GC/MS procedure for the separation of human scent compounds both in full scan and in SIM mode. These were some of the compounds previously reported as components of human scent which were detected in collected hand odor samples. The frequencies of occurrence of the chosen compounds are shown in Table 5. This data was obtained from a study performed by Curran et al. (27). The properties of the compounds of interest are shown in Table 6.

Table 5: List of compounds previously reported as human scent compounds and their frequency of occurrence in a population study

\begin{tabular}{|l|c|}
\hline & \\
\hline Compound & Frequency of occurrence (\%) \\
\hline Octane & 1.67 \\
\hline Furfural & 98.33 \\
\hline 2-Furanmethanol & 81.67 \\
\hline Nonane & 20.00 \\
\hline Heptanal & 13.33 \\
\hline Propanedioic acid, dimethyl ester & 56.67 \\
\hline Benzaldehyde & 15.00 \\
\hline Phenol & 100.00 \\
\hline 6-methyl-5-Hepten-2-one & 40.00 \\
\hline Octanal & 16.67 \\
\hline Benzyl Alcohol & 15.00 \\
\hline 2-Octenal, (E) & Not Reported \\
\hline 1-Octanol & 5.00 \\
\hline Undecane & 10.00 \\
\hline
\end{tabular}




\begin{tabular}{|l|c|}
\hline 3,7-dimethyl-1,6-Octadien-3-ol & 20.00 \\
\hline Nonanal & 100.00 \\
\hline Phenylethyl Alcohol & 5.00 \\
\hline Octanoic acid, methyl ester & 33.33 \\
\hline 1-Nonanol & 3.33 \\
\hline Naphthalene & 5.00 \\
\hline 2-Decanone & 3.33 \\
\hline Dodecane & 33.33 \\
\hline Decanal & 100.00 \\
\hline Hexanedioic acid, dimethyl ester & 73.33 \\
\hline Tridecane & 28.33 \\
\hline Undecanal & 38.33 \\
\hline n-Decanoic acid & 1.67 \\
\hline Tetradecane & 41.67 \\
\hline Dodecanal & 3.33 \\
\hline 6,10-dimethyl-5,9-undecadien-2-one & 65.00 \\
\hline Pentadecane & 1.67 \\
\hline Tridecanal & 5.00 \\
\hline Dodecanoic acid, methyl ester & 20.00 \\
\hline Dodecanoic acid & 21.67 \\
\hline Hexadecane & 1.67 \\
\hline Heptadecane & 5.00 \\
\hline Methyl tetradecanoate & 6.67 \\
\hline Pentadecanoic acid & 5.00 \\
\hline Hexadecanoic acid, methyl ester & \\
\hline & \\
\hline
\end{tabular}


Table 6: Properties of the compounds used for optimization of the GC/MS procedure for optimal separation of human scent samples

\begin{tabular}{|c|c|c|}
\hline Compound Name & Molecular Weight (g/mol) & BP $\left({ }^{0} \mathrm{C}\right)$ \\
\hline \multicolumn{3}{|c|}{ Acids } \\
\hline Dodecanoic Acid & 200 & 225 \\
\hline Pentadecanoic acid & 242 & 257 \\
\hline Decanoic Acid & 172 & 269 \\
\hline \multicolumn{3}{|c|}{ Alcohols } \\
\hline 2-Furanmethanol & 98 & 171 \\
\hline Phenol & 94 & 182 \\
\hline 3,7-dimethyl-1,6-octadien-3-ol & 154 & 198 \\
\hline Benzyl alcohol & 108 & 205 \\
\hline Phenylethyl alcohol & 122 & 219 \\
\hline 1-octanol & 130 & 195 \\
\hline Nonanol & 144 & 215 \\
\hline \multicolumn{3}{|c|}{ Aldehydes } \\
\hline Furfural & 96 & 162 \\
\hline Heptanal & 114 & 153 \\
\hline Benzaldehyde & 106 & 178 \\
\hline Octanal & 128 & 163 \\
\hline Nonanal & 142 & 93 \\
\hline Decanal & 156 & 207 \\
\hline Dodecanal & 184 & 240 \\
\hline Undecanal & 170 & 223 \\
\hline (E)-2-Octenal & 126 & 84 \\
\hline Tridecanal & 198 & 132 \\
\hline \multicolumn{3}{|c|}{ Aliphatics/Aromatics } \\
\hline Octane & 114 & 125 \\
\hline Nonane & 128 & 151 \\
\hline Undecane & 156 & 196 \\
\hline
\end{tabular}




\begin{tabular}{|c|c|c|}
\hline Naphthalene & 128 & 218 \\
\hline Dodecane & 170 & 216 \\
\hline Pentadecane & 212 & 268 \\
\hline Tridecane & 184 & 234 \\
\hline Tetradecane & 198 & 253 \\
\hline Hexadecane & 226 & 287 \\
\hline Heptadecane & 240 & 302 \\
\hline \multicolumn{3}{|c|}{ Ketones } \\
\hline 6-methyl-5-hepten-2-one & 126 & 73 \\
\hline 6,10-dimethyl-5,9-undecadien-2-one & 194 & 254 \\
\hline 2-Decanone & 156 & 209 \\
\hline \multicolumn{3}{|c|}{ Esters } \\
\hline Propanedioic acid, dimethyl ester & 160 & 183 \\
\hline Octanoic acid, methyl ester & 158 & 79 \\
\hline Hexanedioic acid, dimethyl ester & 174 & 109 \\
\hline Dodecanoic acid, methyl ester & 214 & 261 \\
\hline Methyl Tetradecanoate & 242 & 323 \\
\hline Hexadecanoic acid, methyl ester & 271 & 185 \\
\hline
\end{tabular}

\subsubsection{Optimization of a full scan GC/MS method}

Different GC temperature ramps were evaluated in an effort to provide optimal separation of all compounds. For all analyses, $1 \mu \mathrm{l}$ of a $60 \mathrm{ppm}$ standard mixture was injected onto the GC/MS. Some of the chromatograms obtained using different temperature ramps are shown in Figure 14. Listed below are the parameters for some of the different temperature ramps which were evaluated.

(A) - initial oven temperature of $40{ }^{0} \mathrm{C}$, hold for 5 minutes, ramp to $80{ }^{\circ} \mathrm{C}$ at $10{ }^{\circ} \mathrm{C} /$ minute and hold for 2.75 minutes, ramp to $150{ }^{0} \mathrm{C}$ at $10{ }^{\circ} \mathrm{C} /$ minute and hold for 2.5 minutes then ramp to $300{ }^{0} \mathrm{C}$ at $50{ }^{0} \mathrm{C} /$ minute. 
(B) - initial oven temperature of $40{ }^{\circ} \mathrm{C}$, hold for 5 minutes, ramp to $80{ }^{\circ} \mathrm{C}$ at $10{ }^{\circ} \mathrm{C} /$ minute and hold for 2.75 minutes, ramp to $180{ }^{\circ} \mathrm{C}$ at $5{ }^{\circ} \mathrm{C}$ /minute and hold for 2.5 minutes then ramp to $300{ }^{\circ} \mathrm{C}$ at $50{ }^{\circ} \mathrm{C} /$ minute.

(C) - initial oven temperature of $40{ }^{\circ} \mathrm{C}$, hold for 2 minutes, ramp to $100{ }^{0} \mathrm{C}$ at 10 ${ }^{0} \mathrm{C} /$ minute and hold for 1 minute, ramp to $180{ }^{0} \mathrm{C}$ at $10{ }^{\circ} \mathrm{C} /$ minute and hold for 2.5 minutes then ramp to $300{ }^{\circ} \mathrm{C}$ at $50{ }^{\circ} \mathrm{C} /$ minute.

(D) - initial oven temperature of $40{ }^{0} \mathrm{C}$, hold for 2 minutes, ramp to $100{ }^{\circ} \mathrm{C}$ at 10 ${ }^{0} \mathrm{C} /$ minute and hold for 1 minute, ramp to $150{ }^{0} \mathrm{C}$ at $10{ }^{\circ} \mathrm{C} /$ minute and hold for 2.5 minutes then ramp to $300{ }^{\circ} \mathrm{C}$ at $80{ }^{\circ} \mathrm{C} /$ minute.

Figure 14: Examples of different temperature ramps evaluated to obtain optimum separation of human scent compounds

A
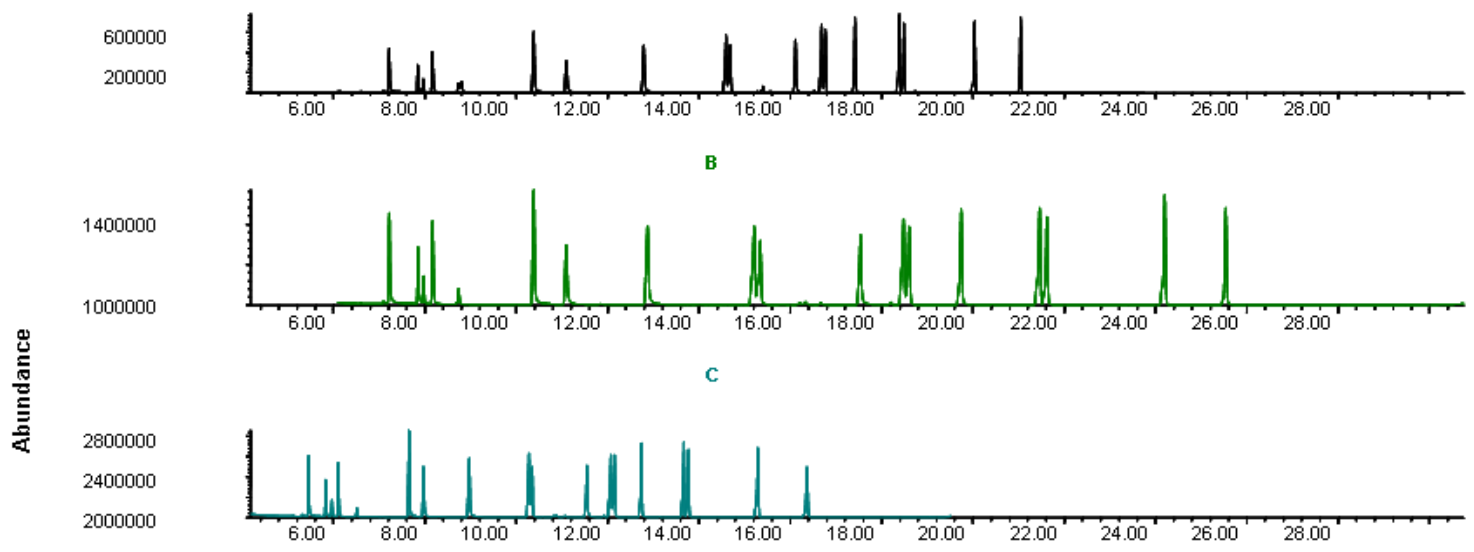

D

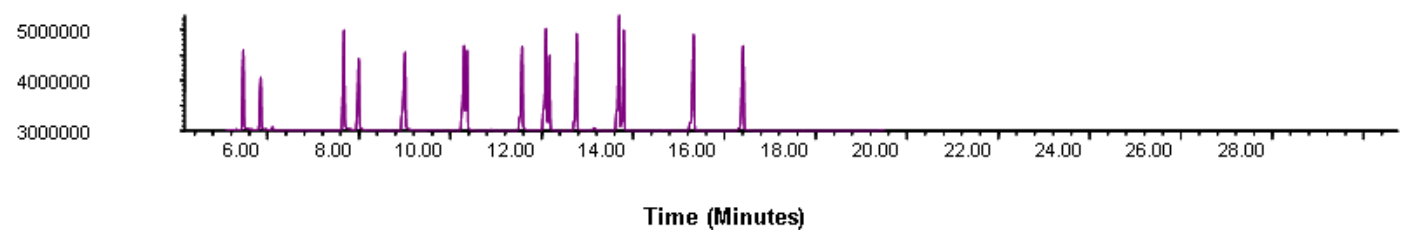


It was determined that an initial GC oven temperature of $40{ }^{0} \mathrm{C}$ held for 5 minutes, followed by a temperature ramp of $10{ }^{\circ} \mathrm{C}$ per minute to a final temperature of $250{ }^{\circ} \mathrm{C}$ and held for 2 minutes provided optimal separation of the human scent compounds and also reduced column bleed and analysis time. Two of the more problematic compounds were undecane (retention time of 12.99 minutes) and 3, 7-dimethyl-1, 6-octadien-3-ol (retention time of 13.025 minutes). These compounds were extremely difficult to separate due to their close retention times. With the chosen method, undecane and 3, 7-dimethyl1, 6-octadien-3-ol could be separated, but only at concentrations above $20 \mathrm{ppm}(\mathrm{ng} / \mu \mathrm{l})$. A narrowing of the spectrometer scan range was also evaluated using seven of the thirtynine compounds previously reported as high frequency human scent compounds by Curran et al. (27). The compounds used were furfural, 2-furanmethanol, phenol, nonanal, decanal, hexanedioic acid dimethyl ester and 6, 10-dimethyl-5, 9-undecadien-2-one. The mass spectrometer scan range was narrowed from the default setting of 45-550 to 39-300 based on the mass fragments and the molecular masses of the compounds of interest.

One microliter of a $60 \mathrm{ppm}$ standard mixture containing the seven high frequency compounds were injected into the GC/MS and analyses were performed using both the 45-550 scan range and the 39-300 scan range. Using both methods, all seven compounds were detected with the narrowing of the scan range producing increased abundances and also an increase of approximately 25 percent in the detected mass of compounds (Figure 15 and Figure 16). By narrowing the scan range, greater numbers of scans were achieved per unit time for the various $\mathrm{m} / \mathrm{z}$ ratios resulting in improved sensitivity. 
Figure 15: Abundances obtained for standard human scent compounds analyzed using mass spectrometer scan ranges of 45-550 and 39-300

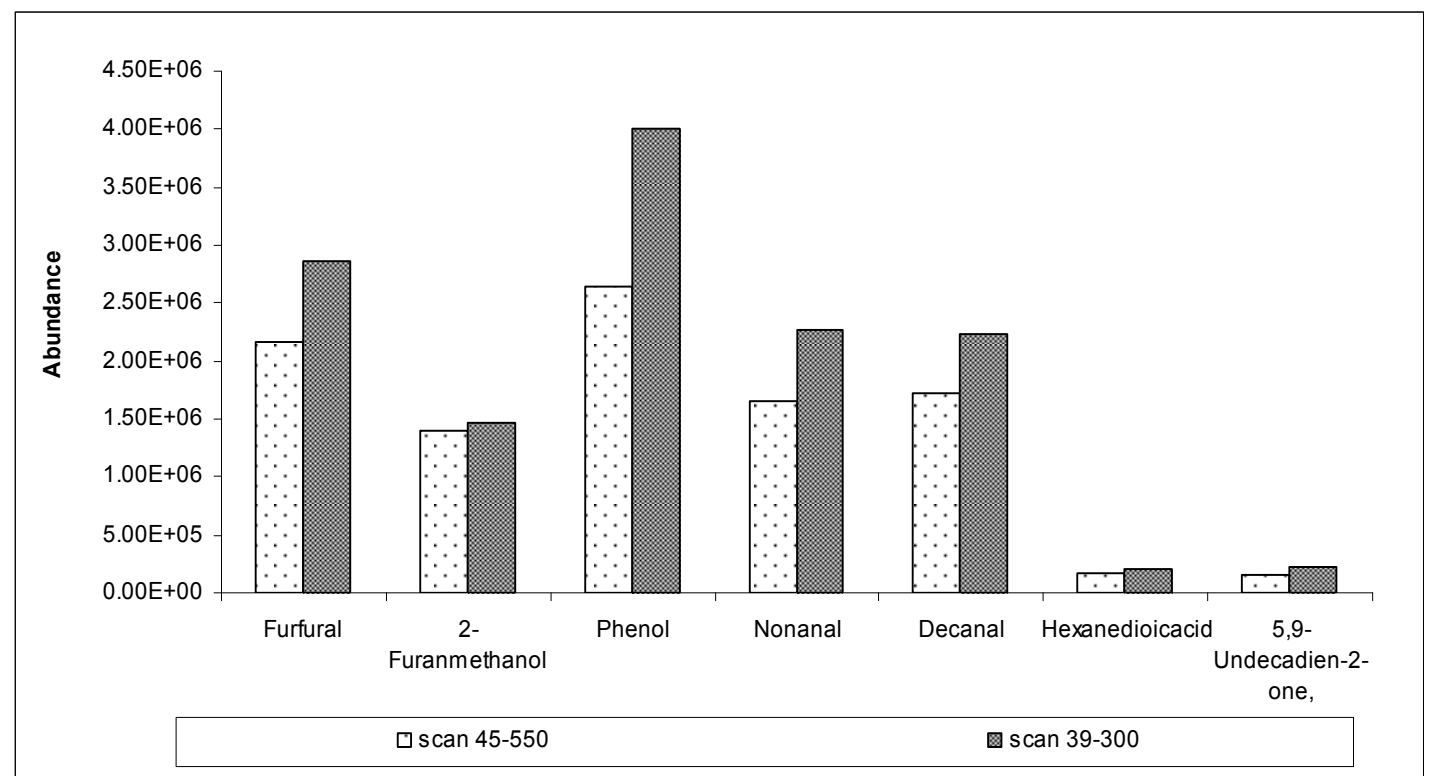

Figure 16: Ratio of standard human scent compounds analyzed using mass spectrometer scan ranges of 45-550 and 39-300

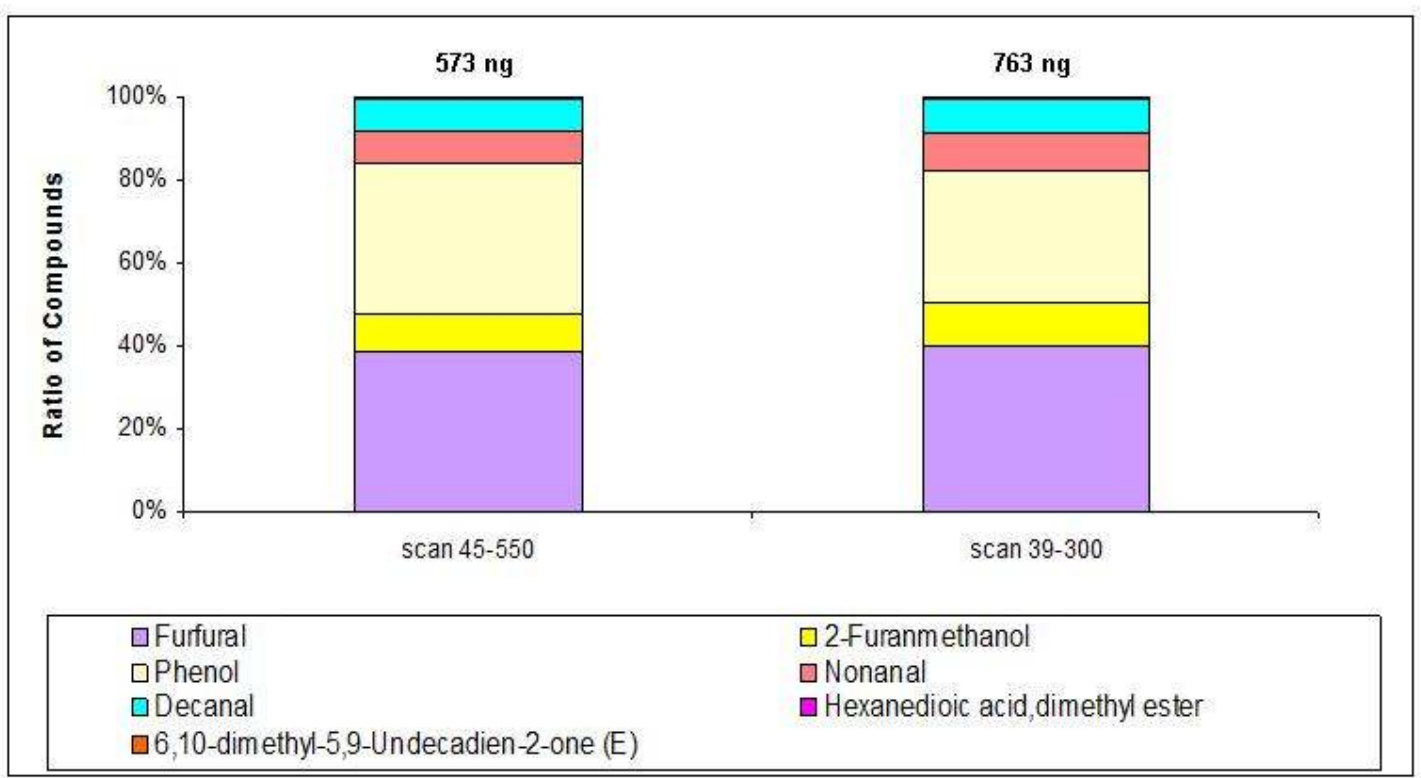


The thirty nine standard compounds were analyzed in full scan mode using the optimized GC/MS procedure that was developed. This was performed to obtain the relevant retention times and the mass fragments for all the compounds which would be used to generate a SIM method. Five point calibration curves (5 ppm, 10 ppm, 20 ppm, 40 ppm and $60 \mathrm{ppm}$ ) were also generated for all the compounds and these calibration curves were used to quantify analyzed samples. Calibration curves were analyzed by injecting $1 \mu \mathrm{L}$ of each concentration in triplicates. Calibration curves were analyzed on a weekly basis. Some calibration curves which were generated can be found in appendix A. The error bars shown represent two standard deviations ( $95 \%$ confidence interval).

\subsubsection{Development of a selected ion monitoring (SIM) GC/MS method}

In mass spectrometry analysis, data can be acquired using a full scan method or a selected ion monitoring method (SIM). SIM is a data acquisition technique in which only a few selected ion fragments are monitored as the spectrometer is set at a specific $\mathrm{m} / \mathrm{z}$ value in order to obtain maximum sensitivity. This increased sensitivity is often a result of increased collection time of the selected ions so a greater number of ions strike the detector. The data that were obtained by analyzing the standard compounds in full scan mode was used to develop a SIM method. The retention times and the qualifying ions used for development of the SIM method are listed below. 
Table 7: Retention times and qualifying ions of standard compounds used to develop GC/MS SIM method

\begin{tabular}{|c|c|c|c|c|c|c|}
\hline $\begin{array}{l}\text { Compound } \\
\text { Name }\end{array}$ & $\begin{array}{l}\text { Retention } \\
\text { Time } \\
\text { (Minutes) }\end{array}$ & $\begin{array}{l}\text { Molecular } \\
\text { Weight } \\
\text { (g/mol) }\end{array}$ & $\begin{array}{l}\text { Qualifying } \\
\text { ion 1 }\end{array}$ & $\begin{array}{l}\text { Qualifying } \\
\text { ion 2 }\end{array}$ & $\begin{array}{l}\text { Qualifying } \\
\text { ion 3 }\end{array}$ & $\begin{array}{l}\text { Qualifying } \\
\text { ion } 4\end{array}$ \\
\hline Octane & 6.407 & 114 & 43 & 85 & 57 & 114 \\
\hline Furfural & 7.356 & 96 & 96 & 95 & 39 & \\
\hline 2-Furanmethanol & 7.983 & 98 & 98 & 97 & 81 & 41 \\
\hline Nonane & 9.015 & 128 & 57 & 43 & 41 & 70 \\
\hline Heptanal & 9.065 & 114 & 70 & 44 & 55 & 41 \\
\hline $\begin{array}{l}\text { Propanedioic acid } \\
\text { dimethyl ester }\end{array}$ & 9.74 & 132 & 101 & 59 & 74 & 57 \\
\hline Benzaldehyde & 10.385 & 106 & 106 & 105 & 77 & 51 \\
\hline Phenol & 10.851 & 94 & 94 & 66 & 65 & 39 \\
\hline $\begin{array}{l}\text { 6-methyl-5- } \\
\text { hepten-2-one }\end{array}$ & 10.949 & 126 & 43 & 108 & 69 & 41 \\
\hline Octanal & 11.249 & 128 & 43 & 41 & 57 & 84 \\
\hline Benzyl Alcohol & 11.882 & 108 & 108 & 79 & 107 & 77 \\
\hline 2-Octenal(E) & 12.288 & 126 & 70 & 55 & 41 & 83 \\
\hline 1-Octanol & 12.503 & 130 & 56 & 55 & 69 & 70 \\
\hline Undecane & 12.99 & 156 & 57 & 43 & 71 & 41 \\
\hline $\begin{array}{l}\text { 3,7-dimethyl-1,6- } \\
\text { octadien-3-ol }\end{array}$ & 13.025 & 154 & 71 & 43 & 57 & 93 \\
\hline Nonanal & 13.085 & 142 & 57 & 41 & 56 & 98 \\
\hline $\begin{array}{l}\text { Phenylethyl } \\
\text { Alcohol }\end{array}$ & 13.294 & 122 & 91 & 92 & 122 & 65 \\
\hline $\begin{array}{l}\text { Octanoic Acid } \\
\text { Methyl Ester }\end{array}$ & 13.405 & 158 & 74 & 87 & 127 & 43 \\
\hline Nonanol & 14.168 & 144 & 56 & 55 & 70 & 69 \\
\hline Naphthalene & 14.468 & 128 & 128 & 127 & 129 & \\
\hline
\end{tabular}




\begin{tabular}{|c|c|c|c|c|c|c|}
\hline 2-Decanone & 14.506 & 156 & 58 & 43 & 71 & 59 \\
\hline Dodecane & 14.595 & 170 & 57 & 71 & 43 & 85 \\
\hline Decanal & 14.709 & 156 & 57 & 41 & 43 & 55 \\
\hline $\begin{array}{l}\text { Hexanedioic acid } \\
\text { dimethyl ester }\end{array}$ & 15.26 & 174 & 114 & 111 & 143 & 59 \\
\hline Tridecane & 16.054 & 184 & 57 & 71 & 43 & 85 \\
\hline Undecanal & 16.184 & 170 & 57 & 82 & 43 & 41 \\
\hline n-Decanoic acid & 17.083 & 172 & 73 & 60 & 129 & 55 \\
\hline Tetradecane & 17.415 & 198 & 57 & 71 & 43 & 85 \\
\hline Dodecanal & 17.561 & 184 & 57 & 82 & 41 & 43 \\
\hline $\begin{array}{l}\text { 6,10-dimethyl- } \\
\text { 5,9-Undecadien- } \\
\text { 2-one }\end{array}$ & 18.137 & 194 & 43 & 69 & 41 & 151 \\
\hline Pentadecane & 18.69 & 212 & 57 & 71 & 43 & 85 \\
\hline Tridecanal & 18.852 & 198 & 82 & 57 & 43 & 41 \\
\hline $\begin{array}{l}\text { Dodecanoic } \\
\text { acid,methyl este }\end{array}$ & 18.994 & 214 & 74 & 87 & 143 & 171 \\
\hline Dodecanoic acid & 19.504 & 200 & 73 & 60 & 129 & 157 \\
\hline Hexadecane & 19.89 & 226 & 57 & 71 & 85 & 43 \\
\hline Heptadecane & 21.033 & 240 & 57 & 71 & 85 & 43 \\
\hline $\begin{array}{l}\text { Methyl } \\
\text { Tetradecanoate }\end{array}$ & 21.311 & 242 & 74 & 87 & 143 & 199 \\
\hline $\begin{array}{l}\text { Pentadecanoic } \\
\text { acid }\end{array}$ & 22.764 & 242 & 73 & 60 & 129 & 43 \\
\hline $\begin{array}{l}\text { Hexadecanoic } \\
\text { acid methyl ester }\end{array}$ & 23.422 & 270 & 74 & 87 & 143 & 227 \\
\hline
\end{tabular}


All 39 standard compounds were analyzed using both the developed SIM method and the existing full scan method. There is always error associated with instrumental analyses and an important aspect that has to be addressed is how large a signal has to be in order to be distinguishable for background noise. The accepted rule in analytical chemistry is that the signal has to be three times greater than the background noise. This is formally known as the limit of detection (LOD). LOD can be calculated using the calibration data and the regression statistics; the y-intercept and standard deviation of the regression. The LOD of a technique is calculated with the aid of the slope and the $S_{y / x}$ values.

$$
Y_{L O D}=a+3 S_{y / x} \quad \text { Equation } 11
$$

Where "a" is the $\mathrm{y}$-intercept and " $\mathrm{S} / \mathrm{x}$ " is the standard deviation of the regression which was calculated using Microsoft excel.

The limit of quantitation (LOQ) which is defined as the limit for precise quantitative measurements can also be determined by:

$$
Y_{L O Q}=a+10 S_{y / x} \text { Equation } 12
$$

Comparisons between both methods, full scan and SIM, have not shown much difference in the limits of detection of the methods (Table 8). The sensitivity of a technique is defined as the slope of the calibration curve provided the plot is linear. A comparison of the slopes for the full scan and the SIM method did show increases in sensitivity for some compounds but not all as shown by Table 9 . 
Table 8: Limits of detection and quantitation of Agilent 6890/5973 GC/MS using full scan and SIM methods

\begin{tabular}{|c|c|c|c|c|}
\hline \multirow[b]{2}{*}{ Compound } & \multicolumn{2}{|c|}{ Full Scan } & \multicolumn{2}{|c|}{ SIM } \\
\hline & LOD (ng) & LOQ (ng) & LOD(ng) & LOQ (ng) \\
\hline Octane & 7.68 & 25.59 & 6.35 & 21.17 \\
\hline Furfural & 4.92 & 16.40 & 4.86 & 16.20 \\
\hline 2-Furanmethanol & 3.23 & 10.78 & 4.03 & 13.44 \\
\hline Nonane & 5.69 & 18.97 & 7.00 & 23.32 \\
\hline Heptanal & 4.65 & 15.51 & 29.83 & 99.42 \\
\hline Propanedioic acid, dimethyl ester & 1.54 & 5.14 & 2.89 & 9.62 \\
\hline Benzaldehyde & 4.17 & 13.91 & 4.87 & 16.22 \\
\hline Phenol & 1.27 & 4.22 & 1.13 & 3.77 \\
\hline 6-methyl-5-Hepten-2-one, & 19.74 & 65.79 & 6.59 & 21.96 \\
\hline Octanal & 3.71 & 12.38 & 6.37 & 21.25 \\
\hline Benzyl Alcohol & 1.02 & 3.40 & 3.57 & 11.92 \\
\hline 2-Octenal, (E)- & 3.76 & 12.52 & 4.68 & 15.61 \\
\hline 1-Octanol & 0.76 & 2.52 & 6.03 & 20.10 \\
\hline Undecane & 19.53 & 65.11 & 6.21 & 20.71 \\
\hline 3,7-dimethyl-1,6-Octadien-3-ol & ND & ND & ND & ND \\
\hline Nonanal & 4.52 & 15.06 & 4.26 & 14.19 \\
\hline Phenylethyl Alcohol & 3.33 & 11.10 & 4.25 & 14.17 \\
\hline Octanoic acid, methyl ester & 4.40 & 14.68 & 6.62 & 22.08 \\
\hline 1-Nonanol & 3.27 & 10.91 & 4.88 & 16.28 \\
\hline Naphthalene & 4.14 & 13.79 & 5.07 & 16.89 \\
\hline 2-Decanone & 8.10 & 27.00 & 2.63 & 8.76 \\
\hline Dodecane & 6.34 & 21.15 & 9.53 & 31.76 \\
\hline Decanal & 4.30 & 14.34 & 6.41 & 21.38 \\
\hline Hexanedioic acid, dimethyl ester & 2.63 & 8.78 & 4.91 & 16.35 \\
\hline Tridecane & 6.07 & 20.23 & 8.56 & 28.53 \\
\hline Undecanal & 4.13 & 13.75 & 6.30 & 21.00 \\
\hline n-Decanoic acid & 1.29 & 4.29 & 6.58 & 21.93 \\
\hline Tetradecane & 5.97 & 19.88 & 8.03 & 26.78 \\
\hline
\end{tabular}




\begin{tabular}{|l|c|c|c|c|}
\hline Dodecanal & 4.35 & 14.51 & 6.05 & 20.18 \\
\hline 6,10-dimethyl-5,9-undecadien-2-one & 1.77 & 5.89 & 4.55 & 15.15 \\
\hline Pentadecane & 5.98 & 19.94 & 8.21 & 27.38 \\
\hline Tridecanal & 4.71 & 15.70 & 31.52 & 105.08 \\
\hline Dodecanoic acid, methyl ester & 4.14 & 13.82 & 19.27 & 64.24 \\
\hline Dodecanoic acid & 5.23 & 17.43 & 4.63 & 15.45 \\
\hline Hexadecane & 6.60 & 22.00 & 8.55 & 28.50 \\
\hline Heptadecane & 6.02 & 20.05 & 8.19 & 27.31 \\
\hline Methyl tetradecanoate & 4.10 & 13.68 & 5.93 & 19.77 \\
\hline Pentadecanoic acid & $\mathrm{ND}$ & $\mathrm{ND}$ & $\mathrm{ND}$ & $\mathrm{ND}$ \\
\hline Hexadecanoic acid, methyl ester & 5.20 & 17.34 & 6.74 & 22.47 \\
\hline
\end{tabular}

* ND - not determined 
Table 9: Comparison between slopes of calibration curves for human scent compounds analyzed in full scan and SIM mode

\begin{tabular}{|c|c|c|}
\hline Compound & Full Scan & SIM \\
\hline Octane & $1.30 \mathrm{E}+06$ & $7.60 \mathrm{E}+05$ \\
\hline Furfural & $7.34 \mathrm{E}+05$ & $8.95 \mathrm{E}+05$ \\
\hline 2-Furanmethanol & $5.98 \mathrm{E}+05$ & $4.57 \mathrm{E}+05$ \\
\hline Nonane & $9.82 \mathrm{E}+05$ & $9.54 \mathrm{E}+05$ \\
\hline Heptanal & $5.70 \mathrm{E}+05$ & $1.02 \mathrm{E}+06$ \\
\hline Propanedioic acid, dimethyl ester & $7.27 \mathrm{E}+05$ & $8.02 \mathrm{E}+05$ \\
\hline Benzaldehyde & $1.28 \mathrm{E}+06$ & $9.96 \mathrm{E}+05$ \\
\hline Phenol & $7.99 \mathrm{E}+05$ & $8.97 \mathrm{E}+05$ \\
\hline 6-methyl-5-Hepten-2-one & $7.74 \mathrm{E}+05$ & $6.73 \mathrm{E}+05$ \\
\hline Octanal & $5.99 \mathrm{E}+05$ & $2.96 \mathrm{E}+05$ \\
\hline Benzyl Alcohol & $1.05 \mathrm{E}+06$ & $9.86 \mathrm{E}+05$ \\
\hline 2-Octenal, (E) & $7.69 \mathrm{E}+05$ & $4.72 \mathrm{E}+05$ \\
\hline 1-Octanol & $9.64 \mathrm{E}+05$ & $6.25 \mathrm{E}+05$ \\
\hline Undecane & $1.16 \mathrm{E}+06$ & $3.29 \mathrm{E}+05$ \\
\hline 3,7-dimethyl-1,6-Octadien-3-ol & ND & $7.85 \mathrm{E}+05$ \\
\hline Nonanal & $7.59 \mathrm{E}+05$ & $2.13 \mathrm{E}+05$ \\
\hline Phenylethyl Alcohol & $1.39 \mathrm{E}+06$ & $1.57 \mathrm{E}+06$ \\
\hline Octanoic acid, methyl ester & $1.12 \mathrm{E}+06$ & $8.60 \mathrm{E}+05$ \\
\hline 1-Nonanol & $1.25 \mathrm{E}+06$ & $6.74 \mathrm{E}+05$ \\
\hline Naphthalene & $2.02 \mathrm{E}+06$ & $2.07 \mathrm{E}+06$ \\
\hline 2-Decanone & $7.77 \mathrm{E}+05$ & $1.24 \mathrm{E}+06$ \\
\hline Dodecane & $1.14 \mathrm{E}+06$ & $9.87 \mathrm{E}+05$ \\
\hline Decanal & $9.67 \mathrm{E}+05$ & $3.90 \mathrm{E}+05$ \\
\hline Hexanedioic acid, dimethyl ester & $1.27 \mathrm{E}+06$ & $7.54 \mathrm{E}+05$ \\
\hline Tridecane & $1.21 \mathrm{E}+06$ & $9.95 \mathrm{E}+05$ \\
\hline Undecanal & $9.53 \mathrm{E}+05$ & $3.56 \mathrm{E}+05$ \\
\hline n-Decanoic acid & $1.32 \mathrm{E}+06$ & $8.13 \mathrm{E}+05$ \\
\hline Tetradecane & $1.22 \mathrm{E}+06$ & $9.91 \mathrm{E}+05$ \\
\hline Dodecanal & $1.11 \mathrm{E}+06$ & $4.23 \mathrm{E}+05$ \\
\hline
\end{tabular}




\begin{tabular}{|l|c|c|}
\hline 6,10-dimethyl-5,9-undecadien-2-one & $7.35 \mathrm{E}+05$ & $4.77 \mathrm{E}+05$ \\
\hline Pentadecane & $1.27 \mathrm{E}+06$ & $9.91 \mathrm{E}+05$ \\
\hline Tridecanal & $1.16 \mathrm{E}+06$ & $3.16 \mathrm{E}+05$ \\
\hline Dodecanoic acid, methyl ester & $1.39 \mathrm{E}+06$ & $7.96 \mathrm{E}+05$ \\
\hline Dodecanoic acid & $1.24 \mathrm{E}+06$ & $5.63 \mathrm{E}+05$ \\
\hline Hexadecane & $1.29 \mathrm{E}+06$ & $1.00 \mathrm{E}+06$ \\
\hline Heptadecane & $1.32 \mathrm{E}+06$ & $9.61 \mathrm{E}+05$ \\
\hline Methyl tetradecanoate & $1.45 \mathrm{E}+06$ & $1.01 \mathrm{E}+06$ \\
\hline Pentadecanoic acid & ND & $4.69 \mathrm{E}+05$ \\
\hline Hexadecanoic acid, methyl ester & $2.66 \mathrm{E}+06$ & $1.73 \mathrm{E}+06$ \\
\hline
\end{tabular}

*ND - not determined

Despite not obtaining increased sensitivity for all compounds of interest, application of the SIM method to hand odor samples did produce a decrease in the detection of background compounds (Figure 17 and Figure 18). The background compounds are shown in the highlighted regions of the chromatogram, the full scan method produced greater amounts of background compounds than the SIM method.

Figure 17: Chromatogram showing VOCs present in hand odor sample collected on Dukal brand gauze and analyzed via SPME-GC/MS using a full scan method

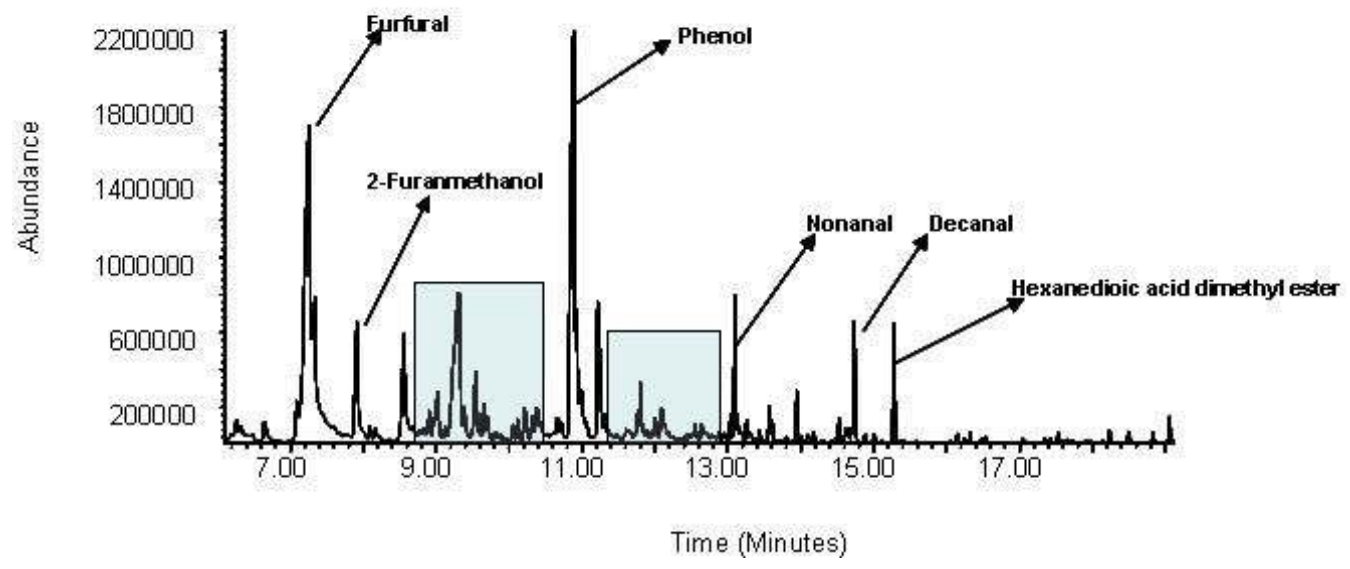


Figure 18: Chromatogram showing VOCs present in hand odor sample collected on Dukal brand gauze and analyzed via SPME-GC/MS using a SIM method

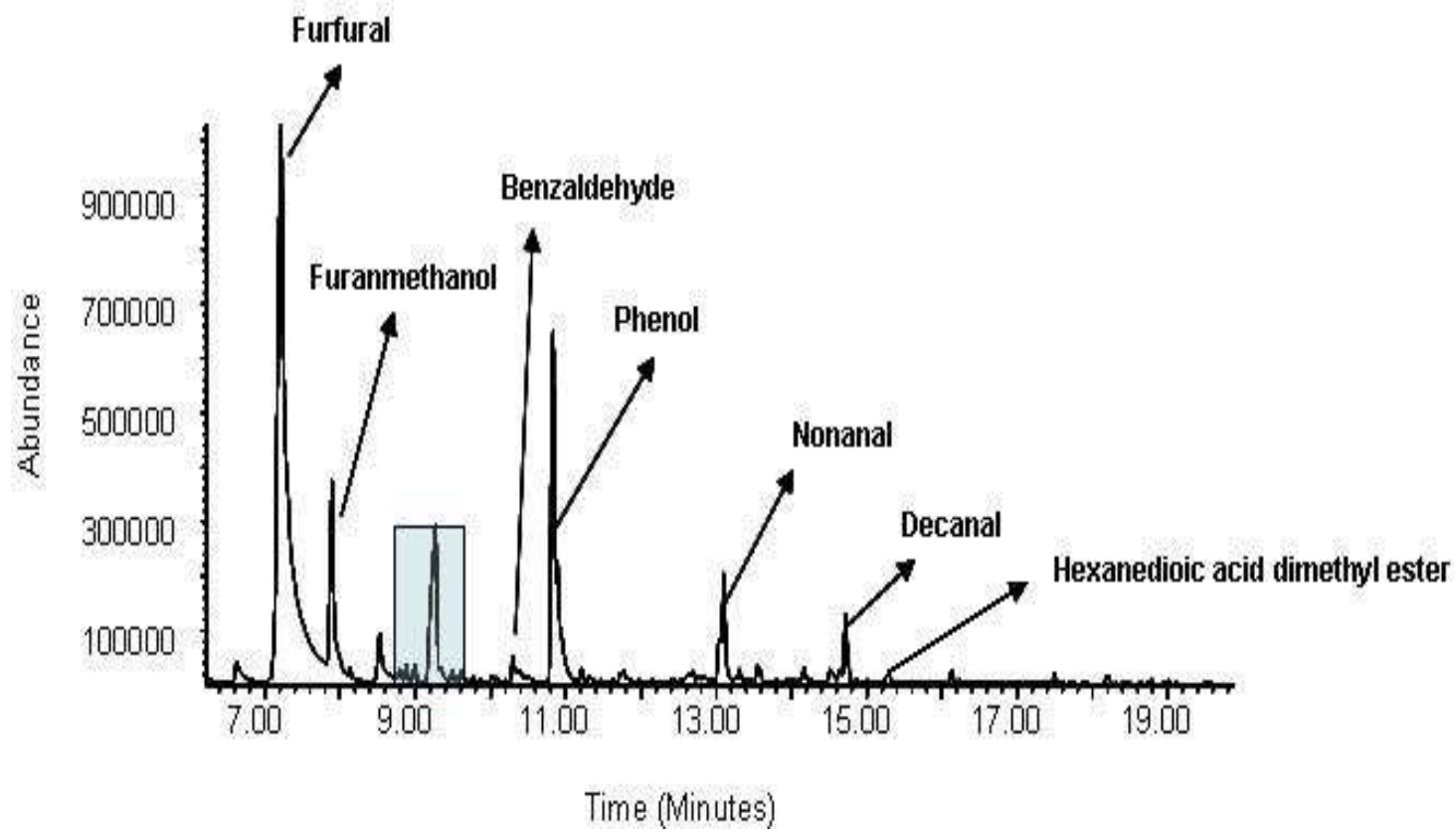

Two sets of triplicate hand odor samples were collected from six different individuals to compare the VOC profile that would be obtained using the full scan and SIM methods. The results show that different profiles were obtained from the same individual using the two different methods of analyses. Below are VOC profiles obtained from the same male subject and subjected to SPME-GC/MS analyses. It can be seen that the profiles for both methods are different (Figure 19 and Figure 20). The profiles despite being different for full scan compared to SIM are reproducible for each method. 
Figure 19: Common VOCs present in hand odor sample collected from a male subject and analyzed by SPME-GC/MS in full scan mode

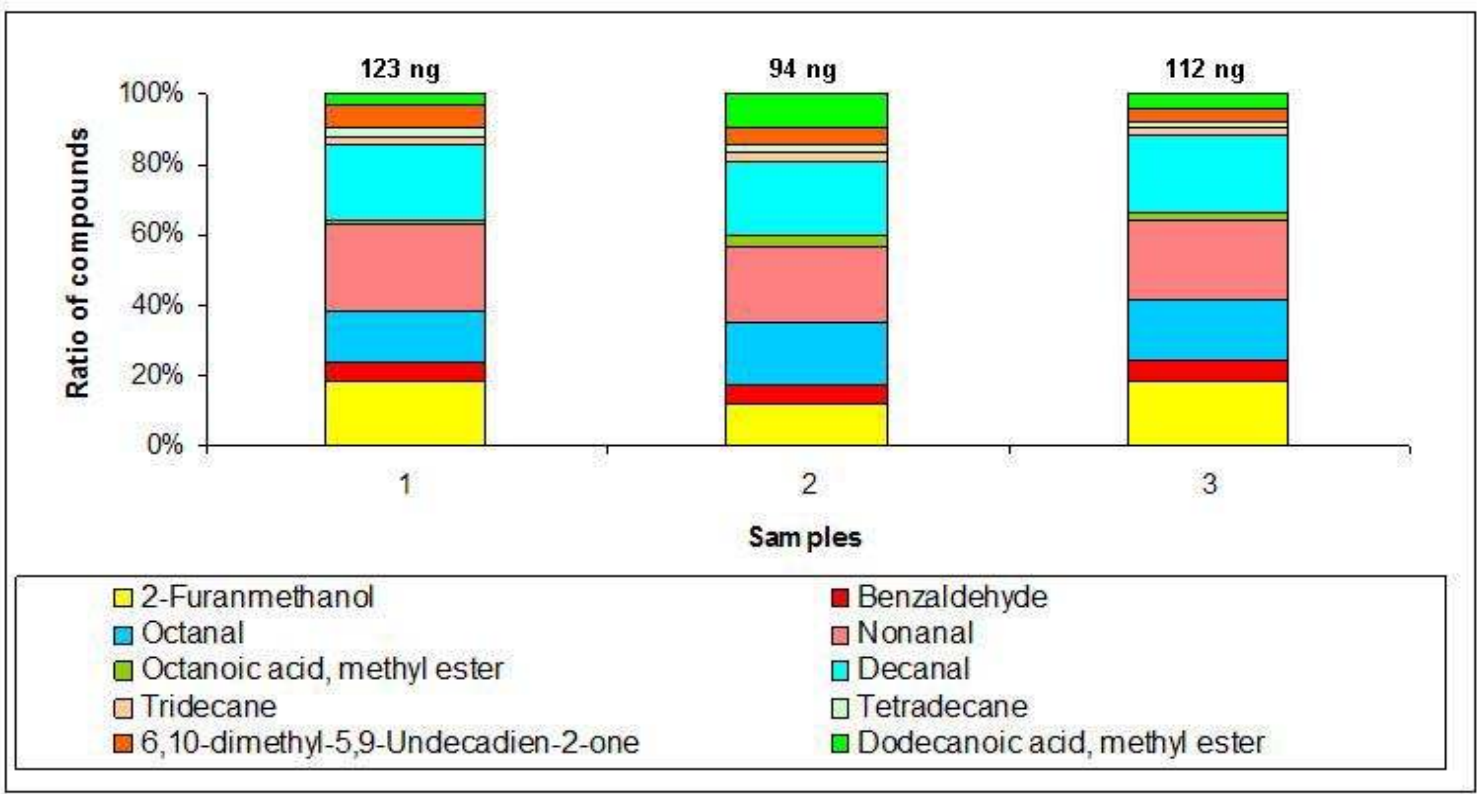

Figure 20: Common VOCs present in hand odor sample collected from a male subject and analyzed by SPME-GC/MS in SIM mode

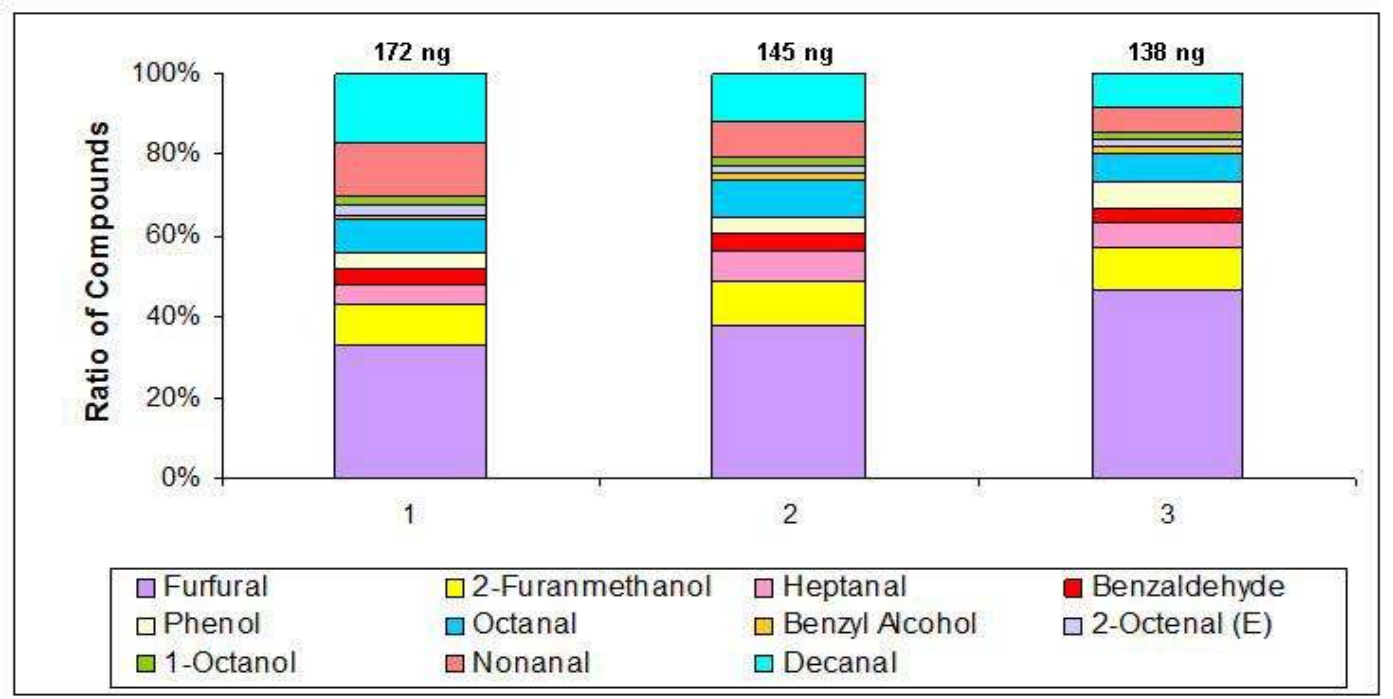




\subsubsection{Optimization of hand odor sample collection method}

The most extensive research conducted on instrumental analysis of hand odor samples was performed by Curran et al. (27). The developed techniques proved to be viable for the collection and analysis of hand odor sample via SPME-GC/MS. Hand odor collection methods developed by Curran et al. required subjects to wash hands and forearms with clear Olive Oil Soap for 30 seconds, rinse with water for 2 minutes, air dry for 4 minutes, and then rub the palms of hands over forearms for 5 minutes. Subjects were then required to sample themselves by holding a pre-treated $2 \times 2$ inch sorbent material between the palms of the hands for 10 minutes while walking outdoors (27). An effort was made to improve upon this method to make it more non-invasive.

Two sets of triplicate hand odor samples were collected from four subjects. The first sample set was collected following the protocol developed by Curran et al. (27) while the second sample set was collected using the same protocol except the subjects were not required to walk outdoors for 10 minutes. The entire sampling procedure was performed inside the laboratory where the temperature and humidity of the entire sample collection protocol could be monitored using I-Buttons. The average temperature and humidity for the sample collections were $20{ }^{0} \mathrm{C} \pm 1{ }^{0} \mathrm{C}$ and $56 \% \pm 6 \%$ respectively. A comparison of the indoor and outdoor collection methods shows the same compounds with similar ratios (Figure 21). 
Figure 21: Comparison between common Volatile organic compounds present in hand odor samples collected from a female subject outdoors and indoors

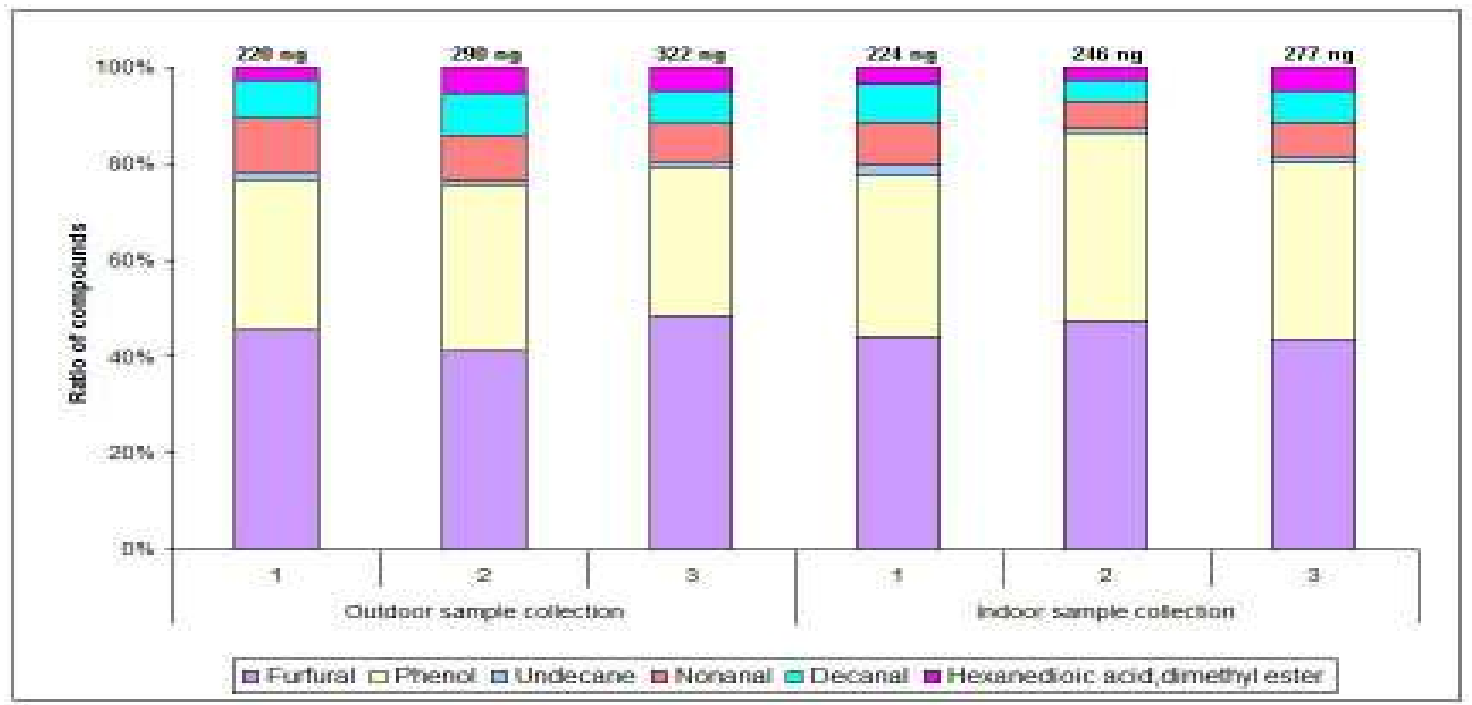

4.2. Evaluation of the effect of different storage conditions on odor profiles

Hand odor samples were collected on three different types of sorbent materials (Dukal brand, Johnson and Johnson brand and Kings Cotton) and stored for seven weeks in four different environmental conditions (light, dark, $-80{ }^{0} \mathrm{C}$ and room temperature (approximately $23{ }^{0} \mathrm{C}$ ). Samples were analyzed using solid phase micro extraction gas chromatography mass spectrometry (SPME-GC/MS).

\subsubsection{Instrumental Evaluations using SPME-GC/MS}

\section{Multiple Headspace Extractions}

Preliminary storage studies were conducted by collecting triplicate hand odor samples from five different individuals on Dukal brand gauze and subjecting them to four different storage conditions; room temperature, $-80{ }^{0} \mathrm{C}$, dark and light conditions. The ratios of the VOCs present in the headspace of the samples were monitored via SPME- 
GC/MS; initially at week one to determine the individuals' primary odor compounds then at weeks three, five and seven. All preliminary studies were conducted by performing multiple headspace extractions from the same vial over the seven week storage period. An individual's primary odor compounds have been defined by Curran et al. as the constituents of the odor that are stable over time regardless of diet or environmental conditions (24). The compounds which were consistently present in the individuals hand odor samples over four days of sampling were chosen to be the primary odor compounds and these compounds were monitored over the storage period (Figure 22 - Figure 25). The primary odor compounds however, only account for a fraction of the overall scent profile (24) and as a result, three dimensional covariance mapping was used to monitor the overall changes in the scent samples (Table 10 - Table 13).

Figure 22: Comparison between common VOCs present in hand odor samples collected on Dukal gauze from a male subject and stored at room temperature over seven weeks (multiple headspace extractions)

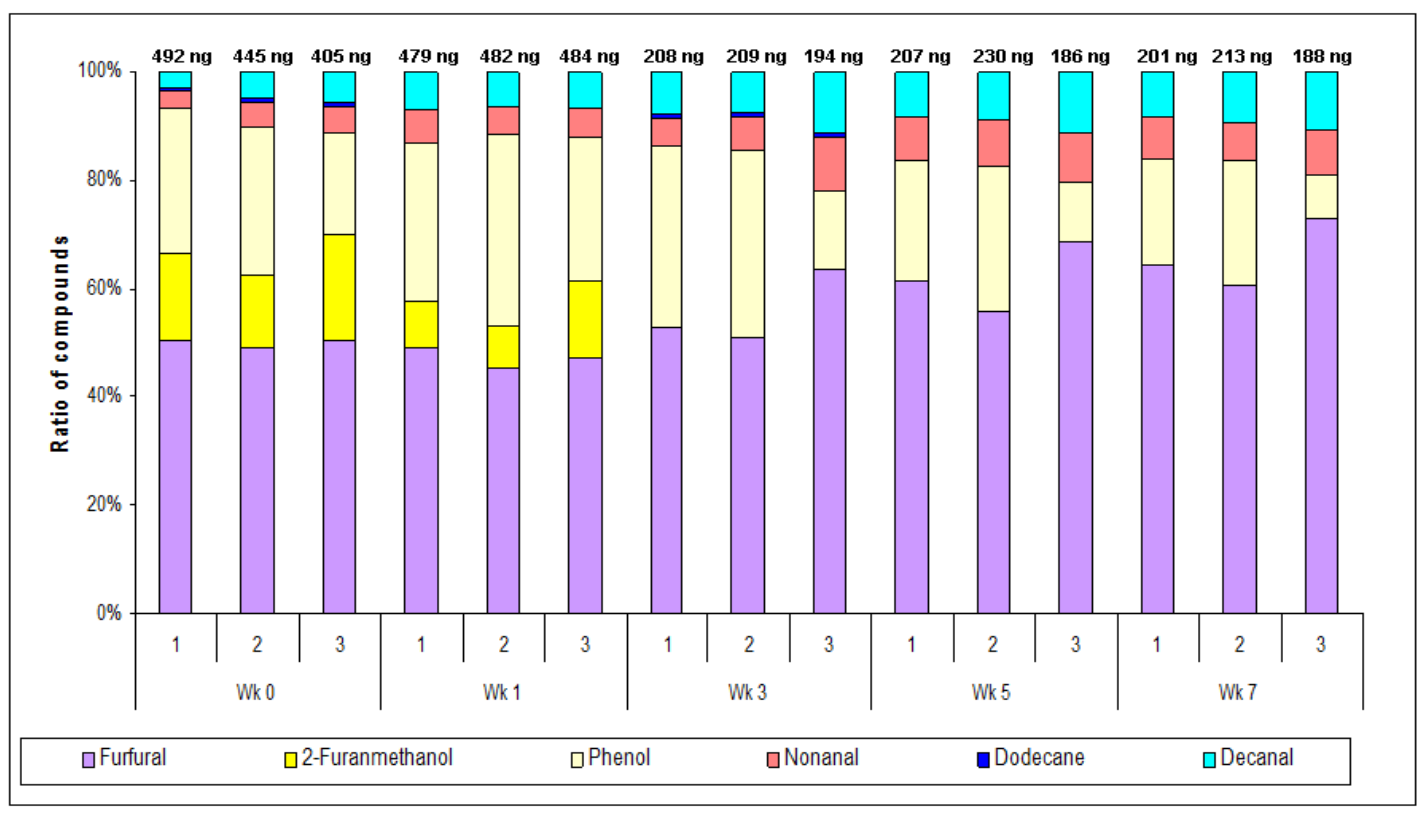


Figure 23: Comparison between common VOCs present in hand odor samples collected on Dukal gauze from a male subject and stored at $-80{ }^{\circ} \mathrm{C}$ over seven weeks (multiple headspace extractions)

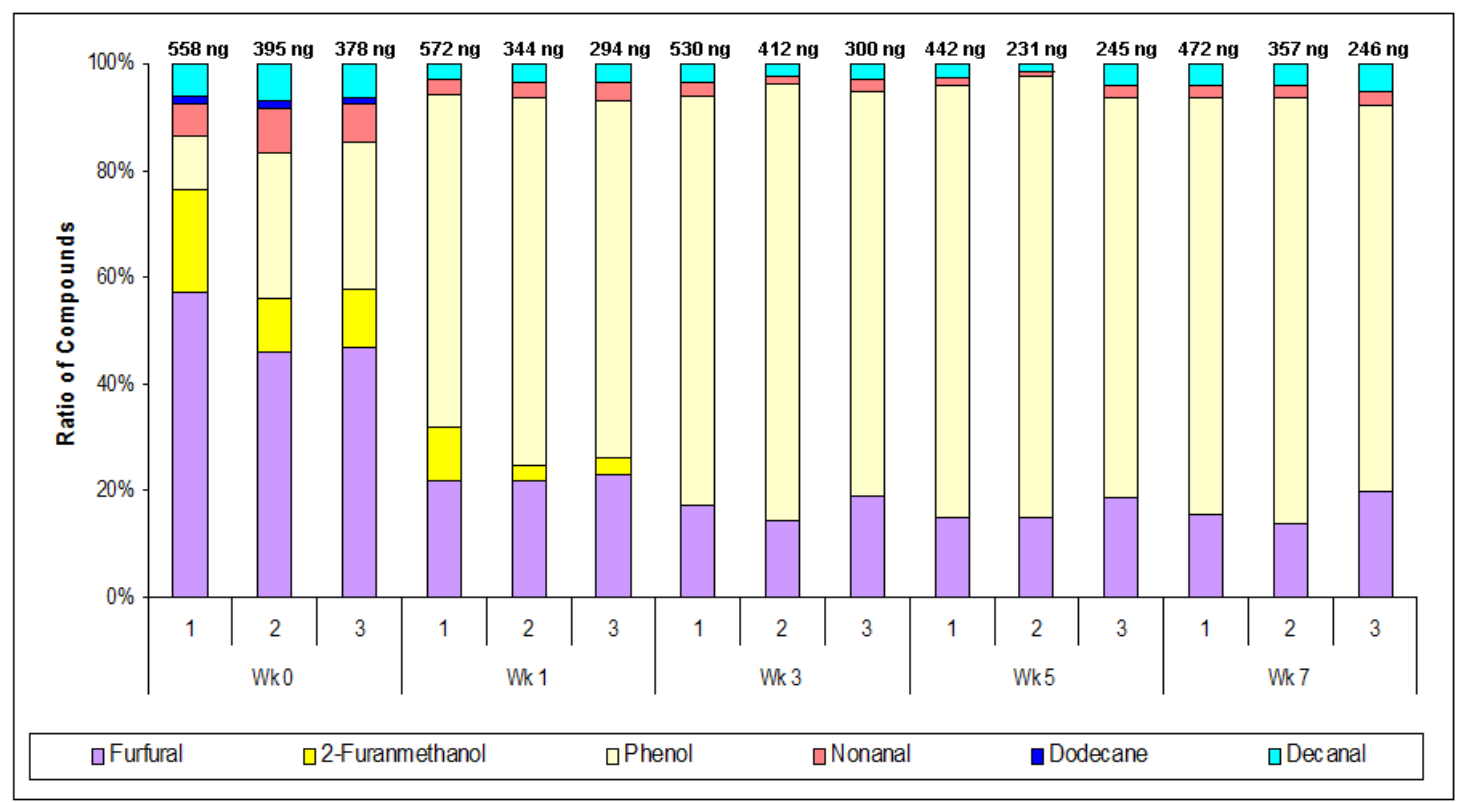

Figure 24: Comparison between common VOCs present in hand odor samples collected on Dukal gauze from a male subject and stored in the dark over seven weeks (multiple headspace extractions)

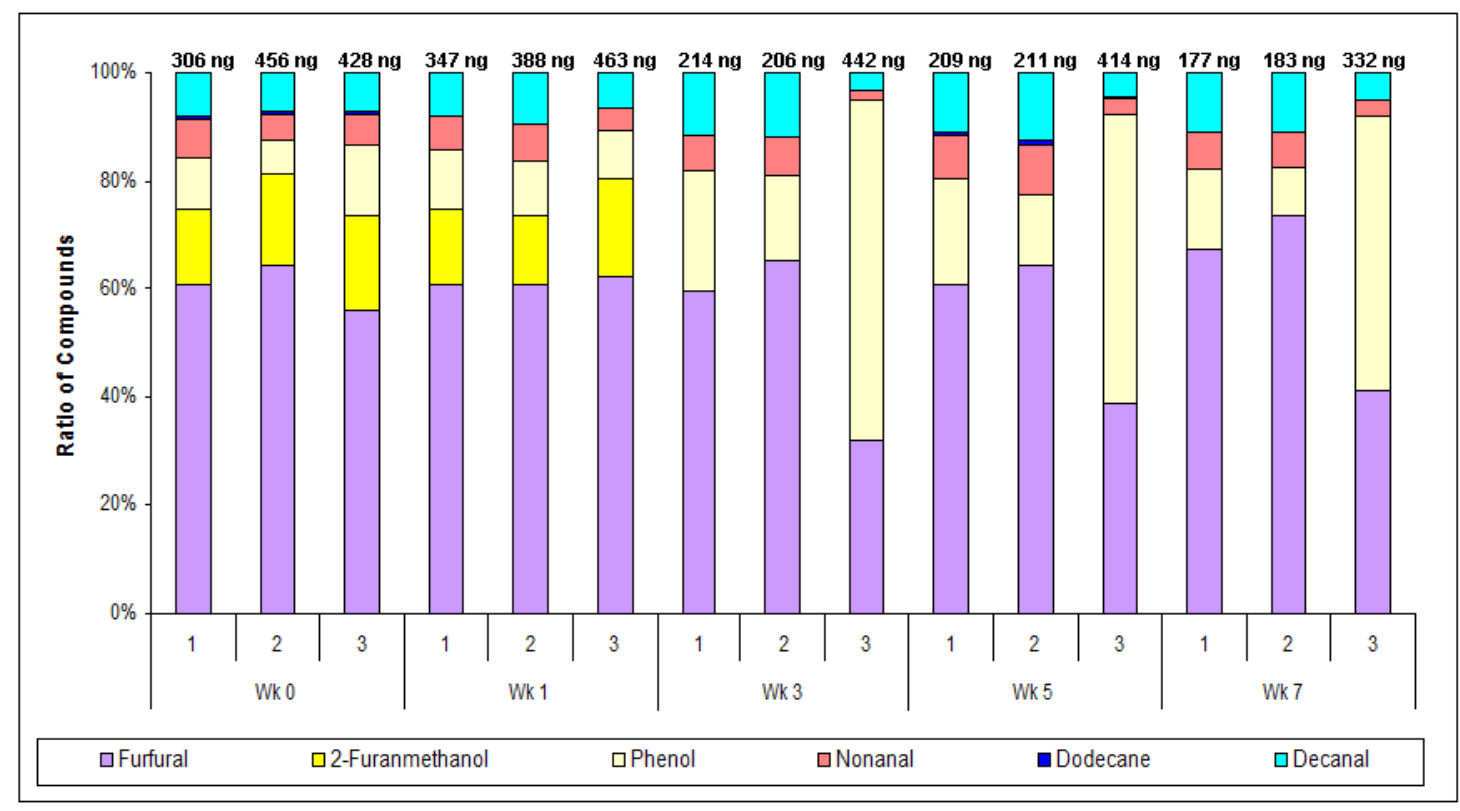


Figure 25: Comparison between common VOCs present in hand odor samples collected on Dukal gauze from a male subject and stored in the UVA/UVB light over seven weeks (multiple headspace extractions)

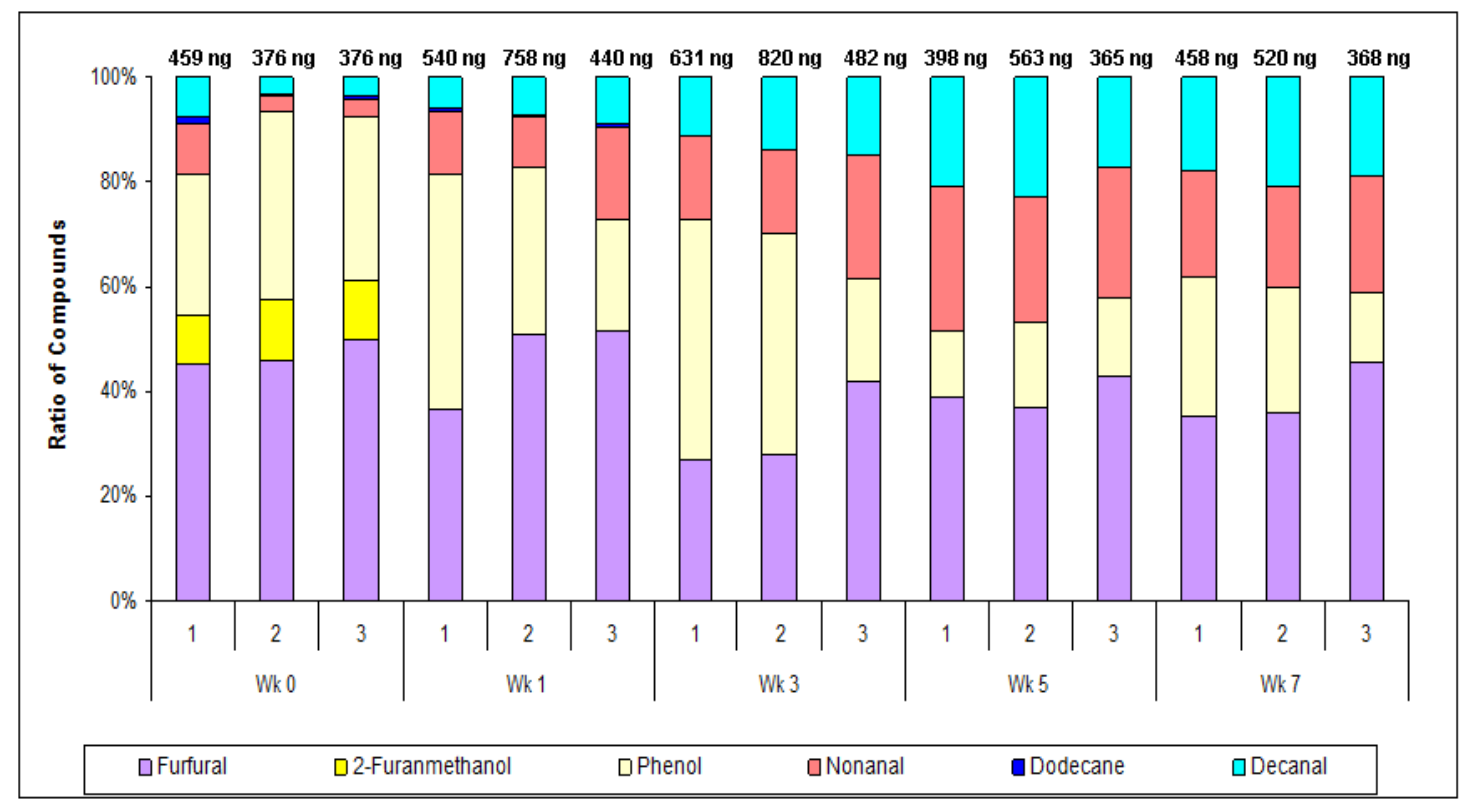

Table 10: Calculated similarity, $S$, between hand odor samples collected from the above male subject on Dukal brand gauze and stored at room temperature over a 7 week period (multiple headspace extractions)

\begin{tabular}{|c|c|c|c|c|c|c|c|c|c|c|c|c|c|c|c|}
\hline & $\begin{array}{l}\text { M1 (1) } \\
\text { RT wk } \\
0\end{array}$ & \begin{tabular}{|l} 
M1 (2) \\
RT wk \\
0
\end{tabular} & $\begin{array}{l}\text { M1 (3) } \\
\text { RT wk } \\
0\end{array}$ & $\begin{array}{l}\text { M1 (1) } \\
\text { RT wk } \\
1\end{array}$ & $\begin{array}{l}\text { M1 (2) } \\
\text { RT wk } \\
1\end{array}$ & $\begin{array}{l}\text { M1 (3) } \\
\text { RT wk } \\
1\end{array}$ & $\begin{array}{l}\text { M1 (1) } \\
\text { RT wk } \\
3\end{array}$ & $\begin{array}{l}\text { M1 (2) } \\
\text { RT wk } \\
3\end{array}$ & $\begin{array}{l}\text { M1 (3) } \\
\text { RT wk } \\
3 \\
\end{array}$ & \begin{tabular}{|l} 
M1 (1) \\
RT wk \\
5
\end{tabular} & $\begin{array}{l}\text { M1 (2) } \\
\text { RT wk } \\
5\end{array}$ & $\begin{array}{l}\text { M1 (3) } \\
\text { RT wk } \\
5\end{array}$ & $\begin{array}{l}\text { M1 (1) } \\
\text { RT wk } \\
7\end{array}$ & $\begin{array}{l}\text { M1 (2) } \\
\text { RT wk } \\
7\end{array}$ & $\begin{array}{l}\text { M1 (3) } \\
\text { RT wk } \\
7 \\
\end{array}$ \\
\hline M1 (1) RT wk 0 & 1.00 & & & & & & & & & & & & & & \\
\hline M1 (2) RT wk 0 & 0.81 & 1.00 & & & & & & & & & & & & & \\
\hline M1 (3) RT wk 0 & 0.79 & 0.93 & 1.00 & & & & & & & & & & & & \\
\hline M1 (1) RT wk 1 & 0.86 & 0.82 & 0.82 & 1.00 & & & & & & & & & & & \\
\hline M1 (2) RT wk 1 & 0.79 & 0.89 & 0.89 & 0.88 & 1.00 & & & & & & & & & & \\
\hline M1 (3) RT wk 1 & 0.78 & 0.87 & 0.87 & 0.85 & 0.93 & 1.00 & & & & & & & & & \\
\hline M1 (1) RT wk 3 & 0.72 & 0.66 & 0.66 & 0.76 & 0.73 & 0.71 & 1.00 & & & & & & & & \\
\hline M1 (2) RT wk 3 & 0.71 & 0.70 & 0.70 & 0.75 & 0.77 & 0.76 & 0.90 & 1.00 & & & & & & & \\
\hline M1 (3) RT wk 3 & 0.73 & 0.73 & 0.73 & 0.77 & 0.80 & 0.81 & 0.83 & 0.90 & 1.00 & & & & & & \\
\hline M1 (1) RT wk 5 & 0.74 & 0.71 & 0.71 & 0.79 & 0.78 & 0.76 & 0.82 & 0.80 & 0.80 & 1.00 & & & & & \\
\hline M1 (2) RT wk 5 & 0.72 & 0.75 & 0.75 & 0.79 & 0.82 & 0.81 & 0.80 & 0.83 & 0.84 & 0.92 & 1.00 & & & & \\
\hline M1 (3) RT wk 5 & 0.73 & 0.75 & 0.75 & 0.78 & 0.81 & 0.82 & 0.79 & 0.83 & 0.88 & 0.89 & 0.93 & 1.00 & & & \\
\hline M1 (1) RT wk 7 & 0.67 & 0.68 & 0.68 & 0.71 & 0.74 & 0.74 & 0.78 & 0.80 & 0.82 & 0.83 & 0.84 & 0.85 & 1.00 & & \\
\hline M1 (2) RT wk 7 & 0.69 & 0.71 & 0.71 & 0.74 & 0.77 & 0.78 & 0.78 & 0.81 & 0.84 & 0.84 & 0.87 & 0.88 & 0.92 & 1.00 & \\
\hline M1 (3) RT wk 7 & 0.66 & 0.70 & 0.70 & 0.71 & 0.76 & 0.78 & 0.72 & 0.76 & 0.81 & 0.78 & 0.83 & 0.85 & 0.88 & 0.92 & 1.00 \\
\hline
\end{tabular}


Table 11: Calculated similarity, $S$, between hand odor samples collected from the above male subject on Dukal brand gauze and stored at $-80^{\circ} \mathrm{C}$ over a 7 week period (multiple headspace extractions)

\begin{tabular}{|c|c|c|c|c|c|c|c|c|c|c|c|c|c|c|c|}
\hline & $\begin{array}{c}\text { M1 (1) } \\
80 w \mathrm{wk} \\
0\end{array}$ & $\begin{array}{c}\text { M1 (2) } \\
80 \text { wk } \\
0\end{array}$ & $\begin{array}{c}\text { M1 (3) } \\
80 \mathrm{wk} \\
0\end{array}$ & $\begin{array}{c}\text { M1 (1) } \\
80 w k \\
1\end{array}$ & $\begin{array}{c}\text { M1 (2) } \\
80 \mathrm{wk} \\
1\end{array}$ & $\begin{array}{c}\text { M1 (3) } \\
80 w k \\
1\end{array}$ & \begin{tabular}{|c} 
M1 (1) \\
80 wk \\
3
\end{tabular} & $\begin{array}{c}\text { M1 (2) } \\
80 \mathrm{wk} \\
3\end{array}$ & \begin{tabular}{|c} 
M1 (3) \\
80 wk \\
3
\end{tabular} & $\mid \begin{array}{c}\text { M1 (1) } \\
80 \text { wk } \\
5\end{array}$ & $\mid \begin{array}{c}\text { M1 (2) } \\
80 \text { wk } \\
5\end{array}$ & $\begin{array}{c}\text { M1 (3) } \\
80 \mathrm{wk} \\
5\end{array}$ & $\mid \begin{array}{c}\text { M1 (1) } \\
80 \mathrm{wk} \\
7\end{array}$ & $\mid \begin{array}{c}\text { M1 (2) } \\
80 w k \\
7\end{array}$ & $\begin{array}{c}\text { M1 (3) } \\
80 \mathrm{wk} \\
7\end{array}$ \\
\hline M1 (1) -80 wk 0 & 1.00 & & & & & & & & & & & & & & \\
\hline M1 (2) -80 wk 0 & 0.79 & 1.00 & & & & & & & & & & & & & \\
\hline M1 (3) -80 wk 0 & 0.85 & 0.89 & 1.00 & & & & & & & & & & & & \\
\hline M1 (1) -80 wk 1 & 0.76 & 0.81 & 0.86 & 1.00 & & & & & & & & & & & \\
\hline M1 (2) -80 wk 1 & 0.57 & 0.68 & 0.66 & 0.72 & 1.00 & & & & & & & & & & \\
\hline M1 (3) -80 wk 1 & 0.58 & 0.64 & 0.67 & 0.72 & 0.92 & 1.00 & & & & & & & & & \\
\hline M1 (1) -80 wk 3 & 0.71 & 0.73 & 0.79 & 0.90 & 0.66 & 0.68 & 1.00 & & & & & & & & \\
\hline M1 (2) -80 wk 3 & 0.52 & 0.58 & 0.60 & 0.65 & 0.83 & 0.85 & 0.65 & 1.00 & & & & & & & \\
\hline M1 (3) -80 wk 3 & 0.55 & 0.57 & 0.62 & 0.70 & 0.81 & 0.87 & 0.70 & 0.89 & 1.00 & & & & & & \\
\hline M1 (1) -80 wk 5 & 0.64 & 0.65 & 0.72 & 0.83 & 0.73 & 0.76 & 0.87 & 0.72 & 0.78 & 1.00 & & & & & \\
\hline M1 (2) -80 wk 5 & 0.33 & 0.39 & 0.37 & 0.40 & 0.54 & 0.52 & 0.39 & 0.59 & 0.53 & 0.44 & 1.00 & & & & \\
\hline M1 (3) -80 wk 5 & 0.58 & 0.60 & 0.66 & 0.73 & 0.79 & 0.86 & 0.70 & 0.78 & 0.86 & 0.80 & 0.48 & 1.00 & & & \\
\hline M1 (1) -80 wk 7 & 0.73 & 0.70 & 0.79 & 0.81 & 0.63 & 0.65 & 0.84 & 0.58 & 0.64 & 0.80 & 0.36 & 0.69 & 1.00 & & \\
\hline M1 (2) -80 wk 7 & 0.63 & 0.65 & 0.71 & 0.79 & 0.77 & 0.82 & 0.77 & 0.74 & 0.82 & 0.86 & 0.46 & 0.89 & 0.76 & 1.00 & \\
\hline M1 (3) -80 wk 7 & 0.60 & 0.62 & 0.68 & 0.76 & 0.76 & 0.83 & 0.75 & 0.75 & 0.83 & 0.85 & 0.46 & 0.92 & 0.74 & 0.94 & 1.00 \\
\hline
\end{tabular}

Table 12: Calculated similarity, $\mathrm{S}$, between hand odor samples collected from the above male subject on Dukal brand gauze and stored in the dark over a 7 week period (multiple headspace extractions)

\begin{tabular}{|c|c|c|c|c|c|c|c|c|c|c|c|c|c|c|c|}
\hline & $\begin{array}{c}\text { M1 (1) } \\
\text { Dark } \\
\text { wk 0 }\end{array}$ & \begin{tabular}{|c} 
M1 (2) \\
Dark \\
wk 0 \\
\end{tabular} & \begin{tabular}{|c} 
M1 (3) \\
Dark \\
wk 0 \\
\end{tabular} & $\begin{array}{c}\text { M1 (1) } \\
\text { Dark } \\
\text { wk 1 } \\
\end{array}$ & \begin{tabular}{|c} 
M1 (2) \\
Dark \\
wk 1 \\
\end{tabular} & \begin{tabular}{|c} 
M1 (3) \\
Dark \\
wk 1 \\
\end{tabular} & $\begin{array}{c}\text { M1 (1) } \\
\text { Dark } \\
\text { wk 3 } \\
\end{array}$ & $\begin{array}{c}\text { M1 (2) } \\
\text { Dark } \\
\text { wk 3 } \\
\end{array}$ & $\begin{array}{c}\text { M1 (3) } \\
\text { Dark } \\
\text { wk 3 } \\
\end{array}$ & $\begin{array}{c}\text { M1 (1) } \\
\text { Dark } \\
\text { wk } 5 \\
\end{array}$ & $\begin{array}{c}\text { M1 (2) } \\
\text { Dark } \\
\text { wk } 5 \\
\end{array}$ & \begin{tabular}{|c} 
M1 (3) \\
Dark \\
wk 5 \\
\end{tabular} & $\begin{array}{c}\text { M1 (1) } \\
\text { Dark } \\
\text { wk } 7 \\
\end{array}$ & \begin{tabular}{|c|} 
M1 (2) \\
Dark \\
wk 7 \\
\end{tabular} & $\begin{array}{c}\text { M1 (3) } \\
\text { Dark } \\
\text { wk } 7\end{array}$ \\
\hline $\begin{array}{c}\text { M1 (1) } \\
\text { Dark wk } 0\end{array}$ & 1.00 & & & & & & & & & & & & & & \\
\hline $\begin{array}{c}\text { M1 (2) } \\
\text { Dark wk } 0\end{array}$ & 0.60 & 1.00 & & & & & & & & & & & & & \\
\hline $\begin{array}{c}\text { M1 (3) } \\
\text { Dark wk } 0\end{array}$ & 0.51 & 0.88 & 1.00 & & & & & & & & & & & & \\
\hline $\begin{array}{c}\text { M1 (1) } \\
\text { Dark wk } 1\end{array}$ & 0.85 & 0.55 & 0.47 & 1.00 & & & & & & & & & & & \\
\hline $\begin{array}{c}\text { M1 (2) } \\
\text { Dark wk } 1\end{array}$ & 0.58 & 0.76 & 0.68 & 0.66 & 1.00 & & & & & & & & & & \\
\hline $\begin{array}{c}\text { M1 (3) } \\
\text { Dark wk } 1\end{array}$ & 0.50 & 0.71 & 0.74 & 0.57 & 0.84 & 1.00 & & & & & & & & & \\
\hline $\begin{array}{c}\text { M1 (1) } \\
\text { Dark wk } 3\end{array}$ & 0.69 & 0.53 & 0.44 & 0.82 & 0.70 & 0.58 & 1.00 & & & & & & & & \\
\hline $\begin{array}{c}\text { M1 (2) } \\
\text { Dark wk } 3\end{array}$ & 0.49 & 0.58 & 0.54 & 0.60 & 0.80 & 0.72 & 0.75 & 1.00 & & & & & & & \\
\hline $\begin{array}{c}\text { M1 (3) } \\
\text { Dark wk } 3\end{array}$ & 0.44 & 0.54 & 0.55 & 0.55 & 0.74 & 0.78 & 0.65 & 0.78 & 1.00 & & & & & & \\
\hline $\begin{array}{c}\text { M1 (1) } \\
\text { Dark wk } 5\end{array}$ & 0.64 & 0.55 & 0.47 & 0.76 & 0.72 & 0.61 & 0.91 & 0.80 & 0.67 & 1.00 & & & & & \\
\hline $\begin{array}{c}\text { M1 (2) } \\
\text { Dark wk } 5\end{array}$ & 0.50 & 0.55 & 0.52 & 0.61 & 0.73 & 0.66 & 0.76 & 0.88 & 0.71 & 0.84 & 1.00 & & & & \\
\hline $\begin{array}{c}\text { M1 (3) } \\
\text { Dark wk } 5\end{array}$ & 0.49 & 0.58 & 0.57 & 0.60 & 0.77 & 0.72 & 0.74 & 0.90 & 0.79 & 0.80 & 0.89 & 1.00 & & & \\
\hline $\begin{array}{c}\text { M1 (1) } \\
\text { Dark wk } 7\end{array}$ & 0.53 & 0.55 & 0.48 & 0.65 & 0.74 & 0.63 & 0.81 & 0.86 & 0.70 & 0.87 & 0.87 & 0.87 & 1.00 & & \\
\hline $\begin{array}{c}\text { M1 (2) } \\
\text { Dark wk } 7\end{array}$ & 0.47 & 0.52 & 0.50 & 0.59 & 0.70 & 0.64 & 0.75 & 0.86 & 0.70 & 0.81 & 0.92 & 0.87 & 0.91 & 1.00 & \\
\hline $\begin{array}{c}\text { M1 (3) } \\
\text { Dark wk } 7\end{array}$ & 0.47 & 0.54 & 0.53 & 0.59 & 0.72 & 0.67 & 0.74 & 0.87 & 0.74 & 0.80 & 0.89 & 0.91 & 0.91 & 0.93 & 1.00 \\
\hline
\end{tabular}


Table 13: Calculated similarity, $\mathrm{S}$, between hand odor samples collected from the above male subject on Dukal brand gauze and stored in the presence of UVA/UVB light over a 7 week period (multiple headspace extractions)

\begin{tabular}{|c|c|c|c|c|c|c|c|c|c|c|c|c|c|c|c|}
\hline & $\begin{array}{c}\text { M1 (1) } \\
\text { Light } \\
\text { wk 0 } \\
\end{array}$ & $\begin{array}{l}\text { M1 (2) } \\
\text { Light } \\
\text { wk 0 } \\
\end{array}$ & $\begin{array}{c}\text { M1 (3) } \\
\text { Light } \\
\text { wk 0 }\end{array}$ & $\begin{array}{c}\text { M1 (1) } \\
\text { Light } \\
\text { wk 1 }\end{array}$ & $\begin{array}{c}\text { M1 (2) } \\
\text { Light } \\
\text { wk 1 } \\
\end{array}$ & $\begin{array}{c}\text { M1 (3) } \\
\text { Light } \\
\text { wk 1 }\end{array}$ & $\begin{array}{c}\text { M1 (1) } \\
\text { Light } \\
\text { wk 3 }\end{array}$ & $\begin{array}{c}\text { M1 (2) } \\
\text { Light } \\
\text { wk 3 }\end{array}$ & $\begin{array}{c}\text { M1 (3) } \\
\text { Light } \\
\text { wk 3 }\end{array}$ & $\begin{array}{c}\text { M1 (1) } \\
\text { Light } \\
\text { wk } 5\end{array}$ & $\begin{array}{c}\text { M1 (2) } \\
\text { Light } \\
\text { wk 5 }\end{array}$ & $\begin{array}{l}\text { M1 (3) } \\
\text { Light } \\
\text { wk 5 }\end{array}$ & $\begin{array}{l}\text { M1 (1) } \\
\text { Light } \\
\text { wk 7 }\end{array}$ & $\begin{array}{l}\text { M1 (2) } \\
\text { Light } \\
\text { wk 7 }\end{array}$ & \begin{tabular}{|l} 
M1 (3) \\
Light \\
wk 7 \\
\end{tabular} \\
\hline $\begin{array}{l}\text { M1 (1) Light } \\
\text { wk } 0\end{array}$ & 1.00 & & & & & & & & & & & & & & \\
\hline $\begin{array}{c}\text { M1 (2) Light } \\
\text { wk } 0\end{array}$ & 0.69 & 1.00 & & & & & & & & & & & & & \\
\hline $\begin{array}{l}\text { M1 (3) Light } \\
\text { wk } 0\end{array}$ & 0.79 & 0.56 & 1.00 & & & & & & & & & & & & \\
\hline $\begin{array}{c}\text { M1 (1) Light } \\
\text { wk } 1\end{array}$ & 0.81 & 0.60 & 0.83 & 1.00 & & & & & & & & & & & \\
\hline $\begin{array}{l}\text { M1 (2) Light } \\
\text { wk } 1\end{array}$ & 0.81 & 0.78 & 0.69 & 0.75 & 1.00 & & & & & & & & & & \\
\hline $\begin{array}{l}\text { M1 (3) Light } \\
\text { wk } 1\end{array}$ & 0.75 & 0.55 & 0.85 & 0.91 & 0.69 & 1.00 & & & & & & & & & \\
\hline $\begin{array}{c}\text { M1 (1) Light } \\
\text { wk } 3\end{array}$ & 0.76 & 0.59 & 0.78 & 0.90 & 0.73 & 0.85 & 1.00 & & & & & & & & \\
\hline $\begin{array}{l}\text { M1 (2) Light } \\
\text { wk } 3\end{array}$ & 0.76 & 0.75 & 0.68 & 0.75 & 0.88 & 0.70 & 0.77 & 1.00 & & & & & & & \\
\hline $\begin{array}{l}\text { M1 (3) Light } \\
\text { wk } 3\end{array}$ & 0.74 & 0.62 & 0.71 & 0.82 & 0.76 & 0.78 & 0.86 & 0.79 & 1.00 & & & & & & \\
\hline $\begin{array}{l}\text { M1 (1) Light } \\
\text { wk } 5\end{array}$ & 0.68 & 0.62 & 0.65 & 0.75 & 0.74 & 0.71 & 0.80 & 0.79 & 0.90 & 1.00 & & & & & \\
\hline $\begin{array}{l}\text { M1 (2) Light } \\
\text { wk } 5\end{array}$ & 0.72 & 0.76 & 0.64 & 0.72 & 0.82 & 0.67 & 0.75 & 0.89 & 0.81 & 0.82 & 1.00 & & & & \\
\hline $\begin{array}{l}\text { M1 (3) Light } \\
\text { wk } 5\end{array}$ & 0.67 & 0.59 & 0.65 & 0.74 & 0.71 & 0.72 & 0.78 & 0.74 & 0.89 & 0.93 & 0.77 & 1.00 & & & \\
\hline $\begin{array}{l}\text { M1 (1) Light } \\
\text { wk } 7\end{array}$ & 0.64 & 0.63 & 0.61 & 0.69 & 0.69 & 0.66 & 0.73 & 0.75 & 0.83 & 0.91 & 0.83 & 0.89 & 1.00 & & \\
\hline $\begin{array}{l}\text { M1 (2) Light } \\
\text { wk } 7\end{array}$ & 0.70 & 0.71 & 0.65 & 0.73 & 0.79 & 0.68 & 0.77 & 0.87 & 0.84 & 0.85 & 0.93 & 0.81 & 0.86 & 1.00 & \\
\hline $\begin{array}{l}\text { M1 (3) Light } \\
\text { wk } 7\end{array}$ & 0.63 & 0.60 & 0.60 & 0.68 & 0.67 & 0.66 & 0.71 & 0.72 & 0.82 & 0.90 & 0.79 & 0.90 & 0.95 & 0.83 & 1.00 \\
\hline
\end{tabular}

The preliminary results showed that the samples which were stored in the presence of light had the greatest variation over the seven week period while the samples which were stored at room temperature and, in the dark, showed the least amount of variation. The samples which were stored at $-80{ }^{0} \mathrm{C}$ showed great variation between weeks zero and week one. The previous storage studies were conducted using borosilicate glass vials (clear glass vials) that could possibly be reacting with volatile organic components present in the headspace of a scent sample. As the preliminary storage study results showed that scent samples stored at room temperature and in the dark produced the least amount of variation, scent samples were subsequently stored at room temperature in 
amber and silanized vials. Silanized vials are non-reactive and so should prevent any reactions with the volatile compounds in the head space of the scent samples.

Figure 26: Comparison between common VOCs present in hand odor samples collected on Dukal gauze from a female subject and stored in different types of $10 \mathrm{ml}$ vials at room temperature over seven weeks (multiple headspace extractions)

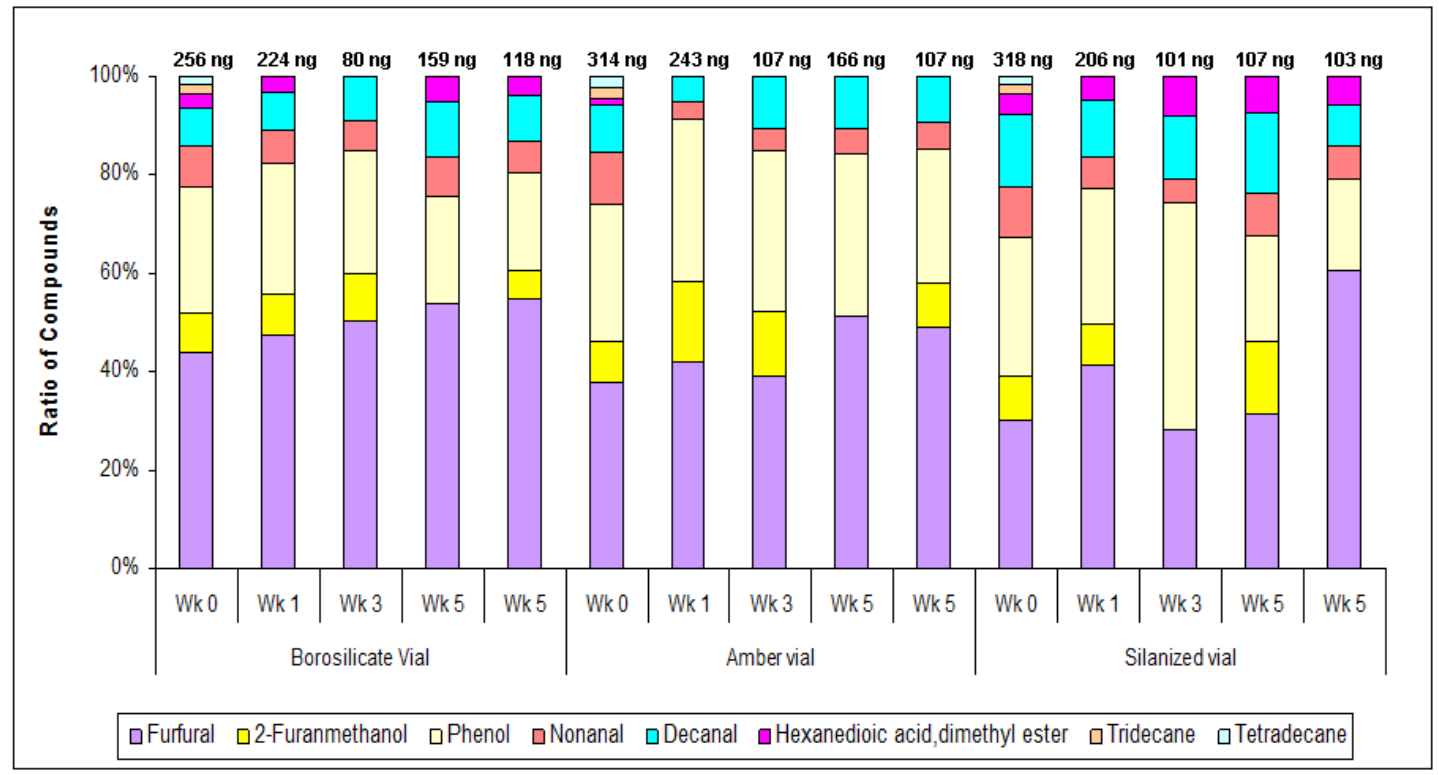

From this experiment, it was determined that the type of vial did not make a difference as variations in the primary odor profiles were still observed. It was then decided that the samples would be stored in borosilicate vials at $4{ }^{0} \mathrm{C}$. Hand odor samples can be considered to be biological samples and so there is a possibility of microbial activity taking place in these samples as they are stored. $4{ }^{0} \mathrm{C}$ storage was therefore incorporated as a storage condition as this is standard protocol for storage of biological samples for short time periods. 
Figure 27: Comparison between common VOCs present in hand odor samples collected on Dukal gauze from a female subject and stored in $4{ }^{\circ} \mathrm{C}$ over seven weeks

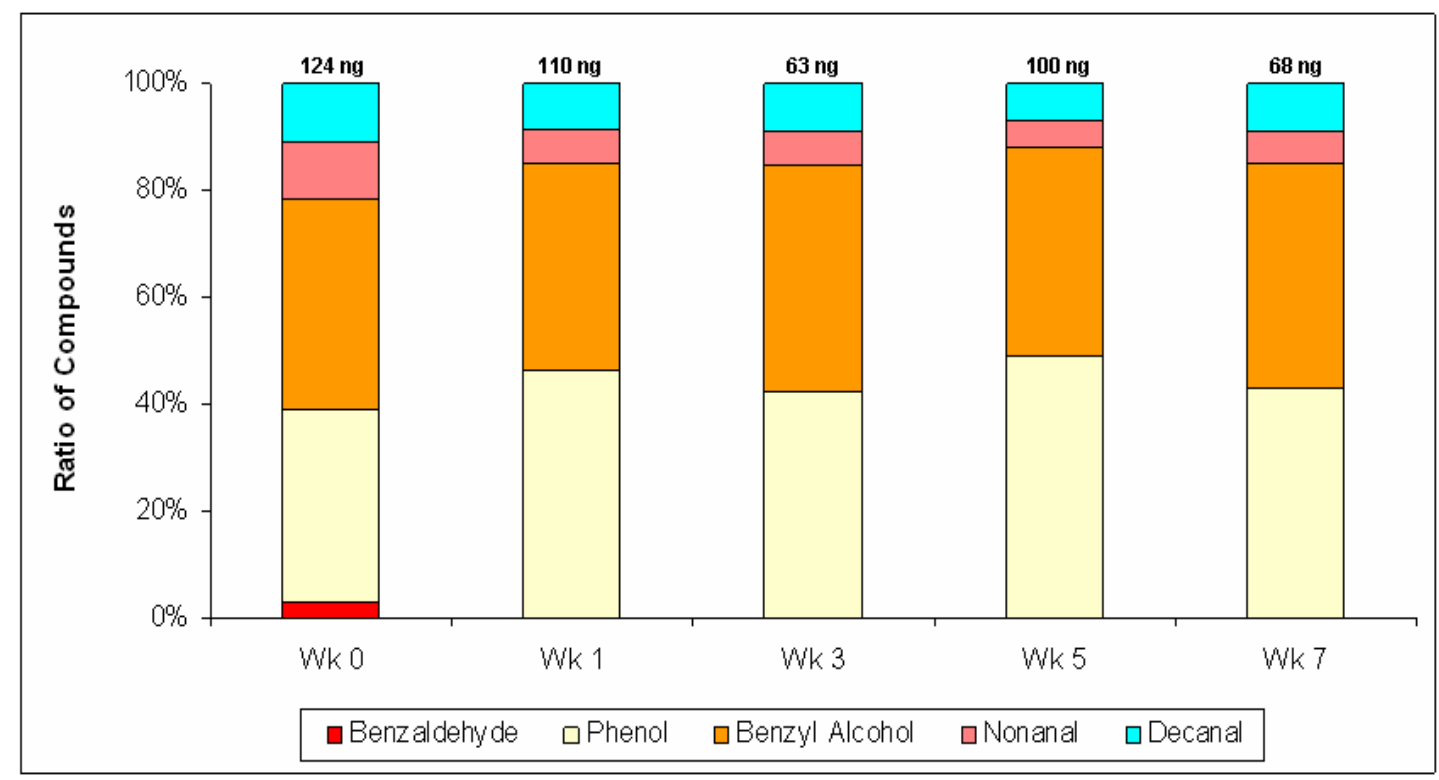

Storage in all conditions (room temperature, $4{ }^{0} \mathrm{C},-80{ }^{0} \mathrm{C}$, dark, and light) and all containers (borosilicate, amber, silanized vial) showed changes in the odor profile over time. As the storage period progressed, some VOCs which were originally present in the primary odor profile of the individuals were no longer detected. This raised questions as to the reason for the changes which were occurring. One possibility was that the headspace of the sample was being depleted by conducting multiple extractions on the same sample. Hand odor samples were collected from a male subject and multiple headspace extractions were performed from the same vial (nine extractions). The total peak area values obtained from each extraction was plotted against the number of extractions that were performed. The plot shows a decrease in the total peak area obtained with successive extractions (Figure 28). 
Figure 28: Graph showing effects of multiple headspace extractions from the same vial

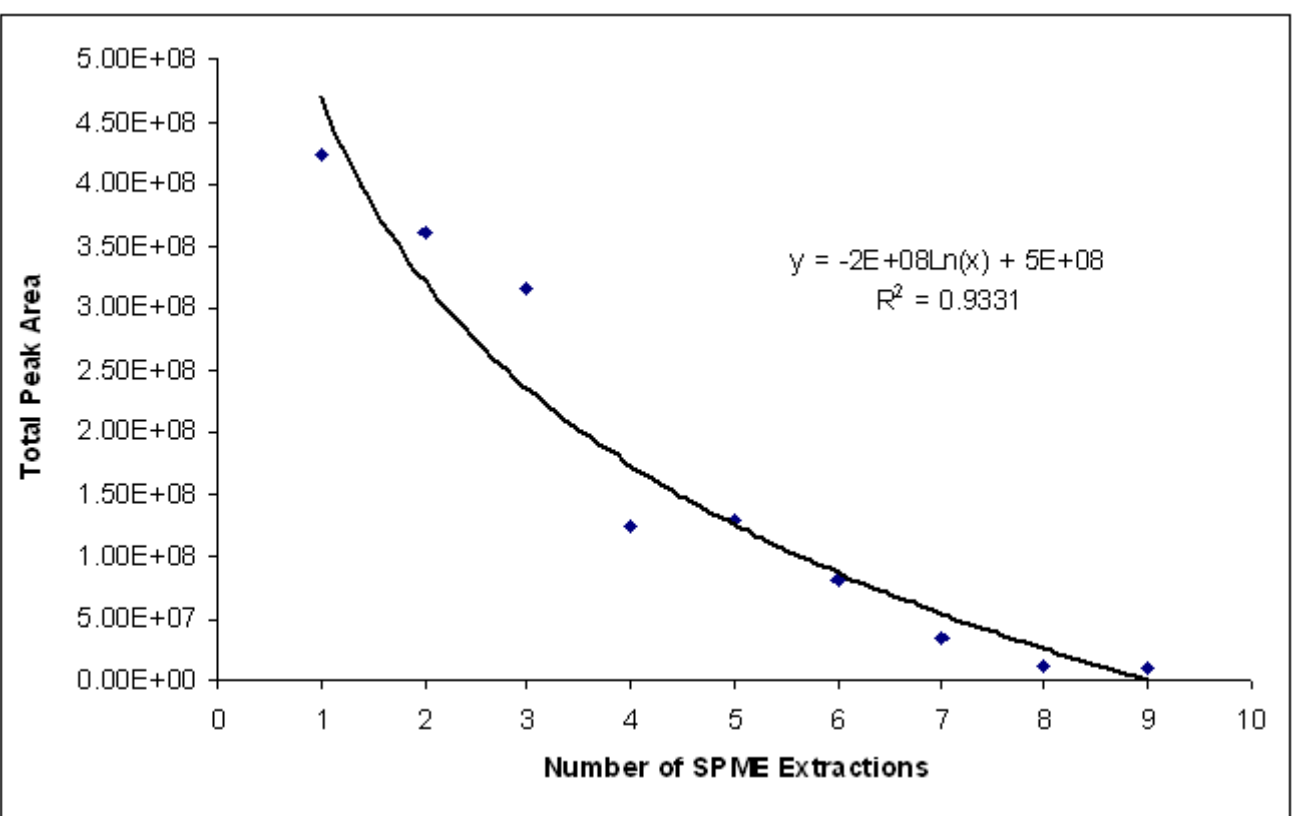

Figure 29: Arrhenius plot showing multiple headspace extractions from the same vial

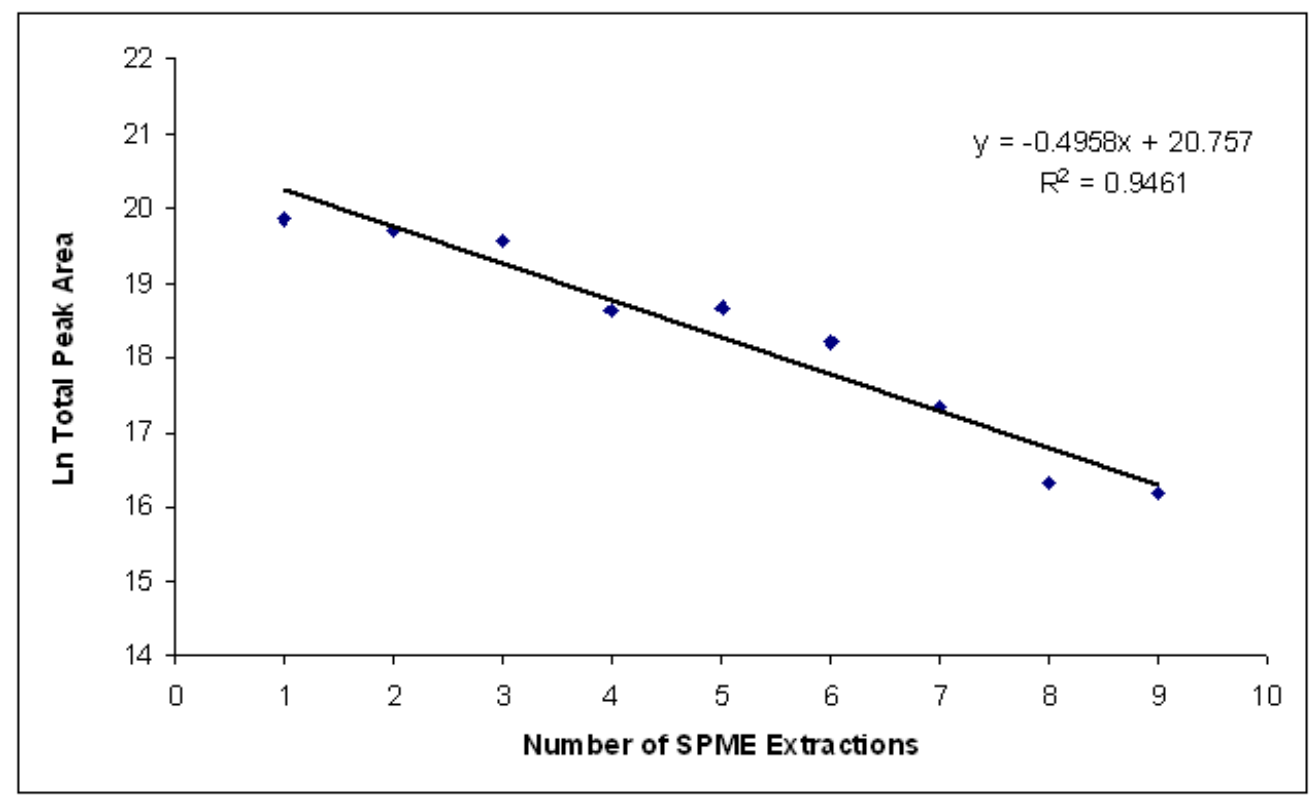




\section{Single headspace extractions}

All subsequent storage studies were subjected to single headspace SPME analyses followed by GC/MS analyses. All hand odor samples were collected on Dukal brand gauze, Kings Cotton sorbent material and Johnson and Johnson brand gauze. Dukal brand gauze and Kings Cotton are both $100 \%$ cotton; whereas, the Johnson and Johnson brand gauze is a blend of polyester, rayon and cellulose.

Throughout the storage period, the human VOCs present in the hand odor sample for each of the subjects were monitored via single headspace SPME extractions followed by analysis via GC/MS. Changes in the scent profile whether from the primary odor compounds or additional human compounds in the scent profile were detected by three dimensional covariance mapping. For all the conditions and sorbent materials monitored, covariance mapping showed that the greatest variation within the scent samples was observed between week zero and week three after which the variations between samples decreased (week three - week seven) (Table 14 - Table 17). Despite the observed changes in the overall scent profile, the ratios of the monitored primary odor compounds remained consistent (Figure 30 - Figure 41).

These results are comparable to an aging study (two weeks to six months) on crime scene objects conducted by Schoon of the Netherlands National Police. The study showed that dogs could faultlessly match odors which were collected on the same day but their performance decreased when instructed to match stored objects to a subject (73). The presence of additional compounds due to storage may mask the primary odor compounds of an individual's scent sample resulting in decreased canine performances when 
matching aged samples. It is believed that the canines were still able to make a match as the primary odor compounds are still present in a consistent ratio.

Table 14: Calculated similarity, S, between hand odor samples collected on different sorbent materials and stored at room temperature over a 7 week period (week 0 vs. weeks $0,1,3,5$ and 7 )

\begin{tabular}{|c|c|c|c|}
\hline Time (weeks) & Dukal Gauze & Kings Cotton & Johnson \& Johnson \\
\hline 0 & 1.00 & 1.00 & 1.00 \\
\hline 1 & 0.79 & 0.71 & 0.74 \\
\hline 3 & 0.59 & 0.58 & 0.67 \\
\hline 5 & 0.66 & 0.52 & 0.53 \\
\hline 7 & 0.64 & 0.54 & 0.49 \\
\hline
\end{tabular}

Table 15: Calculated similarity, S, between hand odor samples collected on different sorbent materials and stored at room temperature over a 7 week period (week 7 vs. weeks 7, 5, 3, 1 and 0 )

\begin{tabular}{|c|c|c|c|}
\hline Time (weeks) & Dukal Gauze & Kings Cotton & Johnson \& Johnson \\
\hline 7 & 1.00 & 1.00 & 1.00 \\
\hline 5 & 0.90 & 0.67 & 0.82 \\
\hline 3 & 0.66 & 0.74 & 0.57 \\
\hline 1 & 0.75 & 0.64 & 0.54 \\
\hline 0 & 0.64 & 0.54 & 0.49 \\
\hline
\end{tabular}


Table 16: Calculated similarity, S, between hand odor samples collected on different sorbent materials and stored at $\mathbf{- 8 0}$ degrees Celsius over a 7 week period (week 0 vs. weeks $0,1,3,5$ and 7)

\begin{tabular}{|c|c|c|c|}
\hline Time (weeks) & Dukal Gauze & Kings Cotton & Johnson \& Johnson \\
\hline 0 & 1.00 & 1.00 & 1.00 \\
\hline 1 & 0.65 & 0.82 & 0.80 \\
\hline 3 & 0.88 & 0.92 & 0.75 \\
\hline 5 & 0.86 & 0.86 & 0.72 \\
\hline 7 & 0.64 & 0.60 & 0.66 \\
\hline
\end{tabular}

Table 17: Calculated similarity, S, between hand odor samples collected on different sorbent materials and stored at $\mathbf{- 8 0}$ degrees Celsius over a 7 week period (week 7 vs. weeks 7, 5, 3, 1 and 0 )

\begin{tabular}{|c|c|c|c|}
\hline Time (weeks) & Dukal Gauze & Kings Cotton & Johnson \& Johnson \\
\hline 7 & 1.00 & 1.00 & 1.00 \\
\hline 5 & 0.58 & 0.66 & 0.86 \\
\hline 3 & 0.65 & 0.58 & 0.82 \\
\hline 1 & 0.73 & 0.67 & 0.73 \\
\hline 0 & 0.64 & 0.60 & 0.66 \\
\hline
\end{tabular}


Table 18: Calculated similarity, S, between hand odor samples collected on different sorbent materials and stored in the dark over a 7 week period (week 0 vs. weeks $0,1,3,5$ and 7)

\begin{tabular}{|c|c|c|c|}
\hline Time (weeks) & Dukal Gauze & Kings Cotton & Johnson \& Johnson \\
\hline 0 & 1.00 & 1.00 & 1.00 \\
\hline 1 & 0.87 & 0.53 & 0.76 \\
\hline 3 & 0.78 & 0.71 & 0.70 \\
\hline 5 & 0.72 & 0.54 & 0.54 \\
\hline 7 & 0.67 & 0.43 & 0.42 \\
\hline
\end{tabular}

Table 19: Calculated similarity, S, between hand odor samples collected on different sorbent materials and stored in the dark over a 7 week period (week 7 vs. weeks 7, 5, 3, 1 and 0)

\begin{tabular}{|c|c|c|c|}
\hline Time (weeks) & Dukal Gauze & Kings Cotton & Johnson \& Johnson \\
\hline 7 & 1.00 & 1.00 & 1.00 \\
\hline 5 & 0.69 & 0.54 & 0.54 \\
\hline 3 & 0.74 & 0.63 & 0.65 \\
\hline 1 & 0.64 & 0.41 & 0.40 \\
\hline 0 & 0.67 & 0.43 & 0.42 \\
\hline
\end{tabular}


Table 20: Calculated similarity, S, between hand odor samples collected on different sorbent materials and stored in the presence of UVA/UVB Light over a 7 week period (week 0 vs. weeks 0,1 , 3, 5 and 7)

\begin{tabular}{|c|c|c|c|}
\hline Time (weeks) & Dukal Gauze & Kings Cotton & Johnson \& Johnson \\
\hline 0 & 1.00 & 1.00 & 1.00 \\
\hline 1 & 0.74 & 0.66 & 0.58 \\
\hline 3 & 0.71 & 0.58 & 0.56 \\
\hline 5 & 0.70 & 0.71 & 0.36 \\
\hline 7 & 0.66 & 0.59 & 0.32 \\
\hline
\end{tabular}

Table 21: Calculated similarity, S, between hand odor samples collected on different sorbent materials and stored in the presence of UVA/UVB Light over a 7 week period (week 7 vs. weeks 7, 5, 3, 1 and 0)

\begin{tabular}{|c|c|c|c|}
\hline Time (weeks) & Dukal & Kings Cotton & Johnson \& Johnson \\
\hline 7 & 1.00 & 1.00 & 1.00 \\
\hline 5 & 0.76 & 0.63 & 0.73 \\
\hline 3 & 0.77 & 0.76 & 0.56 \\
\hline 1 & 0.77 & 0.76 & 0.56 \\
\hline 0 & 0.66 & 0.59 & 0.32 \\
\hline
\end{tabular}


Figure 30: Comparison between common VOCs present in hand odor samples collected on Dukal gauze from a male subject and stored at room temperature (single headspace extractions)

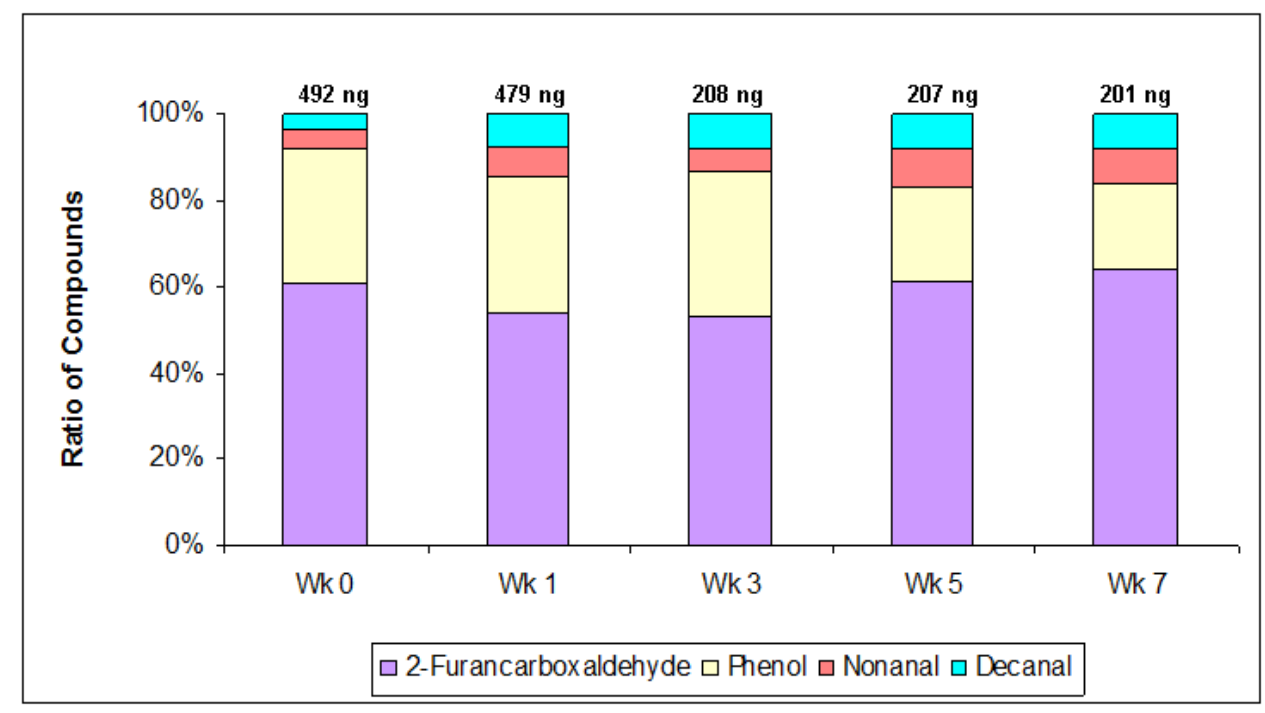

Figure 31: Comparison between common VOCs present in hand odor samples collected on Dukal gauze from a male subject and stored at $-80{ }^{\circ} \mathrm{C}$ (single headspace extractions)

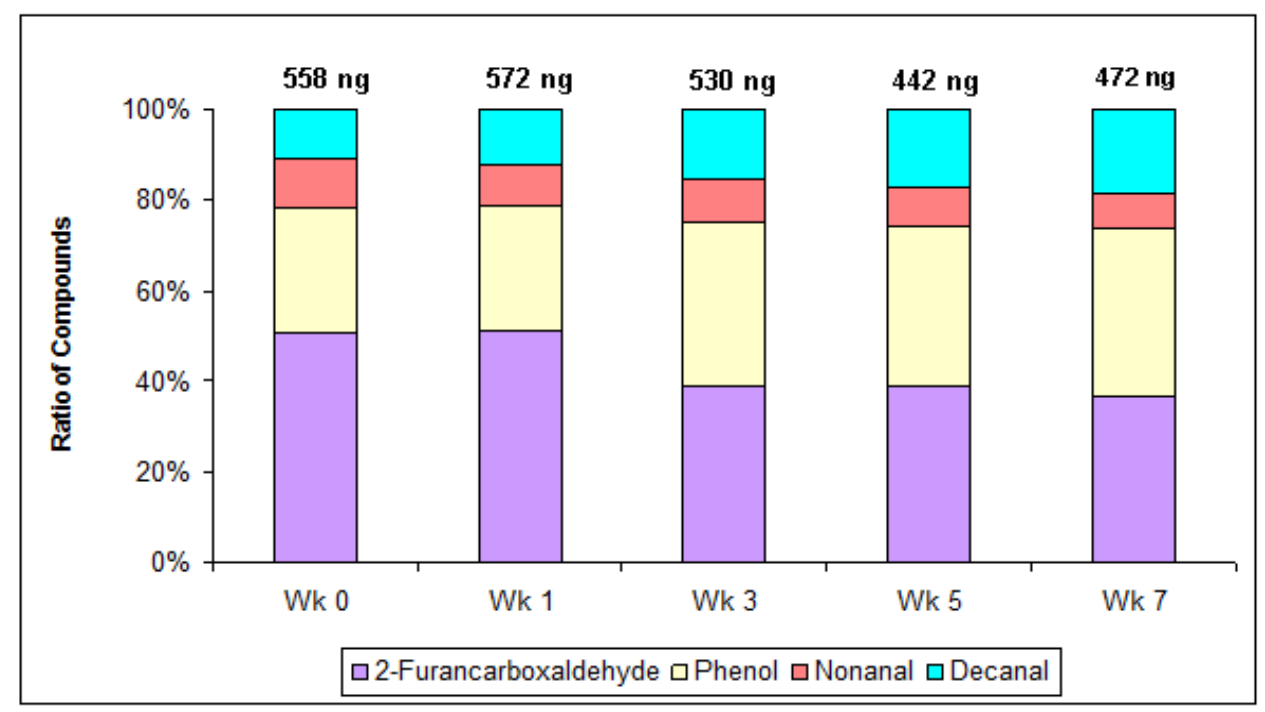


Figure 32: Comparison between common VOCs present in hand odor samples collected on Dukal gauze from a male subject and stored in the dark (single headspace extractions)

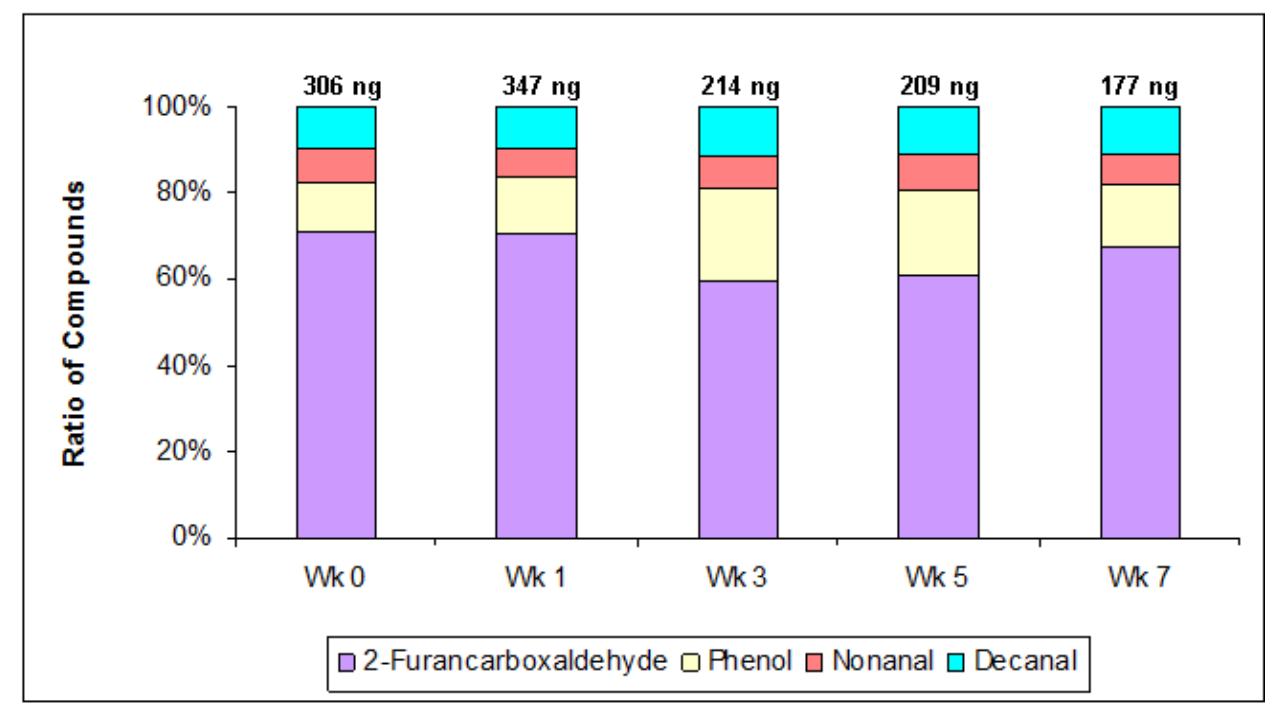

Figure 33: Comparison between common VOCs present in hand odor samples collected on Dukal gauze from a male subject and stored in the presence of UVA/UVB light (single headspace extractions)

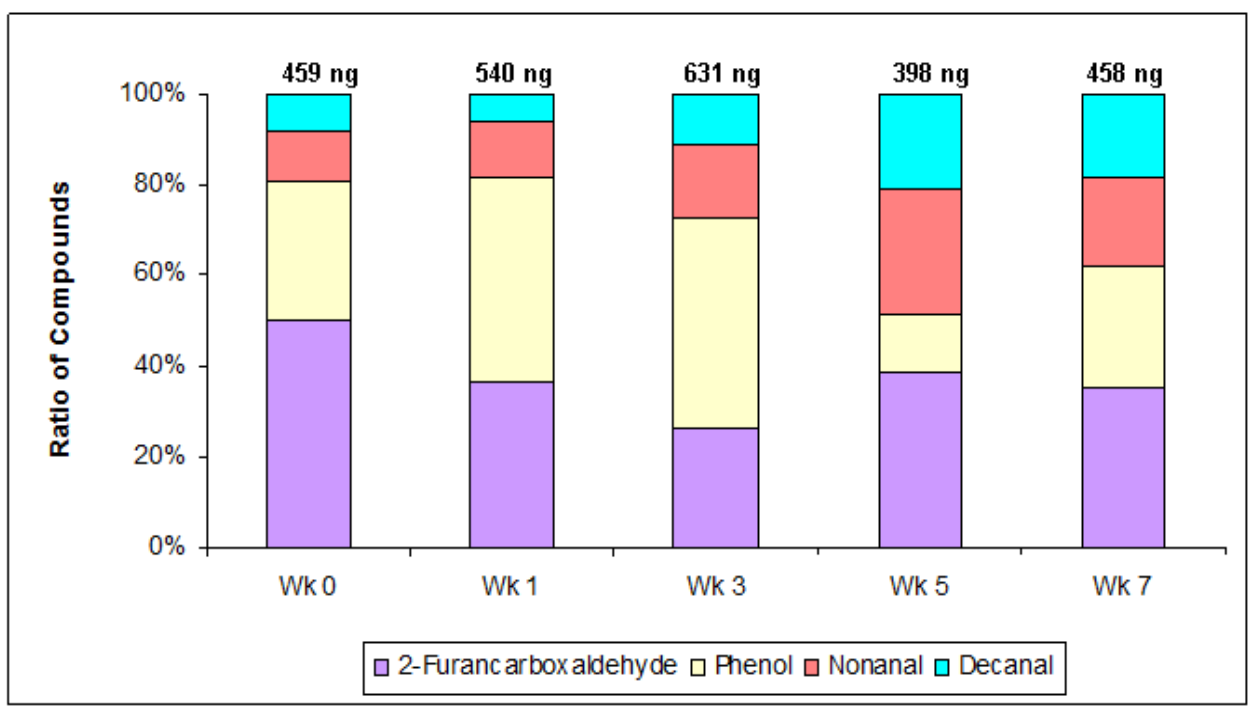


Figure 34: Comparison between common VOCs present in hand odor samples collected on Kings Cotton from a female subject and stored in at room temperature (single headspace extractions)

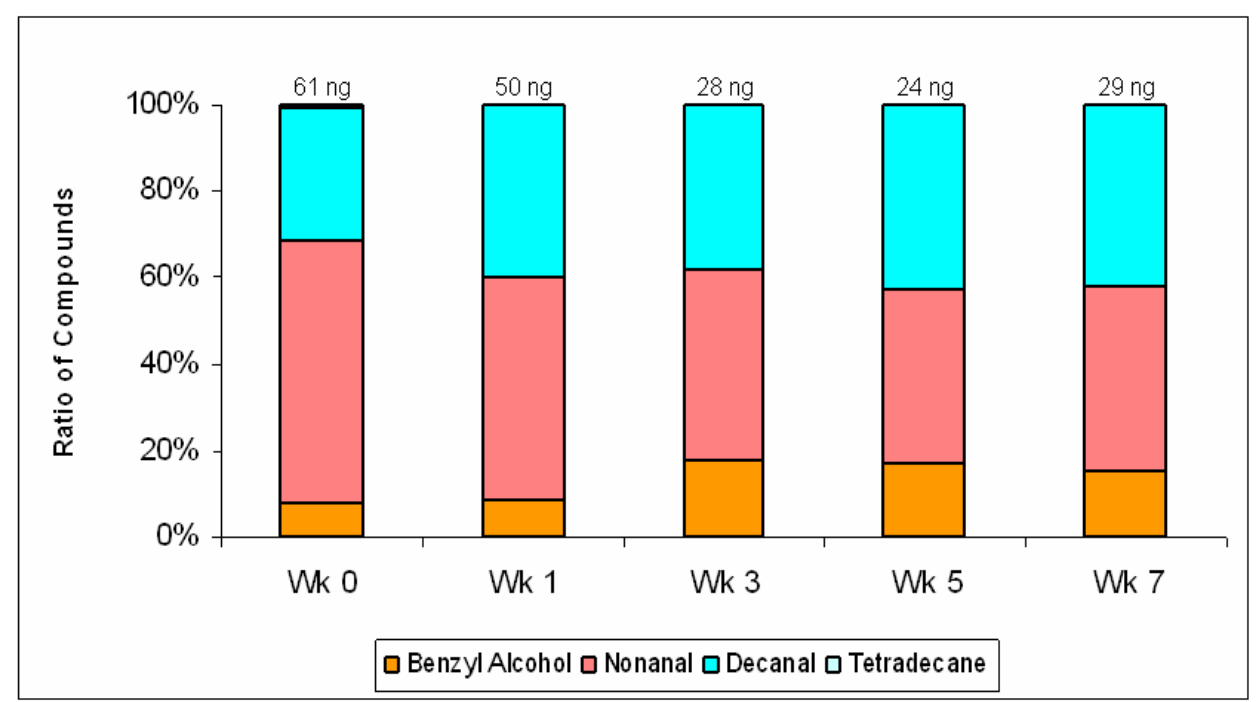

Figure 35: Comparison between common VOCs present in hand odor samples collected on Kings Cotton from a female subject and stored at $-80{ }^{\circ} \mathrm{C}$ (single headspace extractions)

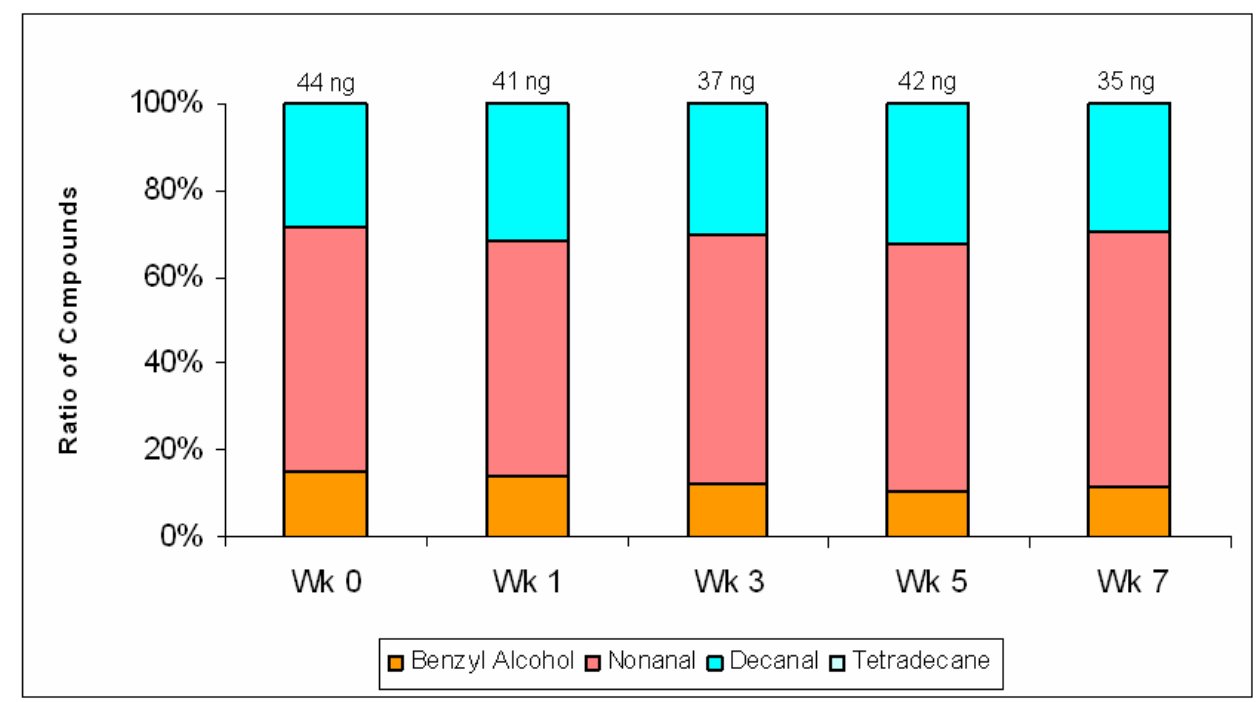


Figure 36: Comparison between common VOCs present in hand odor samples collected on Kings Cotton from a female subject and stored in the dark (single headspace extractions)

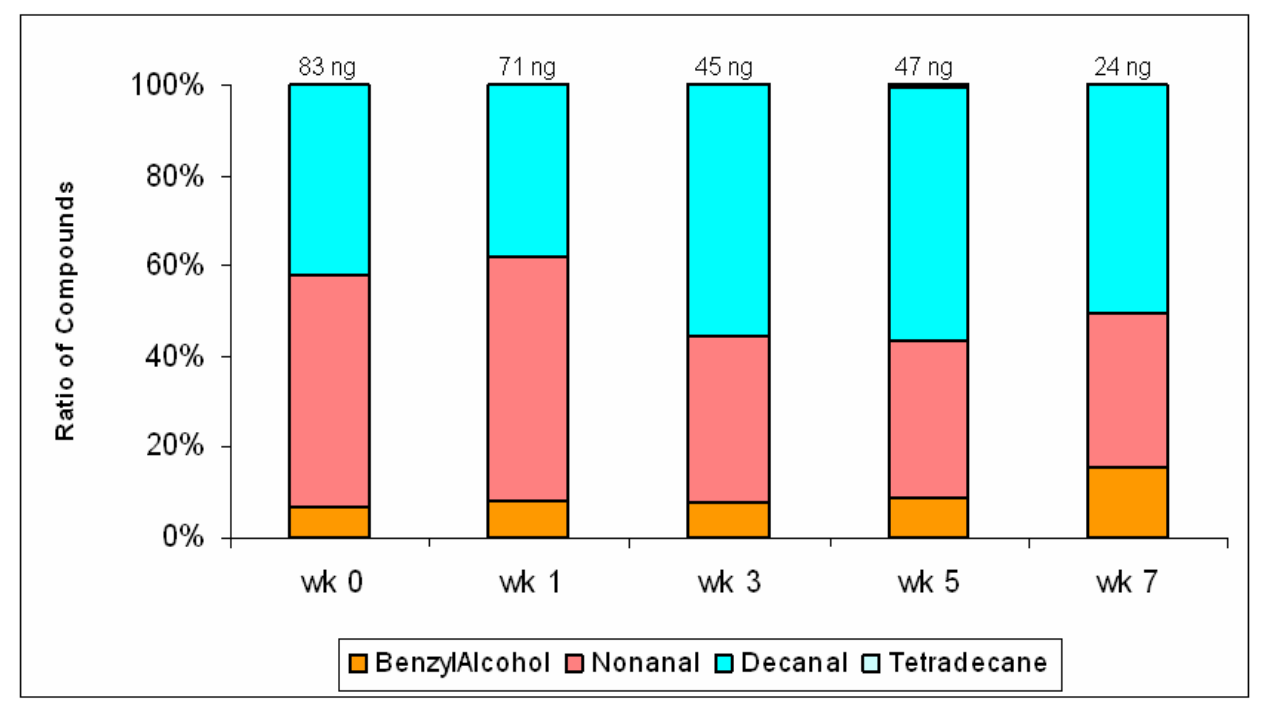

Figure 37: Comparison between common VOCs present in hand odor samples collected on Kings Cotton from a female subject and stored in the presence of UVA/UVB light (single headspace extractions)

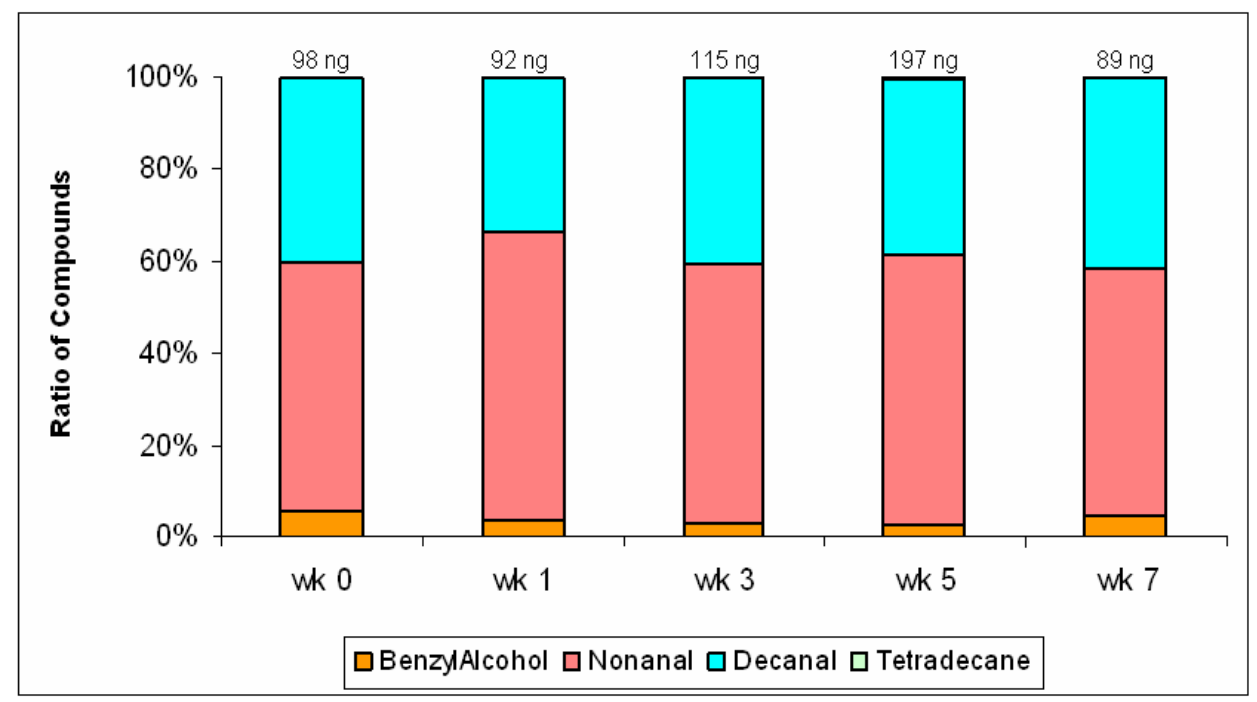


Figure 38: Comparison between common VOCs present in hand odor samples collected on Johnson \& Johnson Gauze from a female subject and stored at room temperature (single headspace extractions)

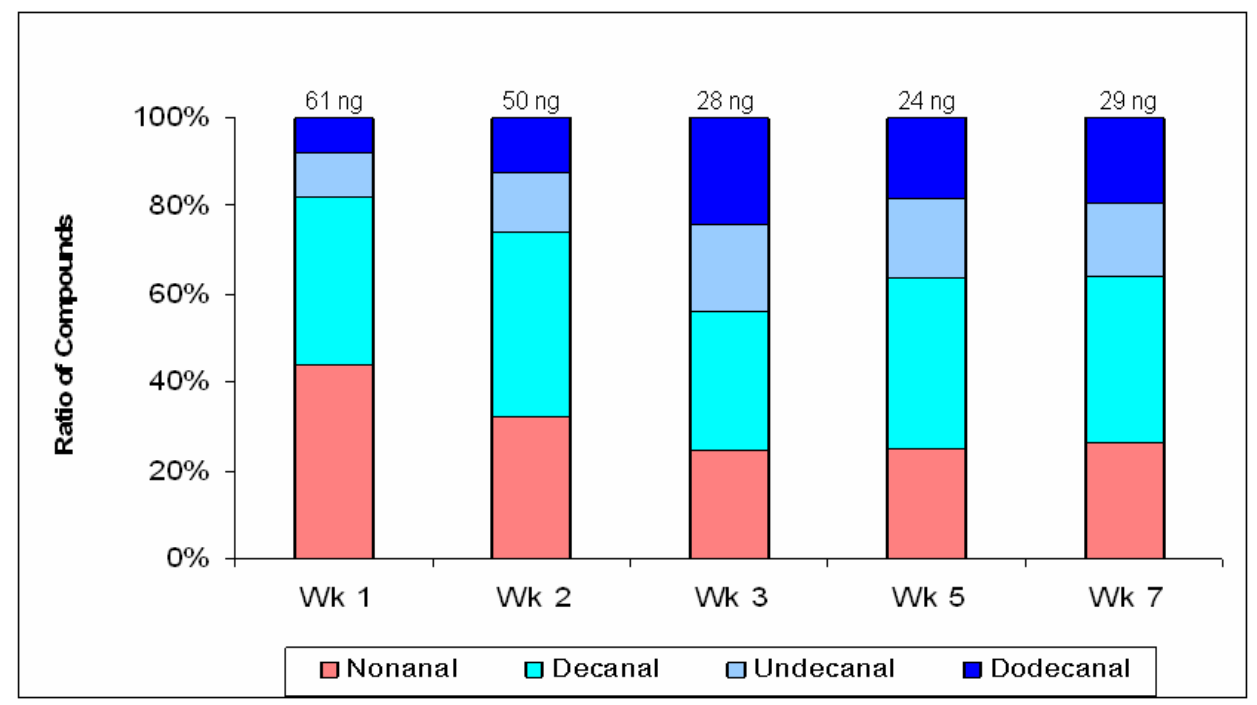

Figure 39: Comparison between common VOCs present in hand odor samples collected on Johnson \& Johnson Gauze from a female subject and stored at $-80^{\circ} \mathrm{C}$ (single headspace extractions)

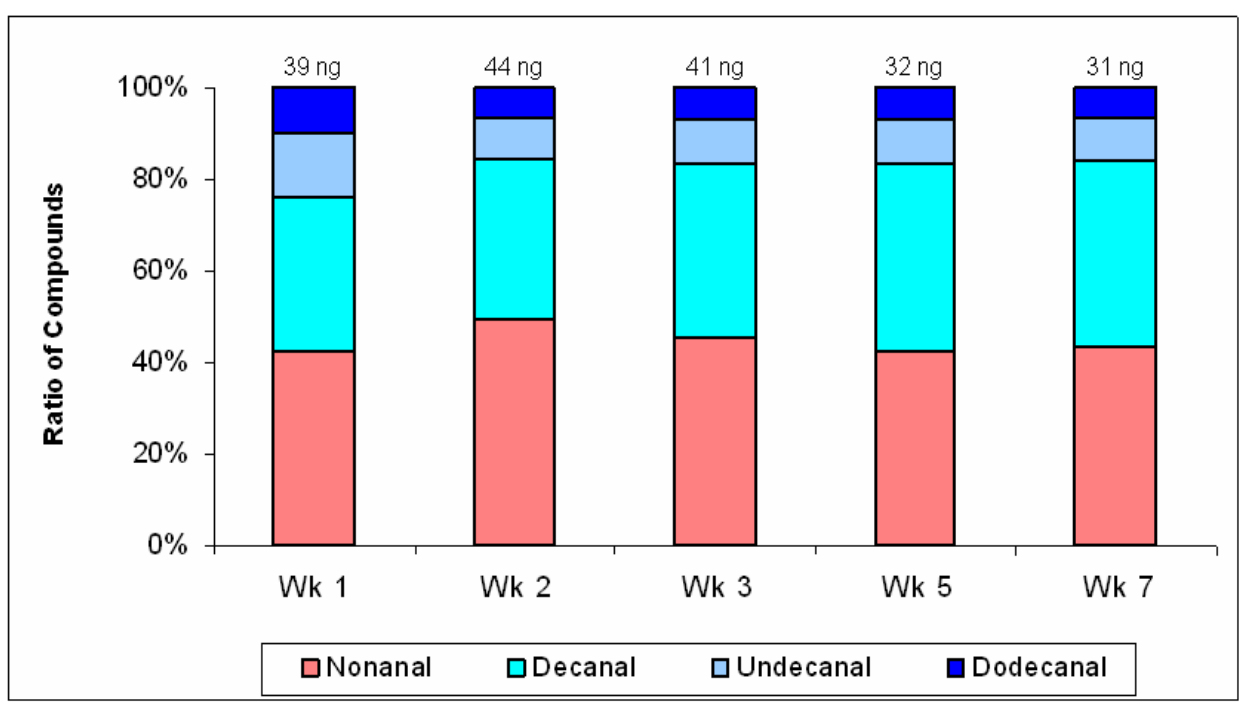


Figure 40: Comparison between common VOCs present in hand odor samples collected on Johnson \& Johnson Gauze from a female subject and stored in the dark (single headspace extractions)

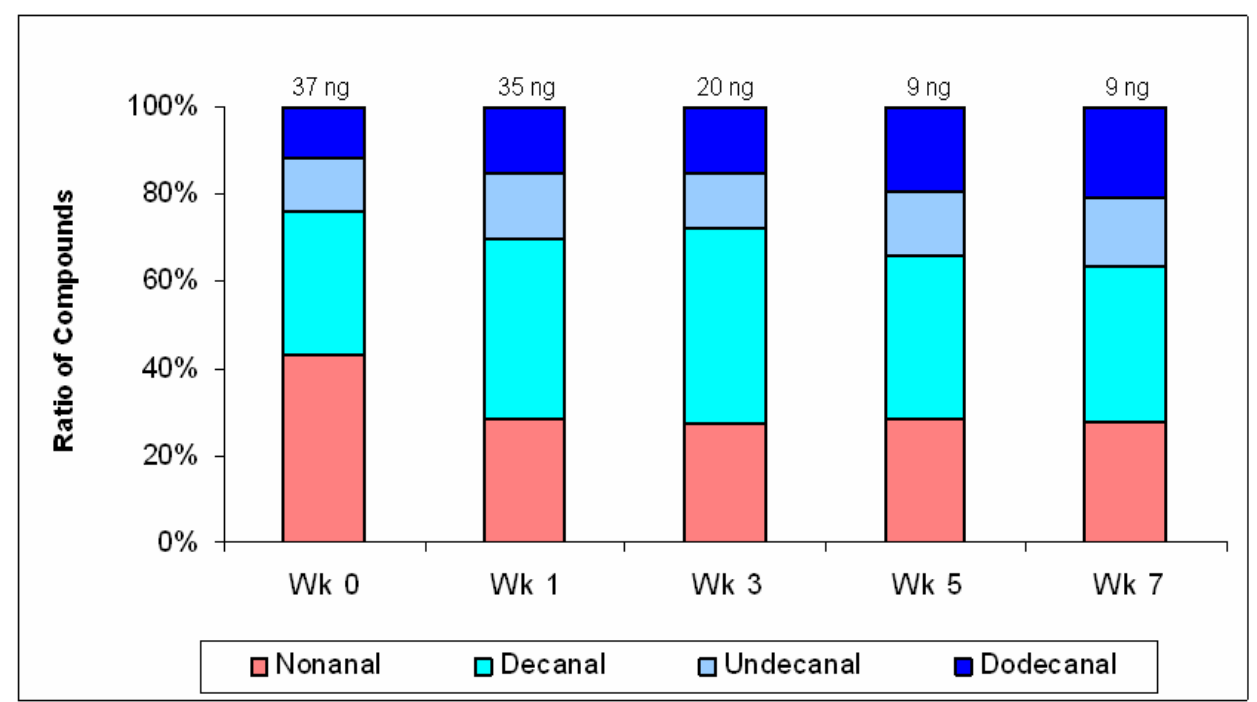

Figure 41: Comparison between common VOCs present in hand odor samples collected on Johnson \& Johnson Gauze from a female subject and stored in the presence of UVA/UVB light (single headspace extractions)

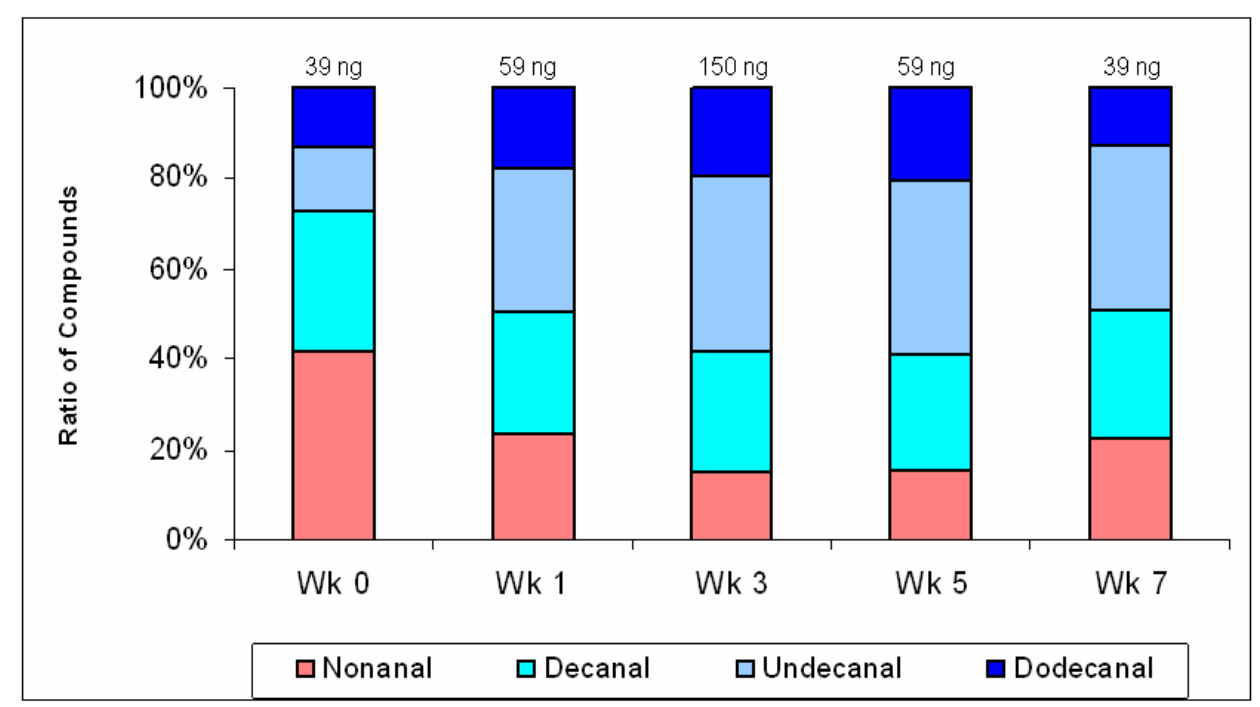




\section{Room Temperature Storage}

Comparisons made utilizing three dimensional covariance mapping values demonstrated that the scent profiles on all the sorbent materials were changing as the storage period progressed (Table 14). The hand odor samples which were stored on the Dukal brand gauze at room temperature produced a similarity value of 0.64 at the end of the storage period while similarity values of 0.54 and 0.49 were obtained for Kings Cotton and Johnson and Johnson brands respectively. This showed that Dukal gave the least variation over the seven week period when compared to the samples stored on the two other sorbent materials. Also, the difference between the similarity values for week zero and week one was greater than the difference between week five and week seven. This trend was observed across all three sorbent materials (Table 14). This suggests that the VOCs in the scent samples were changing less as the storage period progressed. $-80{ }^{\circ} \mathrm{C}$ Storage

Similarity values of $0.64,0.60$ and 0.66 were obtained for Dukal brand, Kings Cotton and Johnson and Johnson brand gauze respectively for the seventh week of storage in $-80{ }^{\circ} \mathrm{C}$. Of all the three sorbent materials, Johnson and Johnson brand showed the greatest similarity between the week zero and the week seven samples. The Johnson and Johnson gauze also showed a smaller difference between the similarity values for week five and seven when compared to Dukal and Kings Cotton (Table 16).

This shows the $100 \%$ cotton materials reacting differently than the Johnson and Johnson gauze in the $-80{ }^{0} \mathrm{C}$ storage condition. This can possibly be explained by the characteristic nature of the samples; cotton fibers are hydrophilic and swell in water whereas polyester is hydrophobic and repels water $(55,59)$. Once hand odor samples are collected, it is 
possible there are small quantities of moisture present on the sorbent material. This could result in the freezing and thawing of the samples during storage and analysis, having a greater effect on the 100 percent cotton sorbent materials more than the Johnson and Johnson brand which is a blend of cotton/rayon and polyester.

\section{Dark Storage}

The samples which were stored on Dukal brand gauze in the dark produced a similarity value of 0.67 at week 7 while similarity values of 0.43 and 0.42 were obtained for Kings Cotton and Johnson and Johnson brand respectively (Table 18). Samples stored in this condition showed a gradual decrease in the similarity values as the storage period progressed. As with the room temperature storage, the differences in the similarity values between the initial weeks (week zero and week one) were greater than between the final weeks (week five and week seven) of storage. This trend was observed for all three sorbent materials.

\section{UVA/UVB Light Storage}

Hand odor samples subjected to storage in the presence of UVA/UVB light also showed a gradual decrease in the similarity values over the storage period for all sorbent materials investigated (Table 20). The Johnson and Johnson brand gave the greatest change over the seven week period; three dimensional covariance mapping value of 0.32 . Storage in the presence of UVA/UVB light resulted in the detection of methyl esters and aldehydes which were not previously detected in the "fresh" (week zero) hand odor samples. These "new" compounds which were often detected by the third week of storage persisted for the remainder of the storage period. 
These compounds were not initially detected in the pre-cleaned gauzes and were only observed with the sorbent materials which were stored in the presence of UVA/UVB light. It is being assumed that the UV light may have caused the creation and/or release of the aldehydes detected on the gauze after storage in this condition. The detection of the aldehydes over time was observed mainly on the 100 percent cotton sorbents. These results suggest that the sorbent materials were being adversely affected by the UVA/UVB light storage. Previous research has shown that materials such as cotton even though they have good resistance to sunlight, degrade with prolonged exposure to ultraviolet light (55).

Also, studies conducted on changes in the lipid composition of fingerprint residue, collected on glass fiber filter paper, have shown that the presence of UV light does produce oxidation reactions resulting in the formation of VOCs such as aldehydes and methyl esters (59). Oxidative degradation of the fatty acid component of sebaceous glands has also been shown to produce aldehydes (25). These are some possible reasons aldehydes and methyl esters were detected but there is no certainty as to whether or not these compounds were created during exposure to UVA/UVB light or they were originally present but not readily released by the sorbent materials. This was not observed in any of the other storage conditions.

The primary odor compounds were determined to be furfural, phenol, nonanal and decanal for the hand odor samples collected on the Dukal brand gauze and stored in the presence of UVA/UVB light. The "new compounds" detected after week three were benzaldehyde, octanal, undecanal, decanoic acid methyl ester and 2-octenal. The hand odor samples collected from a male subject and stored on Kings Cotton in the presence of 
UVA/UVB light had as its primary odor compounds; benzyl alcohol, nonanal, decanal and tetradecane while the "new compounds" detected were benzaldehyde and octanal. For the samples collected from a female subject on Johnson and Johnson brand gauze and stored in UVA/UVB light, the primary odor compounds were found to be nonanal, decanal, undecanal and dodecanal. Unlike the 100 percent cotton sorbents, the "new compounds" that were detected and persisted on the Johnson and Johnson brand gauze after week three were mainly alkanes such as hexadecane and pentadecane.

\subsubsection{Biological evaluations using human scent identification canines}

The preliminary trials used aged hand odor samples which were stored at room temperature for five and seven weeks. The results showed that the canines had difficulty matching fresh (week zero) hand odor samples to the aged samples (Table 22). A more extensive canine trial was conducted using hand odor samples collected from a male subject were stored in the four environmental conditions studied (room temperature, -80 ${ }^{0} \mathrm{C}$, dark and UVA/UVB light). Time was used as a measurement to determine the ease/difficulty that the canine had in matching the samples (Table 23 - Table 26).

Table 22: Preliminary canine trials matching fresh hand odor samples (week zero) to aged hand odor samples (week five and week seven)

\begin{tabular}{|l|l|}
\hline Sample & Canine's Response \\
\hline Fresh Sample & Correct match, no hesitation \\
\hline 5 Week Old Sample & Correct match with hesitation \\
\hline 7 Week Old Sample & $*$ Correct match with hesitation \\
\hline
\end{tabular}

* Canine performed the lineup twice 
Table 23: Canine trials matching fresh (week 0) hand odor samples to aged hand odor samples which were stored at room temperature

\begin{tabular}{|c|c|c|c|c|c|}
\hline Sample & Alert & No Alert & Interest & $\begin{array}{c}\text { Time } \\
\text { (seconds) }\end{array}$ & Comments \\
\hline Week 7 & $\mathrm{x}$ & & & 25 & $\begin{array}{c}\text { canine did line } \\
\text { up twice }\end{array}$ \\
\hline Week 5 & $\mathrm{x}$ & & & 16 & \\
\hline Week 2 & $\mathrm{x}$ & & & 19 & \\
\hline & & & & & \\
\hline Week 1 & $\mathrm{x}$ & & & 5 & \\
\hline
\end{tabular}

Table 24: Canine trials matching fresh (week 0) hand odor samples to aged hand odor samples which were stored at $-80^{\circ} \mathrm{C}$

\begin{tabular}{|c|c|c|c|c|l|}
\hline Sample & Alert & No Alert & Interest & $\begin{array}{c}\text { Time } \\
\text { (seconds) }\end{array}$ & Comments \\
\hline Week 7 & $\mathrm{x}$ & & & 5 & \\
\hline Week 5 & $\mathrm{x}$ & & & 5 & \\
\hline Week 2 & $\mathrm{x}$ & & & & \\
\hline & & & & & canine did \\
Week 1 & $\mathrm{x}$ & & & 9 & \\
\hline
\end{tabular}


Table 25: Canine trials matching fresh (week 0) hand odor samples to aged hand odor samples which were stored in the dark

\begin{tabular}{|c|c|c|c|c|c|}
\hline Sample & Alert & No Alert & Interest & $\begin{array}{c}\text { Time } \\
\text { (seconds) }\end{array}$ & Comments \\
\hline Week 7 & $\mathrm{X}$ & & & 20 & $\begin{array}{l}\text { Canine did } \\
\text { lineup } 3 \text { times }\end{array}$ \\
\hline Week 5 & $\mathrm{x}$ & & & 5 & \\
\hline Week 2 & $\mathrm{X}$ & & & 12 & \\
\hline Week 1 & $\mathrm{x}$ & & & 6 & \\
\hline
\end{tabular}

Table 26: Canine trials matching fresh (week 0) hand odor samples to aged hand odor samples which were stored in the presence of UVA/UVB light

\begin{tabular}{|c|c|c|c|c|c|}
\hline Sample & Alert & No Alert & Interest & $\begin{array}{c}\text { Time } \\
\text { (seconds) }\end{array}$ & Comments \\
\hline Week 7 & & & & & \\
\hline Week 5 & $\mathrm{x}$ & & & & \\
\hline Week 2 & $\mathrm{x}$ & & & 5 & \\
\hline & & & & & \\
\hline Week 1 & $\mathrm{x}$ & & & 3 & \\
\hline
\end{tabular}


The results show that the canine was able to match all the aged samples stored in different conditions to the fresh hand odor sample presented. The results indicate that the canine had more difficulty matching the older samples to the fresh sample. This was observed with the samples which were stored at room temperature and in the dark. The results also show that the canine appeared to have difficulty matching the fresh sample to the two week old samples which were stored at $-80{ }^{\circ} \mathrm{C}$ and in the presence of UVA/UVB light. Regardless of the condition in which the hand odor samples are stored, the canine was still able to provide a match. These results are comparable with the instrumental data acquired.

\subsection{Trapping and releasing capabilities of sorbent materials}

The storage study revealed that hand odor samples collected from an individual on materials which possessed different chemical compositions, produced odor profile obtained via SPME-GC/MS which possessed different VOCs. Below are hand odor samples collected from a male and a female subject on Dukal brand gauze, Kings Cotton and Johnson and Johnson brand gauze.

Collection of hand odor samples on all three materials showed differences in the functional groups of the VOCs collected. The Dukal brand gauze and the Kings Cotton released primarily aldehydes and alkanes while the Johnson and Johnson brand gauze released not only aldehydes and alkanes but also alcohols. Two of the major differences between these materials are their surface morphologies and their chemical compositions. The surface morphologies of these three materials as observed via SEM are shown in Figure 44. The chemical compositions of the different materials are shown in Table 27. 
Figure 42: VOCs present in hand odor samples collected from a male subject on different sorbent materials

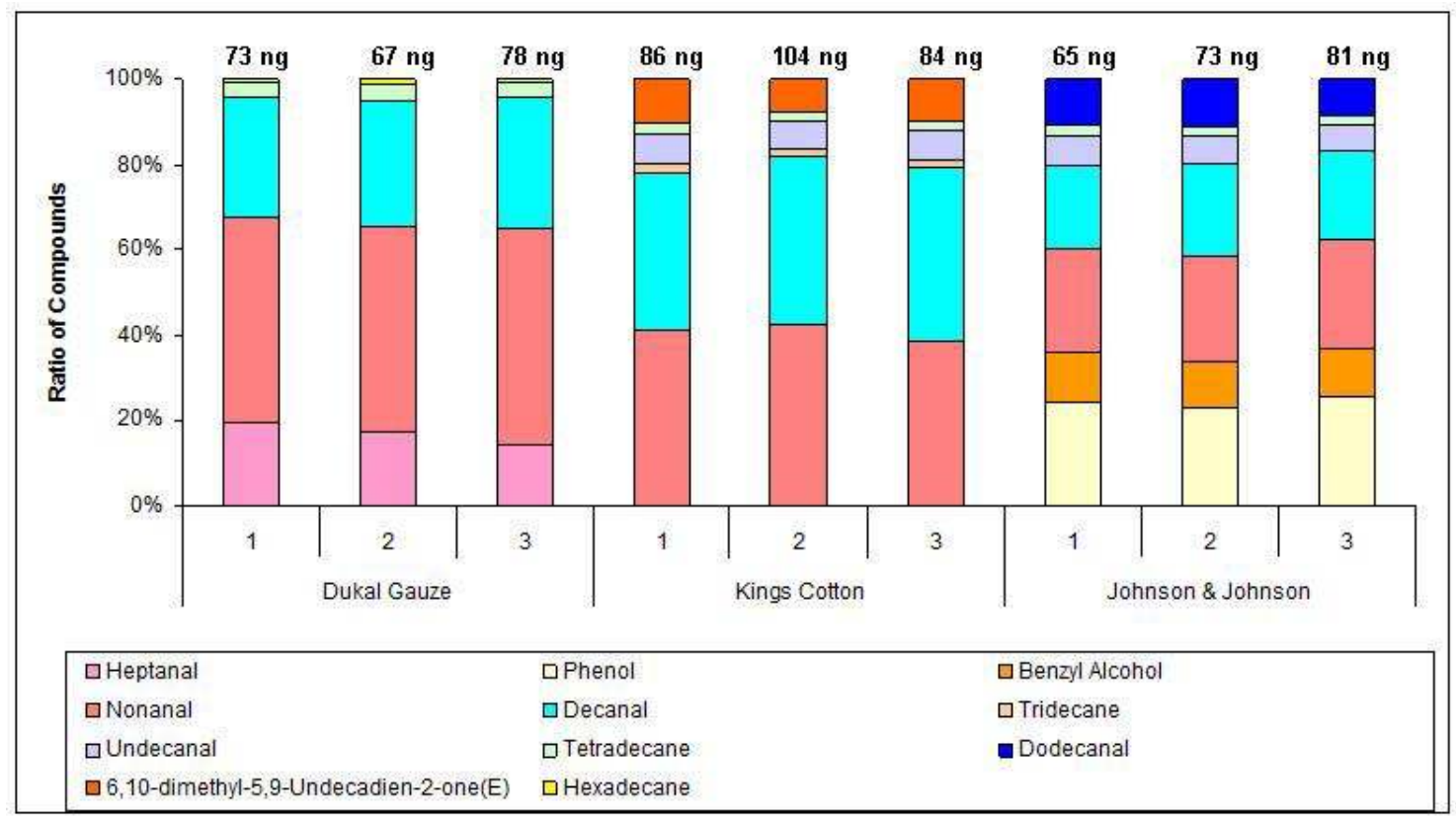

Figure 43: VOCs present in hand odor samples collected from a female subject on different sorbent materials

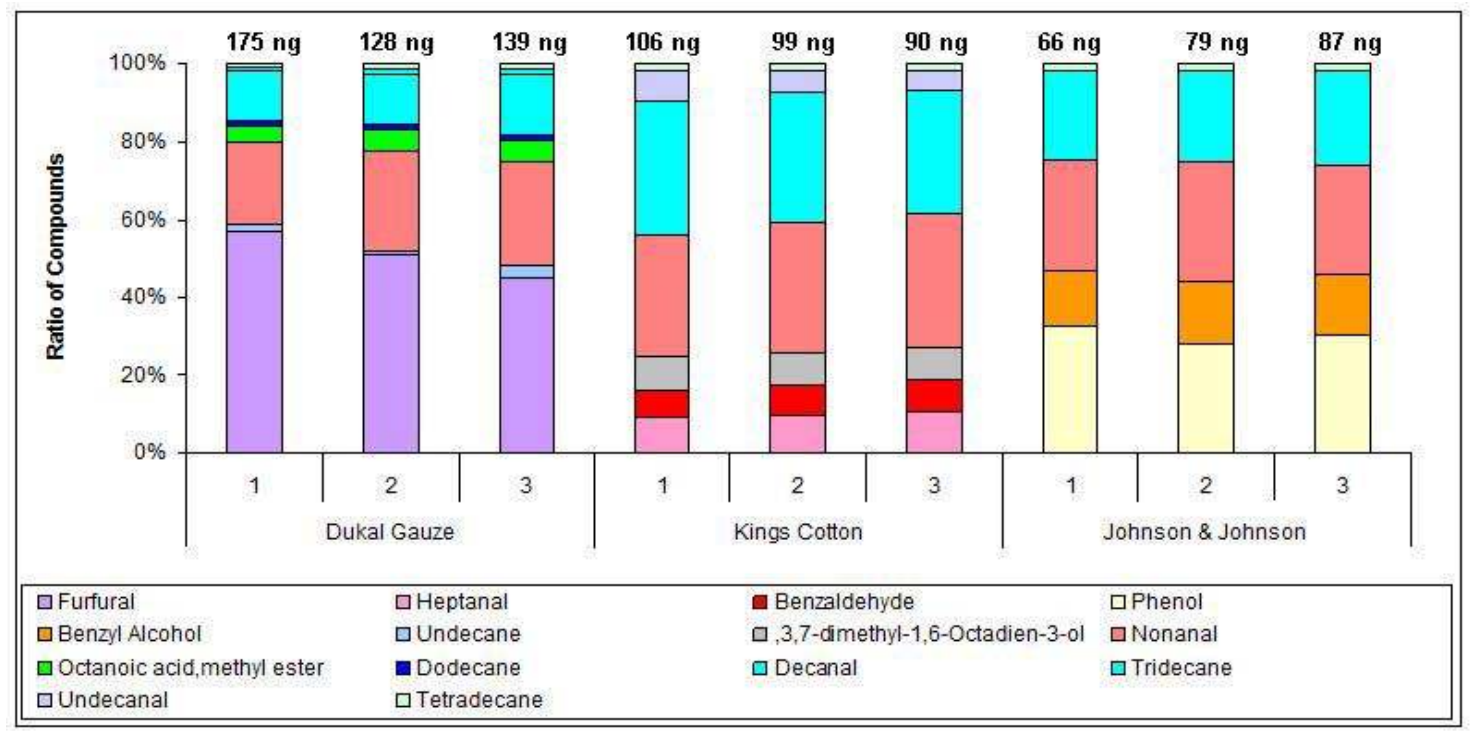


Figure 44: SEM Images of (a) Dukal brand gauze (b) Johnson and Johnson brand gauze (cotton blend) (c) Kings Cotton (Resolution x25)

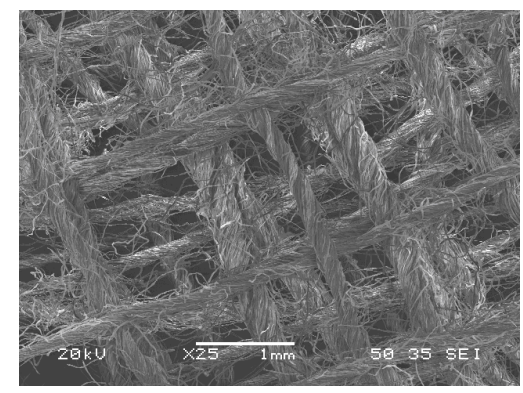

(a)

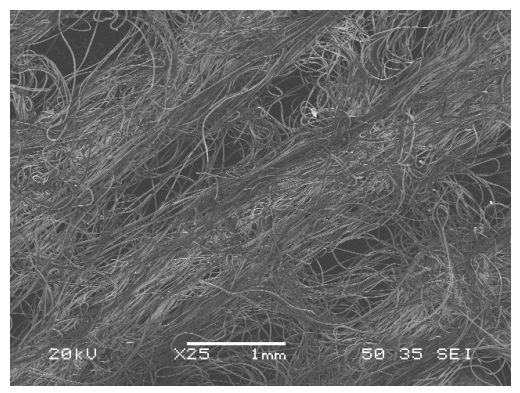

(b)

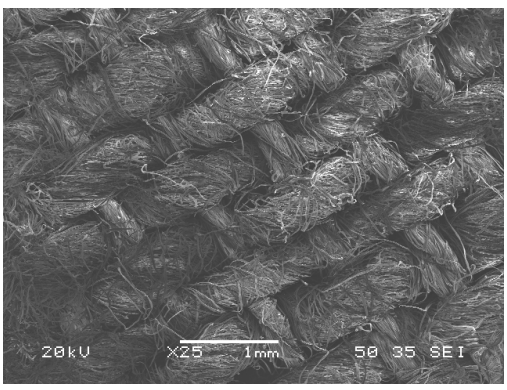

(c)

Table 27: Properties of different sorbent materials

\begin{tabular}{|l|l|}
\hline \multicolumn{1}{|c|}{ Materials } & \multicolumn{1}{c|}{ Properties } \\
\hline Dukal Brand Gauze & Sterile, $100 \%$ Cotton \\
\hline Kings Cotton & Non-sterile, 100\% Cotton \\
\hline Johnson and Johnson Brand (Cotton Blend) & Sterile, Rayon/Polyester/Cellulose \\
\hline
\end{tabular}

To determine the reason(s) for the observed differences, six different sorbent materials were chosen; Dukal brand gauze, Johnson and Johnson cotton gauze, Johnson and Johnson cotton blend gauze, Polish cotton, Hungarian cotton and Kings cotton. These six materials were chosen as Polish cotton, Hungarian cotton and Kings Cotton are from Poland, Hungary and the Netherlands respectively; which are three of the leading countries in which human scent identification is currently employed. Johnson and Johnson cotton gauze is the sorbent material of choice used in the United States by the Federal Bureau of Investigation while research groups have been utilizing Dukal brand 
gauze. The Johnson and Johnson cotton blend material was chosen to investigate the interaction between a synthetic material and human scent compounds.

Previous research has shown that even though materials are determined to be biologically sterile, they are not necessarily analytically clean (24). Prior to use, all sorbent materials were pre-cleaned to remove any human scent compounds which may have been present on the materials using the method previously described in section 3.2.1. Once the materials were cleaned, they were subjected to headspace SPME-GC/MS to verify analytical cleanliness. Of the six materials investigated, only the Dukal brand gauze, Kings Cotton and Johnson and Johnson cotton blend were free of all human scent compounds following the cleaning procedure. All experiments were subsequently conducted using Dukal brand gauze, Kings Cotton and Johnson and Johnson brand cotton blend gauze.

To remove all biases obtained through the use of human subjects, a standard VOC mixture comprised of 39 compounds previously reported as human scent components was created and used to spike the different sorbent materials. Of the total amount of VOCs spiked (23.4 mg) in the $10 \mathrm{ml}$ glass vial (positive control) an average of $2040 \mathrm{ng}$ was recovered using SPME-GC/MS analysis. From the Dukal brand gauze an average of $591 \mathrm{ng}$ of compounds was recovered; from Kings Cotton an average of $581 \mathrm{ng}$ of VOCs was recovered while the Johnson and Johnson brand gauze released a total of $857 \mathrm{ng}$ of compounds. Using a one way ANOVA, it was determined that the masses recovered for the sorbent materials were significantly different from that of the positive control demonstrating that the sorbent materials are retaining significant amounts of VOCs (Figure 45). 
Figure 45: Average mass of VOCs recovered from positive control and sorbent materials

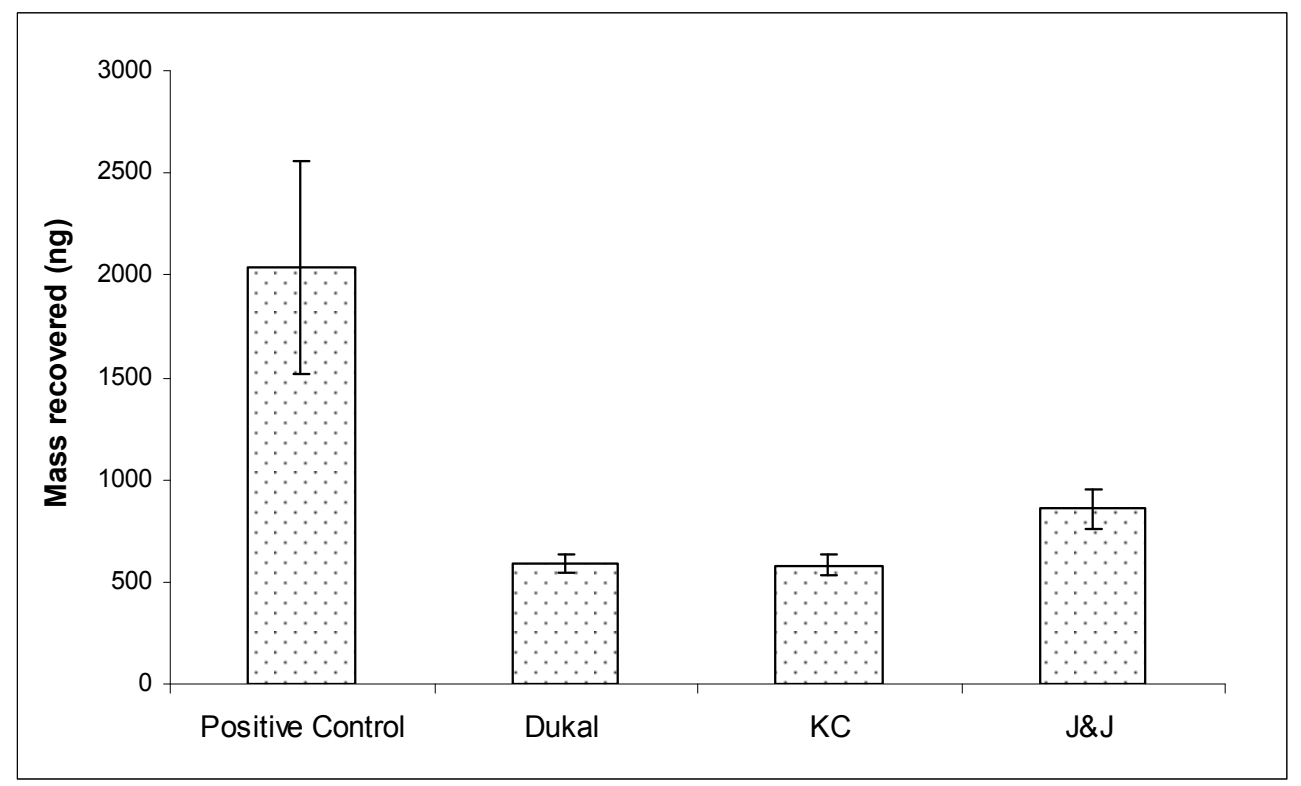

A one way ANOVA used to compare the mean masses from the three sorbent materials showed that the recovered masses were significantly different as the calculated $\mathrm{F}$ value was greater than the critical $\mathrm{F}$ value at a $95 \%$ confidence level. This resulted in rejection of the null hypothesis which states that there is no difference in the masses obtained from the different materials. A Fishers least significant difference (LSD) post hoc test was performed upon rejection of the null hypothesis. Pair wise comparisons of the difference between the means obtained from each sorbent material were compared to the least significant difference (LSD). All pairs of interest were tested; Dukal/KC, Dukal/J\&J and $\mathrm{KC} / \mathrm{J} \& \mathrm{~J}$. Comparison of the differences in means to the LSD shows that the amount of VOCs recovered by the Dukal brand gauze and the Kings Cotton were not significantly different but the amount recovered from the Johnson and Johnson Brand was significantly different from the other two sorbent materials. 
Various functional groups were recovered from the positive control and the sorbent materials in the following order; Aldehydes $>$ Aliphatics/Aromatics $>$ Alcohols $>$ Esters $>$ Ketones $>$ Acids. The order of recovery of the functional groups is a result of the SPME fiber preference. This should not affect the results as this bias was observed in all the samples.

Figure 46: Average mass of functional groups recovered from each sorbent material

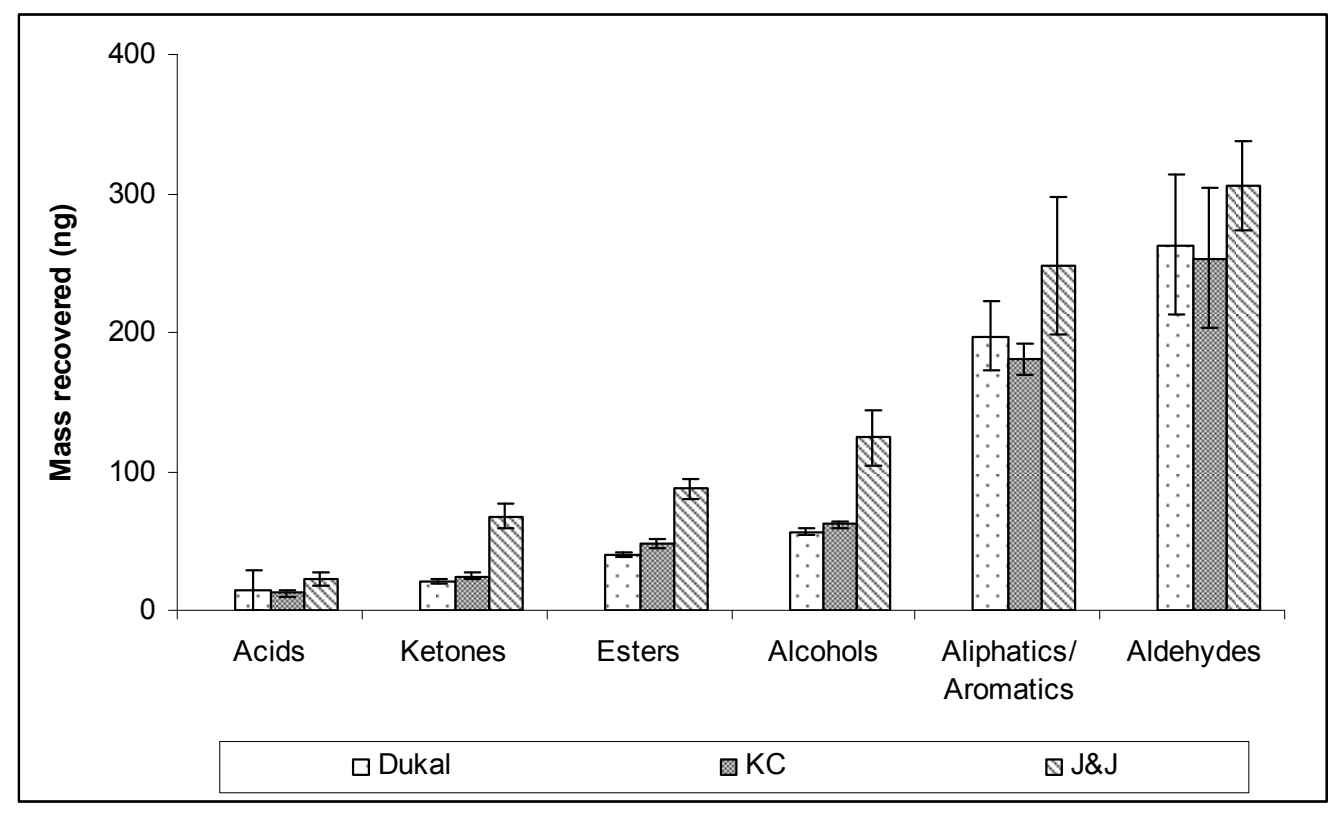

For all functional groups studied, the Johnson and Johnson brand gauze released greater masses of VOCs than the Dukal brand and Kings Cotton. A one way ANOVA showed significant differences in the masses of alcohols, esters, aliphatics/aromatics and ketones released by the Johnson and Jonson brand compared to the 100 percent cotton materials. Ketones and alcohols are polar compounds which are expected to have very strong interactions with the polar surfaces present on the cellulose backbone of the cotton materials; more specifically by the formation of hydrogen bond interactions between the cellulose backbone of the 100 percent cotton materials and the hydroxyl portions and 
carbonyl portions of the alcohols and ketones respectively. The Johnson and Johnson brand gauze is not entirely comprised of cellulose and so would possess a greater ability to release alcohols and ketones more readily than the polar cotton materials. The observed differences in the trapping and releasing capabilities of the 100 percent cotton materials and the cotton blend material could be as a result of the cotton materials having solely polar surfaces while the cotton blend material possess a combination of both polar and non-polar sites due to the presence of the rayon, polyester and cotton backbone.

Similar results were obtained with the hand odor samples from the different subjects. The 100 percent cotton materials released primarily aldehydes and alkanes while the cotton blend material released not only aldehydes and alkanes but also alcohols. The cellulose backbone of the one hundred cotton materials has a high affinity for polar compounds such as alcohols possibly resulting in these compounds being poorly released; hence, the non-detection instrumentally of the alcohols from these materials but their detection from the less polar cotton blend material. The non-detection of the more polar compounds from the 100 percent cotton materials is however no indication of their absence on these sorbent materials. These materials have such high affinities for polar compounds that they are possibly being released in quantities which are below the detection limit of the GC/MS used for analyses. This would explain the differences in the human scent profiles obtained for the same individual on different materials. Even though this may be a drawback to matching the scent profiles of individuals instrumentally, it may not be significant in using canines for matching odor from individuals as the canines' sense of smell is said to be orders of magnitudes lower than the limit of detection of analytical instruments. 
4.4. Identification of the best procedure to follow in collecting human traces from objects

Experiments were designed to evaluate different sampling methods; contact and noncontact with and without dynamic air flow. The active scent transfer was done using a scent transfer unit (STU-100). Time optimization experiments were also conducted to determine the optimum collection time for each sampling method.

Studies were conducted to determine a cleaning method that would remove all human scent compounds from the stainless steel bars prior to sample collection. The metal bars were washed with an alkaline soap solution, rinsed with acetone and then allowed to oven dry overnight at $105{ }^{\circ} \mathrm{C}$. This cleaning method proved effective in the removal of compounds previously reported as human scent components from the metal bars.

\subsubsection{Passive collection}

Stainless steel metal bars were spiked with a total of $24 \mathrm{mg}$ of a volatile organic compound (VOC) mixture previously reported as being human scent compounds. This was done to simulate a hand odor sample. Sorbent materials were exposed to the bars for various time intervals (three, four, five, six, eight and twelve hours) using a contact and a non-contact method without airflow followed by SPME-GC/MS analysis. The results show that the optimum collection time for each sorbent material varied. A one way ANOVA was used to determine if the amount of VOCs recovered for the various times were significantly different.

The passive contact method for the Dukal brand gauze showed no significant difference in the amount of VOCs collected between three hours and four hours and no significant 
difference between five hours, six hours and twelve hours. Eight hours did show a significant difference from all the other times and it also produced the greatest amount of VOCs (Figure 47). The non-contact method using Dukal brand gauze showed no significant difference between three hours and four hours and no significant difference between five hours, six hours, eight hours and twelve hours. Six hours produced the greatest amount of VOCs (Figure 48). Both the contact and non-contact passive collection methods using Kings Cotton showed that the mass of VOCs collected for the various time intervals were not significantly different (Figure 49 and Figure 50 respectively). The greatest mass of VOCs was obtained at five hours for both collection methods.

Figure 47: Volatile Organic Compounds collected on Dukal Brand Gauze from objects via a passive contact collection method

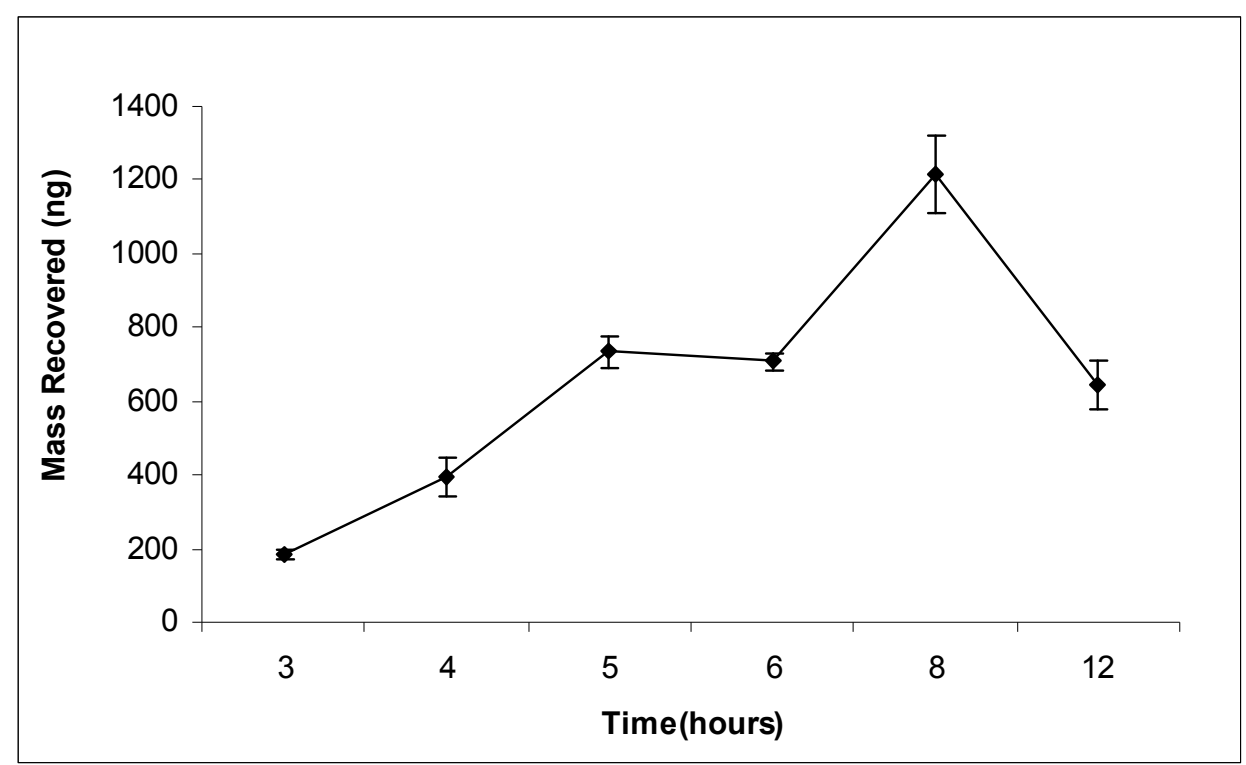


Figure 48: Volatile Organic Compounds collected on Dukal Brand Gauze from objects using a passive non- contact collection method

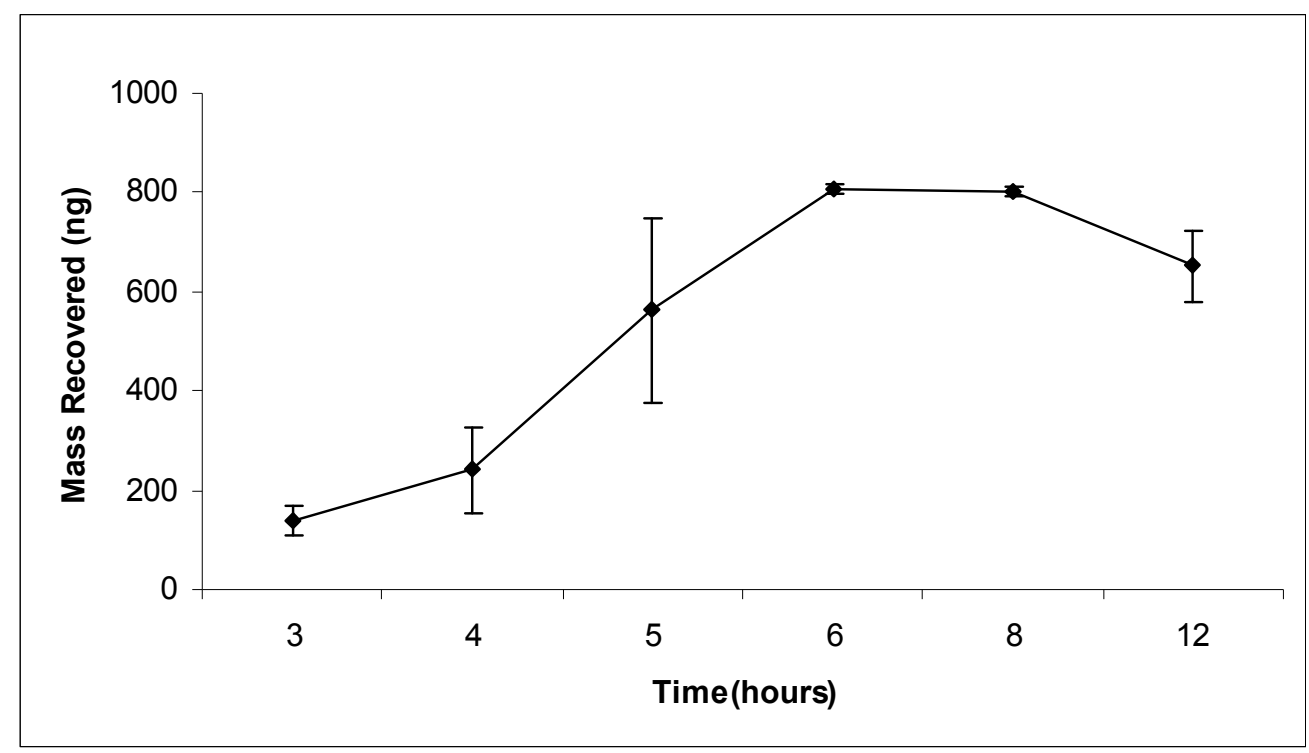

Figure 49: Volatile Organic Compounds collected on Kings Cotton from objects via a passive contact collection method

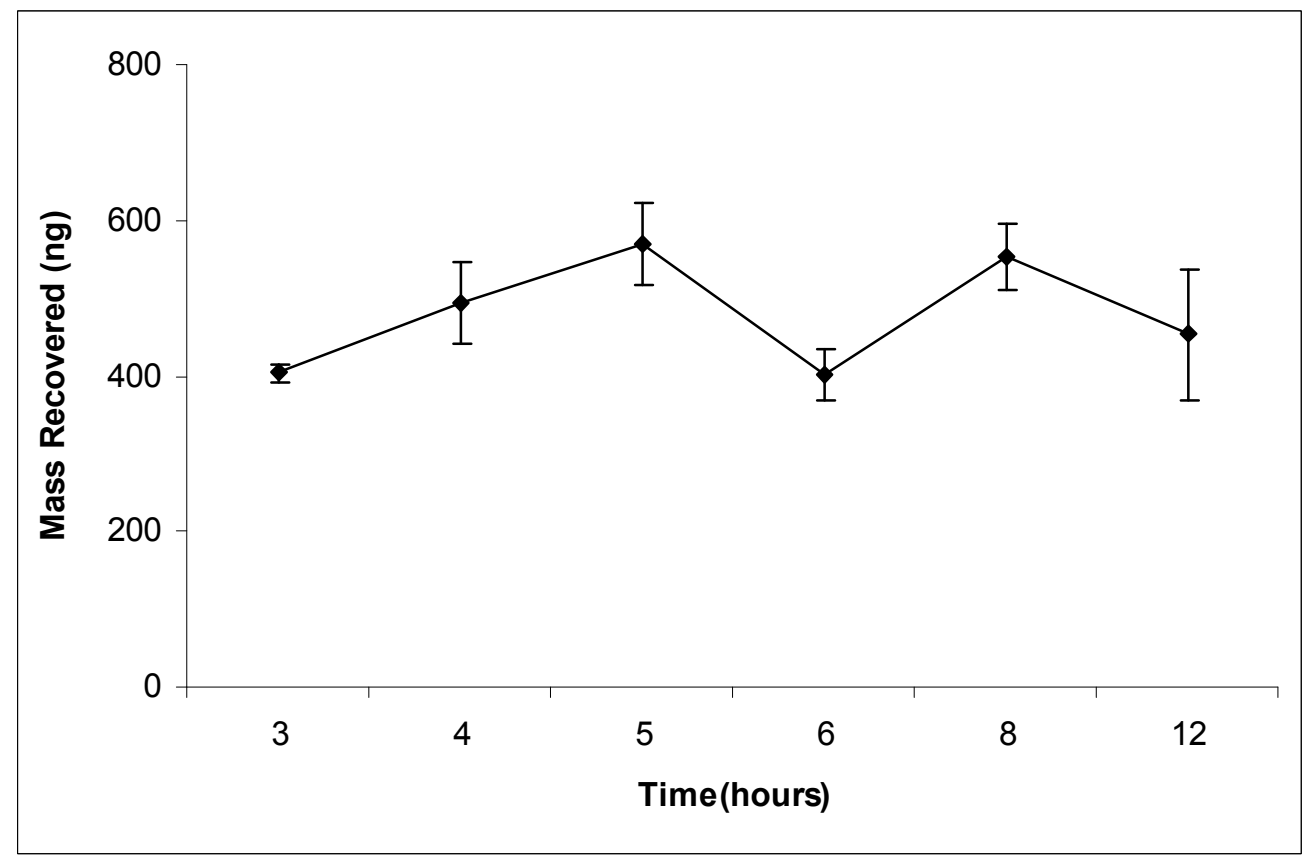


Figure 50: Volatile Organic Compounds collected on Kings Cotton from objects via a passive noncontact collection method

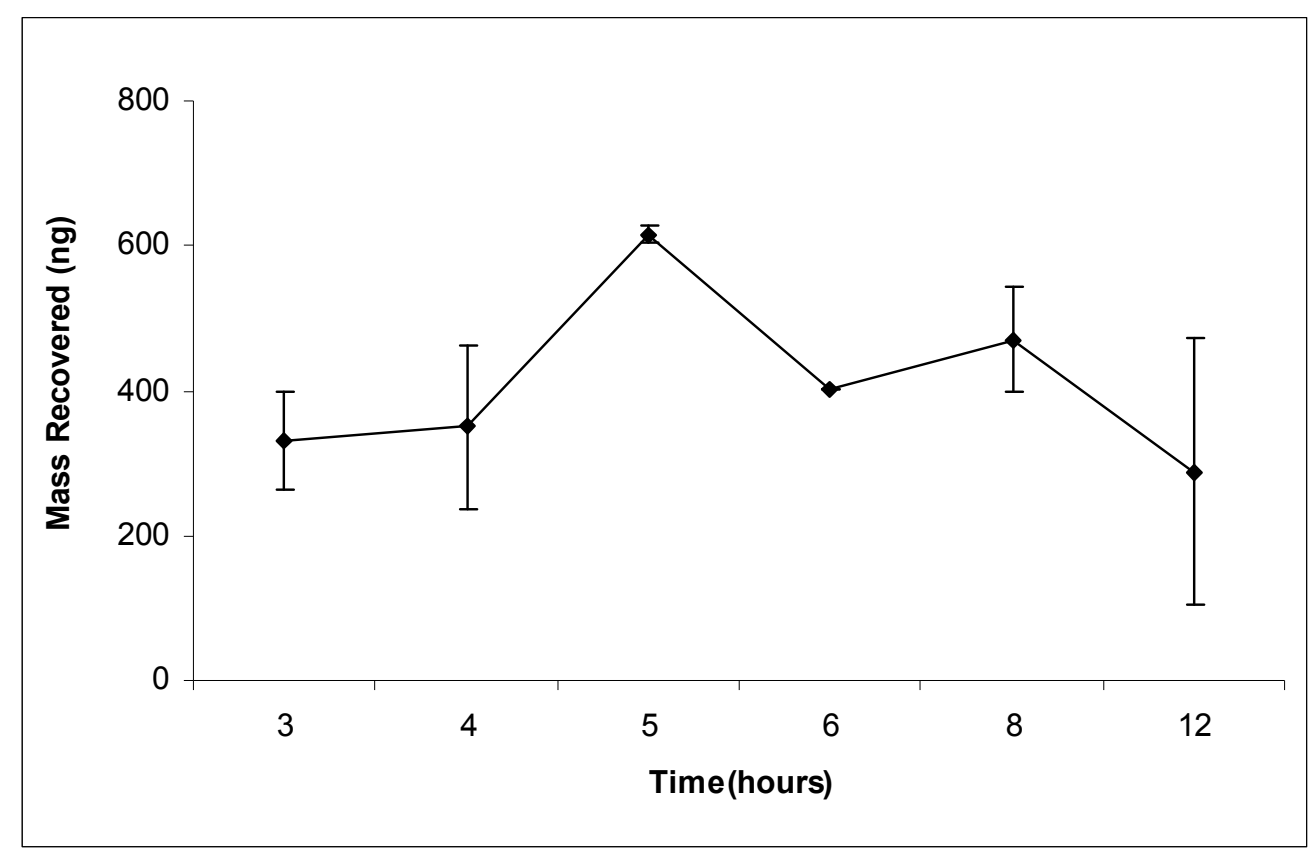

The passive contact collection method for the Johnson and Johnson brand gauze showed that the masses obtained for three hours, four hours, five hours, six hours and eight hours were not significantly different but they were significantly different from the mass obtained at twelve hours. The greatest mass of VOCs was obtained at six hours (Figure 51). The non-contact method showed no significant difference in the masses obtained at three hours, four hours, five hours, six hours and twelve hours. The mass obtained at eight hours was significantly different from the masses obtained for all the other times. The mass obtained at eight hours was also greater than the masses obtained for the other times (Figure 52). 
Figure 51: Volatile Organic Compounds collected on Johnson \& Johnson brand gauze from objects via a passive contact collection method

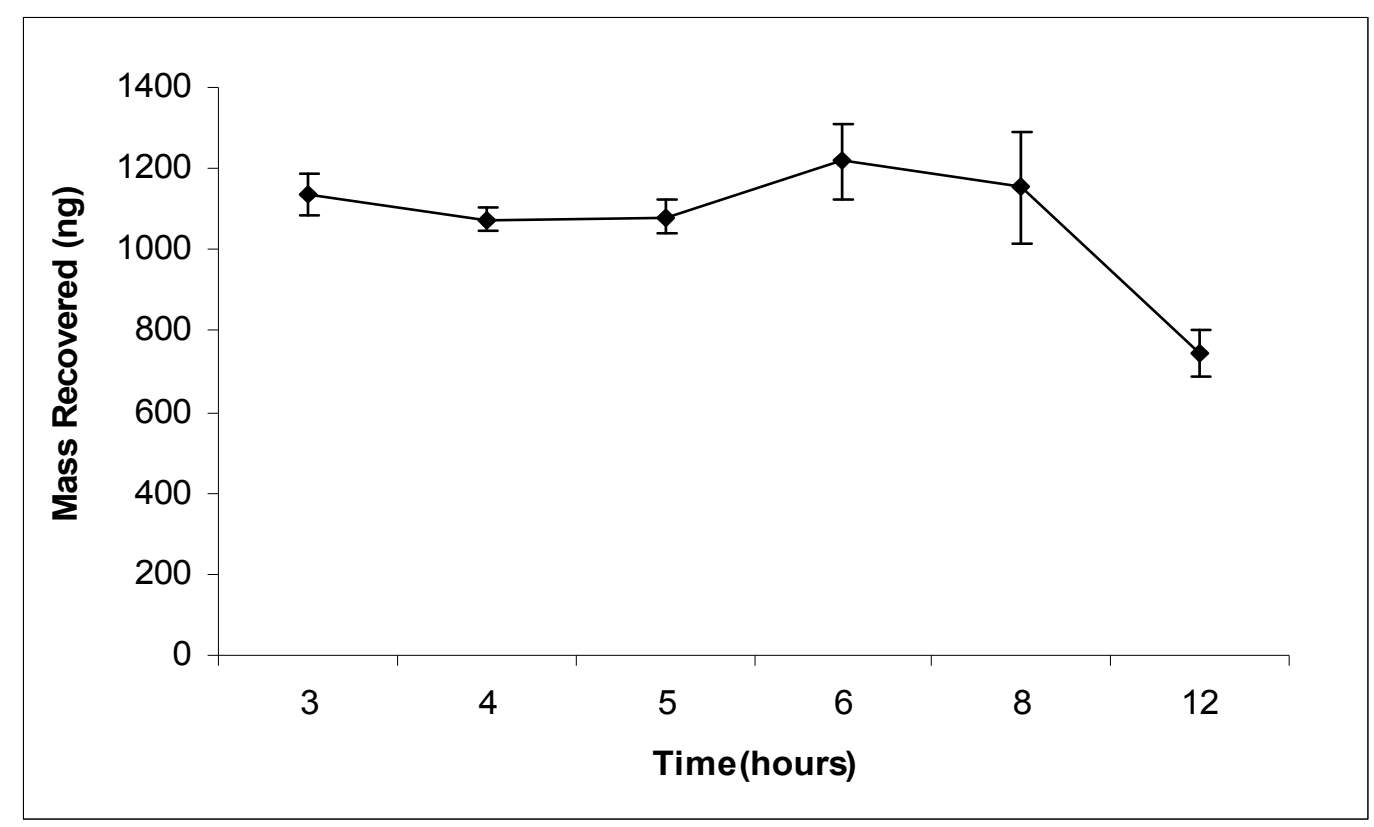

Figure 52: Volatile Organic Compounds collected on Johnson \& Johnson brand gauze from objects via a passive non-contact collection method

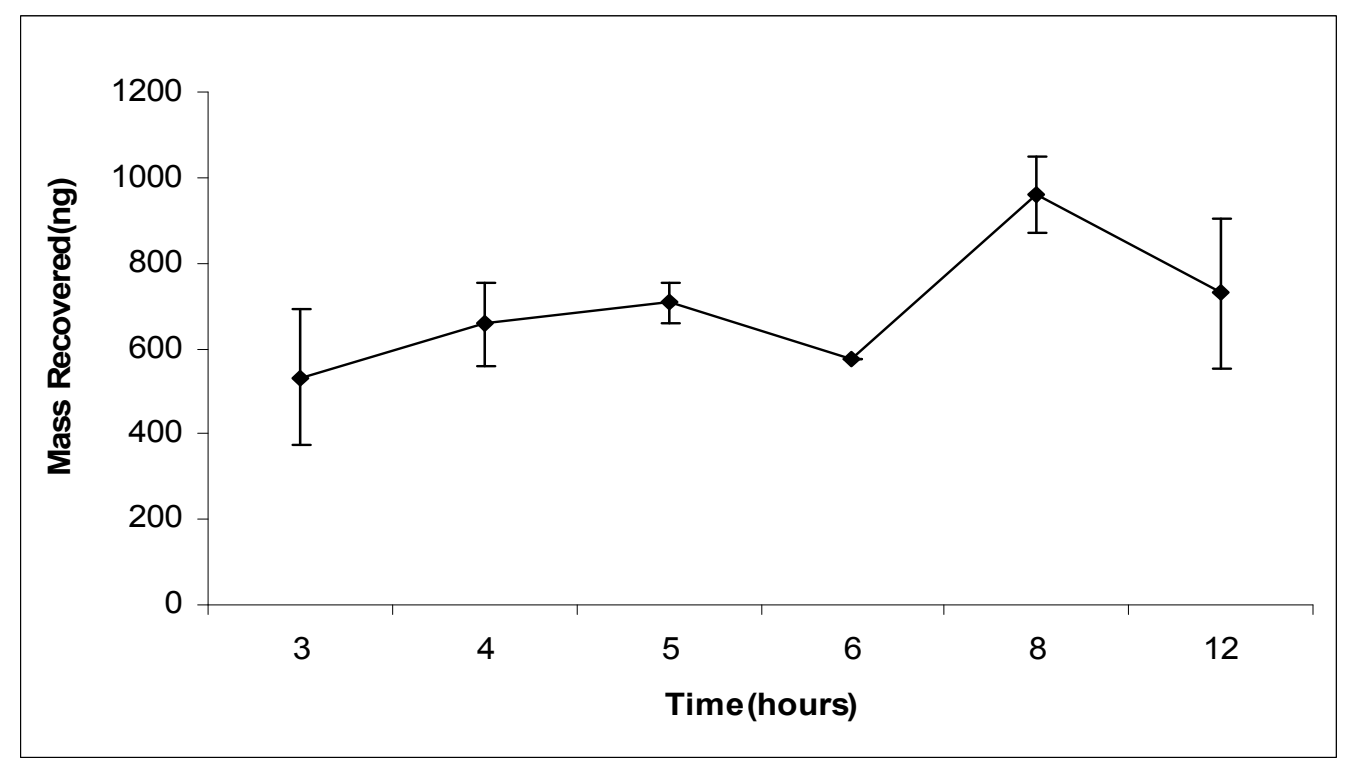




\subsubsection{Active collection}

The flow rates of the STU-100 were calculated as explained in section 3.2.7. The results obtained showed that once the sorbent materials were placed on the STU-100, the flow rates decreased drastically with the Dukal brand gauze having the highest flow rates and the Johnson and Johnson brand gauze giving the lowest flow rates (Figure 53). The Dukal brand gauze had the highest flow rates when compared to the other materials as it is the less tightly woven of the three materials (Figure 44). The Johnson and Johnson brand gauze which is not as tightly woven as the Kings Cotton gave the lowest flow rates and this was rather surprising. It is being assumed that even though the Johnson and Johnson brand gauze is not as tightly woven as the Kings Cotton, it does possess a second layer which would possibly make it more difficult for the air to pass through resulting in lower airflows.

Figure 53: Flow rates of STU-100 with and without sorbent materials

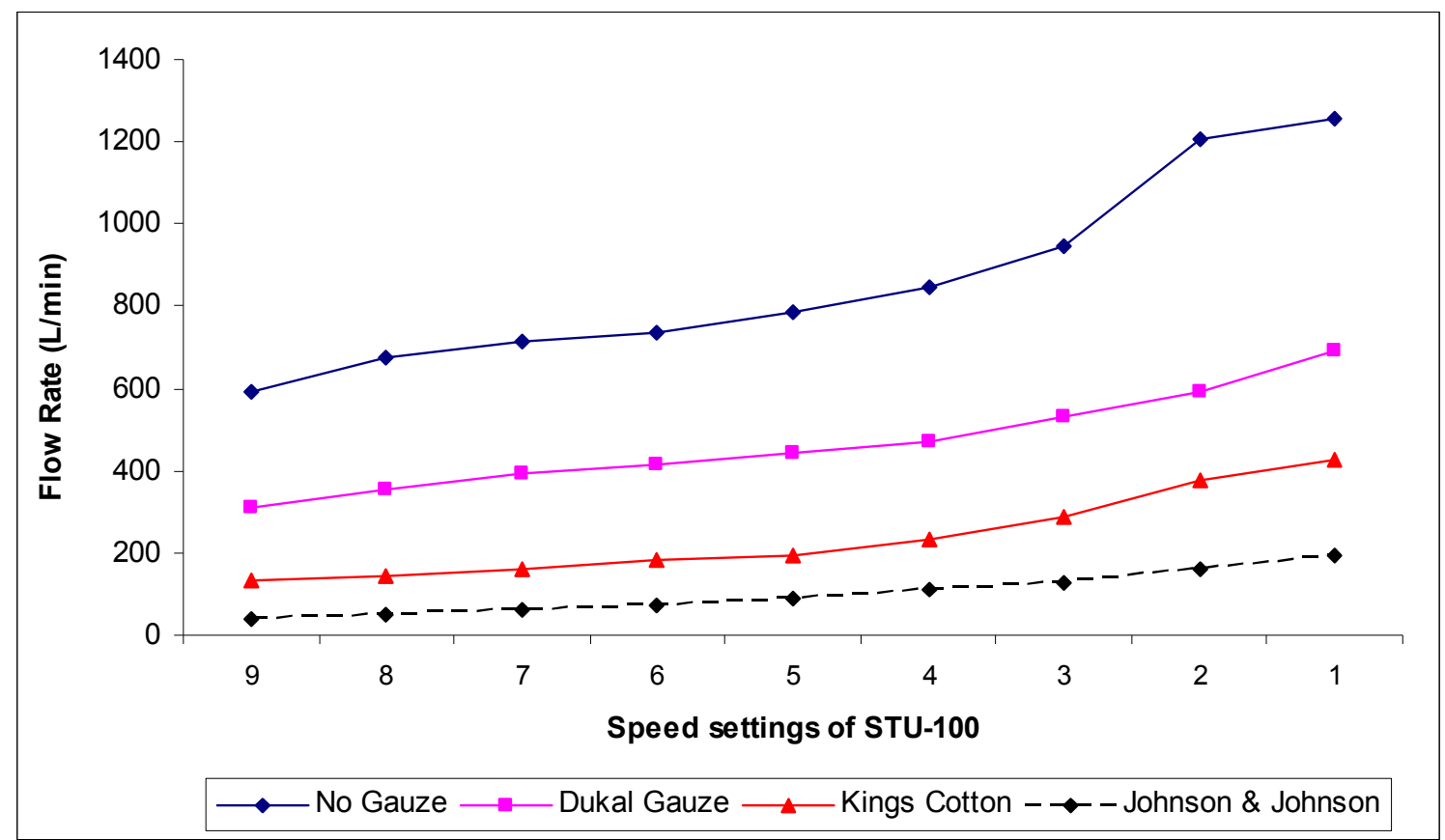


Stainless steel metal bars were spiked with a total of $24 \mathrm{mg}$ of a volatile organic compound (VOC) mixture previously reported as being human scent compounds. This was done to simulate a hand odor sample. The scent transfer unit (STU-100) was used to collect the VOCs from the spiked bars onto the sorbent materials (Dukal, Kings Cotton, Johnson \& Johnson) using different speeds (one, three, five, seven, and nine). This was followed by SPME-GC/MS analysis. The results showed that the optimum collection speed for each sorbent material varied. A one way ANOVA was used to determine if the amount of VOCs recovered for the various speeds were significantly different.

Both the contact and non-contact methods showed no significant difference in the mass of VOCs collected on the Dukal gauze at the different STU-100 speeds investigated Figure 54 and Figure 55). The greatest mass of VOCs was obtained at speed one for the active contact method and speed three for the active non-contact method. The mass of VOCs collected on the Kings Cotton for the contact and non-contact methods were significantly different. The greatest mass of VOCs was recovered using speed nine and speed five for the contact and non-contact methods respectively (Figure 56 and Figure 57). The mass of VOCs collected on the Johnson and Johnson brand gauze for both the contact and non-contact method were not significantly different. The greatest mass of VOCs was recovered using speed three and speed five for the contact and non-contact methods respectively (Figure 58 and Figure 59). 
Figure 54: Volatile Organic Compounds collected on Dukal brand gauze from objects using an active contact collection method

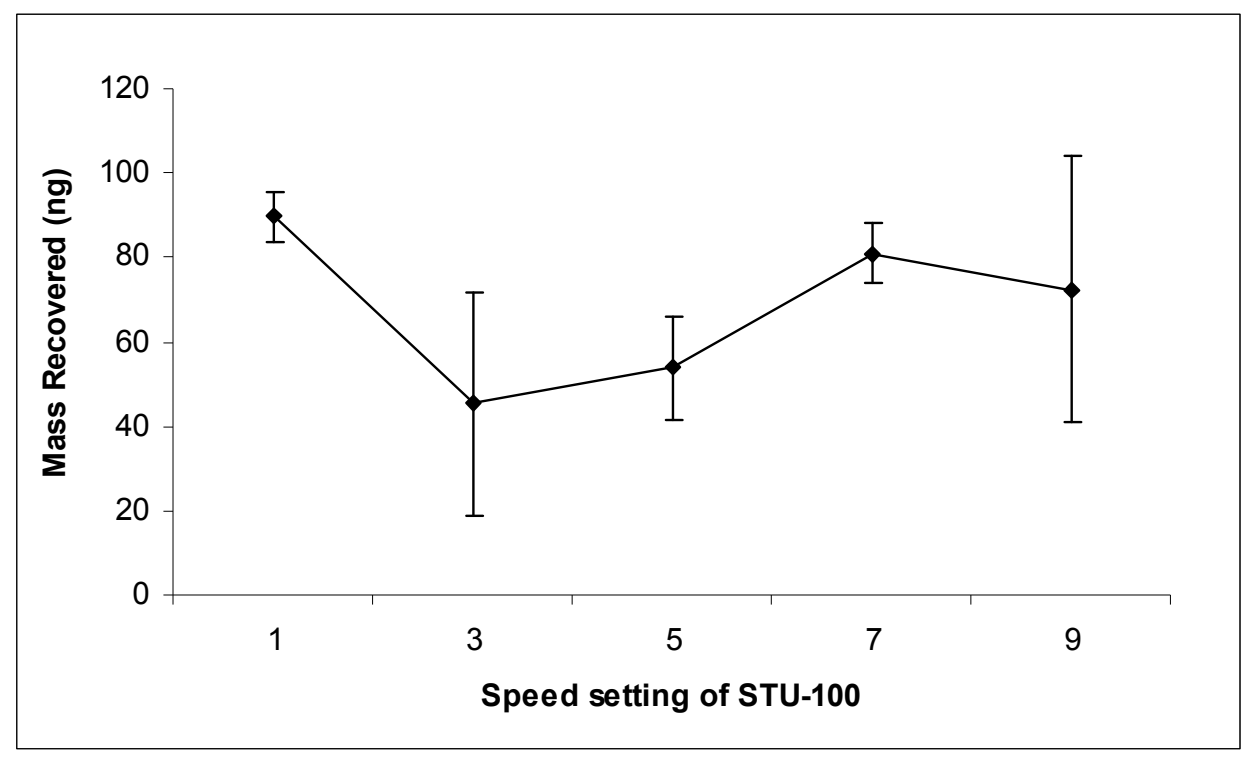

Figure 55: Volatile Organic Compounds collected on Dukal brand gauze from objects using an active non-contact collection method

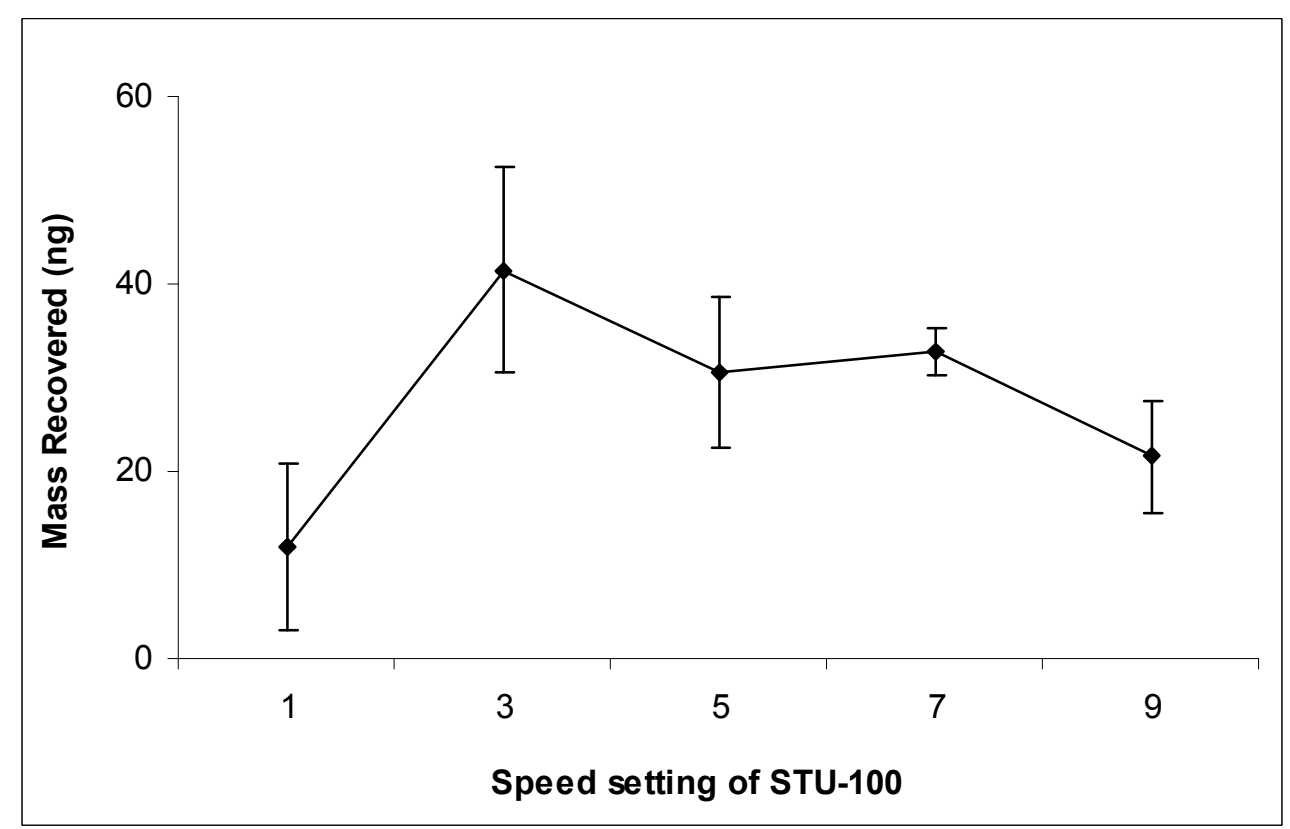


Figure 56: Volatile Organic Compounds collected on Kings Cotton from objects using an active contact collection method

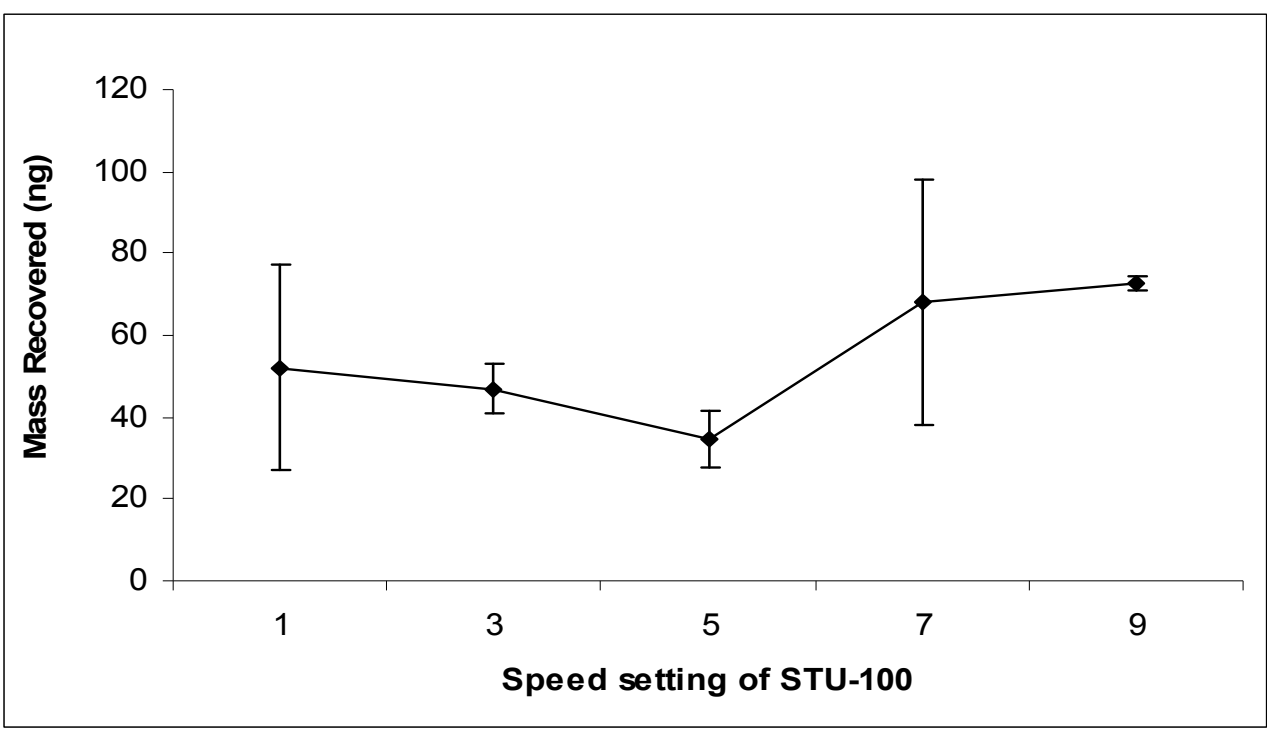

Figure 57: Volatile Organic Compounds collected on Kings Cotton from objects using an active noncontact collection method

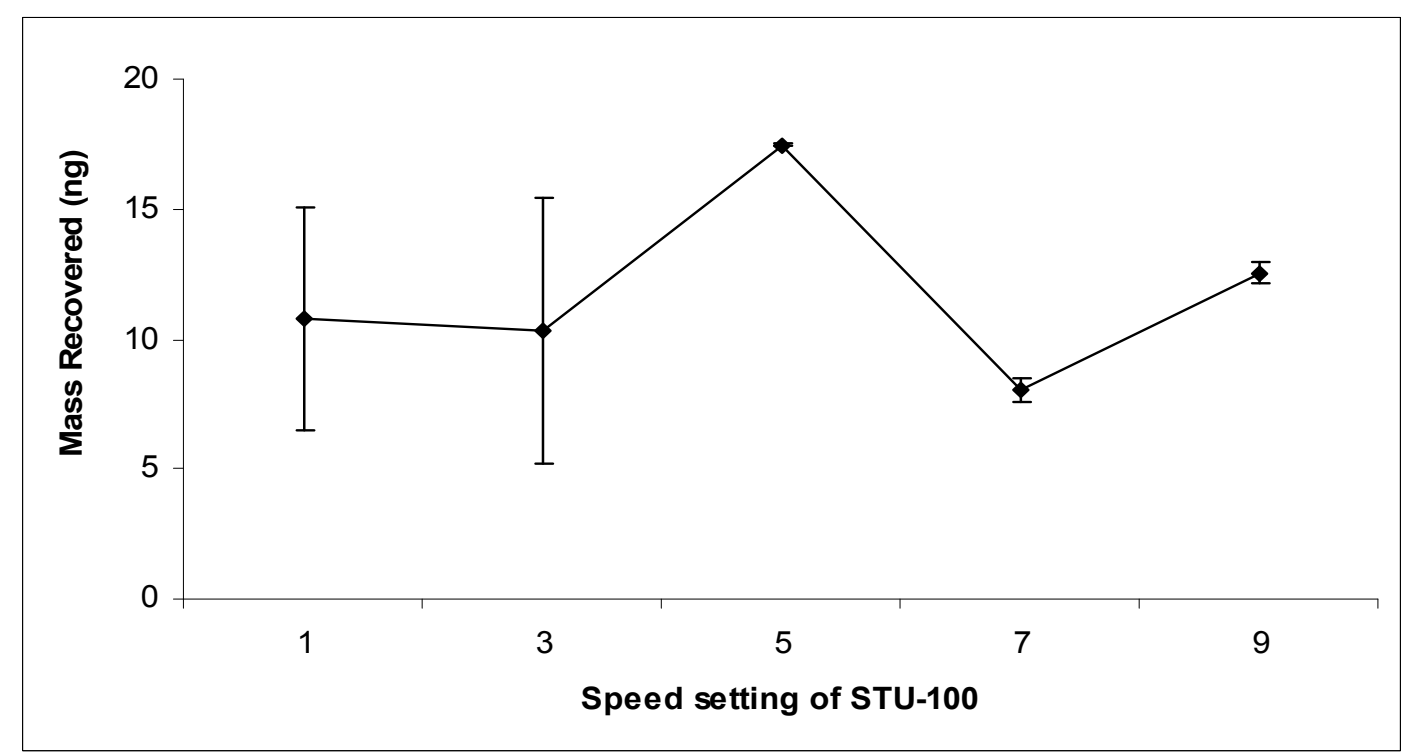


Figure 58: Volatile Organic Compounds collected on Johnson and Johnson brand gauze from objects using an active contact collection method

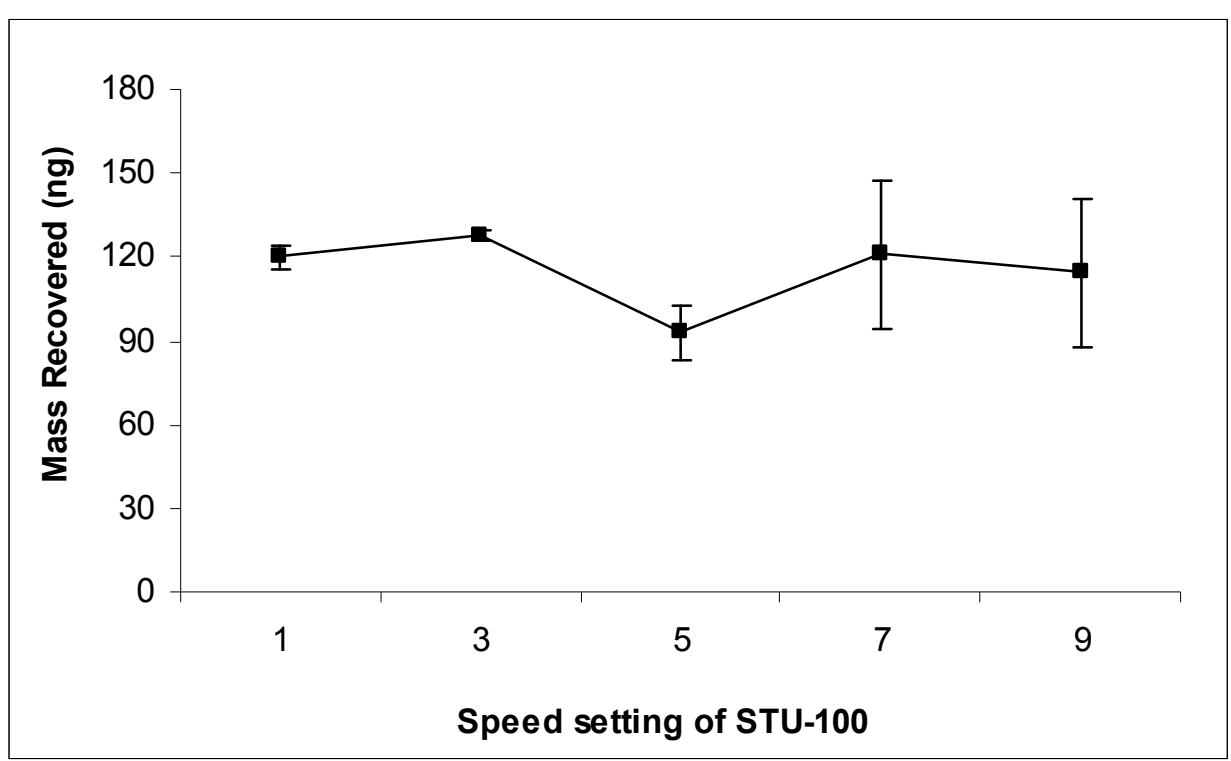

Figure 59: Volatile Organic Compounds collected on Johnson and Johnson brand gauze from objects using an active non-contact collection method

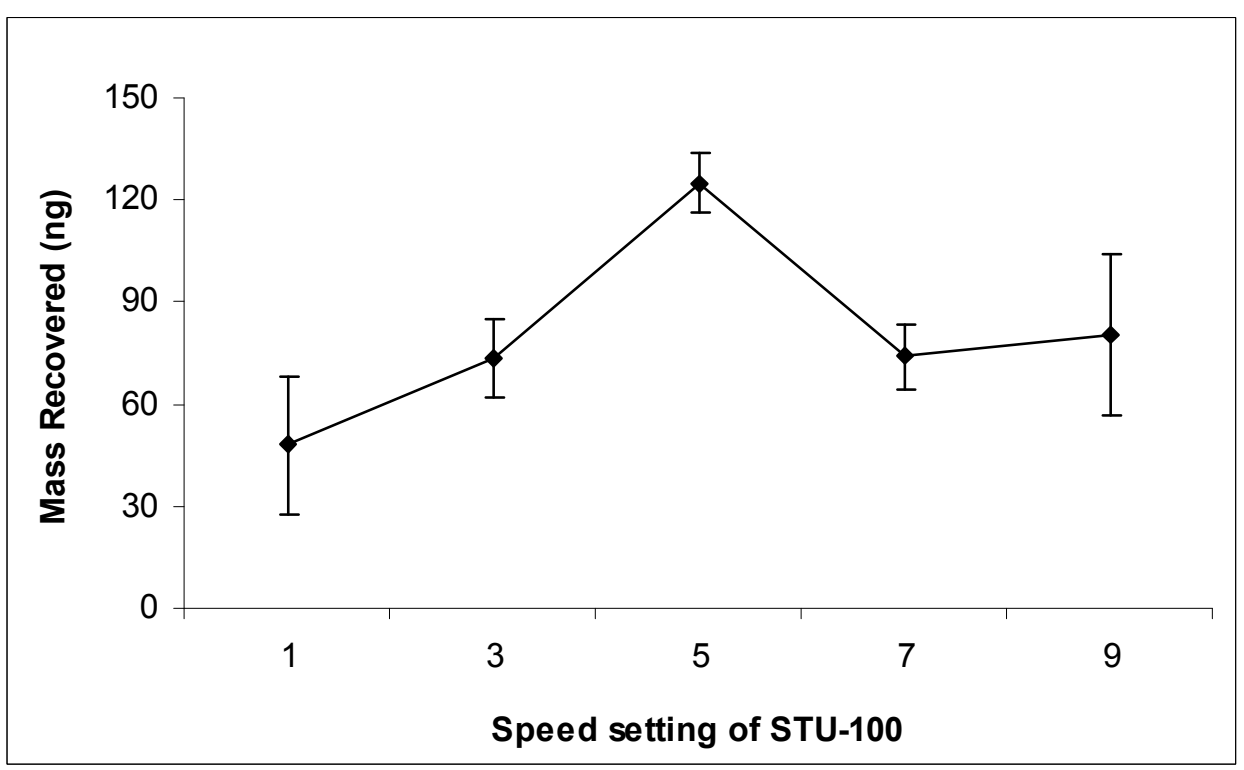




\subsubsection{Contact versus non-contact collection}

The optimum collection times and speeds were selected as the ones that produced the maximum mass of VOCs. A comparison was made between the maximum masses of VOCs obtained for the contact and the non-contact methods and it was determined that the maximum masses of VOCs obtained via the passive contact and passive non-contact methods were not significantly different for any of the materials that were investigated. For the active contact and non-contact methods, the optimum masses obtained were only significantly different for the Kings Cotton. Also, it was determined that the passive contact and non-contact methods give at least ten times more VOCs than the active contact and non-contact methods (Figure 60 and Figure 61). This is believed to be the result of breakthrough effects from using the STU-100.

Figure 60: Comparison between maximum mass of human scent VOCs recovered on the three different sorbent materials using passive collection methods

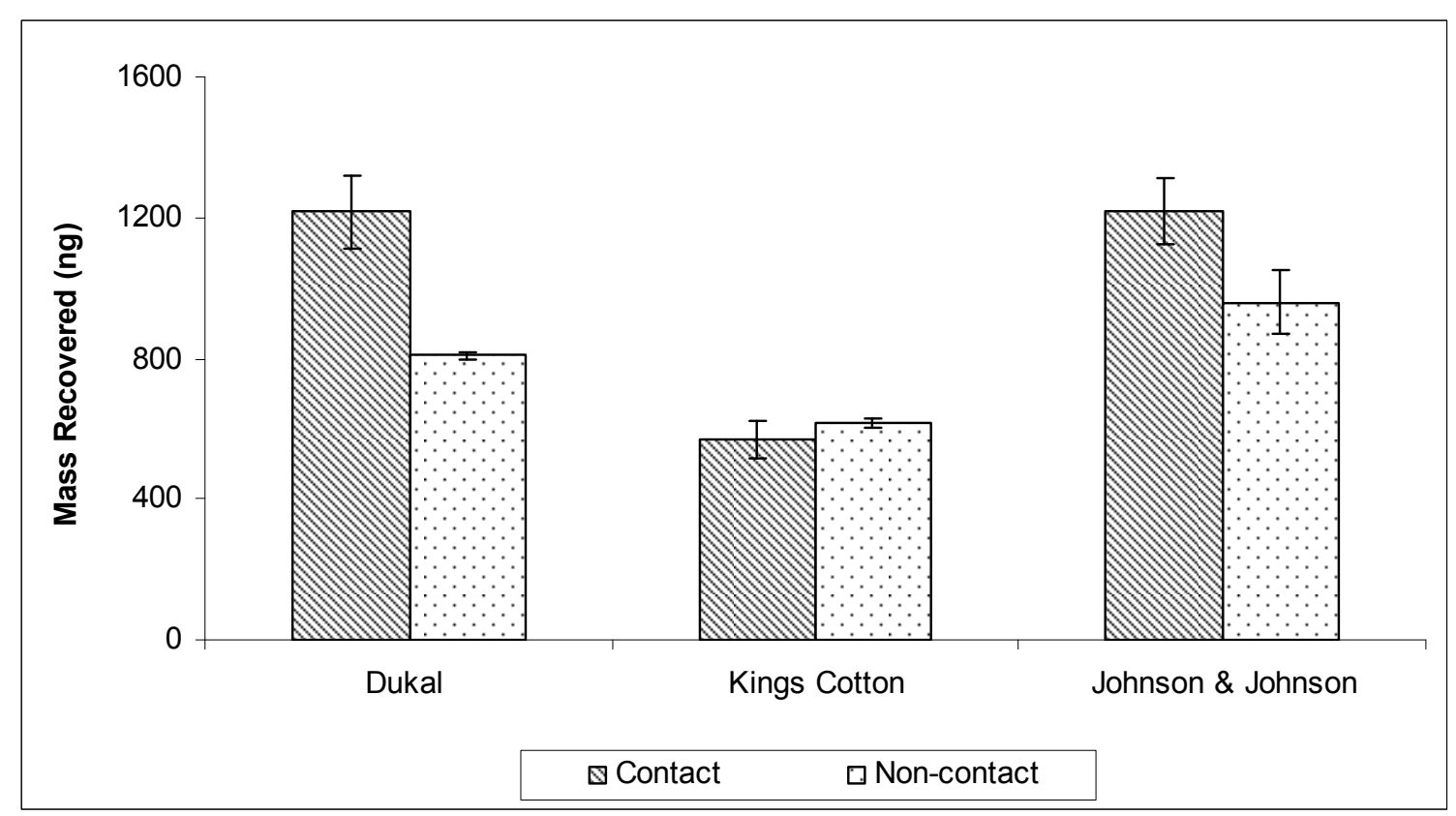


Figure 61: Comparison between maximum mass of human scent VOCs recovered on the three different sorbent materials using active collection methods

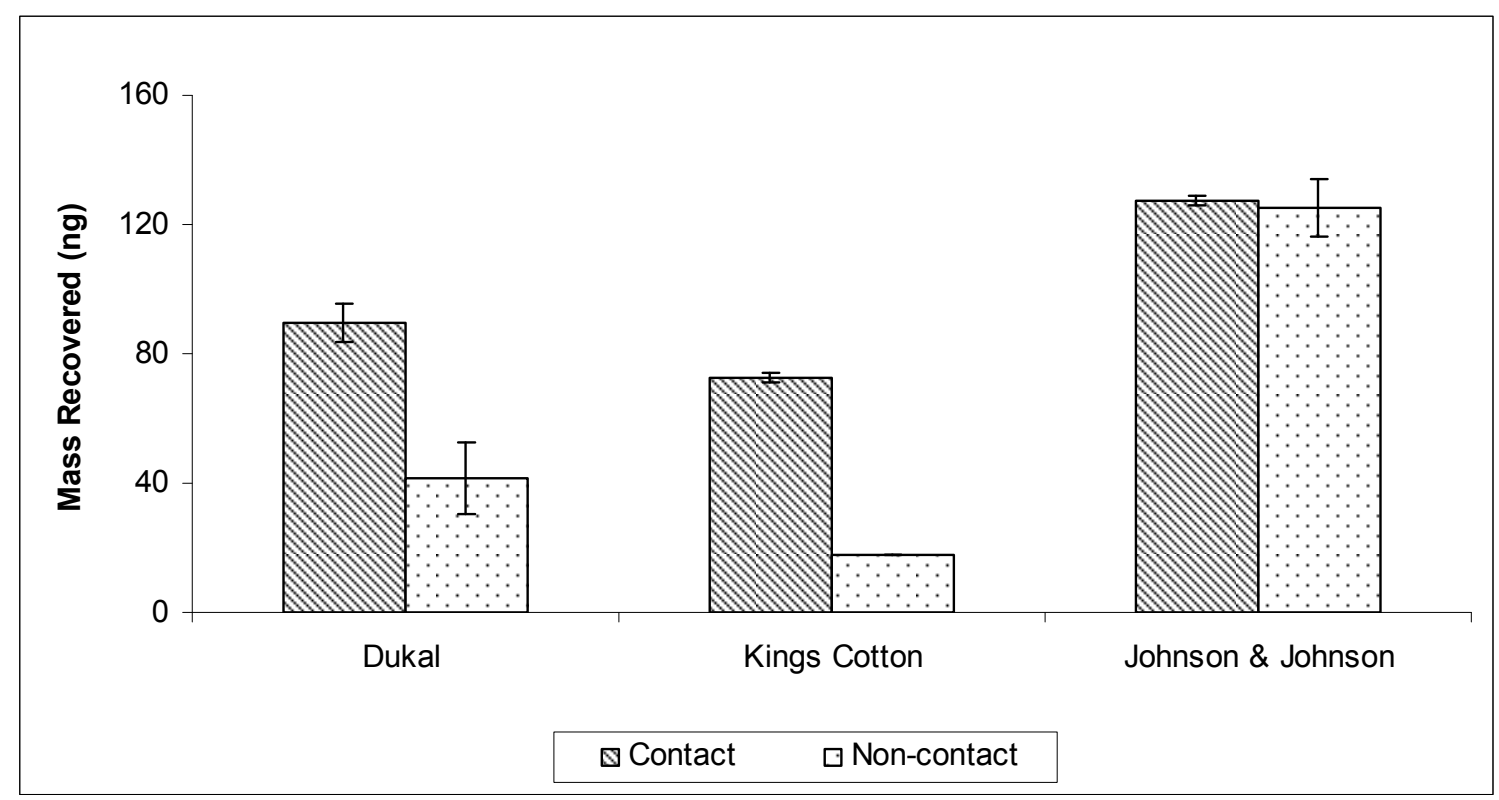

4.4.4. Application to hand odor samples

Having determined the optimum collection times and speeds for each sorbent material through the use of standard compounds, these times and speeds were applied to the collection of hand odor samples. The results of the active/passive/contact/non-contact collection methods were compared to hand odor samples which were collected using the direct hand odor collection protocol described in 3.2.2.

The results suggest that the $6890 / 5973$ GC/MSD was not sensitive enough to detect the minute quantities of human scent being transferred from the stainless steel bar to the sorbent material to the SPME fiber as the samples collected using the passive/active/contact/non-contact methods did not possess all the VOCs which were present in the direct hand odor collection. This trend was observed for all the sorbent materials which were studied (Figure 62 - Figure 70). 
Figure 62: Common VOCs present in hand odor samples collected on Dukal brand gauze from a male subject using the direct hand odor collection method

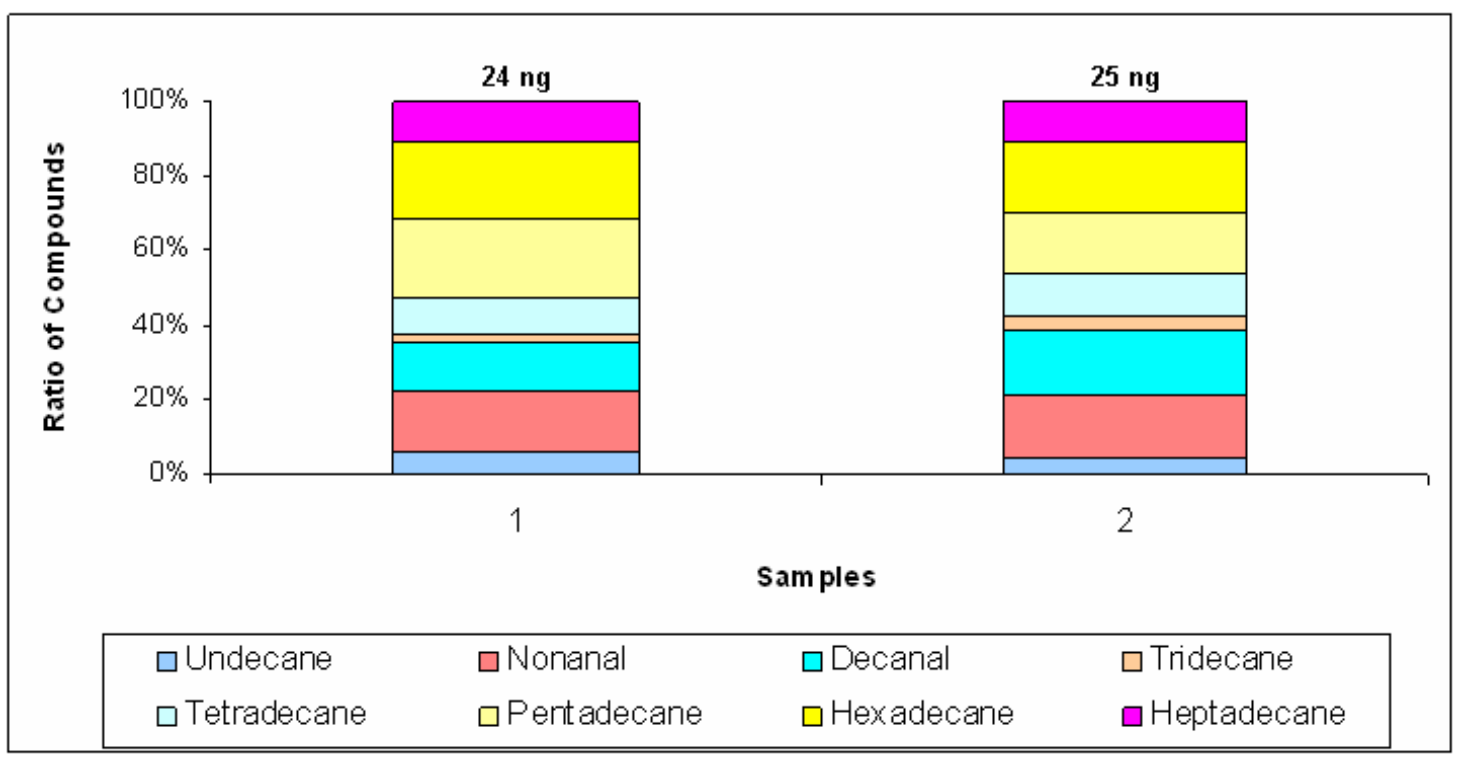

Figure 63: Common VOCs present in hand odor samples collected on from "scented" stainless steel bars onto Dukal brand gauze from a male subject using the passive hand odor collection method

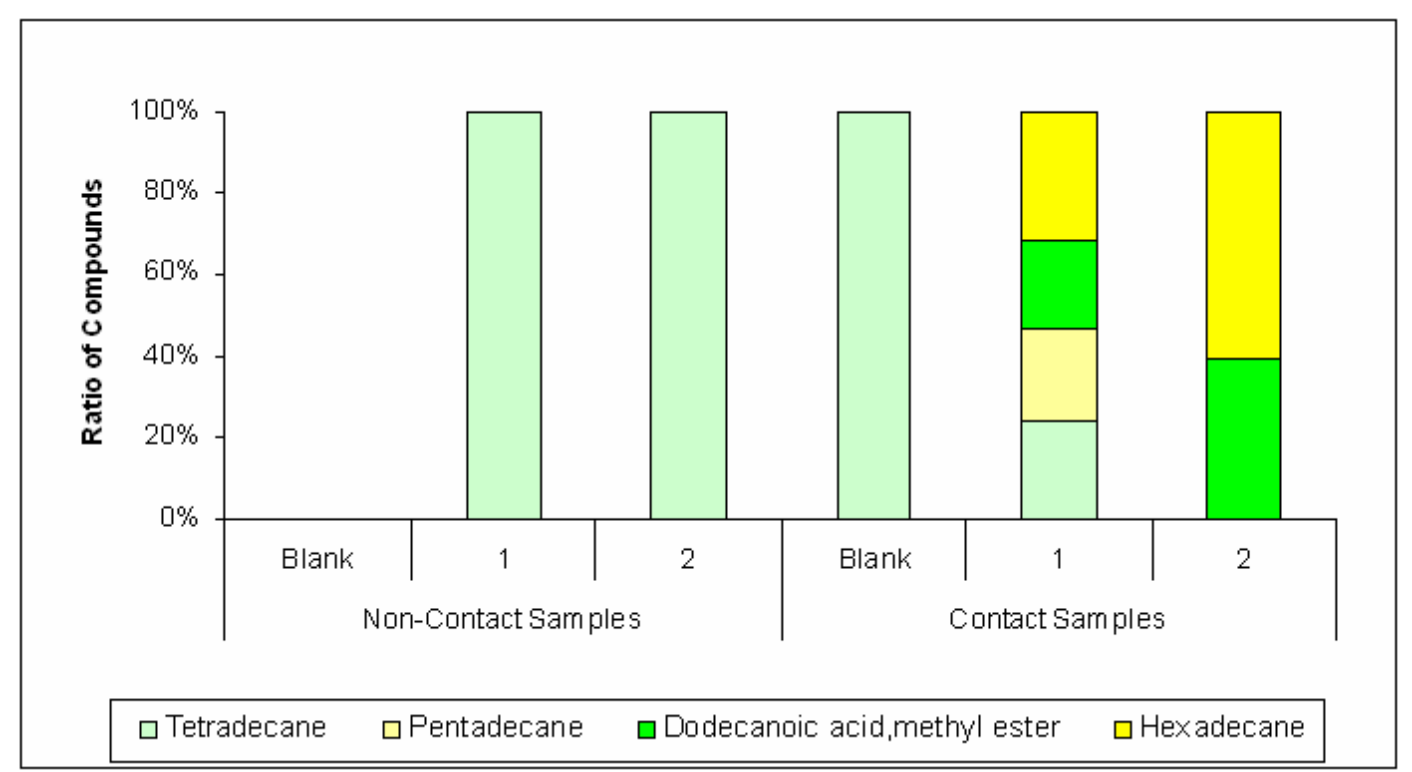


Figure 64: Common VOCs present in hand odor samples collected from a "scented" stainless steel bar onto Dukal brand gauze from a male subject using the active hand odor collection method

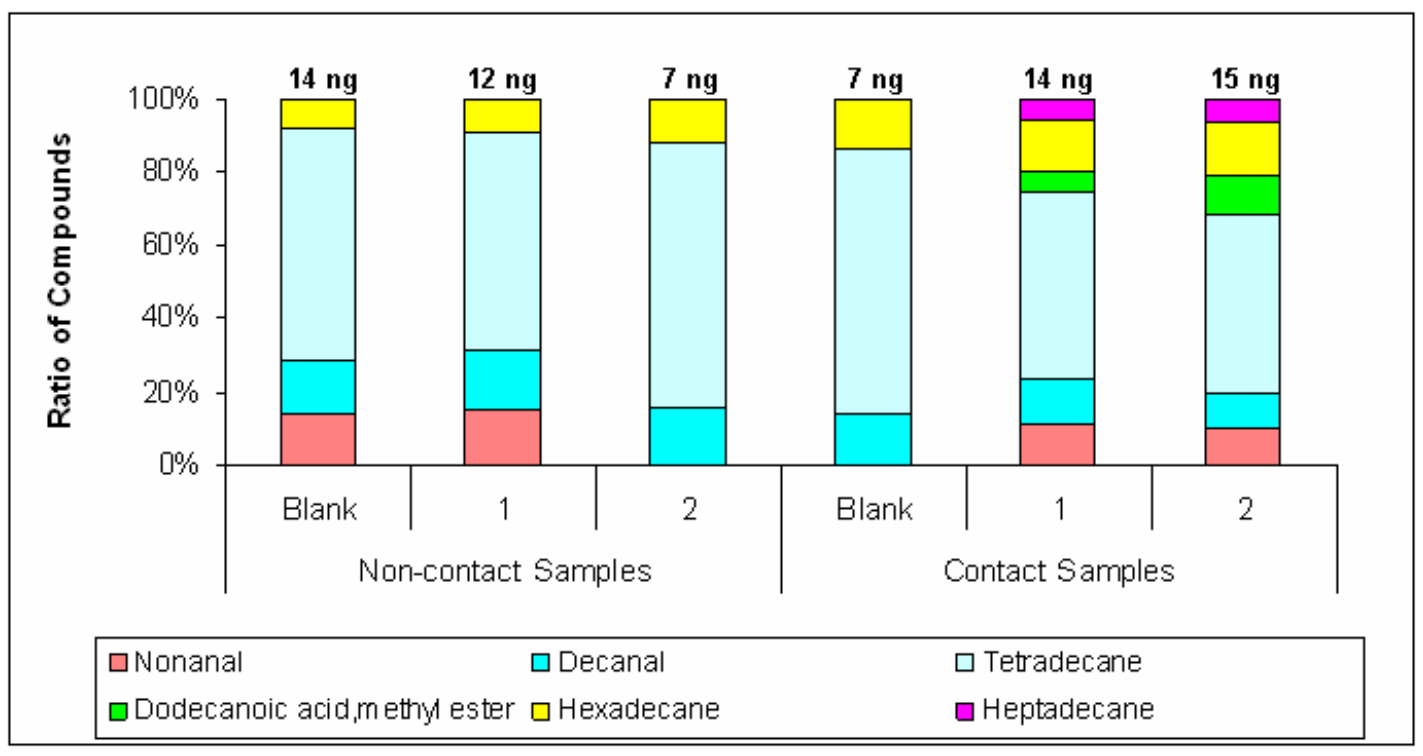

Figure 65: Common VOCs present in hand odor samples collected on Kings Cotton from a male subject using the direct hand odor collection method

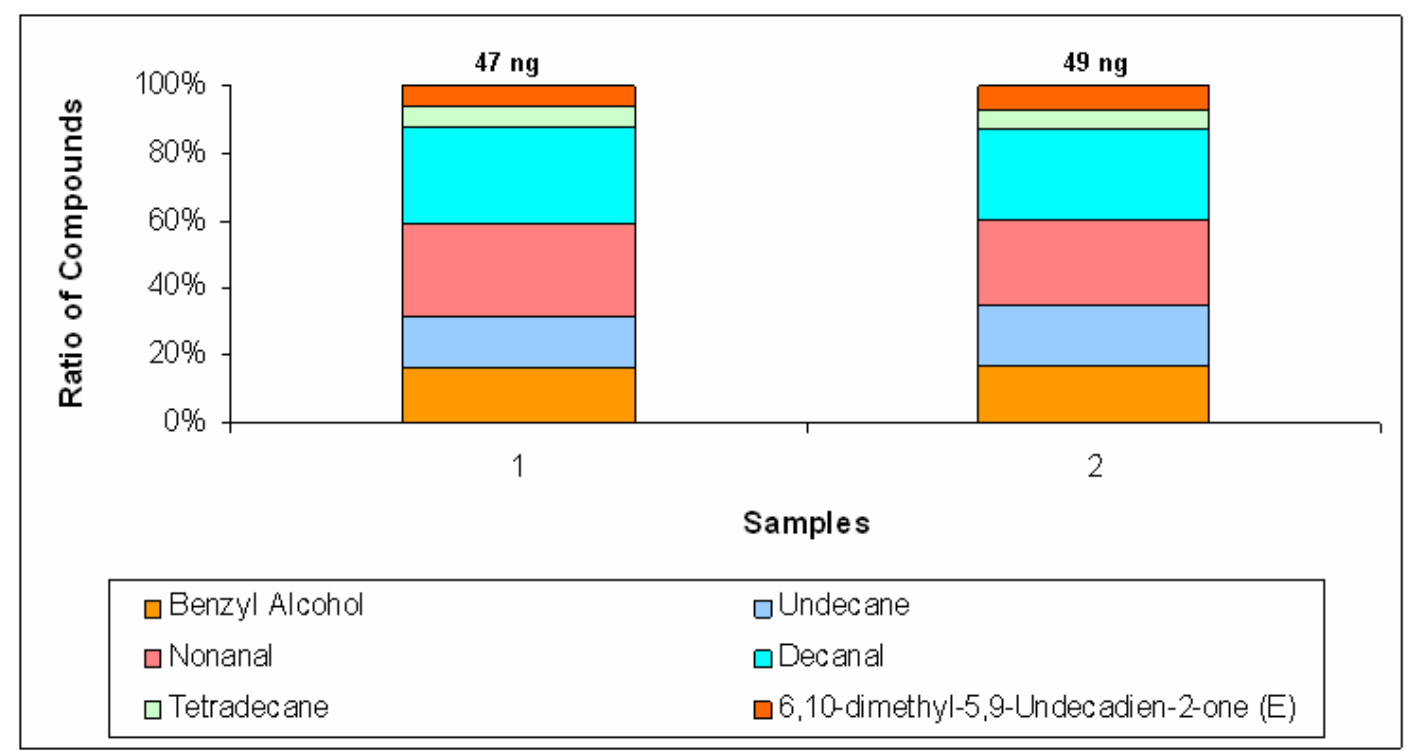


Figure 66: Common VOCs present in hand odor samples collected on from "scented" stainless steel bars onto Kings Cotton from a male subject using the passive hand odor collection method

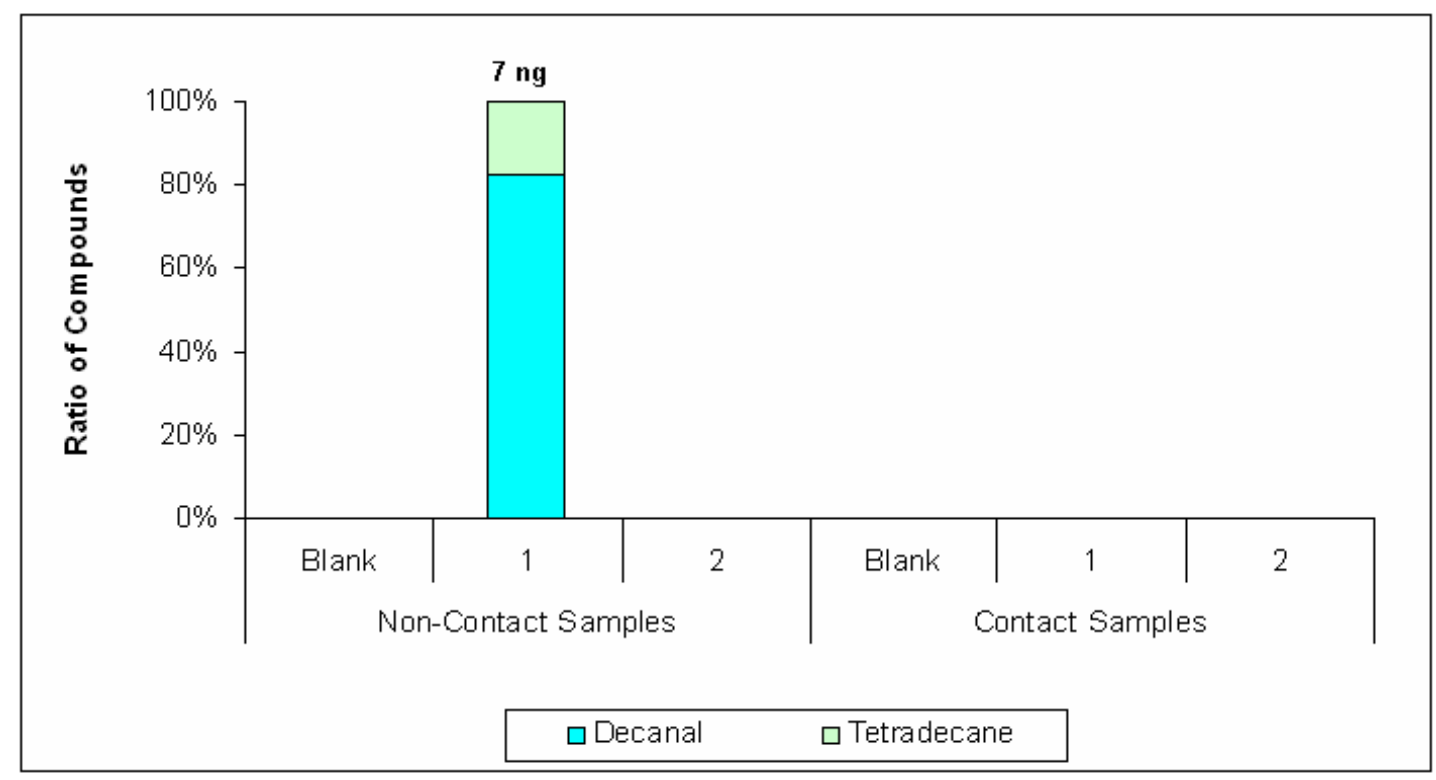

Figure 67: Common VOCs present in hand odor samples collected from a "scented" stainless steel bar onto Kings Cotton from a male subject using the active hand odor collection method

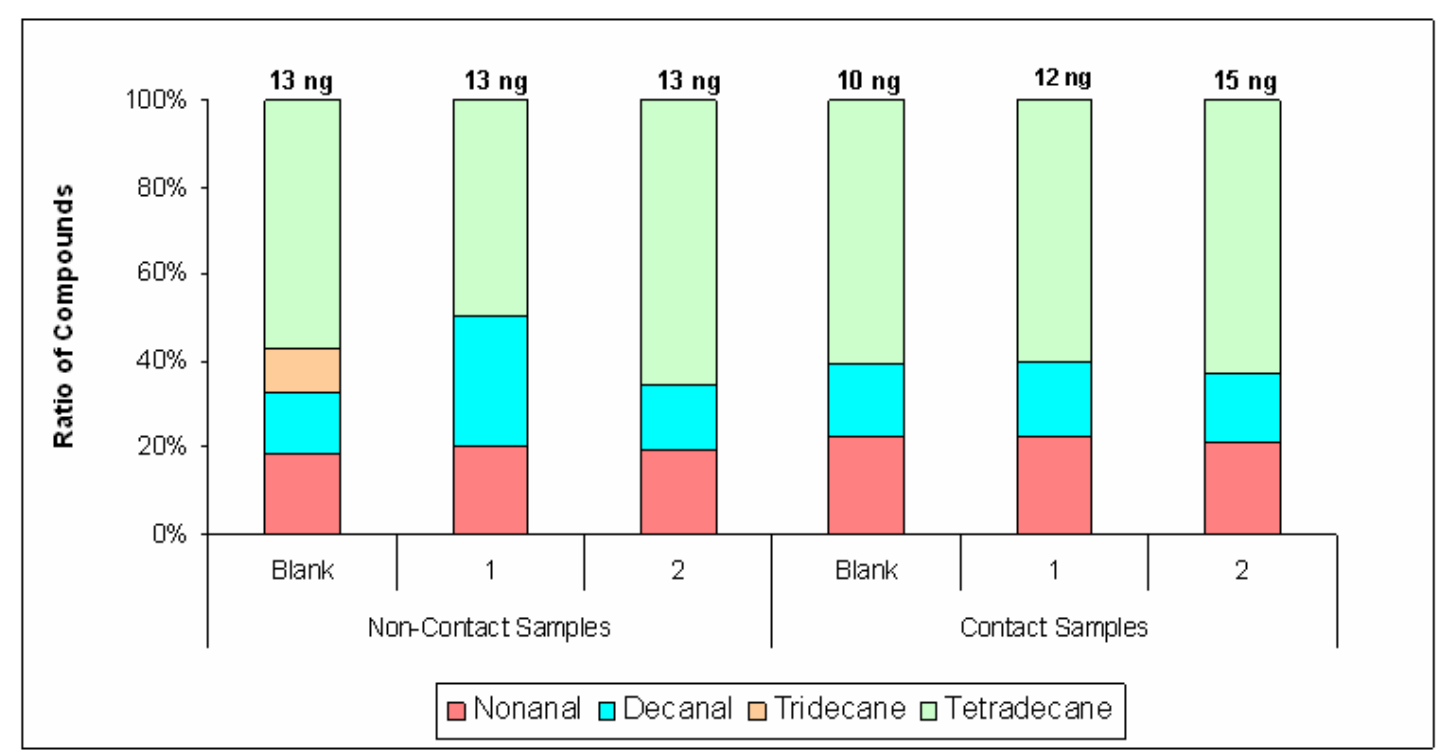


Figure 68: Common VOCs present in hand odor samples collected on Johnson and Johnson Brand Gauze from a male subject using the direct hand odor collection method

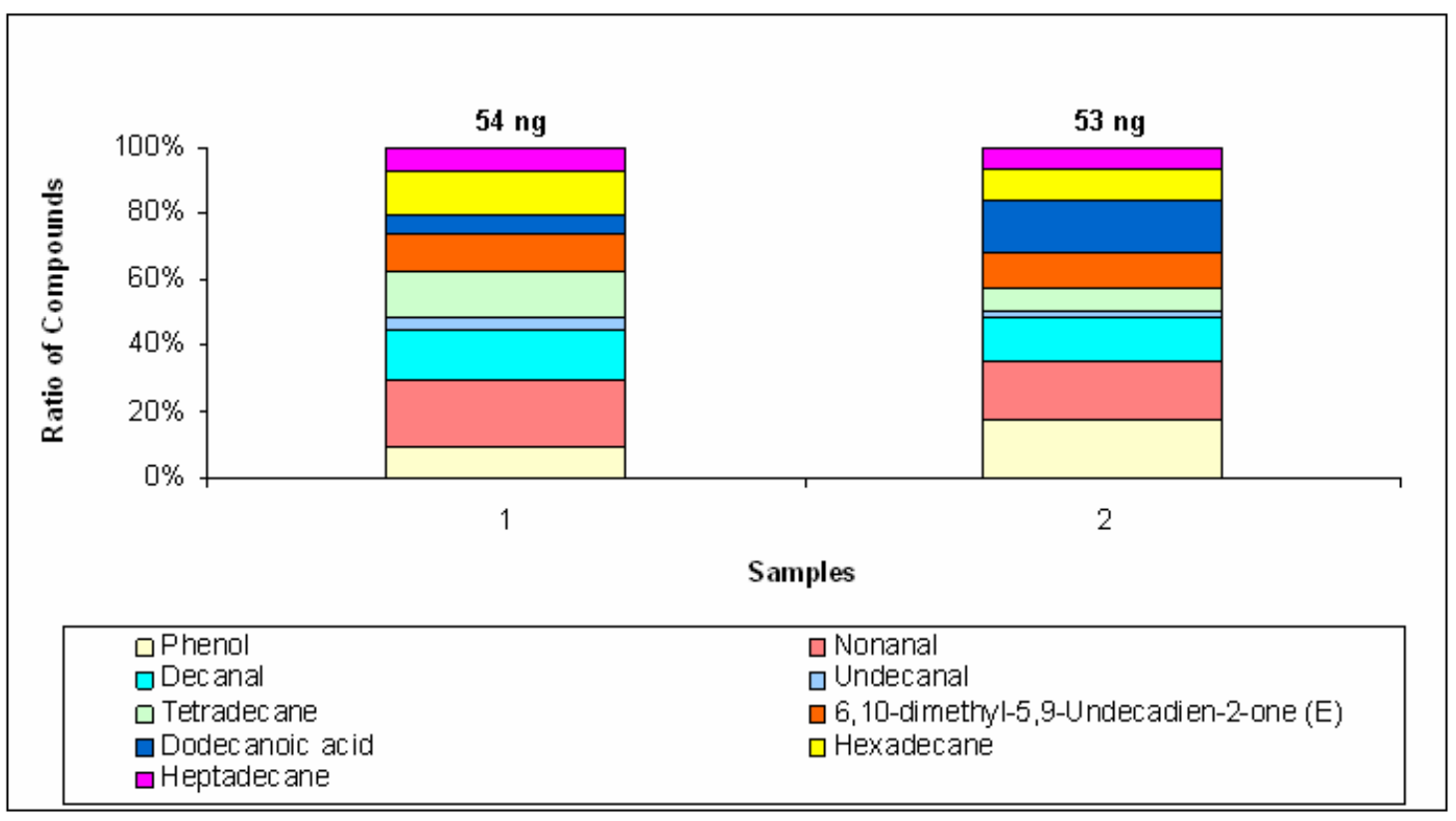

Figure 69: Common VOCs present in hand odor samples collected from "scented" stainless steel bars onto Johnson and Johnson Brand Gauze from a male subject using the passive hand odor collection method

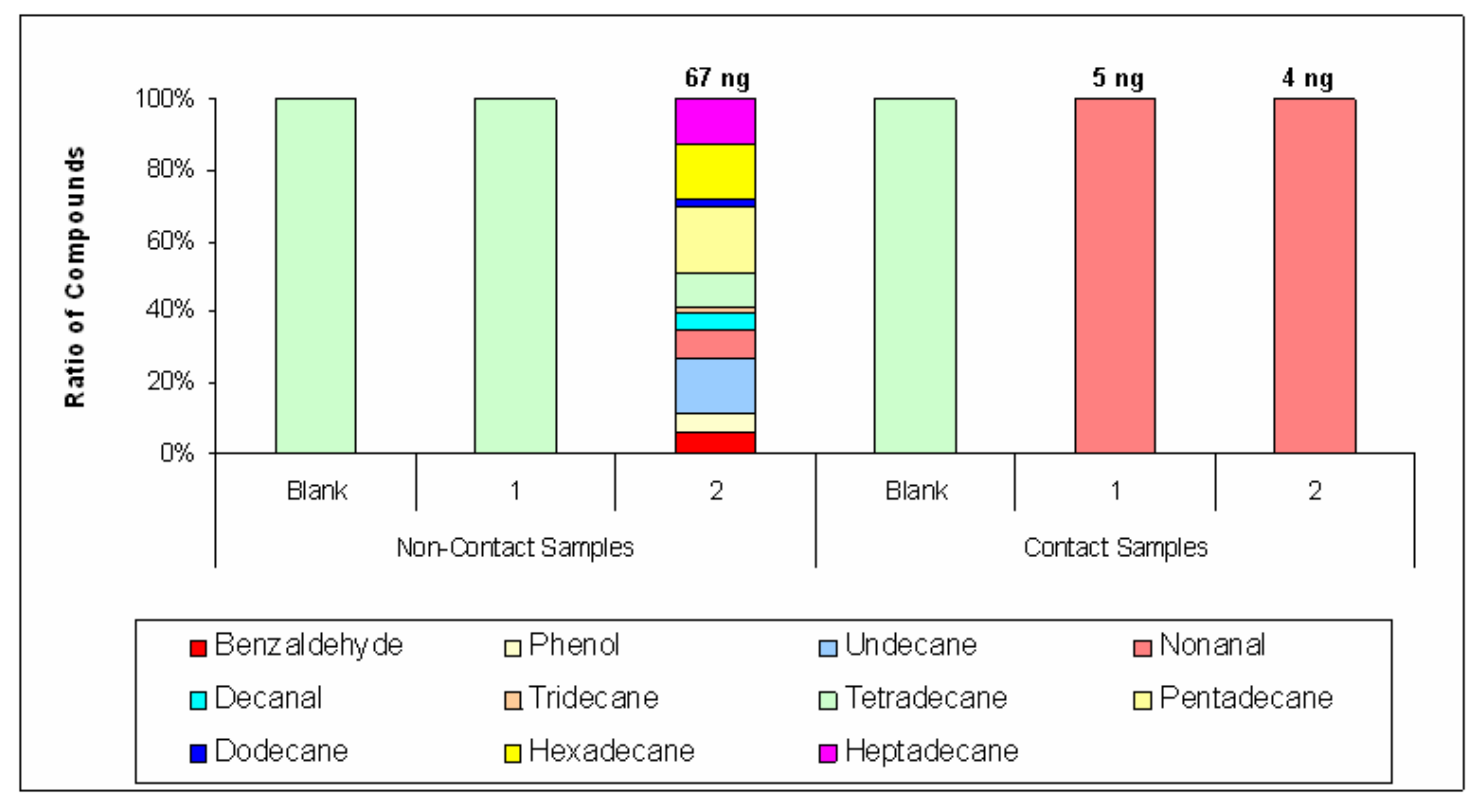


Figure 70: Common VOCs present in hand odor samples collected from a "scented" stainless steel bar onto Johnson and Johnson Brand Gauze from a male subject using the active hand odor collection method

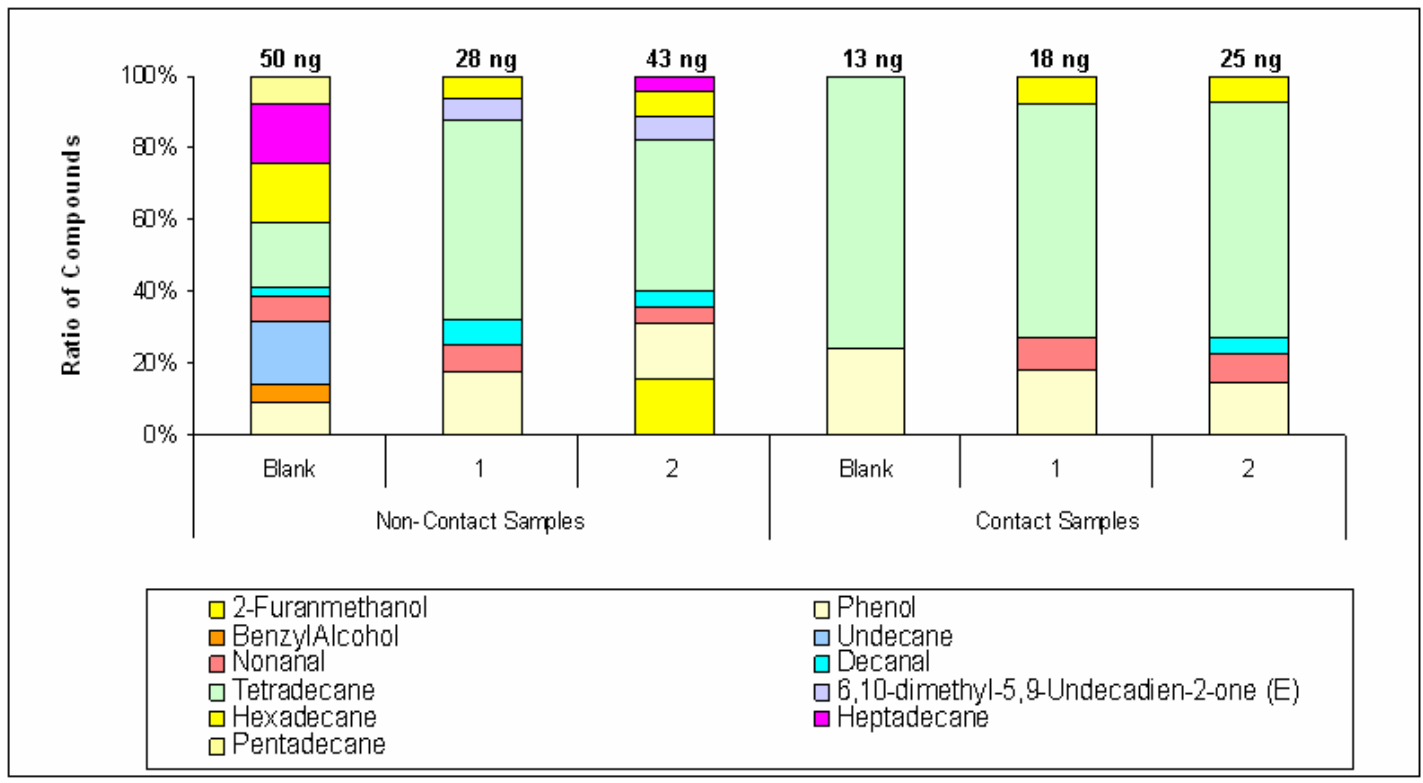

The previous experiments conducted using standard compounds to determine the optimum collection methods showed that a maximum recovery of five percent is attained in transferring the VOCs from bars to gauze to SPME fiber. This may result in the quantities of VOCs being transferred to the SPME fiber being below the limit of detection of the Agilent 6890/5973 GC/MS (Table 8).

Additional experiments were conducted to determine the mass of VOCs that was being deposited onto the stainless steel bar after contact. This required direct headspace extraction of the stainless steel metal bars in $500 \mathrm{ml}$ glass jars. Stainless steel metal bars were spiked with $23.4 \mathrm{mg}$ of standard compounds (one less standard compound used). The samples were equilibrated and SPME extractions performed at various time periods; three, six, 12, 15, 18, 21 and 24 hours. Twenty one hours proved to be the optimum extraction time for VOCs from the $500 \mathrm{ml}$ glass jars (Figure 71). 
Figure 71: Graph showing optimum SPME extraction time for human scent VOCs from the headspace of a $500 \mathrm{ml}$ glass jar

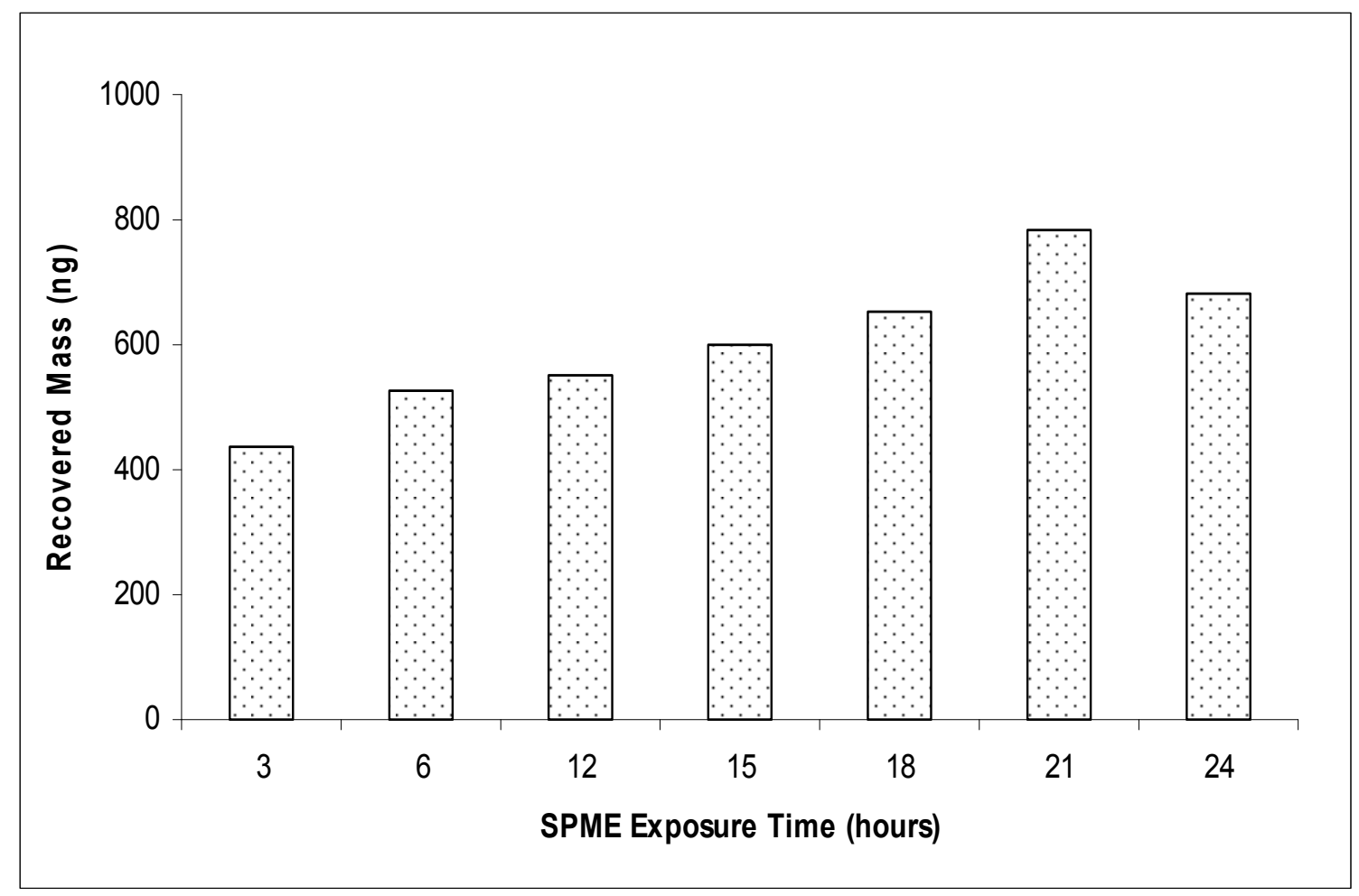

To determine the mass of VOCs that could potentially be deposited onto the stainless steel bars held by an individual, pre-cleaned stainless steel bars were spiked with $23.4 \mathrm{mg}$ of standard human scent compounds and headspace SPME performed for 21 hours. This was then followed by GC/MS analyses. The results obtained show that the recovery from spiked bar to SPME fiber is approximately three percent (Table 28).

Twenty one hour direct headspace extractions of stainless steel bars held by five subjects were performed. Based on experiments which were conducted, the recovery rate of bars to SPME fiber (three percent) and the recovery rate of bars to gauze to SPME fibers (five percent) were applied to the results of the hand odor sample. This was done to determine the amount of VOCs which was present on the bar directly after contact with a persons 
hands and the amount of VOCs present after transfer from bars to gauze and then to SPME fiber. The amount of VOCs present after transfer was compared to the LOD of the Agilent $6890 / 5973 \mathrm{GC} / \mathrm{MS}$ to determine whether the amounts being deposited onto the stainless steel metal bars are too miniscule to allow transfer to a sorbent material followed by SPME-GC/MS analysis.

An example is shown below of hand odor samples collected from a male subject both directly onto sorbent materials (to determine primary odor compounds) and onto precleaned stainless steel bars. The samples collected on the metal bars were subjected to headspace SPME-GC/MS analysis to determine the initial mass of VOCs deposited onto the bars from the hands of the subject. The percent recovery (five percent) from bars to gauze to SPME fibers was then applied to this mass and a comparison between this recovered mass and the LOD of the instrument was done (Table 29).

The results show that once VOCs are transferred from bars to gauzes and headspace extraction performed, the amounts being extracted for some of the VOCs are below the LOD of the Agilent 6890/5973 GC/MS and cannot be reliably identified or quantified. For instrumental purposes, this is a drawback but for canines this may not impede them as their sense of olfaction has been described as being magnitudes lower than the LOD of analytical instruments. 
Table 28: Recovery of human scent VOCs from the headspace of a 500 ml glass jar containing spiked stainless steel bars via 21 hour headspace SPME followed by GC/MS

\begin{tabular}{|c|c|c|c|c|c|c|}
\hline $\begin{array}{l}\text { Standard Human } \\
\text { Scent } \\
\text { Compounds }\end{array}$ & $\begin{array}{c}\text { Mass } \\
\text { Recovered } \\
\text { Sample } 1 \text { (ng) } \\
\end{array}$ & $\begin{array}{c}\text { Mass } \\
\text { Recovered } \\
\text { Sample } 2 \\
\text { (ng) } \\
\end{array}$ & $\begin{array}{c}\text { Mass } \\
\text { Recovered } \\
\text { Sample } 3 \\
\text { (ng) } \\
\end{array}$ & $\begin{array}{c}\text { Mass } \\
\text { Recovered } \\
\text { Sample } 4 \\
\text { (ng) } \\
\end{array}$ & $\begin{array}{c}\text { Mass } \\
\text { Recovered } \\
\text { Sample } 5 \\
\text { (ng) }\end{array}$ & $\begin{array}{c}\text { Mass } \\
\text { Recovered } \\
\text { Sample } 6 \\
\text { (ng) }\end{array}$ \\
\hline Octane & 2.21 & 12.41 & 4.82 & 16.27 & 25.51 & 12.24 \\
\hline Furfural & 10.67 & 25.04 & 14.29 & 19.91 & 57.86 & 25.55 \\
\hline 2-Furanmethanol & 12.43 & 20.26 & 16.11 & 23.22 & 31.22 & 20.65 \\
\hline Nonane & 16.43 & 38.27 & 12.40 & 30.50 & 74.31 & 34.38 \\
\hline Heptanal & 27.47 & 47.28 & 33.38 & 86.25 & 82.98 & 55.47 \\
\hline $\begin{array}{l}\text { Propanedioic acid, } \\
\text { dimethyl ester }\end{array}$ & 13.12 & 25.47 & 24.03 & 27.04 & 40.72 & 26.08 \\
\hline Benzaldehyde & 15.41 & 26.70 & 24.50 & 32.46 & 52.44 & 30.30 \\
\hline Phenol & 10.61 & 14.08 & 13.81 & 14.62 & 17.62 & 14.15 \\
\hline $\begin{array}{l}\text { 6-methyl-5- } \\
\text { Hepten-2-one }\end{array}$ & 24.38 & 41.34 & 33.28 & 42.45 & 65.40 & 41.37 \\
\hline Octanal & 23.77 & 31.72 & 30.65 & 44.88 & 43.49 & 34.90 \\
\hline Benzyl Alcohol & 11.88 & 17.32 & 15.87 & 18.22 & 21.51 & 16.96 \\
\hline 2-Octenal (E) & 17.39 & 25.10 & 26.49 & 32.54 & 41.49 & 28.60 \\
\hline 1-Octanol & 26.35 & 32.47 & 29.35 & 32.43 & 35.84 & 31.29 \\
\hline Undecane & 25.50 & 29.20 & 34.53 & 43.33 & 36.81 & 33.87 \\
\hline $\begin{array}{l}\text { 3,7-dimethyl-1,6- } \\
\text { Octadien-3-ol }\end{array}$ & 25.53 & 25.94 & 28.06 & 31.05 & 24.99 & 27.11 \\
\hline Nonanal & 51.64 & 45.83 & 39.63 & 34.42 & 59.21 & 46.15 \\
\hline $\begin{array}{l}\text { Phenylethyl } \\
\text { Alcohol }\end{array}$ & 14.51 & 20.63 & 16.92 & 18.35 & 19.74 & 18.03 \\
\hline $\begin{array}{l}\text { Octanoic acid, } \\
\text { methyl ester }\end{array}$ & 24.39 & 32.94 & 33.44 & 36.15 & 41.19 & 33.62 \\
\hline Nonanol & 21.35 & 23.94 & 17.84 & 19.37 & 20.61 & 20.62 \\
\hline Naphthalene & 9.15 & 11.27 & 14.34 & 14.43 & 17.70 & 13.38 \\
\hline
\end{tabular}




\begin{tabular}{|c|c|c|c|c|c|c|}
\hline 2-Decanone & 18.14 & 25.78 & 22.47 & 23.00 & 25.68 & 23.01 \\
\hline Dodecane & 23.22 & 29.11 & 30.71 & 32.38 & 32.84 & 29.65 \\
\hline Decanal & 17.82 & 21.89 & 21.81 & 22.86 & 27.30 & 22.34 \\
\hline $\begin{array}{l}\text { Hexanedioic acid, } \\
\text { dimethyl ester }\end{array}$ & 13.46 & 6.68 & 11.12 & 12.43 & 11.94 & 11.13 \\
\hline Tridecane & 15.62 & 18.46 & 18.44 & 18.35 & 23.34 & 18.84 \\
\hline Undecanal & 10.01 & 14.86 & 9.93 & 10.23 & 11.86 & 11.38 \\
\hline n-Decanoic acid & 5.97 & 6.07 & 5.98 & 5.89 & 5.95 & 5.97 \\
\hline Tetradecane & 10.03 & 12.42 & 17.50 & 17.92 & 23.31 & 16.24 \\
\hline Dodecanal & 9.26 & 11.04 & 6.28 & 7.18 & 7.93 & 8.34 \\
\hline $\begin{array}{l}\text { 6,10-dimethyl-5,9- } \\
\text { undecadien-2-one }\end{array}$ & 10.87 & 9.71 & 6.72 & 10.56 & 8.64 & 9.30 \\
\hline Pentadecane & 9.90 & 14.23 & 6.93 & 8.02 & 8.98 & 9.61 \\
\hline Tridecanal & 6.43 & 6.08 & 5.30 & 7.54 & 7.38 & 6.55 \\
\hline $\begin{array}{l}\text { Dodecanoic acid, } \\
\text { methyl ester }\end{array}$ & 7.43 & 5.51 & 4.58 & 9.31 & 6.64 & 6.69 \\
\hline Dodecanoic acid & 6.70 & 6.76 & 6.81 & 6.65 & 6.65 & 6.71 \\
\hline Hexadecane & 8.64 & 9.67 & 4.05 & 5.10 & 5.74 & 6.64 \\
\hline Heptadecane & 6.12 & 6.13 & 4.42 & 7.56 & 7.16 & 6.28 \\
\hline $\begin{array}{l}\text { Methyl } \\
\text { tetradecanoate }\end{array}$ & 7.31 & 7.98 & 6.84 & 4.53 & 5.97 & 6.53 \\
\hline $\begin{array}{l}\text { Pentadecanoic } \\
\text { acid }\end{array}$ & 0.00 & 0.00 & 0.00 & 0.00 & N.D & 0.00 \\
\hline $\begin{array}{l}\text { Hexadecanoic } \\
\text { acid, methyl ester }\end{array}$ & 0.00 & 4.27 & 3.35 & 1.76 & 2.61 & 2.40 \\
\hline $\begin{array}{l}\text { Mass Recovered } \\
\text { (ng) }\end{array}$ & 571.12 & 763.86 & 656.98 & 829.16 & 1040.56 & 772.34 \\
\hline $\begin{array}{l}\text { Average Recovery } \\
\text { (ng) }\end{array}$ & \multicolumn{6}{|c|}{772.34} \\
\hline $\begin{array}{l}\text { Average Percent } \\
\text { Recovery }\end{array}$ & \multicolumn{6}{|c|}{$3.30 \%$} \\
\hline
\end{tabular}


Table 29: Comparison between mass of VOCs transferred from "scented" bars to gauze to SPME fiber and LOD of 6890/5973 GC/MSD

\begin{tabular}{|c|c|c|c|c|}
\hline $\begin{array}{l}\text { Primary odor compounds } \\
\text { present in hand odor of a } \\
\text { male subject }\end{array}$ & $\begin{array}{l}\text { Mass of VOCs } \\
\text { collected from } \\
\text { direct headspace } \\
\text { of bars (ng) }\end{array}$ & $\begin{array}{l}\text { Initial Mass } \\
\text { of VOCs on } \\
\text { bars from } \\
\text { hands (ng) } \\
\end{array}$ & $\begin{array}{c}\text { Mass of } \\
\text { VOCs after } \\
\text { transfer from } \\
\text { bars to gauze } \\
\text { to SPME (ng) } \\
\end{array}$ & $\begin{array}{c}\text { LOD of } \\
\text { instrument } \\
\text { (ng) }\end{array}$ \\
\hline Undecane & 3 & 110 & 6 & 20 \\
\hline Nonanal & 35 & 1172 & 59 & 5 \\
\hline Decanal & 6 & 202 & 10 & 4 \\
\hline Tridecane & 3 & 96 & 5 & 6 \\
\hline Tetradecane & 3 & 86 & 4 & 6 \\
\hline Pentadecane & 2 & 64 & 3 & 6 \\
\hline Hexadecane & 2 & 55 & 3 & 6 \\
\hline Heptadecane & 2 & 72 & 4 & 6 \\
\hline
\end{tabular}

\subsubsection{Headspace extractions using Activated Charcoal Strips (ACS)}

Activated charcoal strips were used in an effort to transfer greater masses of VOCs from the scented bars to the sorbent material and ultimately to the GC/MS. Preliminary experiments were conducted to compare the extraction capabilities of the DVB/carboxen/PDMS SPME fiber with the ACS. Curran et al. established that the optimal collection time for human scent compounds using the carboxen /DVB /PDMS SPME fiber was 21 hours (27). Experiments described in section 3.2.7 were designed to determine the optimum extraction time for human scent compounds using the ACS.

The ACS extraction times used were half of an hour, one hour, three hours, six hours, twelve hours and 24 hours. It was determined that the existing optimized SPME method of 21 hours extracts a greater number of compounds than all the ACS extraction times 
which were examined (Table 30 - Table 36). The most compounds extracted using the ACS method was after 24 hours at which time only an average of seven compounds were recovered whereas with the established SPME method, an average of 18 compounds were recovered after 21 hours of extraction. The chromatograms of the ACS extracts showed many compounds between 20 and 22 minutes, none of which were human scent compounds. It was discovered that these compounds were from the ACS strips as they were present in the blank sample (Figure 72). The chromatograms obtained also show that the SPME extractions give more reproducible results than the ACS extractions (Figure 73 - Figure 79 ).

Table 30 - Table 35 shows the human scent compounds which were extracted from the headspace of the $10 \mathrm{ml}$ glass vials using the ACS while Table 36 shows the human scent compounds which were recovered using the carboxen/DVB/PDMS SPME fiber. The results show that the SPME fibers extracted greater numbers of compounds than the ACS. It was determined that the ACS extracted mainly straight chain alkanes and a few aldehydes whereas the SPME fiber extracted a wider variety of functional groups. The results suggest that SPME is a more efficient extraction technique than ACS for human scent VOCS. 
Table 30: Table showing the number of human scent compounds extracted in 0.5 hour from the headspace of a $10 \mathrm{ml}$ glass vial using ACS

\begin{tabular}{|c|c|c|c|c|}
\hline $\begin{array}{c}\text { Retention } \\
\text { Time } \\
\text { (Minutes) }\end{array}$ & Compound Name & $\begin{array}{c}\text { Compounds } \\
\text { extracted } \\
\text { sample } 1 \\
\end{array}$ & $\begin{array}{c}\text { Compounds } \\
\text { extracted } \\
\text { sample } 2 \\
\end{array}$ & $\begin{array}{c}\text { Compounds } \\
\text { extracted } \\
\text { sample } 3 \\
\end{array}$ \\
\hline 6.407 & Octane & & & \\
\hline 7.356 & Furfural & & & \\
\hline 7.983 & 2-Furanmethanol & & & \\
\hline 9.015 & Nonane & & & \\
\hline 9.065 & Heptanal & & & \\
\hline 9.74 & $\begin{array}{l}\text { Propanedioic Acid Dimethyl } \\
\text { Ester }\end{array}$ & & & \\
\hline 10.385 & Benzaldehyde & & & \\
\hline 10.851 & Phenol & & & \\
\hline 10.949 & 6-methyl-5-hepten-2-one & & & \\
\hline 11.249 & Octanal & & & \\
\hline 11.882 & Benzyl Alcohol & & & \\
\hline 12.288 & 2-Octenal(E) & & & \\
\hline 12.503 & 1-Octanol & & & \\
\hline 12.99 & Undecane & & & \\
\hline 13.025 & $\begin{array}{l}\text { 3,7-dimethyl-1,6-octadien-3- } \\
\text { ol }\end{array}$ & & & \\
\hline 13.085 & Nonanal & & & \\
\hline 13.294 & Phenylethyl Alcohol & & & \\
\hline 13.405 & Octanoic Acid Methyl Ester & & & \\
\hline 14.168 & Nonanol & & & \\
\hline 14.468 & Naphthalene & & & \\
\hline
\end{tabular}




\begin{tabular}{|c|c|c|c|}
\hline 14.506 & 2-Decanone & & \\
\hline 14.595 & Dodecane & & \\
\hline 14.709 & Decanal & & \\
\hline 15.26 & $\begin{array}{l}\text { Hexanedioic Acid Dimethyl } \\
\text { Ester }\end{array}$ & & \\
\hline 16.054 & Tridecane & & \\
\hline 16.184 & Undecanal & & \\
\hline 17.083 & n-Decanoic Acid & & \\
\hline 17.415 & Tetradecane & & \\
\hline 17.561 & Dodecanal & & \\
\hline 18.137 & $\begin{array}{l}\text { 6,10-dimethyl- 5,9- } \\
\text { Undecadien-2-one }\end{array}$ & & \\
\hline 18.69 & Pentadecane & & \\
\hline 18.994 & $\begin{array}{l}\text { Dodecanoic Acid, Methyl } \\
\text { Ester }\end{array}$ & & \\
\hline 19.504 & Dodecanoic Acid & & \\
\hline 19.89 & Hexadecane & & \\
\hline 21.033 & Heptadecane & & \\
\hline 21.311 & Methyl Tetradecanoate & & \\
\hline 22.764 & Pentadecanoic Acid & & \\
\hline 23.422 & $\begin{array}{l}\text { Hexadecanoic Acid Methyl } \\
\text { Ester }\end{array}$ & $\mathrm{X}$ & X \\
\hline \multicolumn{2}{|c|}{ Average number of compounds } & 1 & \\
\hline
\end{tabular}


Table 31: Table showing the number of human scent compounds extracted in 1 hour from the headspace of a $10 \mathrm{ml}$ glass vial using ACS

\begin{tabular}{|c|c|c|c|c|}
\hline $\begin{array}{c}\text { Retention } \\
\text { Time } \\
\text { (Minutes) }\end{array}$ & Compound Name & $\begin{array}{c}\text { Compounds } \\
\text { extracted } \\
\text { sample } 1\end{array}$ & $\begin{array}{c}\text { Compounds } \\
\text { extracted } \\
\text { sample } 2\end{array}$ & $\begin{array}{c}\text { Compounds } \\
\text { extracted } \\
\text { sample } 3\end{array}$ \\
\hline 6.407 & Octane & & & \\
\hline 7.356 & Furfural & & & \\
\hline 7.983 & 2-Furanmethanol & & & \\
\hline 9.015 & Nonane & & & \\
\hline 9.065 & Heptanal & & & \\
\hline 9.74 & $\begin{array}{l}\text { Propanedioic Acid Dimethyl } \\
\text { Ester }\end{array}$ & & & \\
\hline 10.385 & Benzaldehyde & & & \\
\hline 10.851 & Phenol & & & \\
\hline 10.949 & 6-methyl-5-hepten-2-one & & & \\
\hline 11.249 & Octanal & & & \\
\hline 11.882 & Benzyl Alcohol & & & \\
\hline 12.288 & 2-Octenal(E) & & & \\
\hline 12.503 & 1-Octanol & & & \\
\hline 12.99 & Undecane & & & $\mathrm{X}$ \\
\hline 13.025 & $\begin{array}{l}\text { 3,7-dimethyl-1,6-octadien-3- } \\
\text { ol }\end{array}$ & & & \\
\hline 13.085 & Nonanal & & & \\
\hline 13.294 & Phenylethyl Alcohol & & & \\
\hline 13.405 & Octanoic Acid Methyl Ester & & & \\
\hline 14.168 & Nonanol & & & \\
\hline 14.468 & Naphthalene & & & \\
\hline
\end{tabular}




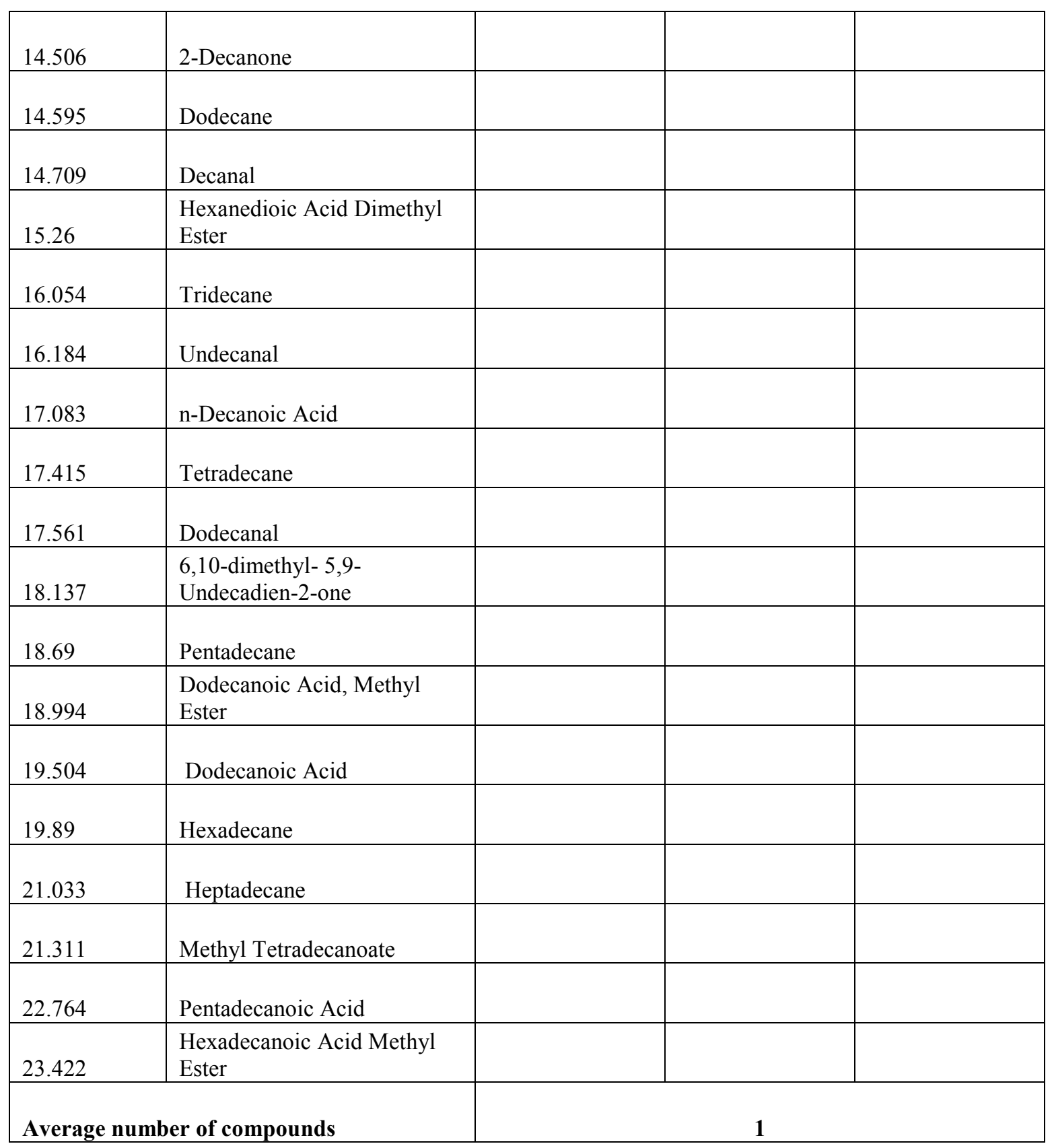


Table 32: Table showing the number of human scent compounds extracted in 3 hours from the headspace of a $10 \mathrm{ml}$ glass vial using ACS

\begin{tabular}{|c|c|c|c|c|}
\hline $\begin{array}{l}\text { Retention } \\
\text { Time } \\
\text { (Minutes) }\end{array}$ & Compound Name & $\begin{array}{c}\text { Compounds } \\
\text { extracted } \\
\text { sample } 1\end{array}$ & $\begin{array}{c}\text { Compounds } \\
\text { extracted } \\
\text { sample } 2\end{array}$ & $\begin{array}{c}\text { Compounds } \\
\text { extracted } \\
\text { sample } 3\end{array}$ \\
\hline 6.407 & Octane & & & \\
\hline 7.356 & Furfural & & & \\
\hline 7.983 & 2-Furanmethanol & & & \\
\hline 9.015 & Nonane & $\mathrm{X}$ & & \\
\hline 9.065 & Heptanal & $\mathrm{X}$ & & \\
\hline 9.74 & $\begin{array}{l}\text { Propanedioic Acid Dimethyl } \\
\text { Ester }\end{array}$ & & & \\
\hline 10.385 & Benzaldehyde & $\mathrm{X}$ & $\mathrm{X}$ & $\mathrm{X}$ \\
\hline 10.851 & Phenol & & & \\
\hline 10.949 & 6-methyl-5-hepten-2-one & & & \\
\hline 11.249 & Octanal & & & \\
\hline 11.882 & Benzyl Alcohol & & & \\
\hline 12.288 & 2-Octenal(E) & & & \\
\hline 12.503 & 1-Octanol & & & \\
\hline 12.99 & Undecane & $\mathrm{X}$ & $\mathrm{X}$ & $\mathrm{X}$ \\
\hline 13.025 & $\begin{array}{l}\text { 3,7-dimethyl-1,6-octadien-3- } \\
\text { ol }\end{array}$ & & & \\
\hline 13.085 & Nonanal & & & \\
\hline 13.294 & Phenylethyl Alcohol & & & \\
\hline 13.405 & Octanoic Acid Methyl Ester & & & \\
\hline 14.168 & Nonanol & & & \\
\hline 14.468 & Naphthalene & $\mathrm{X}$ & $\mathrm{X}$ & $\mathrm{X}$ \\
\hline
\end{tabular}




\begin{tabular}{|c|c|c|c|c|}
\hline 14.506 & 2-Decanone & & & \\
\hline 14.595 & Dodecane & $\mathrm{X}$ & & \\
\hline 14.709 & Decanal & & & \\
\hline 15.26 & $\begin{array}{l}\text { Hexanedioic Acid Dimethyl } \\
\text { Ester }\end{array}$ & & & \\
\hline 16.054 & Tridecane & & & \\
\hline 16.184 & Undecanal & & & \\
\hline 17.083 & n-Decanoic Acid & & & \\
\hline 17.415 & Tetradecane & & & \\
\hline 17.561 & Dodecanal & & & \\
\hline 18.137 & $\begin{array}{l}\text { 6,10-dimethyl- 5,9- } \\
\text { Undecadien-2-one }\end{array}$ & & & \\
\hline 18.69 & Pentadecane & & & \\
\hline 18.994 & $\begin{array}{l}\text { Dodecanoic Acid, Methyl } \\
\text { Ester }\end{array}$ & & & \\
\hline 19.504 & Dodecanoic Acid & & & \\
\hline 19.89 & Hexadecane & & & \\
\hline 21.033 & Heptadecane & & & \\
\hline 21.311 & Methyl Tetradecanoate & & & \\
\hline 22.764 & Pentadecanoic Acid & & & \\
\hline 23.422 & $\begin{array}{l}\text { Hexadecanoic Acid Methyl } \\
\text { Ester }\end{array}$ & & & \\
\hline \multicolumn{2}{|c|}{ Average number of compounds extracted } & \multicolumn{3}{|c|}{4} \\
\hline
\end{tabular}


Table 33: Table showing the number of human scent compounds extracted in 6 hours from the headspace of a $10 \mathrm{ml}$ glass vial using ACS

\begin{tabular}{|c|c|c|c|c|}
\hline $\begin{array}{l}\text { Retention } \\
\text { Time } \\
\text { (Minutes) }\end{array}$ & Compound Name & $\begin{array}{c}\text { Compounds } \\
\text { extracted } \\
\text { sample } 1\end{array}$ & $\begin{array}{c}\text { Compounds } \\
\text { extracted } \\
\text { sample } 2\end{array}$ & $\begin{array}{c}\text { Compounds } \\
\text { extracted } \\
\text { sample } 3\end{array}$ \\
\hline 6.407 & Octane & & & \\
\hline 7.356 & Furfural & & & \\
\hline 7.983 & 2-Furanmethanol & & & \\
\hline 9.015 & Nonane & & & \\
\hline 9.065 & Heptanal & & & \\
\hline 9.74 & $\begin{array}{l}\text { Propanedioic Acid Dimethyl } \\
\text { Ester }\end{array}$ & & & \\
\hline 10.385 & Benzaldehyde & $\mathrm{X}$ & & $\mathrm{X}$ \\
\hline 10.851 & Phenol & & & \\
\hline 10.949 & 6-methyl-5-hepten-2-one & & & \\
\hline 11.249 & Octanal & & & \\
\hline 11.882 & Benzyl Alcohol & & & \\
\hline 12.288 & 2-Octenal(E) & & & \\
\hline 12.503 & 1-Octanol & & & \\
\hline 12.99 & Undecane & $\mathrm{X}$ & & \\
\hline 13.025 & $\begin{array}{l}\text { 3,7-dimethyl-1,6-octadien-3- } \\
\text { ol }\end{array}$ & & & \\
\hline 13.085 & Nonanal & & & \\
\hline 13.294 & Phenylethyl Alcohol & & & \\
\hline 13.405 & Octanoic Acid Methyl Ester & & & \\
\hline 14.168 & Nonanol & & & \\
\hline 14.468 & Naphthalene & $\mathrm{X}$ & & $\mathrm{X}$ \\
\hline
\end{tabular}




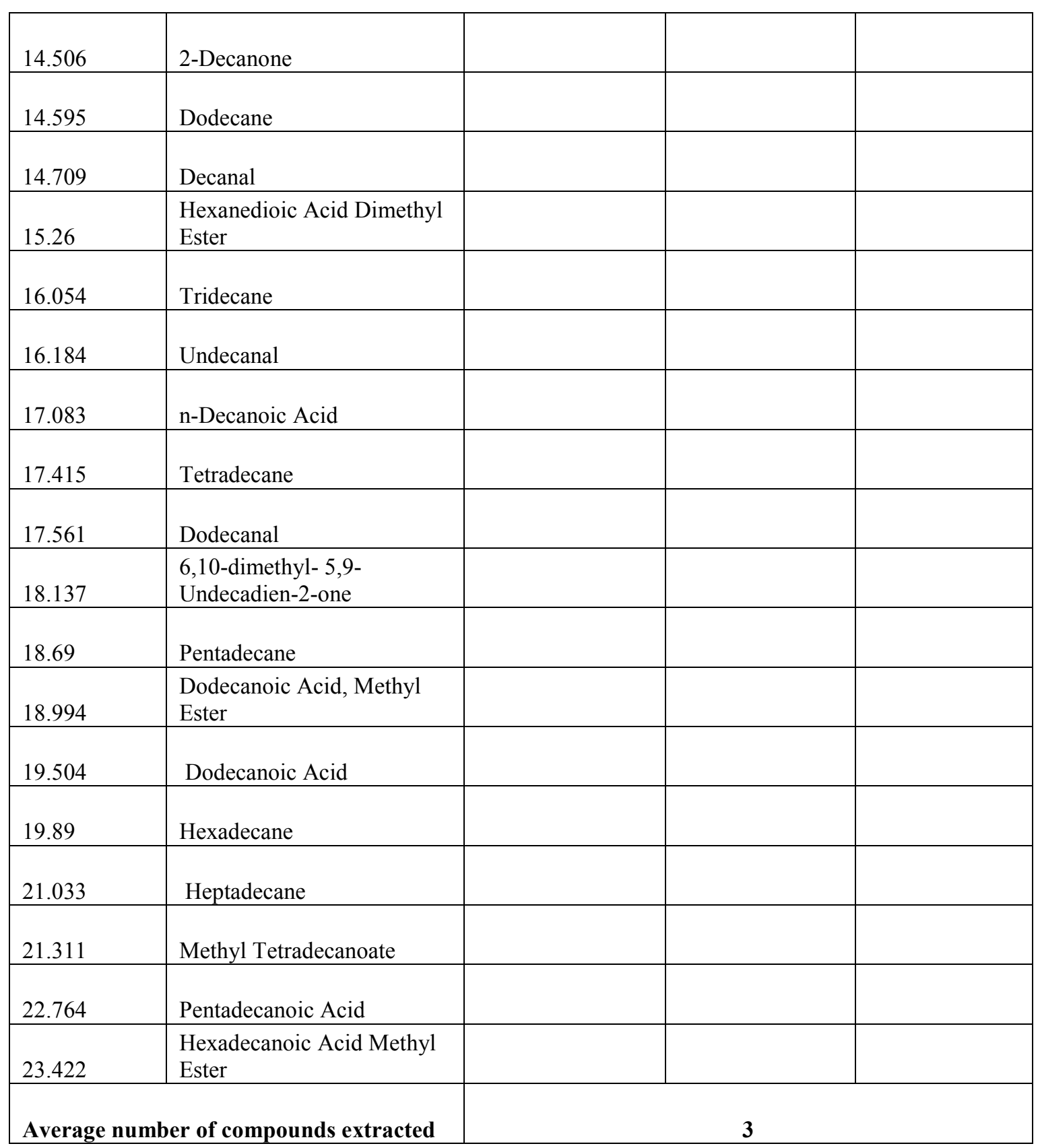


Table 34: Table showing the number of human scent compounds extracted in 12 hours from the headspace of a $10 \mathrm{ml}$ glass vial using ACS

\begin{tabular}{|c|c|c|c|c|}
\hline $\begin{array}{l}\text { Retention } \\
\text { Time } \\
\text { (Minutes) }\end{array}$ & Compound Name & $\begin{array}{c}\text { Compounds } \\
\text { extracted } \\
\text { sample } 1\end{array}$ & $\begin{array}{c}\text { Compounds } \\
\text { extracted } \\
\text { sample } 2\end{array}$ & $\begin{array}{c}\text { Compounds } \\
\text { extracted } \\
\text { sample } 3\end{array}$ \\
\hline 6.407 & Octane & & & $\mathrm{X}$ \\
\hline 7.356 & Furfural & & & \\
\hline 7.983 & 2-Furanmethanol & & & \\
\hline 9.015 & Nonane & $\mathrm{X}$ & & $\mathrm{X}$ \\
\hline 9.065 & Heptanal & $\mathrm{X}$ & & $\mathrm{X}$ \\
\hline 9.74 & $\begin{array}{l}\text { Propanedioic Acid Dimethyl } \\
\text { Ester }\end{array}$ & & & \\
\hline 10.385 & Benzaldehyde & $\mathrm{X}$ & & $\mathrm{X}$ \\
\hline 10.851 & Phenol & & & \\
\hline 10.949 & 6-methyl-5-hepten-2-one & $\mathrm{X}$ & & \\
\hline 11.249 & Octanal & & & \\
\hline 11.882 & Benzyl Alcohol & & & \\
\hline 12.288 & 2-Octenal(E) & & & \\
\hline 12.503 & 1-Octanol & & & \\
\hline 12.99 & Undecane & $\mathrm{X}$ & & $\mathrm{X}$ \\
\hline 13.025 & $\begin{array}{l}\text { 3,7-dimethyl-1,6-octadien-3- } \\
\text { ol }\end{array}$ & & & \\
\hline 13.085 & Nonanal & & & \\
\hline 13.294 & Phenylethyl Alcohol & & & \\
\hline 13.405 & Octanoic Acid Methyl Ester & & & \\
\hline 14.168 & Nonanol & & & \\
\hline 14.468 & Naphthalene & $\mathrm{X}$ & & $\mathrm{X}$ \\
\hline
\end{tabular}




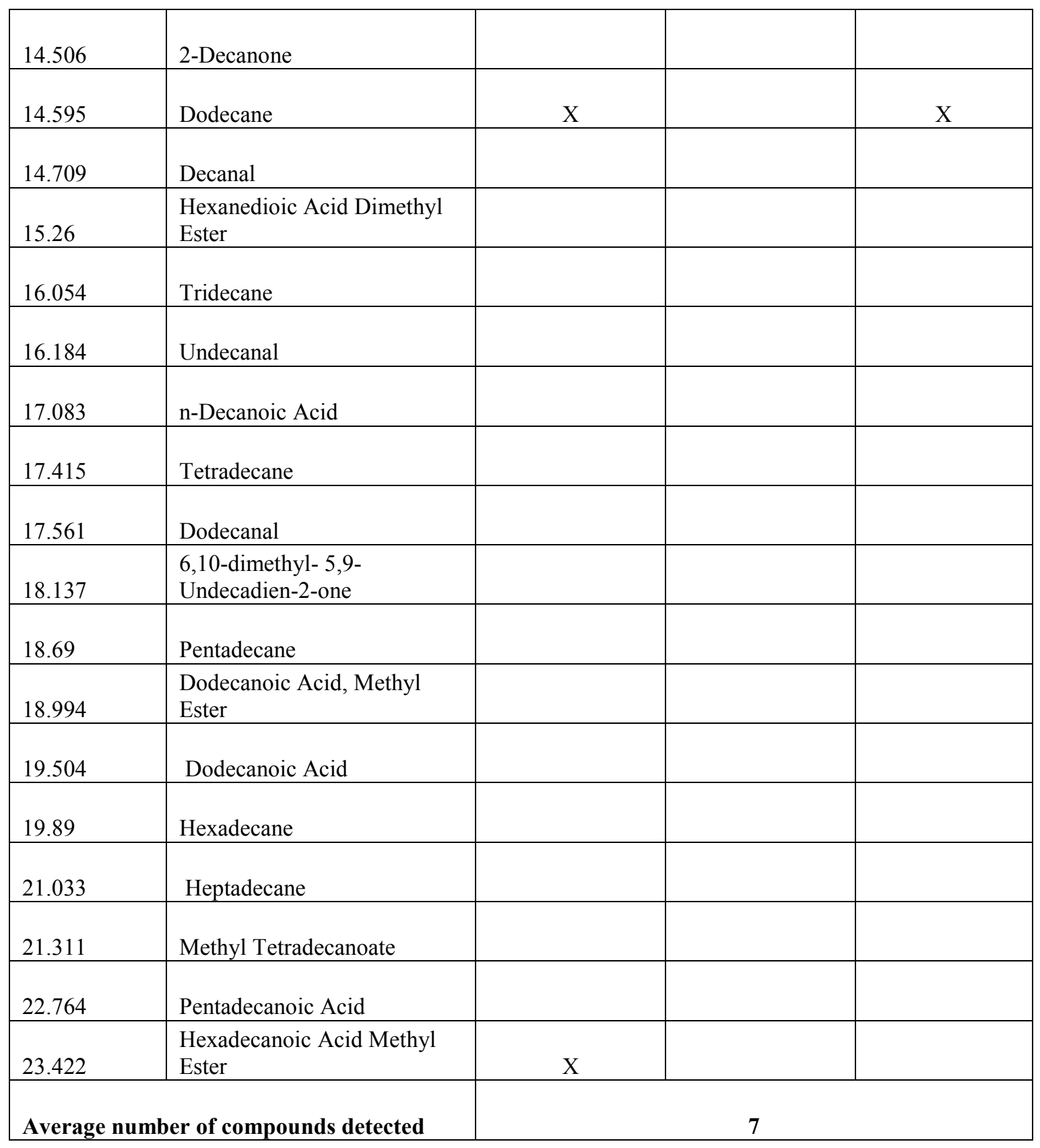


Table 35: Table showing the number of human scent compounds extracted in 24 hours from the headspace of a $10 \mathrm{ml}$ glass vial using ACS

\begin{tabular}{|c|c|c|c|c|}
\hline $\begin{array}{l}\text { Retention } \\
\text { Time } \\
\text { (Minutes) }\end{array}$ & Compound Name & $\begin{array}{c}\text { Compounds } \\
\text { extracted } \\
\text { sample } 1\end{array}$ & $\begin{array}{c}\text { Compounds } \\
\text { extracted } \\
\text { sample } 2\end{array}$ & $\begin{array}{c}\text { Compounds } \\
\text { extracted } \\
\text { sample } 3\end{array}$ \\
\hline 6.407 & Octane & $\mathrm{X}$ & $\mathrm{X}$ & $\mathrm{X}$ \\
\hline 7.356 & Furfural & & & \\
\hline 7.983 & 2-Furanmethanol & & & \\
\hline 9.015 & Nonane & $\mathrm{X}$ & $\mathrm{X}$ & $\mathrm{X}$ \\
\hline 9.065 & Heptanal & $\mathrm{X}$ & $\mathrm{X}$ & \\
\hline 9.74 & $\begin{array}{l}\text { Propanedioic Acid Dimethyl } \\
\text { Ester }\end{array}$ & & & \\
\hline 10.385 & Benzaldehyde & $\mathrm{X}$ & $\mathrm{X}$ & $\mathrm{X}$ \\
\hline 10.851 & Phenol & & & \\
\hline 10.949 & 6-methyl-5-hepten-2-one & $\mathrm{X}$ & $\mathrm{X}$ & $\mathrm{X}$ \\
\hline 11.249 & Octanal & & & \\
\hline 11.882 & Benzyl Alcohol & & & \\
\hline 12.288 & 2-Octenal(E) & & & \\
\hline 12.503 & 1-Octanol & & & \\
\hline 12.99 & Undecane & $\mathrm{X}$ & & \\
\hline 13.025 & $\begin{array}{l}\text { 3,7-dimethyl-1,6-octadien-3- } \\
\text { ol }\end{array}$ & & & \\
\hline 13.085 & Nonanal & & & \\
\hline 13.294 & Phenylethyl Alcohol & & & \\
\hline 13.405 & Octanoic Acid Methyl Ester & $\mathrm{X}$ & & \\
\hline 14.168 & Nonanol & & & \\
\hline 14.468 & Naphthalene & $\mathrm{X}$ & $\mathrm{X}$ & \\
\hline
\end{tabular}




\begin{tabular}{|c|c|c|c|c|}
\hline 14.506 & 2-Decanone & & & \\
\hline 14.595 & Dodecane & $\mathrm{X}$ & $\mathrm{X}$ & \\
\hline 14.709 & Decanal & & & \\
\hline 15.26 & $\begin{array}{l}\text { Hexanedioic Acid Dimethyl } \\
\text { Ester }\end{array}$ & & & \\
\hline 16.054 & Tridecane & $\mathrm{X}$ & & \\
\hline 16.184 & Undecanal & & & \\
\hline 17.083 & n-Decanoic Acid & & & \\
\hline 17.415 & Tetradecane & & & \\
\hline 17.561 & Dodecanal & & & \\
\hline 18.137 & $\begin{array}{l}\text { 6,10-dimethyl- 5,9- } \\
\text { Undecadien-2-one }\end{array}$ & & & \\
\hline 18.69 & Pentadecane & & & \\
\hline 18.994 & $\begin{array}{l}\text { Dodecanoic Acid, Methyl } \\
\text { Ester }\end{array}$ & & & \\
\hline 19.504 & Dodecanoic Acid & & & \\
\hline 19.89 & Hexadecane & & & \\
\hline 21.033 & Heptadecane & & & \\
\hline 21.311 & Methyl Tetradecanoate & & & \\
\hline 22.764 & Pentadecanoic Acid & & & \\
\hline 23.422 & $\begin{array}{l}\text { Hexadecanoic Acid Methyl } \\
\text { Ester }\end{array}$ & & & \\
\hline \multicolumn{2}{|c|}{ Average number of compounds detected } & \multicolumn{3}{|c|}{7} \\
\hline
\end{tabular}


Table 36: Table showing the number of human scent compounds extracted from the headspace of a 10ml glass vial using a 21 hour SPME extraction

\begin{tabular}{|c|c|c|c|c|}
\hline $\begin{array}{c}\text { Retention } \\
\text { Time } \\
\text { (Minutes) }\end{array}$ & Compound Name & $\begin{array}{l}\text { Compounds } \\
\text { extracted } \\
\text { sample } 1\end{array}$ & $\begin{array}{c}\text { Compounds } \\
\text { extracted } \\
\text { sample } 2\end{array}$ & $\begin{array}{c}\text { Compounds } \\
\text { extracted } \\
\text { sample } 3\end{array}$ \\
\hline 6.407 & Octane & & & \\
\hline 7.356 & Furfural & & & \\
\hline 7.983 & 2-Furanmethanol & & & \\
\hline 9.015 & Nonane & $\mathrm{X}$ & $\mathrm{X}$ & $\mathrm{X}$ \\
\hline 9.065 & Heptanal & & & \\
\hline 9.74 & $\begin{array}{l}\text { Propanedioic Acid Dimethyl } \\
\text { Ester }\end{array}$ & & & \\
\hline 10.385 & Benzaldehyde & $\mathrm{X}$ & $\mathrm{X}$ & $\mathrm{X}$ \\
\hline 10.851 & Phenol & $\mathrm{X}$ & & $\mathrm{X}$ \\
\hline 10.949 & 6-methyl-5-hepten-2-one & & & $\mathrm{X}$ \\
\hline 11.249 & Octanal & & & \\
\hline 11.882 & Benzyl Alcohol & & & \\
\hline 12.288 & 2-Octenal(E) & $\mathrm{X}$ & & $\mathrm{X}$ \\
\hline 12.503 & 1-Octanol & & & $X$ \\
\hline 12.99 & Undecane & $\mathrm{X}$ & $\mathrm{X}$ & $\mathrm{X}$ \\
\hline 13.025 & $\begin{array}{l}\text { 3,7-dimethyl-1,6-octadien-3- } \\
\text { ol }\end{array}$ & & & \\
\hline 13.085 & Nonanal & & & \\
\hline 13.294 & Phenylethyl Alcohol & $\mathrm{X}$ & & $\mathrm{X}$ \\
\hline 13.405 & Octanoic Acid Methyl Ester & $\mathrm{X}$ & $\mathrm{X}$ & $\mathrm{X}$ \\
\hline 14.168 & Nonanol & $\mathrm{X}$ & & $\mathrm{X}$ \\
\hline 14.468 & Naphthalene & $\mathrm{X}$ & $\mathrm{X}$ & $\mathrm{X}$ \\
\hline
\end{tabular}




\begin{tabular}{|c|c|c|c|c|}
\hline 14.506 & 2-Decanone & & & \\
\hline 14.595 & Dodecane & $\mathrm{X}$ & $\mathrm{X}$ & $X$ \\
\hline 14.709 & Decanal & $\mathrm{X}$ & & $\mathrm{X}$ \\
\hline 15.26 & $\begin{array}{l}\text { Hexanedioic Acid Dimethyl } \\
\text { Ester }\end{array}$ & $X$ & & $\mathrm{X}$ \\
\hline 16.054 & Tridecane & $\mathrm{X}$ & $\mathrm{X}$ & $\mathrm{X}$ \\
\hline 16.184 & Undecanal & $\mathrm{X}$ & & $\mathrm{X}$ \\
\hline 17.083 & n-Decanoic Acid & & & \\
\hline 17.415 & Tetradecane & $\mathrm{X}$ & $\mathrm{X}$ & $\mathrm{X}$ \\
\hline 17.561 & Dodecanal & $\mathrm{X}$ & $\mathrm{X}$ & $\mathrm{X}$ \\
\hline 18.137 & $\begin{array}{l}\text { 6,10-dimethyl- 5,9- } \\
\text { Undecadien-2-one }\end{array}$ & & & \\
\hline 18.69 & Pentadecane & $\mathrm{X}$ & $\mathrm{X}$ & $\mathrm{X}$ \\
\hline 18.994 & $\begin{array}{l}\text { Dodecanoic Acid, Methyl } \\
\text { Ester }\end{array}$ & $\mathrm{X}$ & & $\mathrm{X}$ \\
\hline 19.504 & Dodecanoic Acid & & & \\
\hline 19.89 & Hexadecane & $\mathrm{X}$ & $\mathrm{X}$ & $\mathrm{X}$ \\
\hline 21.033 & Heptadecane & $\mathrm{X}$ & $\mathrm{X}$ & $\mathrm{X}$ \\
\hline 21.311 & Methyl Tetradecanoate & & & \\
\hline 22.764 & Pentadecanoic Acid & & & \\
\hline 23.422 & $\begin{array}{l}\text { Hexadecanoic Acid Methyl } \\
\text { Ester }\end{array}$ & & & \\
\hline \multicolumn{2}{|c|}{ Average number of compounds } & \multicolumn{3}{|c|}{18} \\
\hline
\end{tabular}


Figure 72: Chromatogram of blank Activated Charcoal Strip which was eluted with carbon disulfide and analyzed by GC/MS

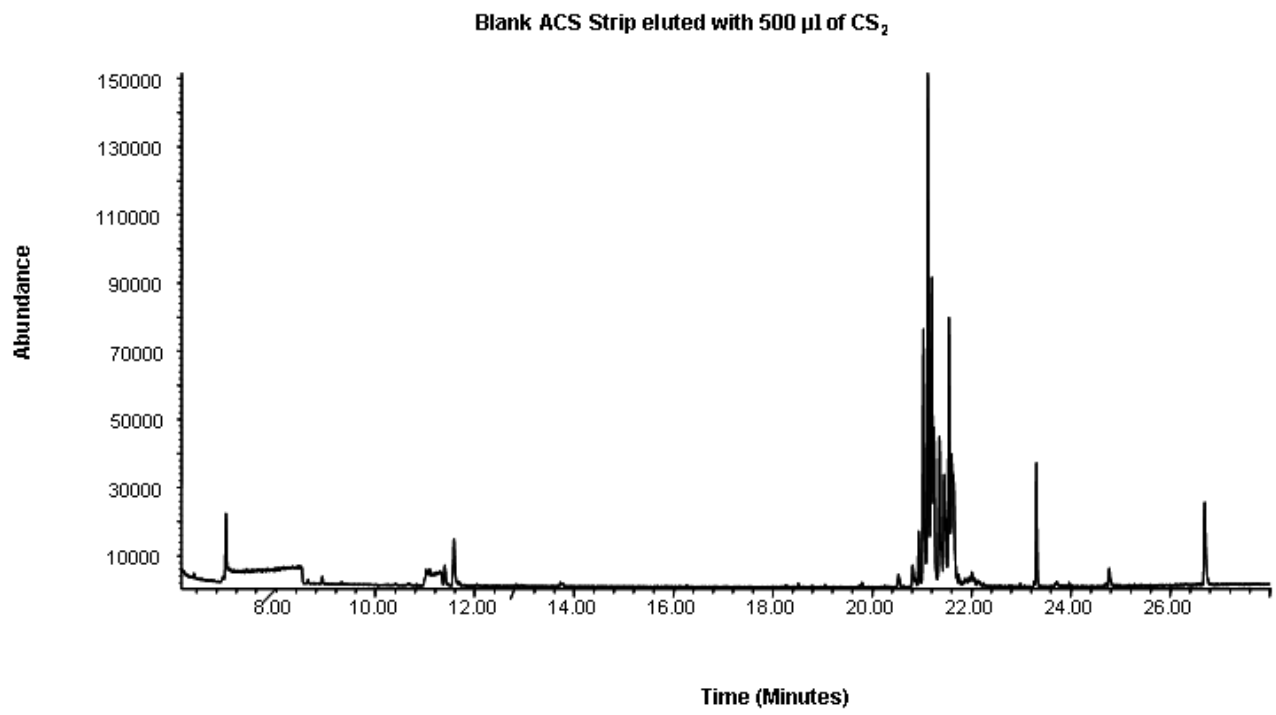

Figure 73: Chromatograms obtained for 0.5 hour ACS extraction of human scent VOCs present in the headspace of a $10 \mathrm{ml}$ glass vial analyzed using GC/MS
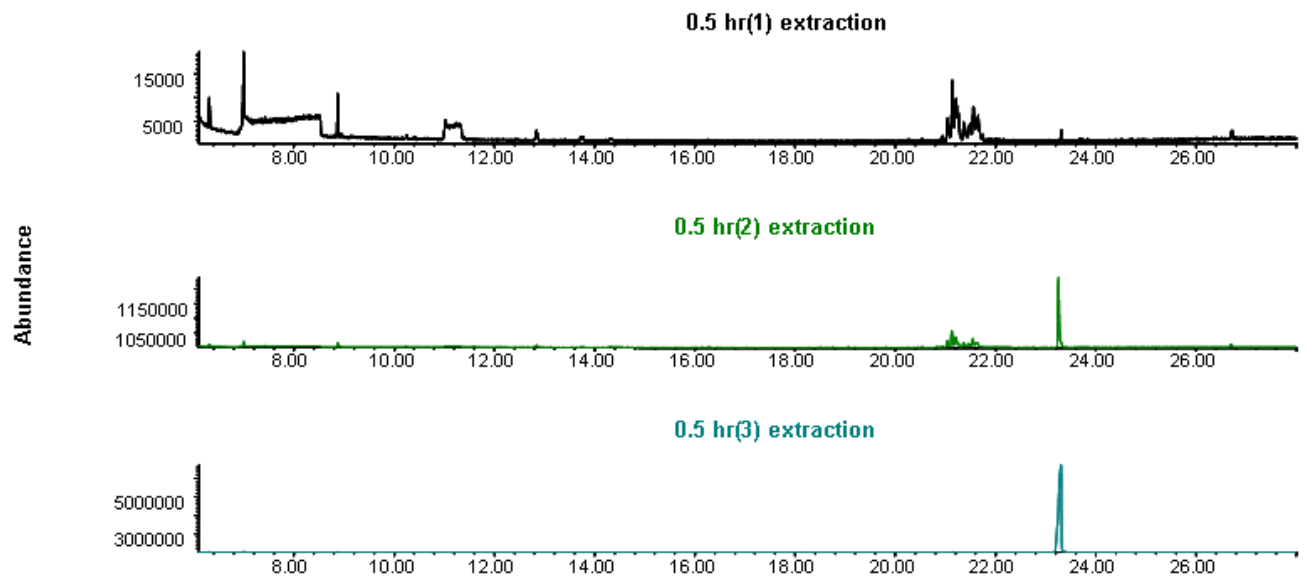

Time (Minutes) 
Figure 74: Chromatograms obtained for 1 hour ACS extraction of human scent VOCs present in the headspace of a $10 \mathrm{ml}$ glass vial analyzed using GC/MS

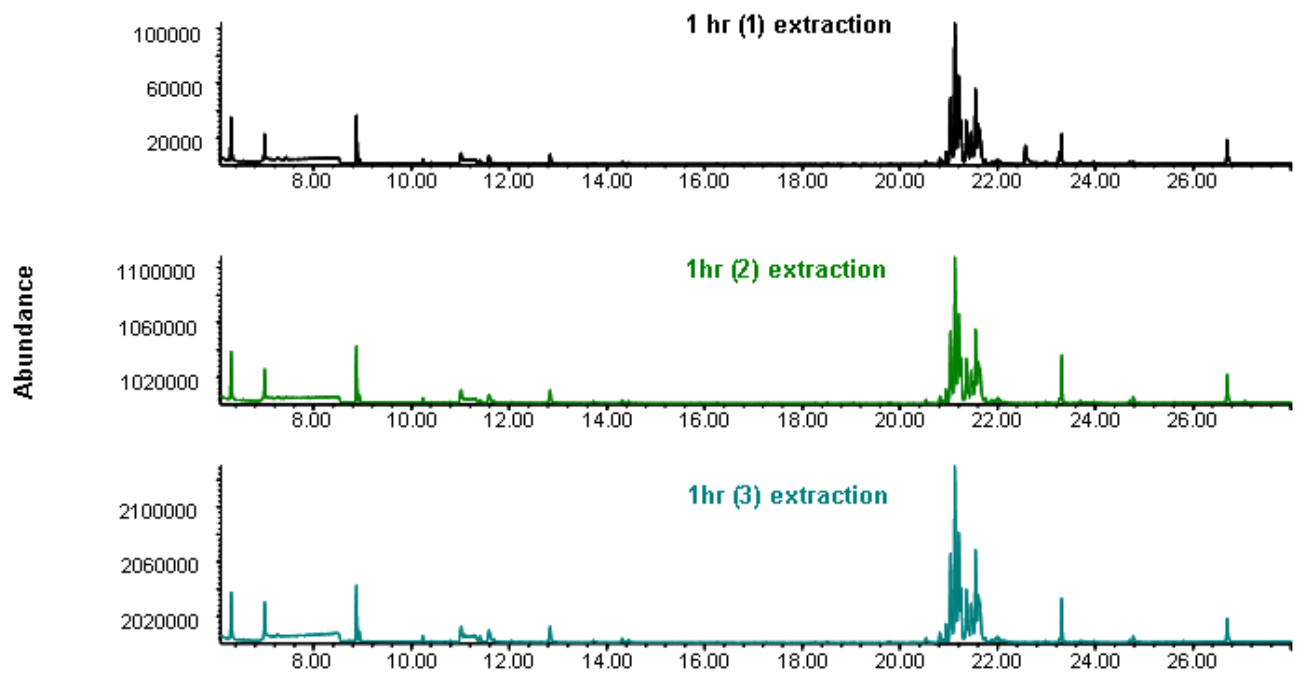

Time (Minutes)

Figure 75: Chromatograms obtained for 3 hour ACS extraction of human scent VOCs present in the headspace of a 10ml glass vial analyzed using GC/MS
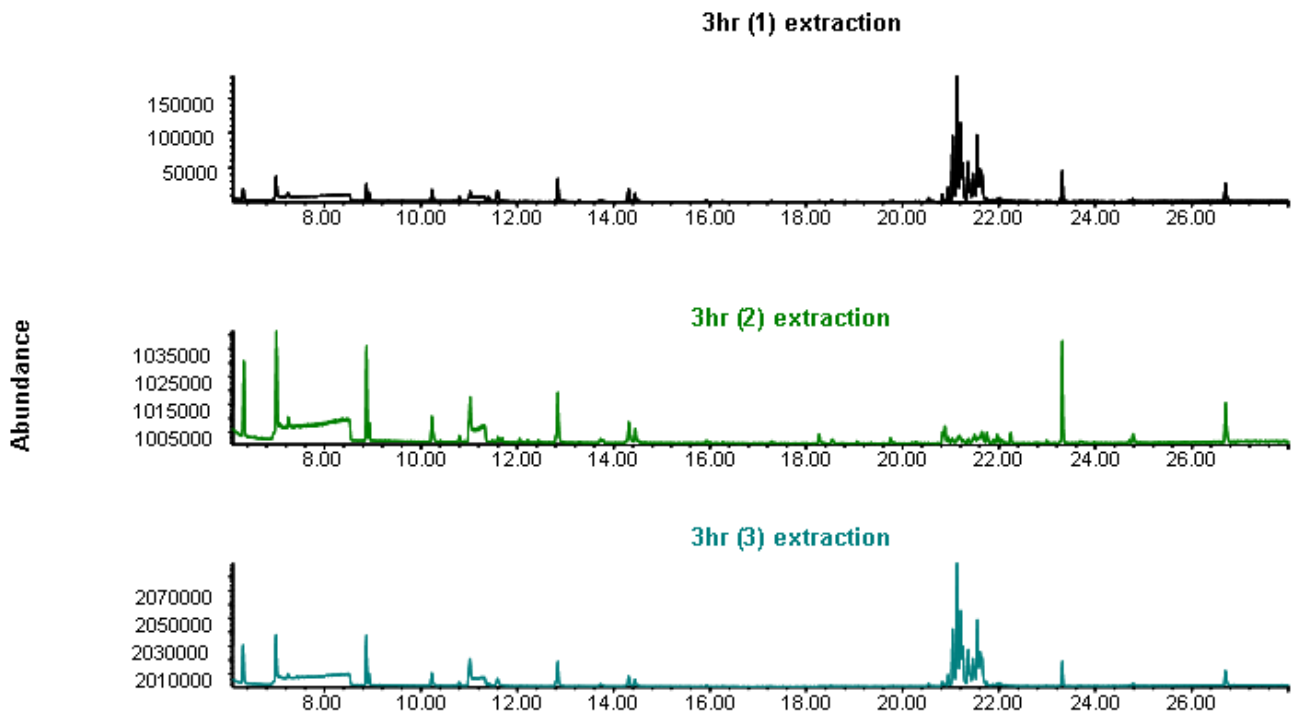

Time (Minutes) 
Figure 76: Chromatograms obtained for 6 hour ACS extraction of human scent VOCs present in the headspace of a $10 \mathrm{ml}$ glass vial analyzed using GC/MS
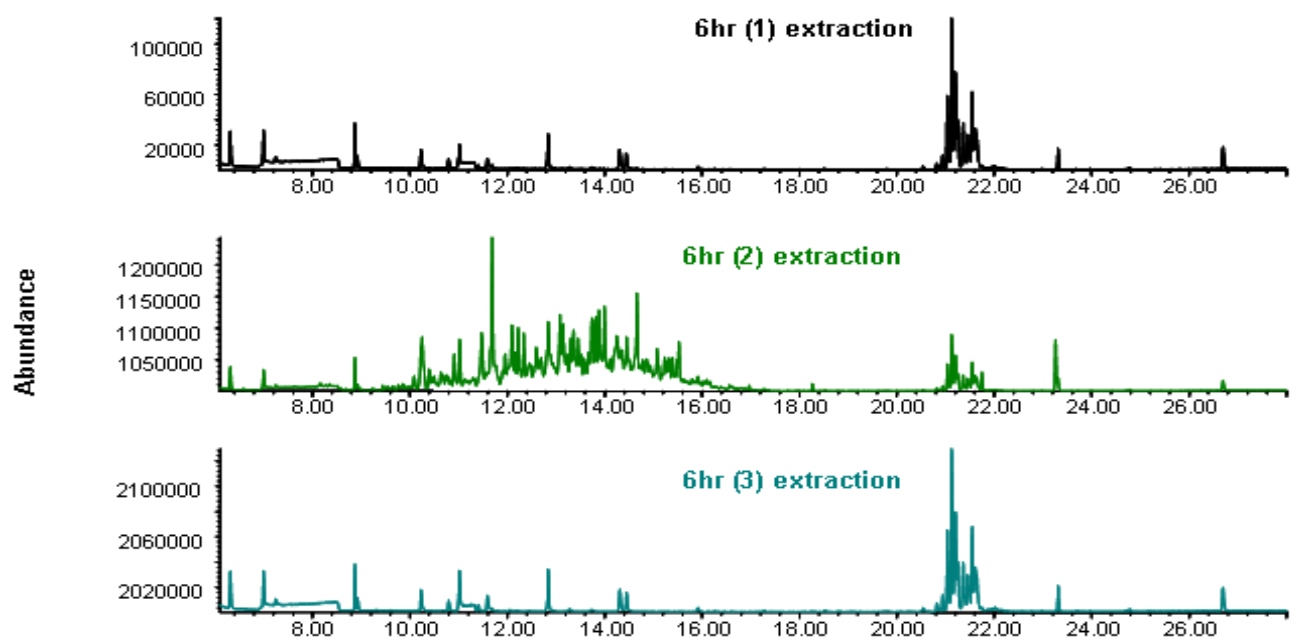

Time (Minutes)

Figure 77: Chromatograms obtained for 12 hour ACS extraction of human scent VOCs present in the headspace of a $10 \mathrm{ml}$ glass vial analyzed using GC/MS
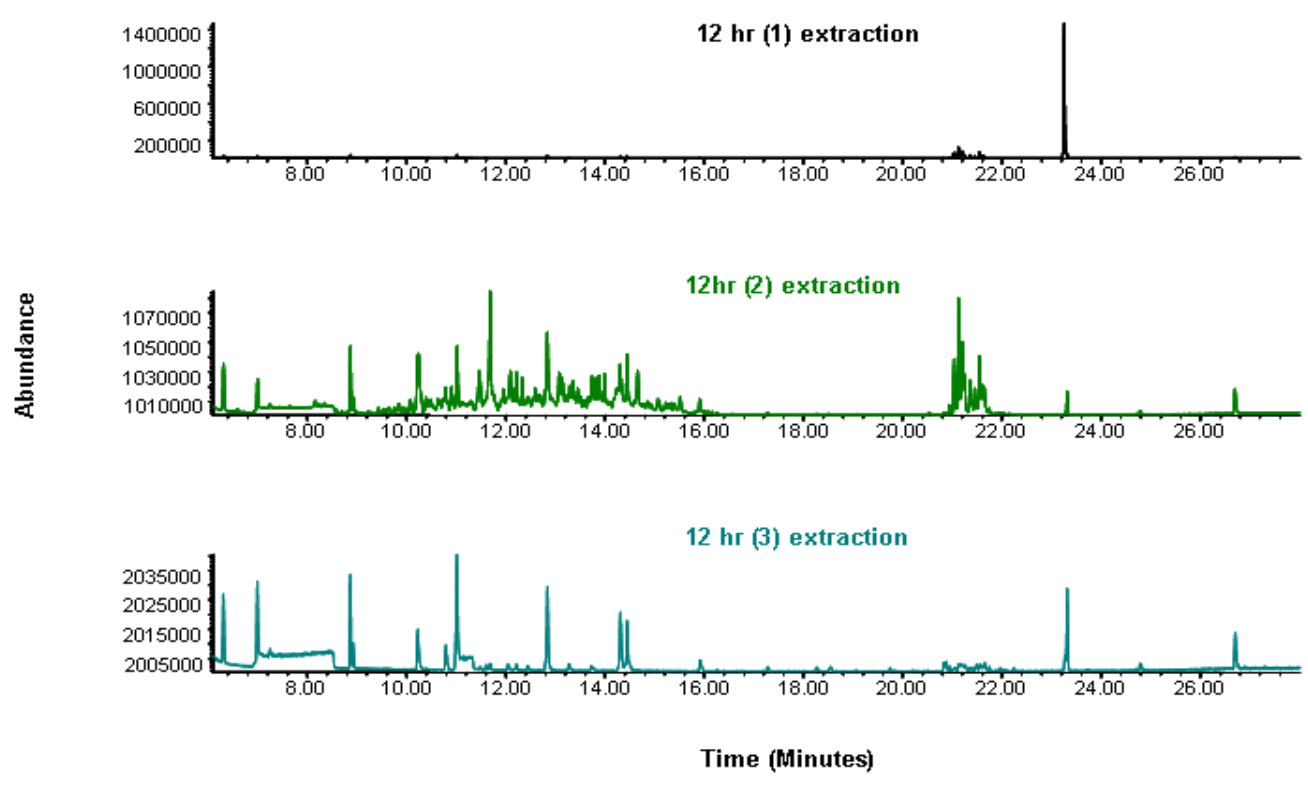
Figure 78: Chromatograms obtained for 24 hour ACS extraction of human scent VOCs present in the headspace of a $10 \mathrm{ml}$ glass vial analyzed using GC/MS
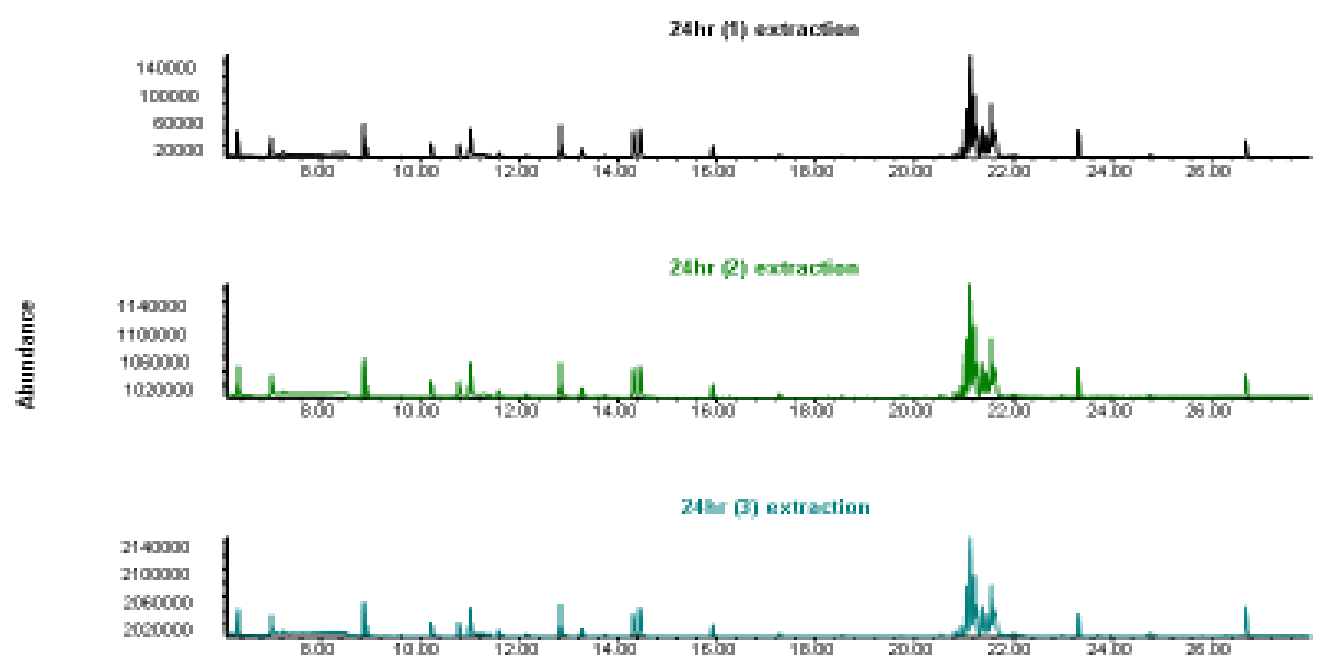

Time fo: insted

Figure 79: Chromatograms obtained for 21 hour headspace SPME of human scent VOCs present in the headspace of a $10 \mathrm{ml}$ glass vial analyzed using GC/MS
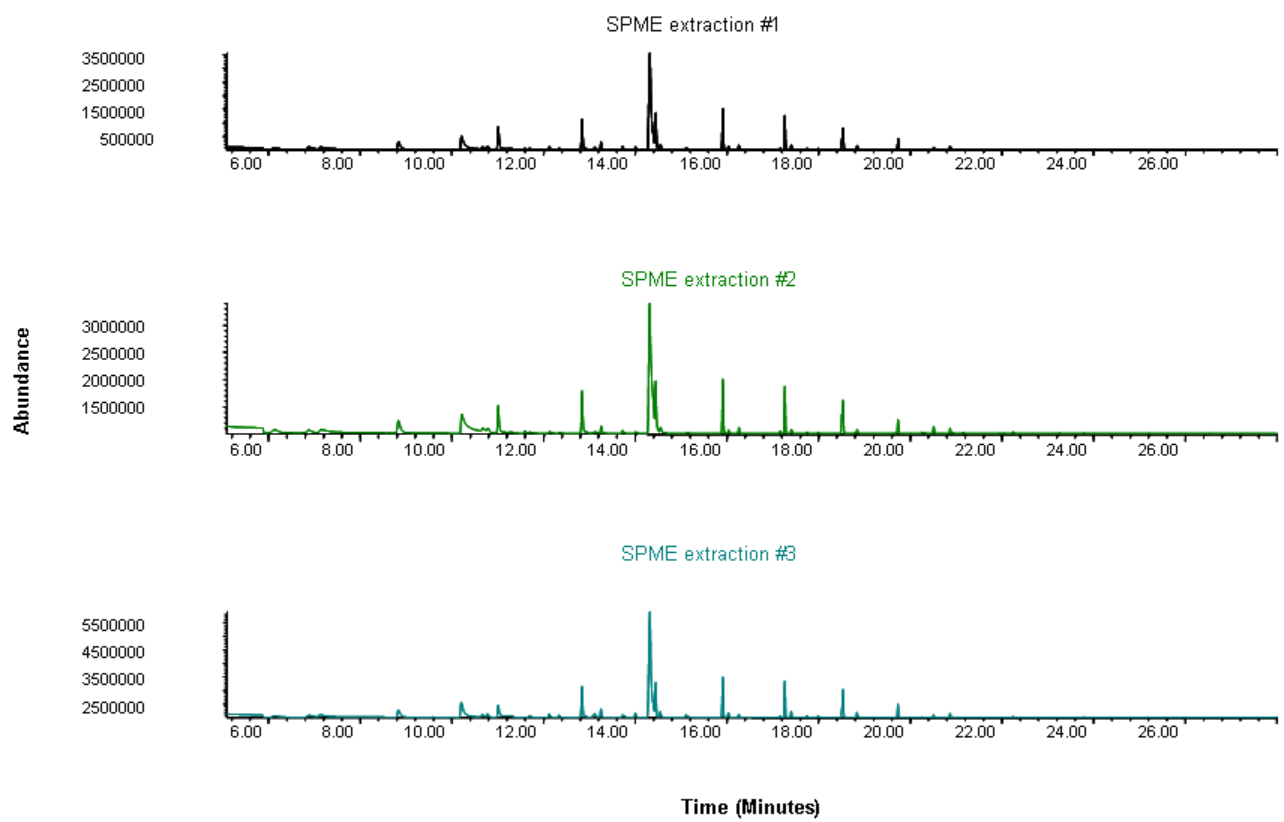


\subsection{Analysis of shedder status}

It was observed that human scent identification canines alerted differently to persons. Scent line ups conducted by the Netherlands National Police using eleven different individuals showed that the canines alerted more readily to six of these individuals than to the remaining five individuals. The ease of alert was based on the number of times that the canines had to perform the lineup before producing an alert. For the six individuals who were classified as the "easy persons" the canines would perform the lineups once while for the remaining five individuals, classified as the "difficult persons" the canines would have to perform the lineups repeatedly before providing a positive alert.

Literature shows that persons can be considered to be "good shedders" or "poor shedders" based on the amount of DNA (epithelial cells) left behind once an individual comes into contact with an object (50). It was thus hypothesized that the persons who were easily identified by the canines were good shedders (deposits more DNA upon contact with an object) while the difficult persons were bad shedders (deposits less DNA upon contact with an object).

Experiments were designed (see section 3.2.9) to evaluate DNA (human and non-human) profiles from hand odor samples collected on sterile 100 percent cotton swabs. Preliminary experiments showed that sufficient DNA material is deposited after a 10 minute hand sampling procedure which can be extracted and analyzed using real time Polymerase Chain Reaction (PCR). Human scent profiles were also evaluated using SPME-GC/MS.

Preliminary experiments were conducted to determine the effects of hand washing on the mass of DNA deposited. Two sets of samples were collected from the eleven individuals; 
washed and unwashed hands onto cotton swabs. The mass of human DNA was quantified using real time PCR. The results show that for the majority of the subjects, the unwashed hands provided the greatest mass of human DNA (Figure 80). For subsequent studies, subjects were not required to wash their hands.

Figure 80: Mass of human DNA recovered from washed and unwashed hands

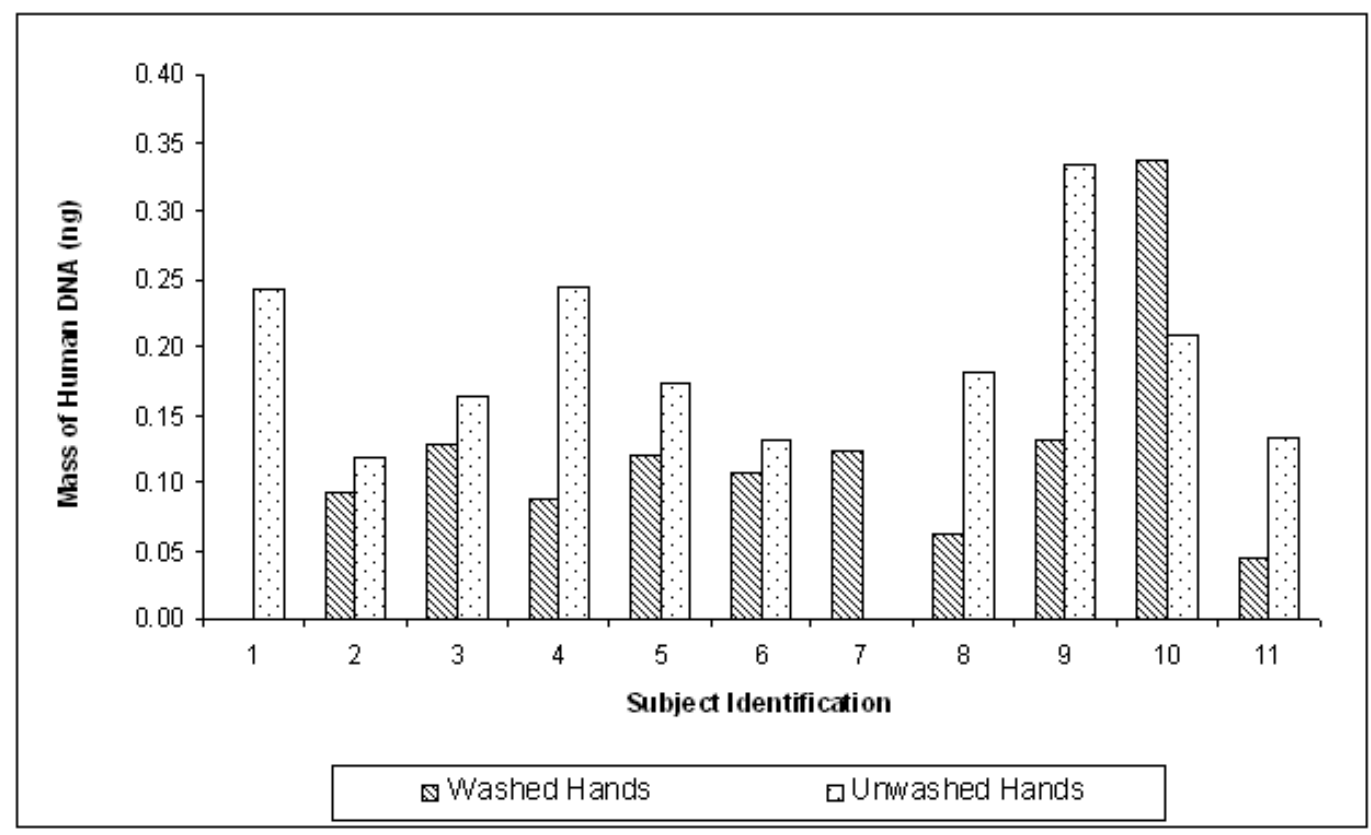

Human DNA (nuclear) present in hand odor samples

DNA extractions were conducted on the samples collected from the eleven individuals. As only two sets of samples were collected from subjects six and ten, duplicate samples were used for all other subjects to facilitate statistical evaluations. The average mass of nuclear DNA that was obtained ranged from $0.03 \mathrm{ng}$ to $1.26 \mathrm{ng}$. A one way ANOVA which was used to compare the mean masses which were obtained showed a significant difference between the mean mass obtained from subjects number four and nine and all the remaining subjects. There is, therefore, no correlation between the amount of DNA 
that was shed and the two groups of individuals. The individuals also did not shed a consistent amount of human DNA over time (Figure 81). This is consistent with results obtained by a research group in New Zealand that investigated the tendency of individuals to transfer DNA to handled items (51). The obtained results indicate that it is difficult to classify individuals as 'good' shedders or 'bad' shedders due to the variability in the amount of DNA recovered from items with which a person was in contact. However, it still cannot be disputed that 'good' shedders and 'poor' shedders do not exist until a more extensive study has been conducted.

Figure 81: Average mass of nuclear DNA present in hand odor samples collected from individuals who are easily identified by canines and individuals who are difficult for canines to identify

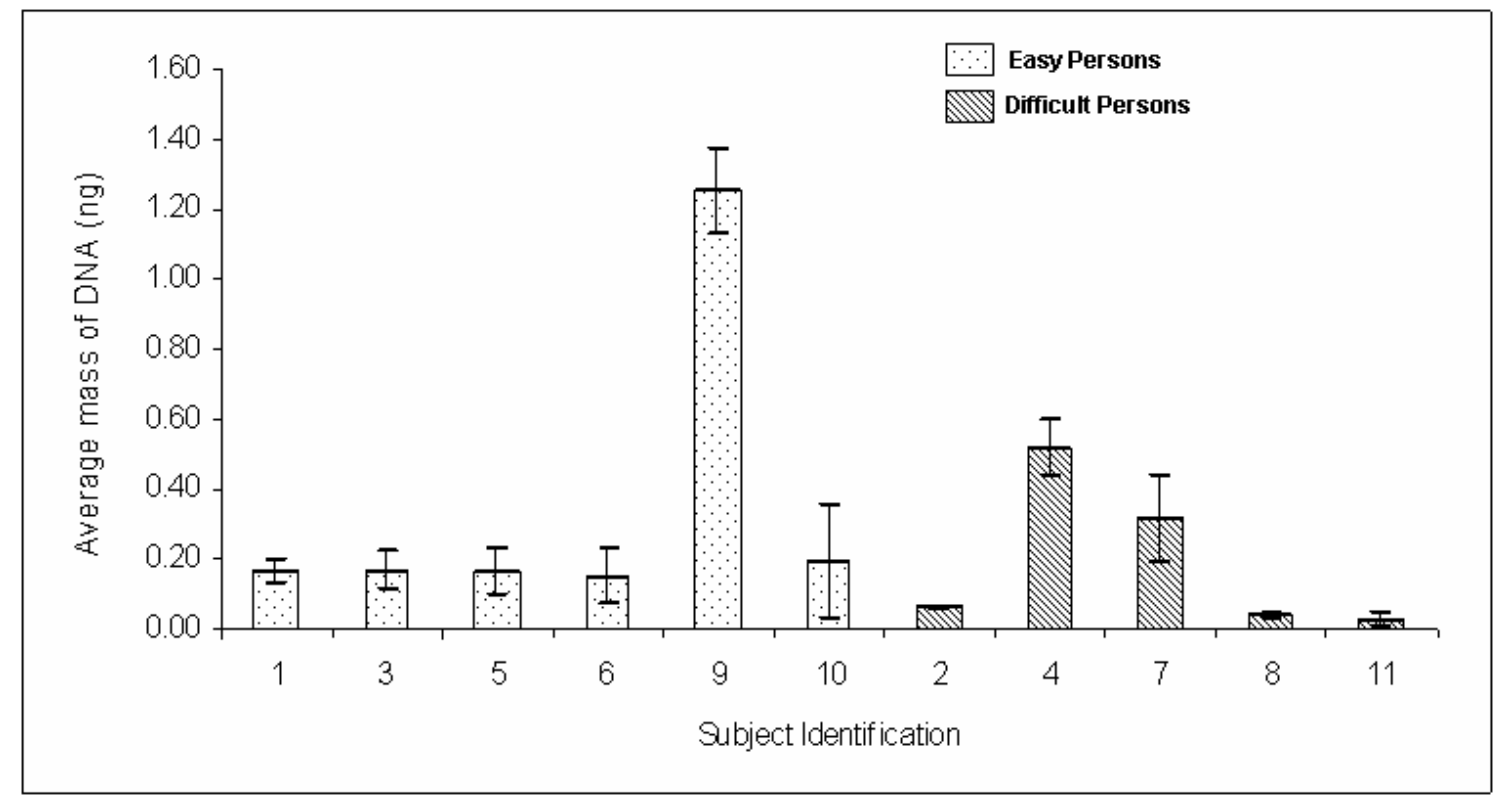

Nuclear DNA from head hair samples

Head hair samples were also collected from the eleven individuals to analyze for nuclear DNA using real time PCR. The hair samples which were obtained were analyzed 
microscopically to ensure that they were telogen shed hairs. Following microscopic examination, it was determined that the majority of the hairs which were obtained possessed root follicles and so had to be discarded. The numbers of useable hairs obtained from the subjects are shown in Table 4. As some subjects only had one useable strand of hair, the results obtained from one strand for the individuals are represented in Figure 82 below (subjects one, ten and two had no useable hairs).

Figure 82: Nuclear DNA present in telogen shed head hair from the persons easily identified and the persons difficult for canines to identify

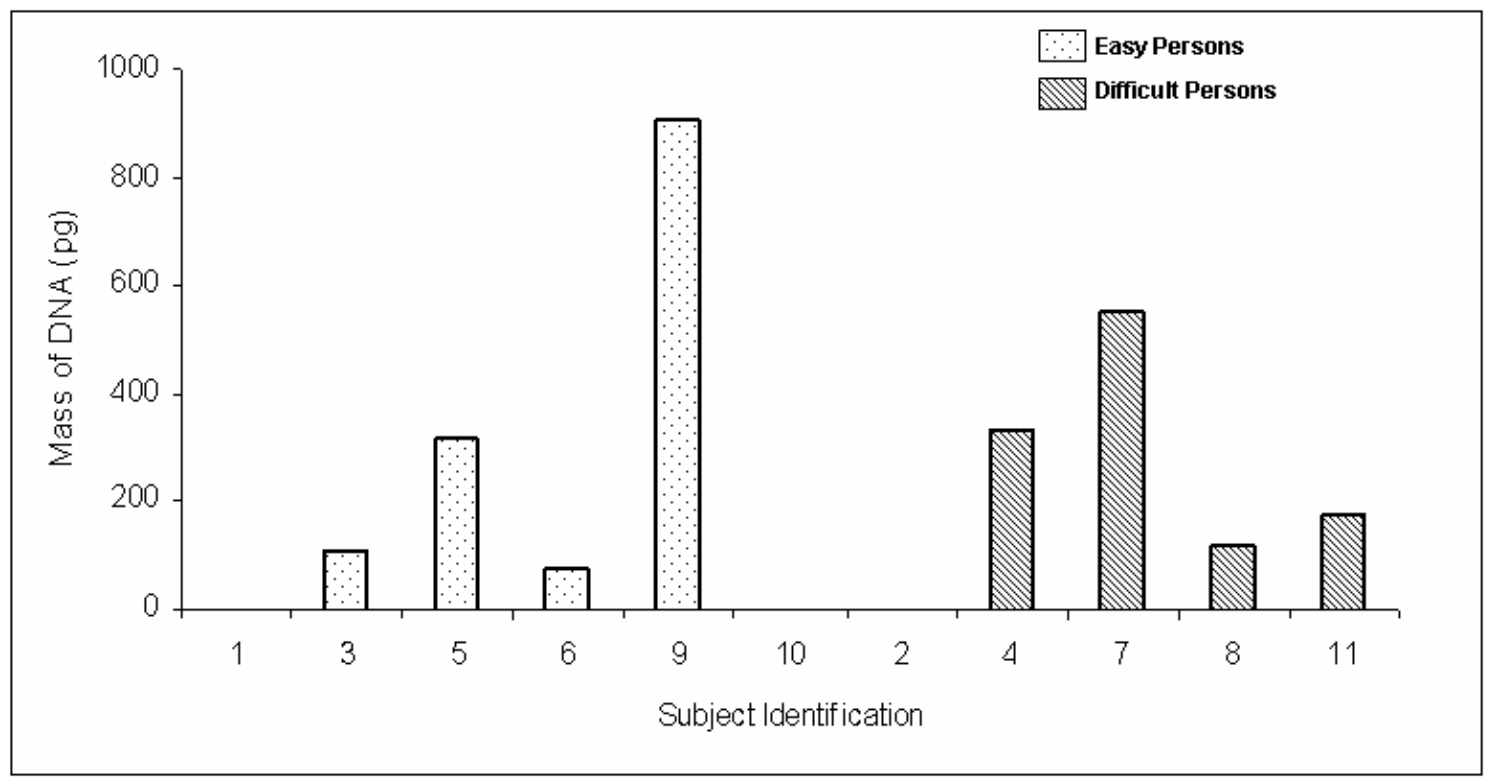

Non-Human (Microbial) DNA

Microbial DNA analysis conducted on the hand odor samples collected from eleven (11) individuals showed no correlation between the amount of microbial DNA shed and the two groups of individuals. The mean masses obtained ranged between $0.45 \mathrm{pg}$ and 0.05 ng. A majority of the difficult persons did possess greater masses of microbial DNA than 
the easy persons; however, the masses were not significantly different based on the one way ANOVA which was performed. The individuals did not shed a consistent amount of microbial DNA over time with the greatest inconsistencies seen with the difficult persons (Figure 83).

Figure 83: Average mass of microbial DNA present in hand odor samples collected from individuals who are easily identified by canines and individuals who are difficult for canines to identify

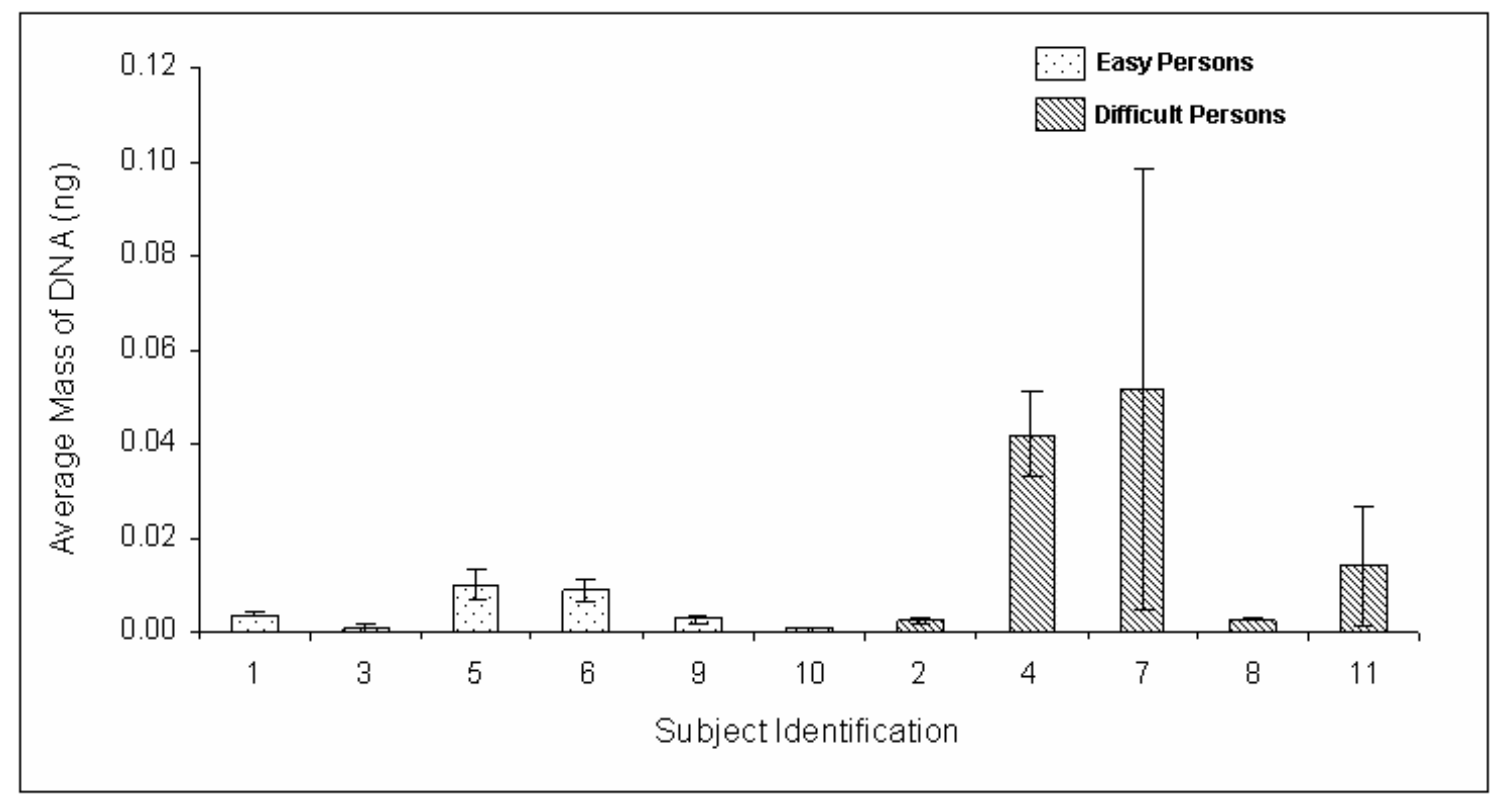

Analysis of the microbial communities showed that the greatest similarity obtained between persons was 80 percent (Figure 84). Research conducted by the American Society for Microbiology has shown that the number of bacterial species living on the skin could approach 500 . This is indicating that there is a possibility that everyone has a unique bacterial signature (10). 
Figure 84: Multi-dimensional scaling plot of Bray Curtis Similarity indices between microbial communities present in hand odor samples of individuals who are easily identified by canines and individuals who are difficult for canines to identify

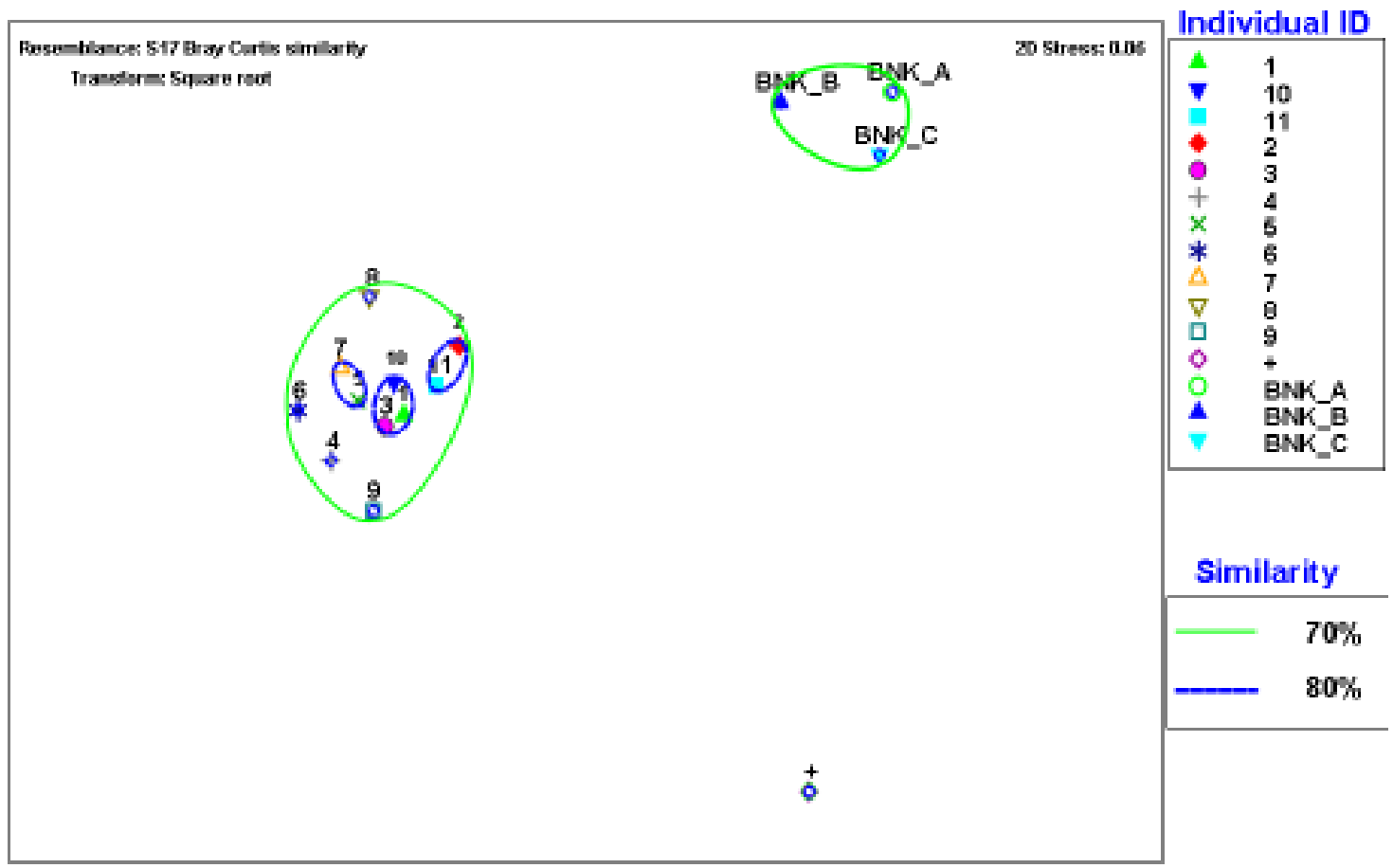

SPME-GC/MS analysis of hand odor samples

As the hand odor samples were collected in The Netherlands, the samples had to be transported to the United States. The effects that air transport had on the samples were investigated to ensure that the primary odor compounds would not be affected by changes in air pressure or by the wear and tear of traveling. Experiments were conducted in which triplicate hand odor samples were collected from two individuals and the primary odor compounds determined using SPME-GC/MS. One of the samples remained in the laboratory at room temperature while the remaining two samples were packaged for transport for round trip travel from Miami to Los Angeles. One of the samples was 
transported in cabin baggage while the other sample was transported in checked baggage. The results obtained show that the ratio of the primary odor compounds remained consistent showing that it was feasible to ship the samples from The Netherlands to The United States (Figure 85).

Headspace analysis of scent samples collected from the eleven individuals were analyzed and it was determined that each individual had varying ratios and combinations of VOCs (Figure 86). As with the DNA analyses, duplicate samples were used. The unique VOC profile that is inherent to individuals could also be due to the unique microbial communities which each individual possess. Despite the varying ratios and combinations of VOCs for the individuals, there was common VOCs within each group of individuals but these VOCs were different between groups (easy and difficult) (Figure 87). Further analyses between the recurring VOCs present in both groups were done and it was found that these compounds though not exclusive to each group, highlighted a possible cause for the canines not being able to readily identify persons from the difficult group.

It has generally been accepted that the perception of odor is a result of interactions between chemicals and olfactory receptors. The obtained data is suggesting that specific compounds could possibly be adhering to G-proteins and triggering responses from the canines. Not much research has been conducted regarding canine olfactory receptors and their response to specific compounds. This has been done in human and it has been shown that odorants could act as agonist and antagonist for certain olfactory receptors (74). 
The experiments conducted showed that individuals did not shed a consistent amount of DNA over time making it difficult to classify the individuals as good or poor shedders.

The results obtained suggest that the canine alerts are not dependent on quantities of DNA (human or non-human) but possibly on the VOCs which are present. The quantities of VOCs were also analyzed to determine if the easy persons produced greater quantities than the difficult persons (Figure 88). A one way ANOVA showed that the mean masses of VOCs from the eleven individuals were significantly different. However this significant difference was not limited to one particular group.

Figure 85: Ratio of VOCs present in hand odor samples collected from a female subject and subjected to air transportation

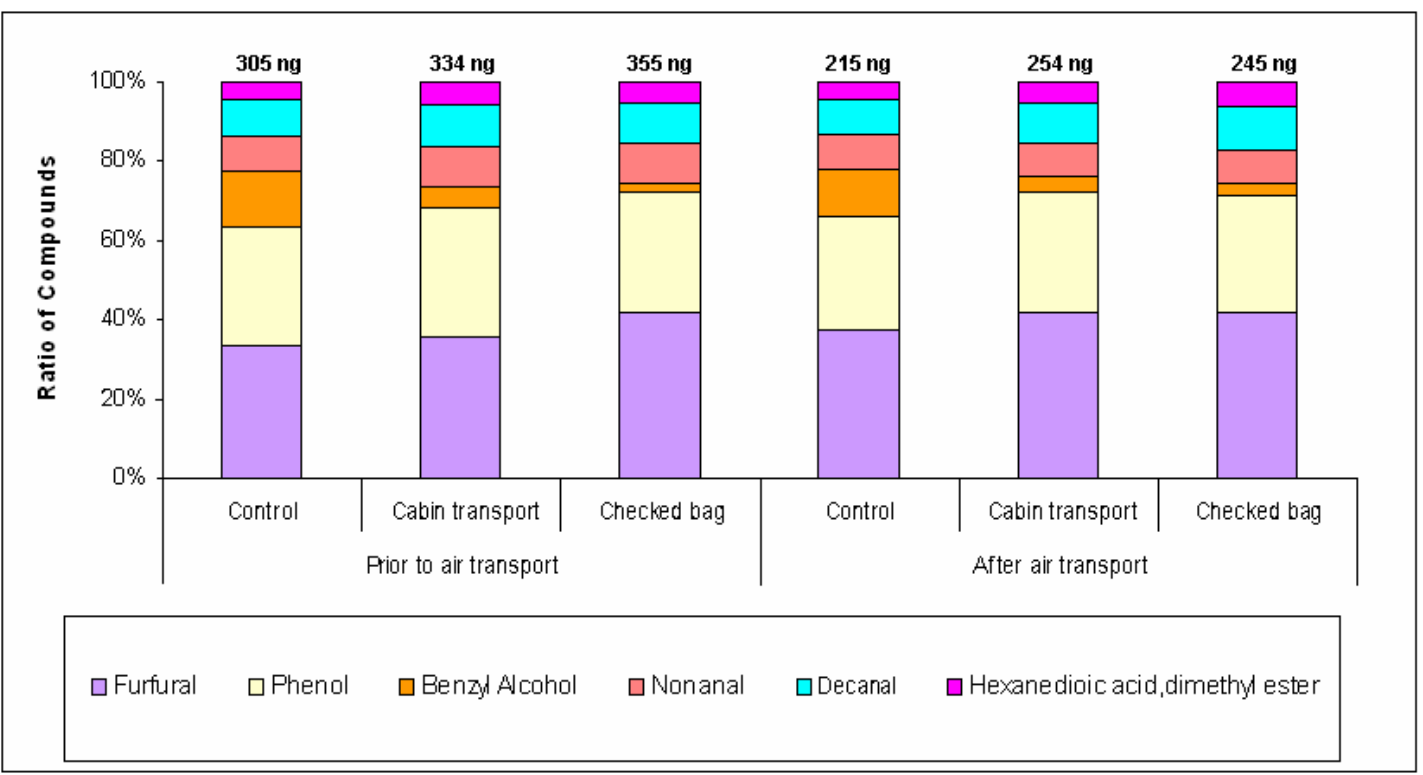


Figure 86: VOCs present in the hand odor samples collected from individuals who are easily identified by canines and individuals who are difficult for canines to identify

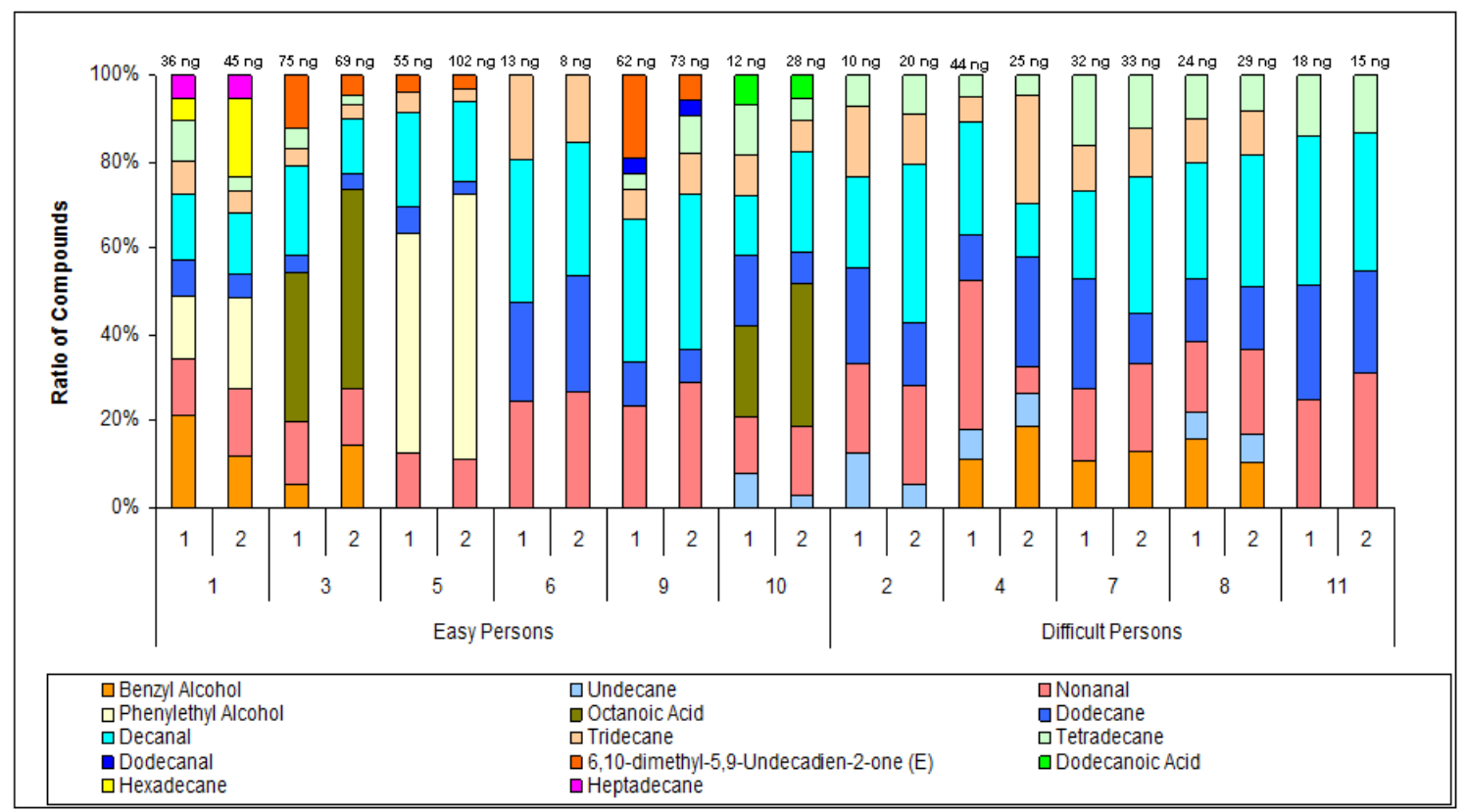

Figure 87: Recurring VOCs present in the hand odor samples collected from individuals who are easily identified by canines and individuals who are difficult for canines to identify

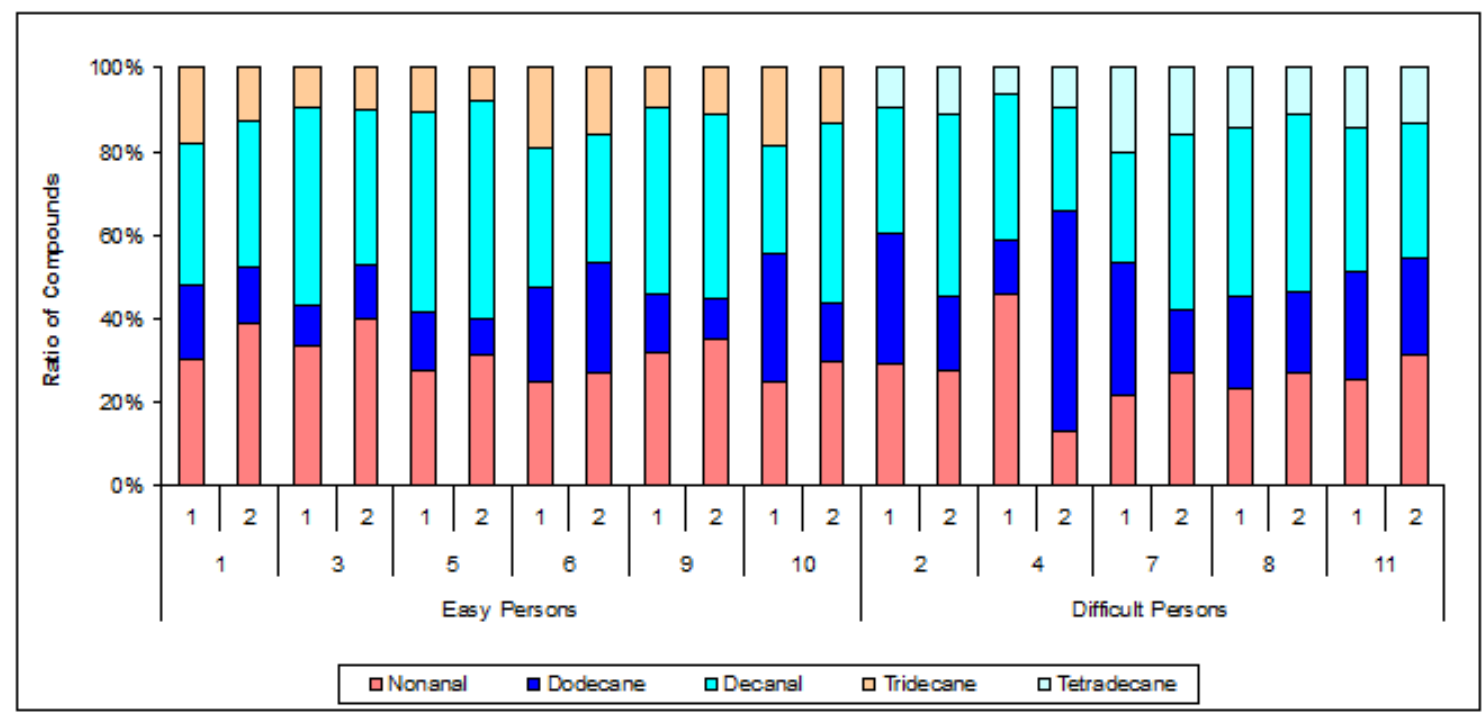


Figure 88: Average masses of VOCs present in hand odor samples collected from individuals who are easily identified by canines and individuals who are difficult for canines to identify

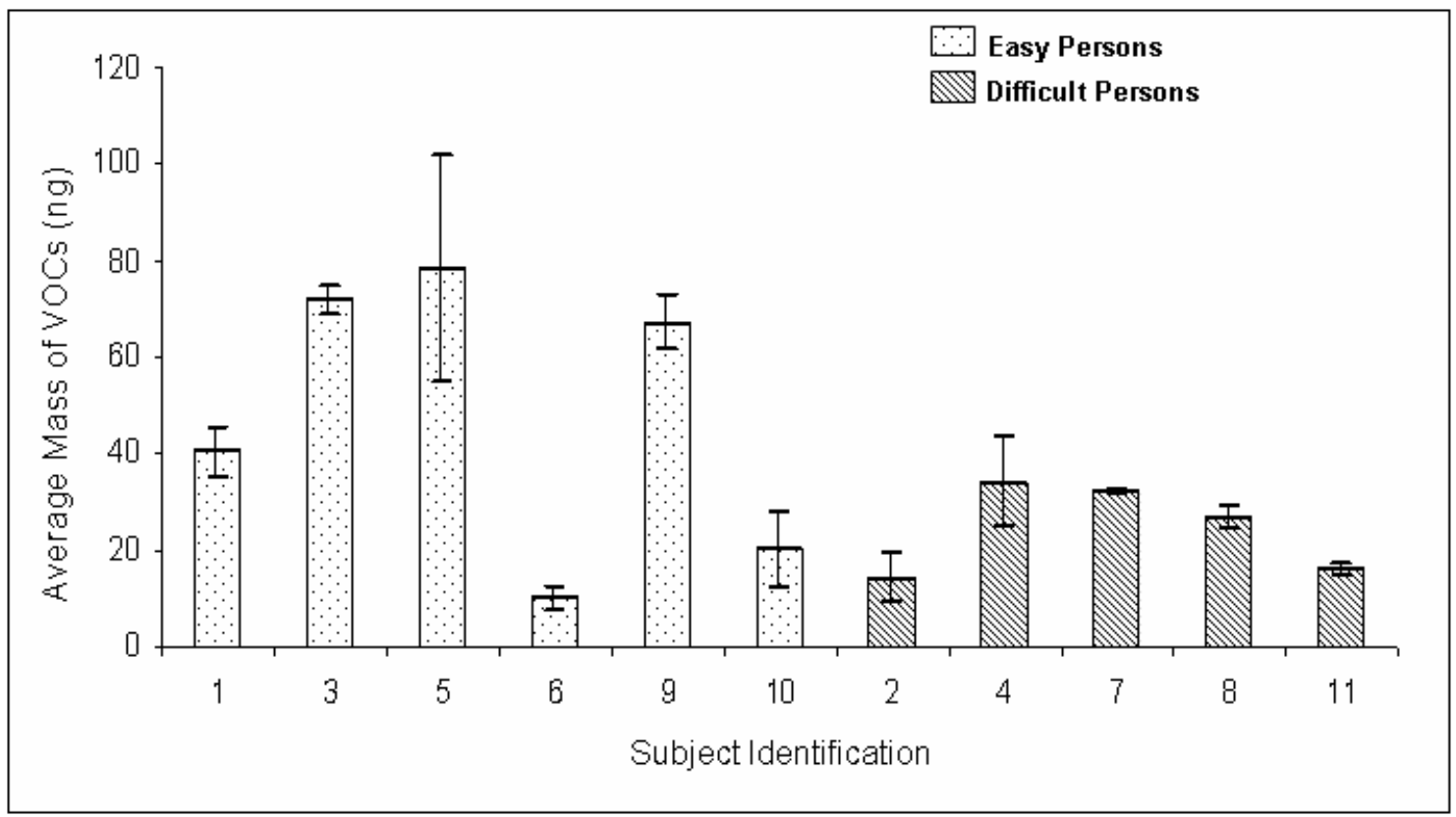

Figure 89: Correlation between average mass of VOCs and the average mass of nuclear DNA present in hand odor samples

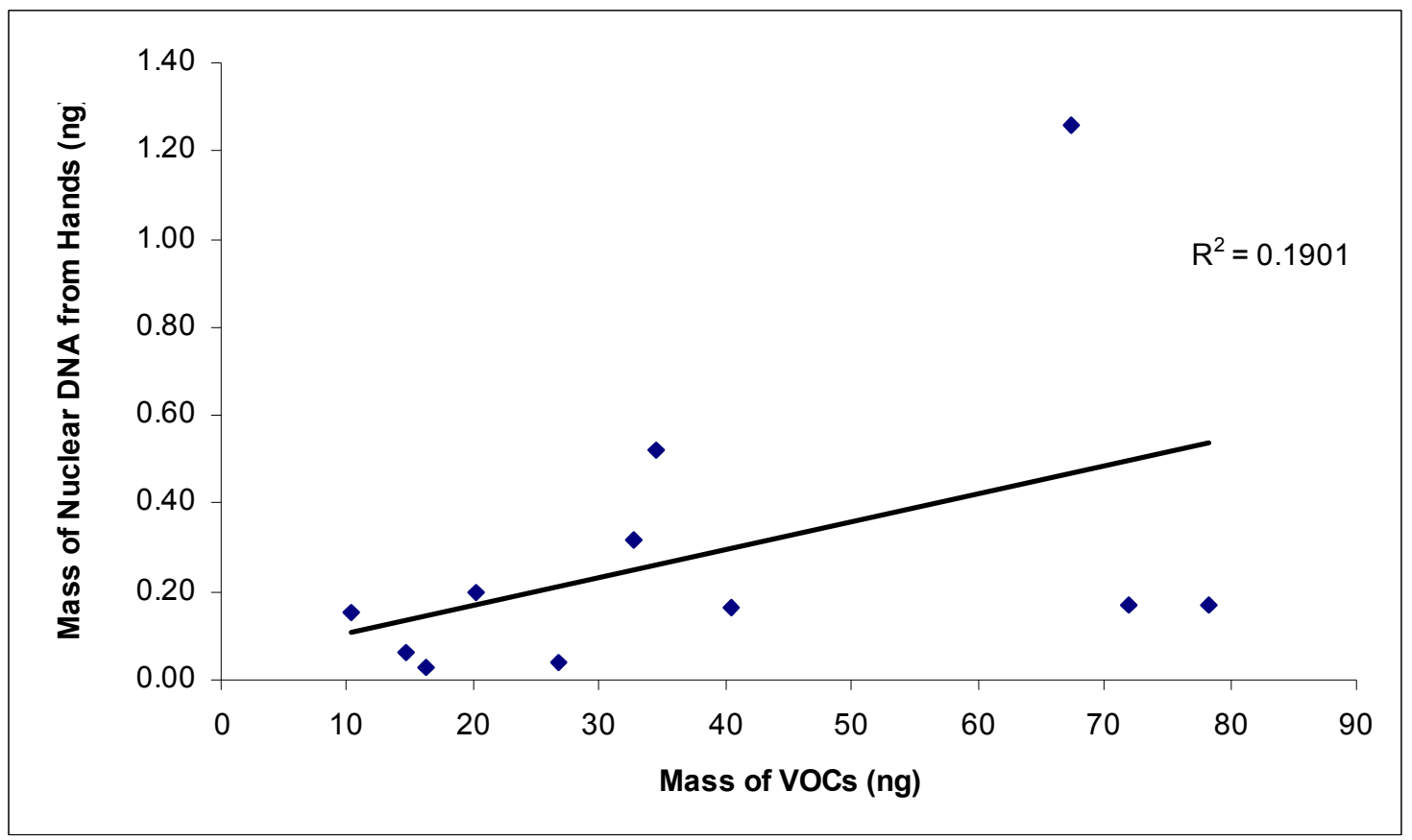


Figure 90: Correlation between average mass of VOCs and the average mass of microbial DNA present in hand odor samples

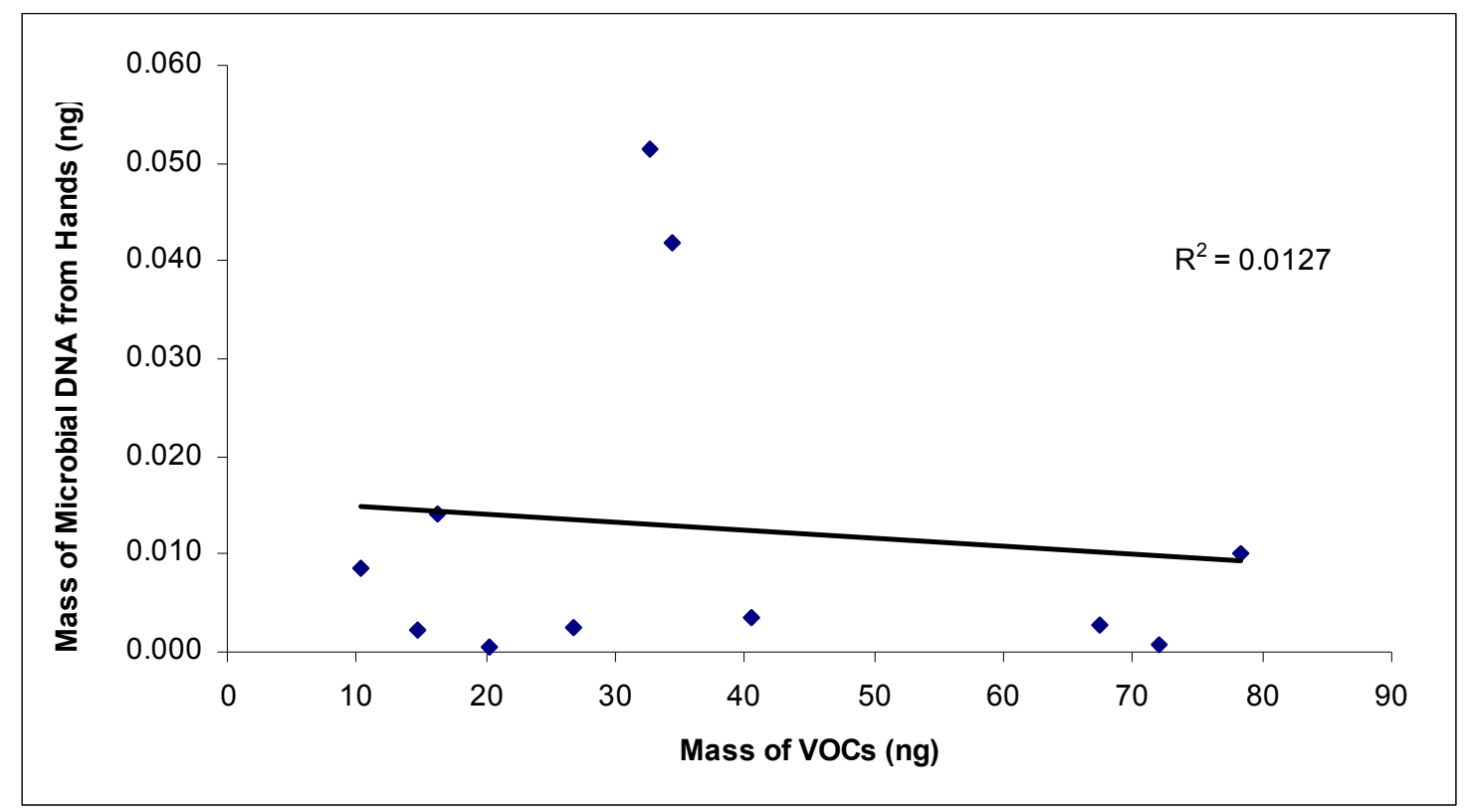

Figure 91: Correlation between average mass of nuclear DNA and the average mass of microbial DNA present in hand odor samples

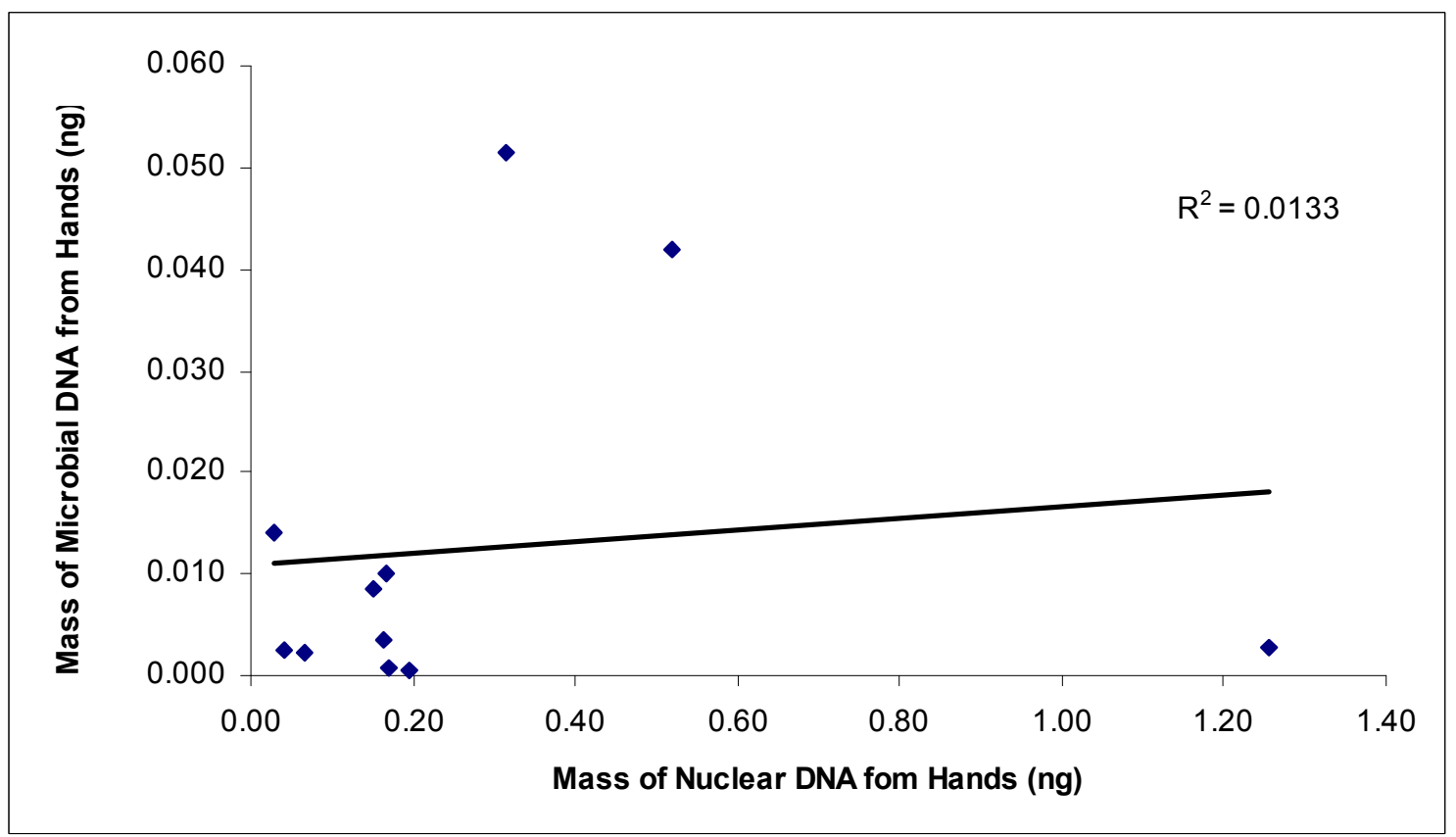




\section{Correlation between variables}

The masses of the nuclear DNA from hands, microbial DNA from hands and VOCs from hands were compared to determine if there was a correlation between each of these variables. Correlation plots were performed using Microsoft Excel and the correlation value determined from these plots. The plots show no correlation between each of the different variables suggesting that they are independent of each other (Figure 89 - Figure 91).

\subsection{Creation of Pseudo human scent}

A method was developed using the GC/MS connected to an olfactory detection port (ODP) which allowed the fractionation of a standard compound mixture comprised of 39 human scent compounds (Table 5). One microliter of the $100 \mathrm{ppm}$ standard mixture was injected onto the GC column via an auto sampler. Twenty percent of the sample was directed to the mass spectrometer while the remaining 80 percent was directed to the ODP where the various fractions were collected onto Dukal brand gauze. Once the collection material was placed on the opening of the ODP, the opening of the ODP was covered with aluminum foil to ensure that all the compounds would be trapped onto the material. The fractions were collected at 6.19 - 11.39 minutes (fraction \#1), 11.41 15.94 minutes (fraction \#2), 16.00 - 21.07 minutes (fraction \#3) and 21.16 - 26.00 minutes (fraction \#4). Once collected, the fractions were sealed into $10 \mathrm{ml}$ glass vials, equilibrated for 24 hours and then subjected to a 21 hour headspace SPME extraction.

Fractionation of a standard sample mix produced results which were promising with fractions one and two showing discrete sets of compounds associated with different 
regions of a sample chromatogram. Fraction three had a few compounds while fraction four did not have any of the higher molecular weight compounds which were expected to be seen (Figure 92). Despite the promising results, the experiments using the GC/MS connected to the ODP had to be discontinued. This was because the connection between the GC/MS and the ODP resulted in elevated quantities of air being introduced into the MS system as the ODP is open to the atmosphere resulting in a gradual reduction in sensitivity of the GC/MS.

Figure 92: Overlaid chromatograms showing fractioned samples of a standard compound mixture obtained using a GC/MS connected to an ODP

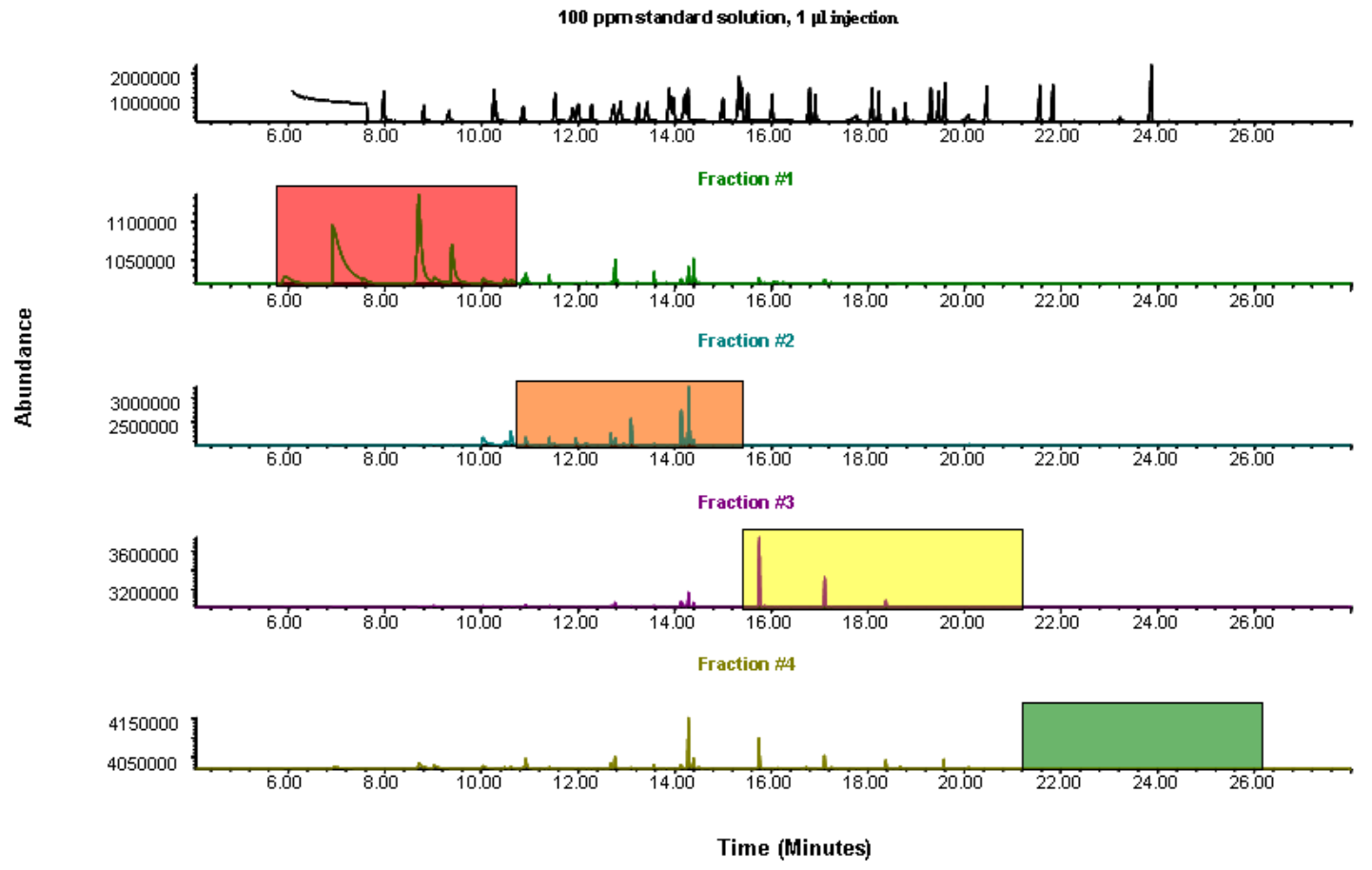

Since the GC/MS connected to the ODP could no longer be used, a megabore capillary column which has the same stationary phase and phase ratio as the previous column used for GC/MS analyses, was procured and installed in a gas chromatograph flame ionization detector instrument (5890 GC/FID). Two microliters of a $200 \mathrm{ppm}$ standard compound 
mixture was injected into the GC-FID to ensure that the compounds of interest could be efficiently separated (Figure 93). Based on the separations that were obtained using the GC/FID, it was decided that the fractions would be collected at $4.00-10.50$ minutes (fraction \#1), 10.50 - 16.00 minutes (fraction \#2), 16.00 - 20.00 minutes (fraction \#3) and $20.00-28.00$ minutes (fraction \#4).

For the collection of the fractions, the FID was turned off (so that the sample would not be pyrolyzed) and a $10 \mathrm{ml}$ glass vial containing a pre-cleaned gauze placed directly above the FID opening (hydrogen and air were not flowing only helium) (Figure 94).

With the initial GC/FID trials, discrete fractions were not obtained (Figure 95). It was assumed that enough of the VOCs were not being trapped onto the gauze pad. In an effort to ensure that the majority of the VOCs were being trapped by the gauze pad, the GC column length was adjusted to within $3 \mathrm{~cm}$ of the "FID opening." In order to do this, the FID was disassembled by removing the parts shown in Figure 96.

Figure 93: Chromatogram showing the separation of human scent compounds using the 5890 GC/FID

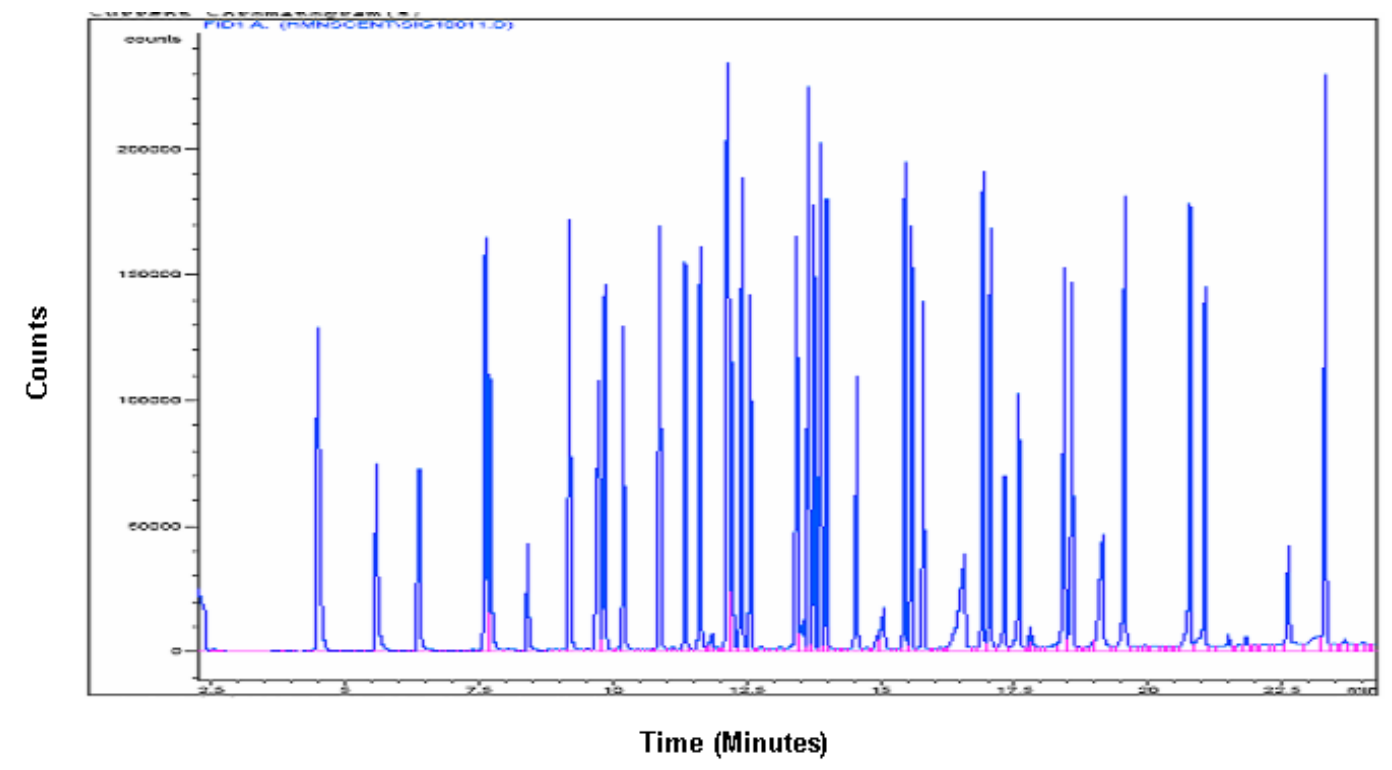


Figure 94: Schematic showing collection of fractions using the GC/FID

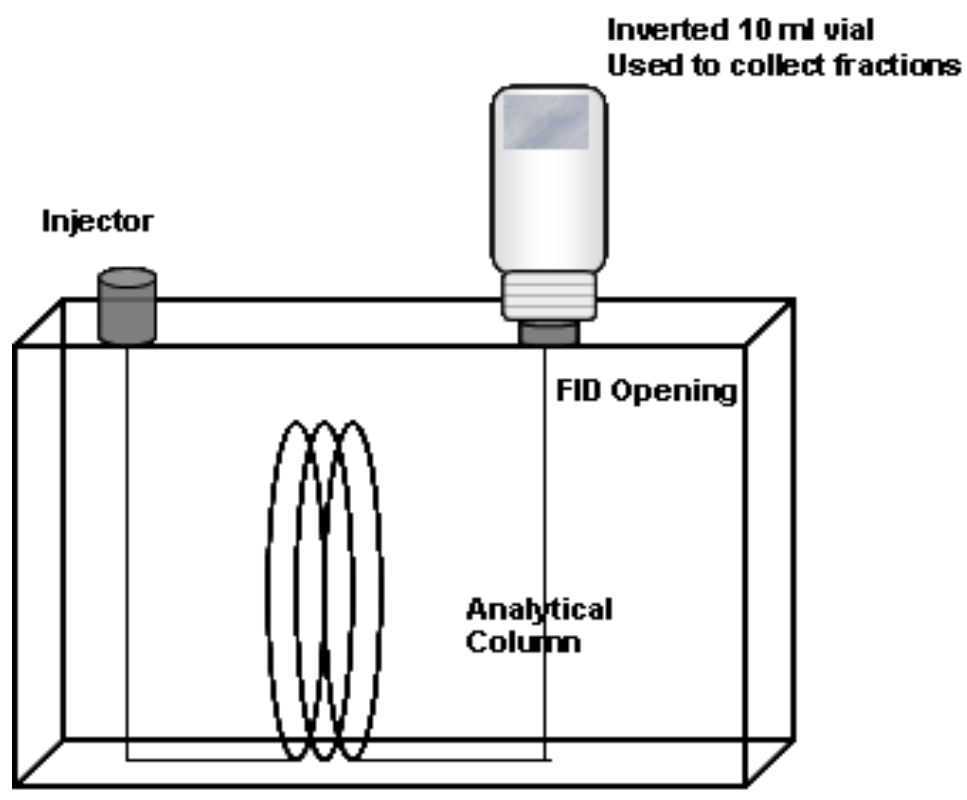

Figure 95: Overlaid chromatograms showing fractioned samples of a standard compound mixture obtained using a GC/FID followed by SPME-GC/MS analysis
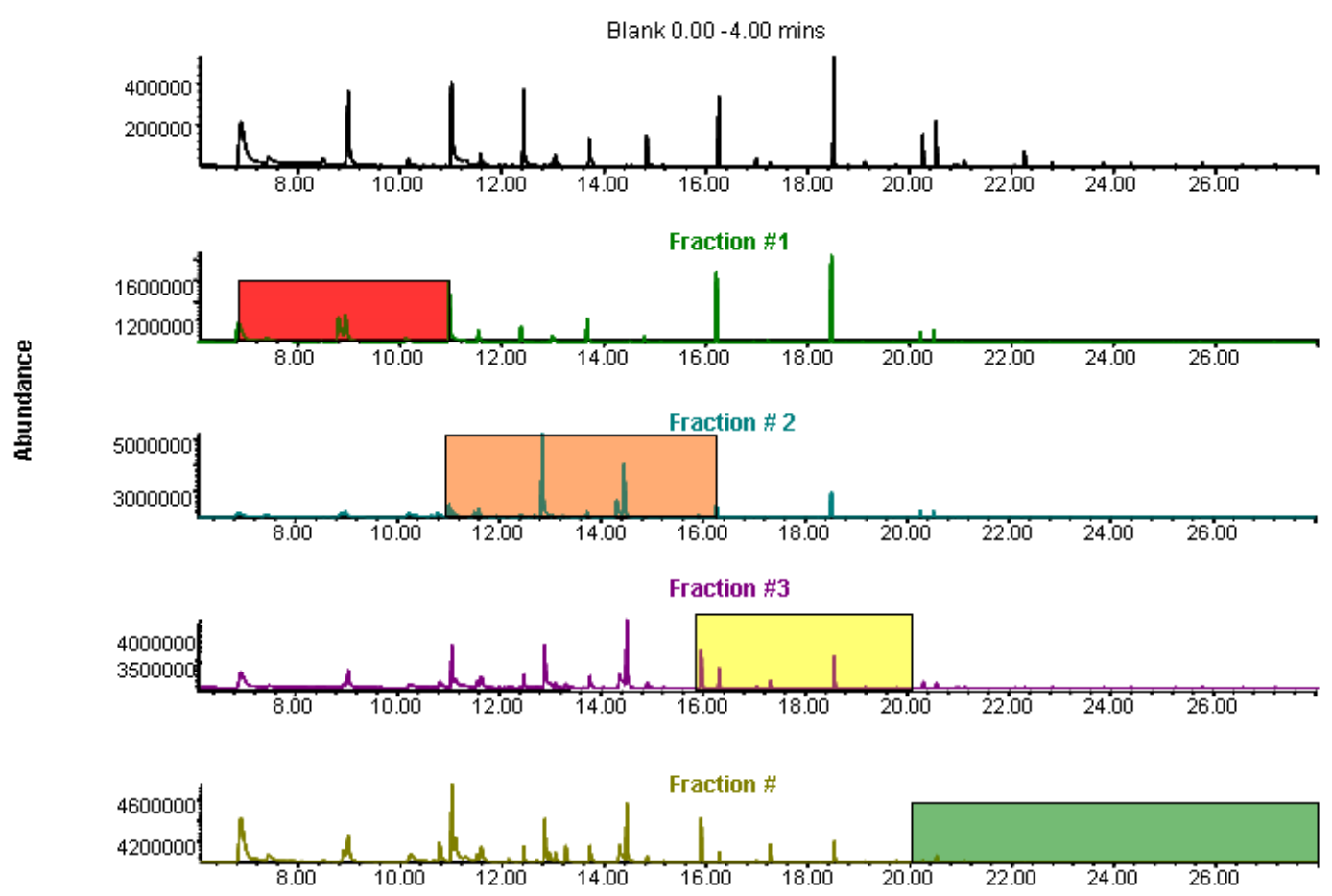

Time (Minutes) 
Figure 96: Parts removed from FID to facilitate maximum trapping of VOCs onto gauze for fractionation

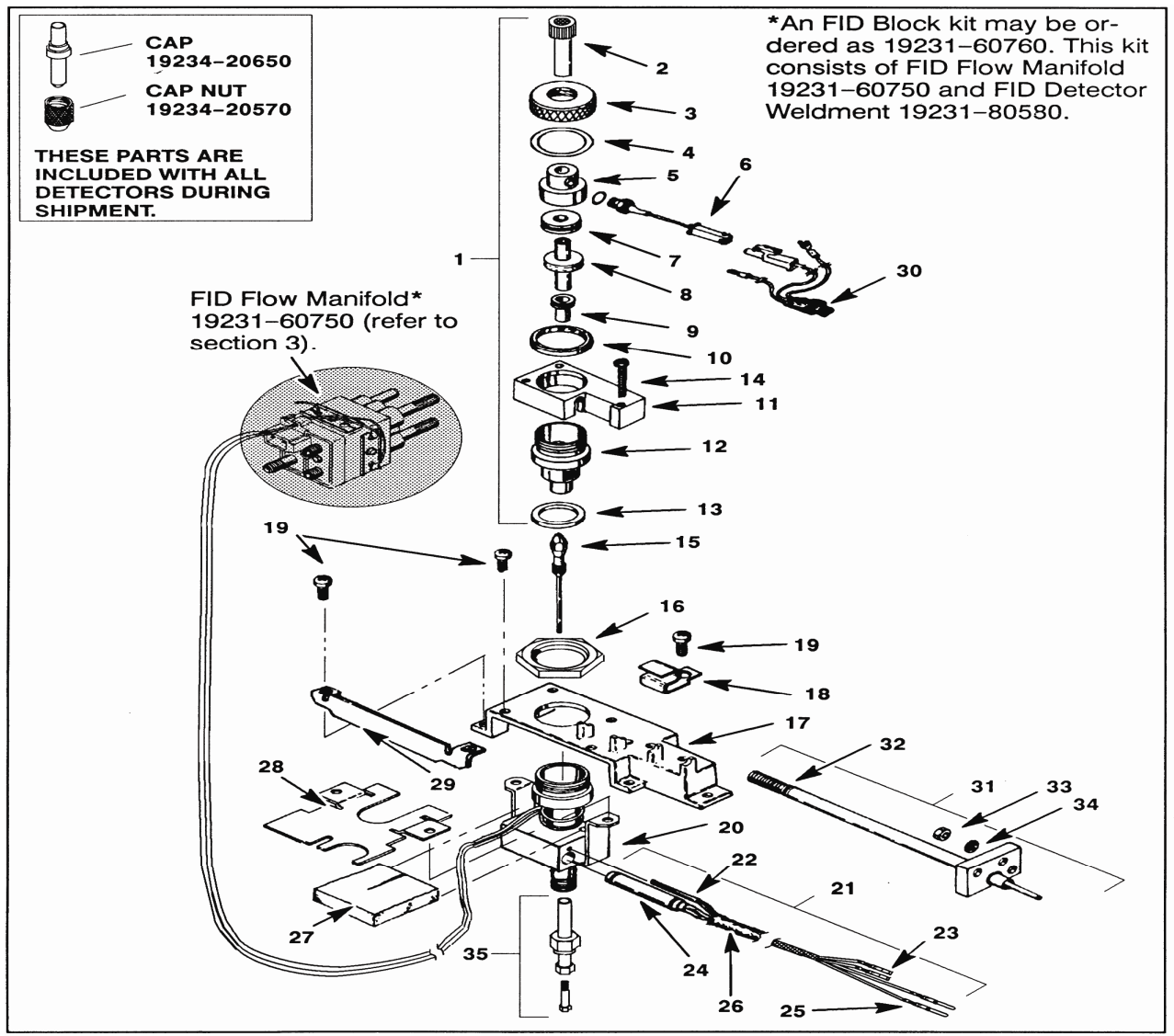

* Diagram obtained from www.agilent.com

*The parts removed were numbers 3 (collector nut), 5 (ignitor castle), 6 (ignitor glow pug assembly), 7 (upper collector insulator), 8 (collector body) and 15 (Jets).

The samples collected included a negative control, positive control and four fractions. The negative control involved allowing the helium gas to flow while the $10 \mathrm{ml}$ glass vial containing the pre-cleaned gauze was inverted above the opening of the FID (no sample was injected). The negative control was collected for the duration of the analysis (28 minutes). The positive control involved injecting $2 \mu 1$ of a $200 \mathrm{ppm}$ standard compound mixture onto the GC column; a $10 \mathrm{ml}$ glass vial containing a pre-cleaned Dukal gauze was placed directly over the opening of the FID and the sample collected for the duration 
of the analysis. This procedure was repeated for the collection of the fractions with each fraction being collected at the respective times. The samples were allowed to equilibrate for 24 hours then analyzed by SPME-GC/MS to determine if discrete fractions were obtained. Discrete fractions were obtained using liquid injections (Figure 97).

Figure 97: Overlaid chromatograms showing fractioned samples of a standard compound mixture obtained using a GC/FID (FID disassembled) followed by SPME-GC/MS analysis

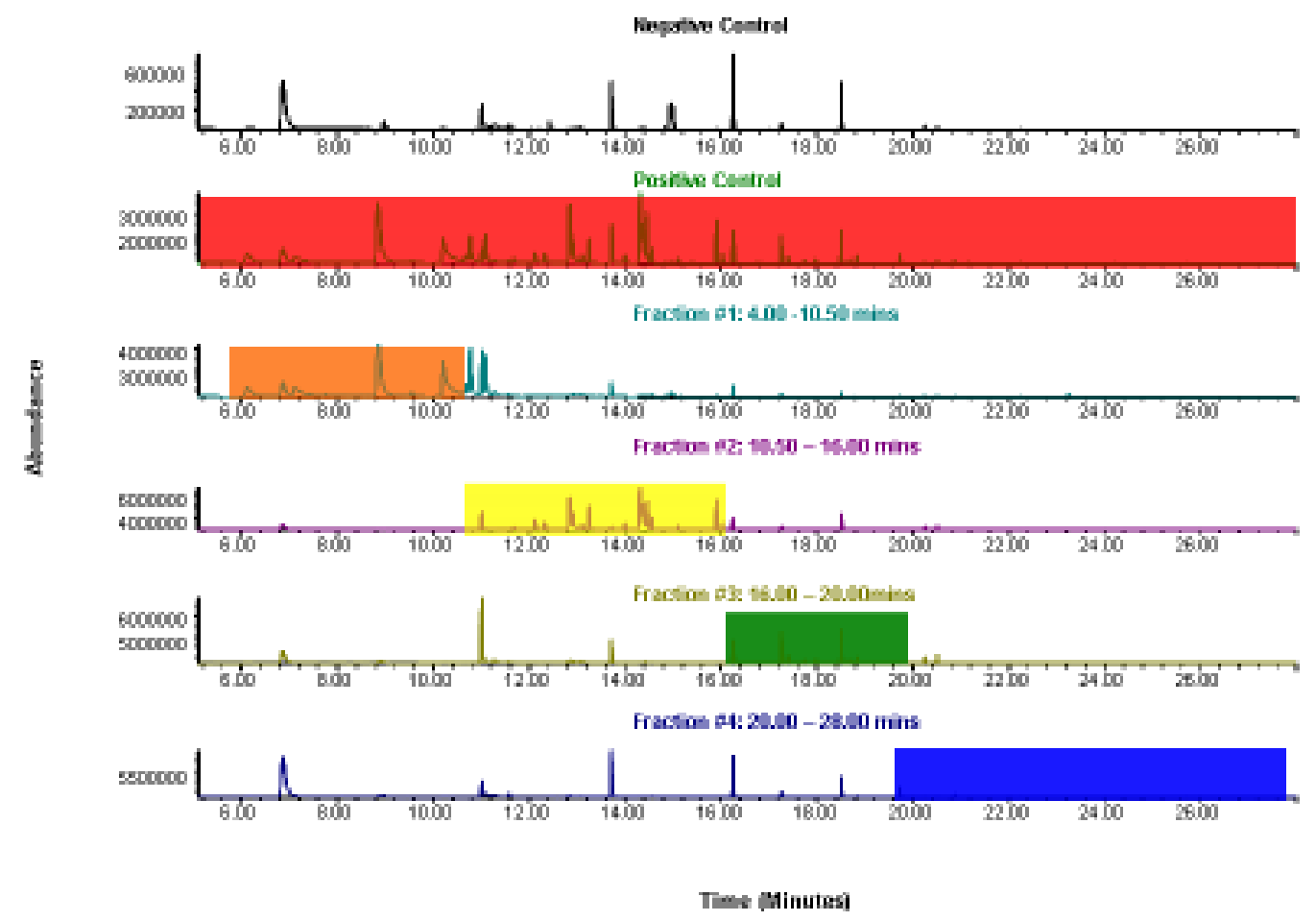

Having obtained discrete fractions using liquid injections, the next step was to obtain discrete fractions from the injection of VOCs onto the GC/FID. A comparison was made between introduction of VOCs using the 7694 static headspace sampler that is attached to the GC/FID and SPME-HS injections. The various parameters for the headspace analyzer had to be optimized to determine which parameters resulted in the most VOCs detected by the FID. The initial method which was tried included a transfer line temperature of 
$200{ }^{\circ} \mathrm{C}$, an oven temperature of $45{ }^{\circ} \mathrm{C}$, a sample loop temperature of $60{ }^{\circ} \mathrm{C}$, a GC cycle time of 34 minutes, vial equilibration time of 30 minutes, vial pressurization time of 0.1 minutes, loop fill time and injection time of 0.3 minutes, carrier pressure of $7.7 \mathrm{psi}$ and vial pressure of 19.9 psi. The vials initially used were $20 \mathrm{ml}$ glass vials. The results obtained gave a maximum count of 1200 (Figure 98). In an effort to increase the VOCs being detected, the oven temperature for the headspace sampler was increased to $105{ }^{\circ} \mathrm{C}$ giving a maximum count of 2000 (Figure 99). The vial size was also decreased to $10 \mathrm{ml}$ to after which the purge time was set to zero. The maximum counts obtained were 3000 and 4000 (Figure 100 and Figure 101 respectively).

Figure 98: Chromatogram showing human scent VOCs detected by GC/FID after injection by headspace sampler (initial trial)

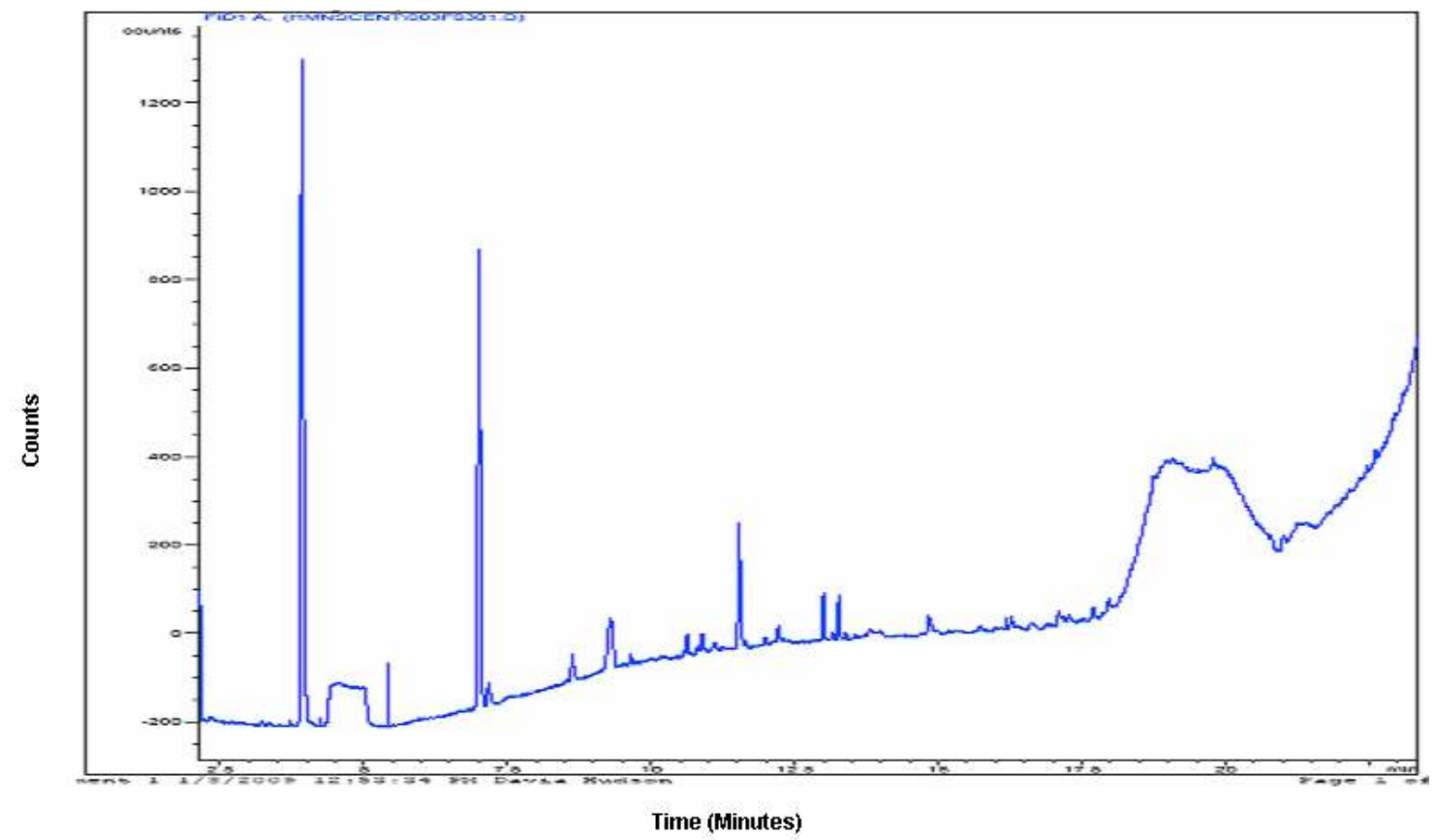


Figure 99: Chromatogram showing human scent VOCs detected by GC/FID after injection by headspace sampler (headspace sampler oven temperature increased)

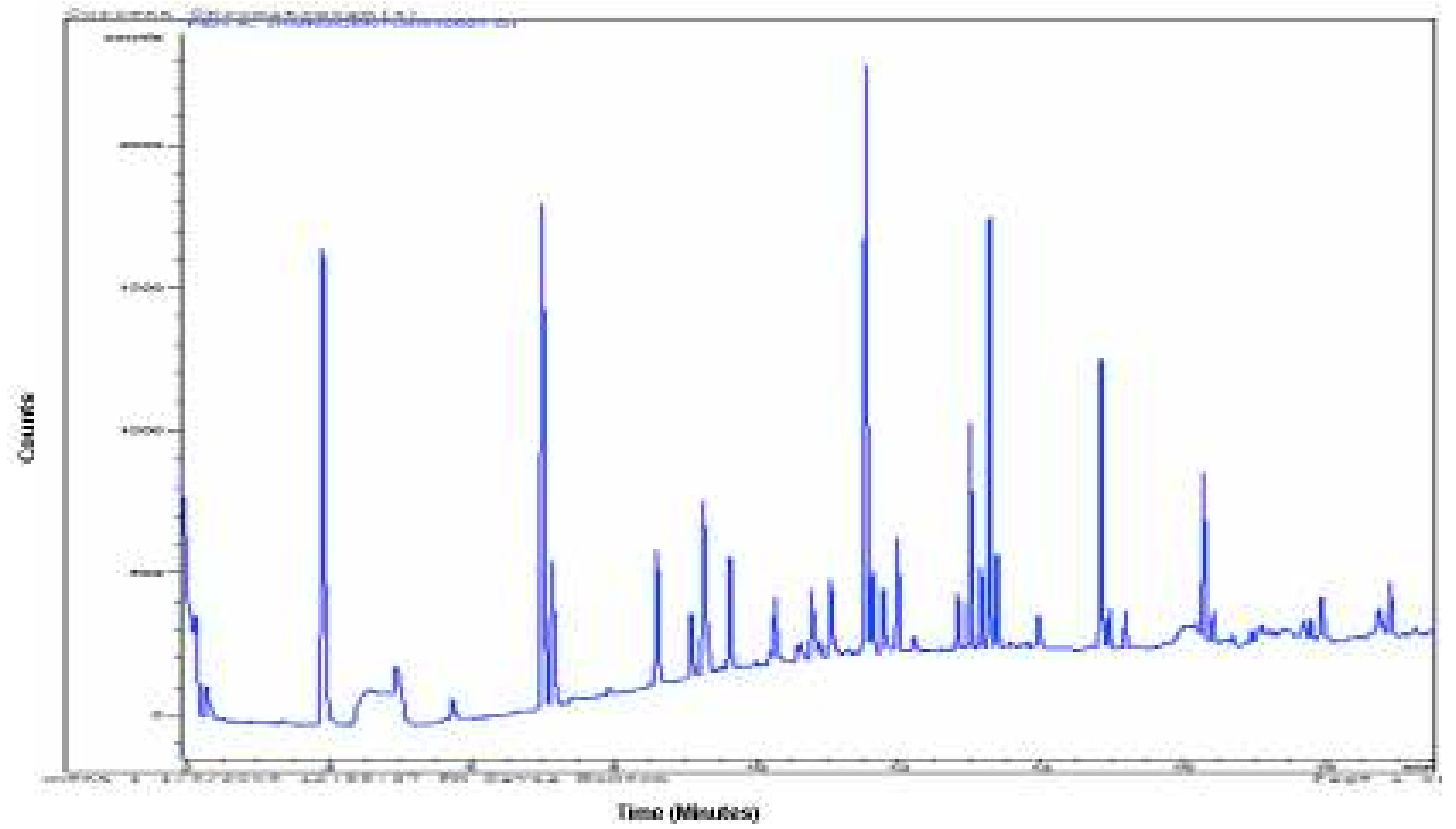

Figure 100: Chromatogram showing human scent VOCs detected by GC/FID after injection by headspace sampler $(20 \mathrm{ml}$ glass vials replaced by $10 \mathrm{ml}$ glass vials $)$

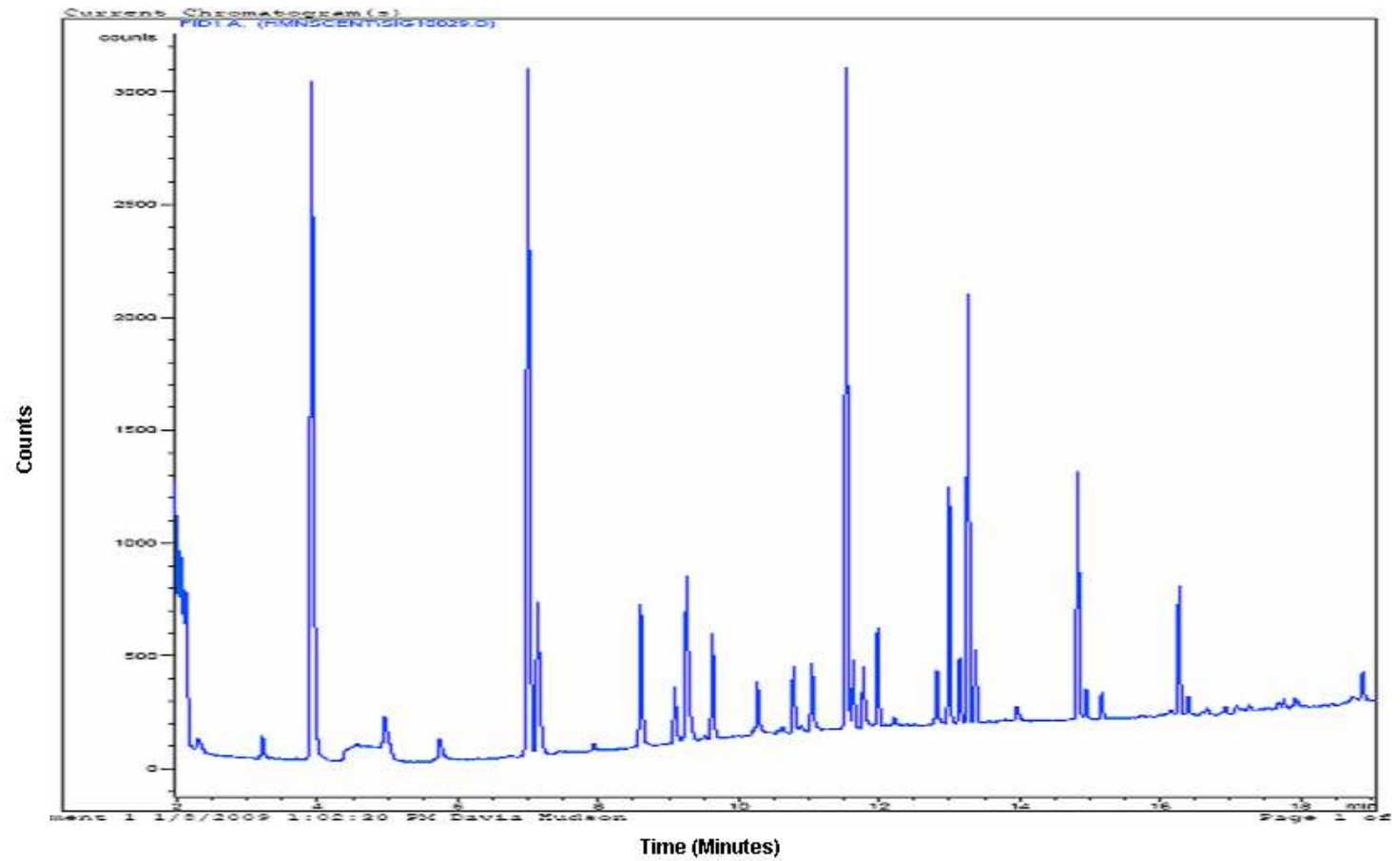


Figure 101: Chromatogram showing human scent VOCs detected by GC/FID after injection by headspace sampler (purge off)

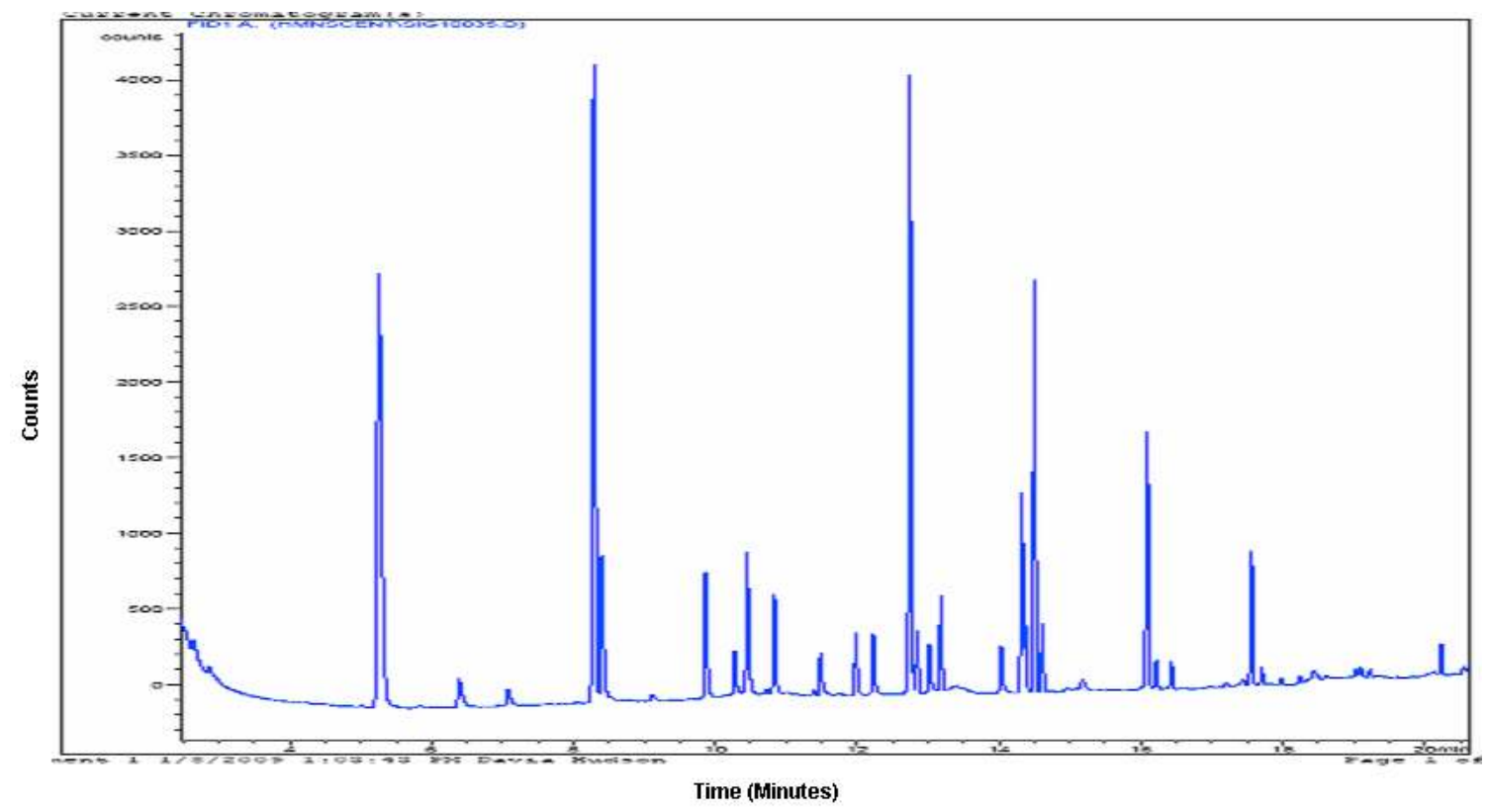

Once the count obtained was 4000 , attempts to change the other parameters proved futile as the counts did not drastically changes. The optimum parameters for transfer of volatiles into the FID using the headspace sampler included; a transfer line temperature of $200{ }^{0} \mathrm{C}$, an oven temperature of $105{ }^{\circ} \mathrm{C}$, a sample loop temperature of $60{ }^{0} \mathrm{C}$, a GC cycle time of 34 minutes, vial equilibration time of 30 minutes, vial pressurization time of 0.1 minutes, loop fill time and injection time of 0.3 minutes, carrier pressure of 7.7 psi and $10 \mathrm{ml}$ glass vials with a pressure of 19.9 psi.

For the headspace sampler injections, $2 \mu 1$ of a 200 ppm standard mixture was spiked into $10 \mathrm{ml}$ glass vials allowed to equilibrate for 24 hours then the VOCs extracted using the headspace sampler and introduced into the GC/FID. For the SPME injections, $2 \mu 1$ of a $200 \mathrm{ppm}$ standard mixture was spiked into $10 \mathrm{ml}$ glass vials allowed to equilibrate for 24 hours followed by a 21 hour SPME extraction. The SPME fiber was then introduced into 
the GC/FID. The area counts obtained for both methods were compared and it was determined that the SPME injections produced greater area counts than the headspace sampler (Figure 102). The maximum count obtained using the headspace sampler was 4000 while using the established SPME method, the maximum count obtained was 100000. All subsequent extractions and introduction of the VOCs into the GC/FID were performed using the established SPME method.

Having determined that SPME extractions resulted in more compounds reaching the detector, 21 hour SPME extractions of gauzes spiked with human scent standard compounds were conducted. Single and triple SPME injections were performed into the FID and the samples sets collected. The results show that the triple SPME injections result in slightly greater numbers of compounds being obtained. Only the positive control and the fractions were performed in triplicates; the negative control was not.

The optimized procedure for the fractionation of VOCs using the GC/FID was applied to hand odor samples. The collected fractions were analyzed using SPME-GC/MS and the GC/MS analysis performed in SIM mode to obtain discrete fractions. Samples were initially collected onto the Dukal brand gauzes but were changed to collection on the Johnson and Johnson brand as the results obtained in section 4.3 showed that this material released the compounds more readily than the Dukal brand gauze. The fractions collected using the Johnson and Johnson brand gauze were more prominent than the fractions collected on the Dukal brand gauze (Figure 105 - Figure 107). The results show that through the use of instrumental analyses, human scent samples can be separated into fractions which can be used to determine if human scent canines require entire VOC profiles or specific VOCs to produce a match. 
Figure 102: Comparison between area counts obtained when VOCs were introduced into GC/FID using a headspace sampler and SPME

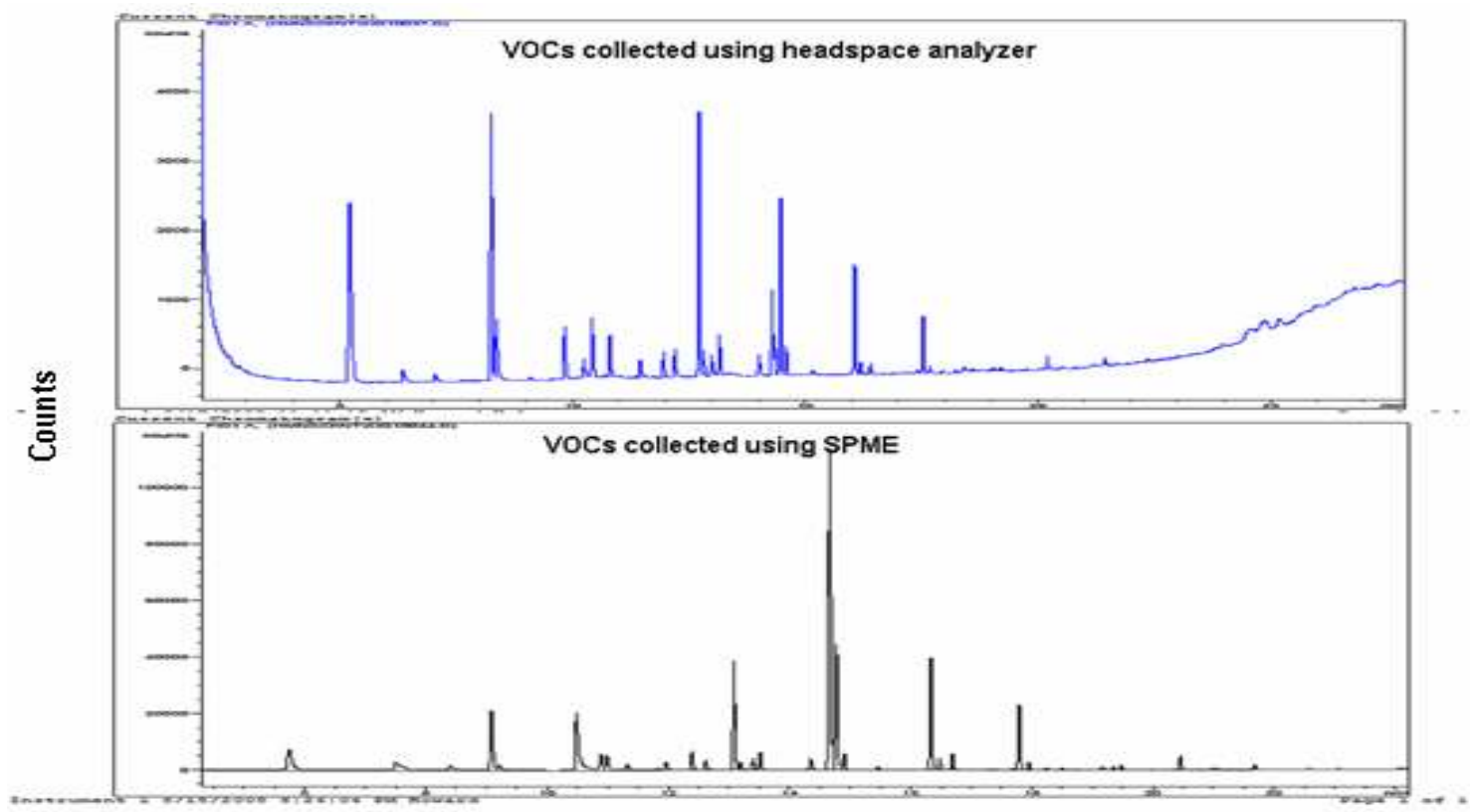

Time (Minutes)

Figure 103: Fractions collected on Dukal brand gauze from single SPME injection onto GC/FID followed by SPME-GC/MS

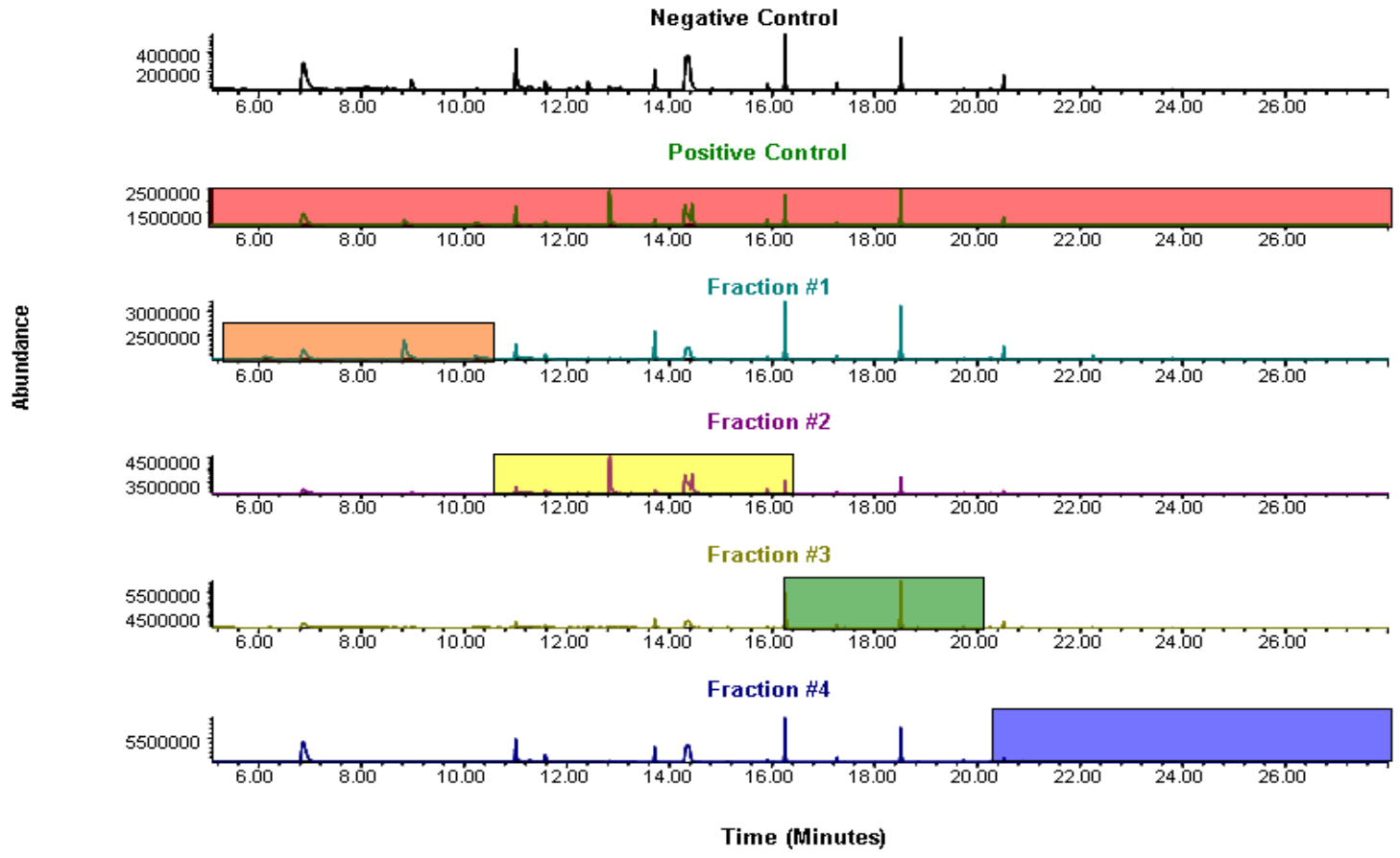


Figure 104: Fractions collected on Dukal brand gauze from triple SPME injection onto GC/FID followed by SPME-GC/MS

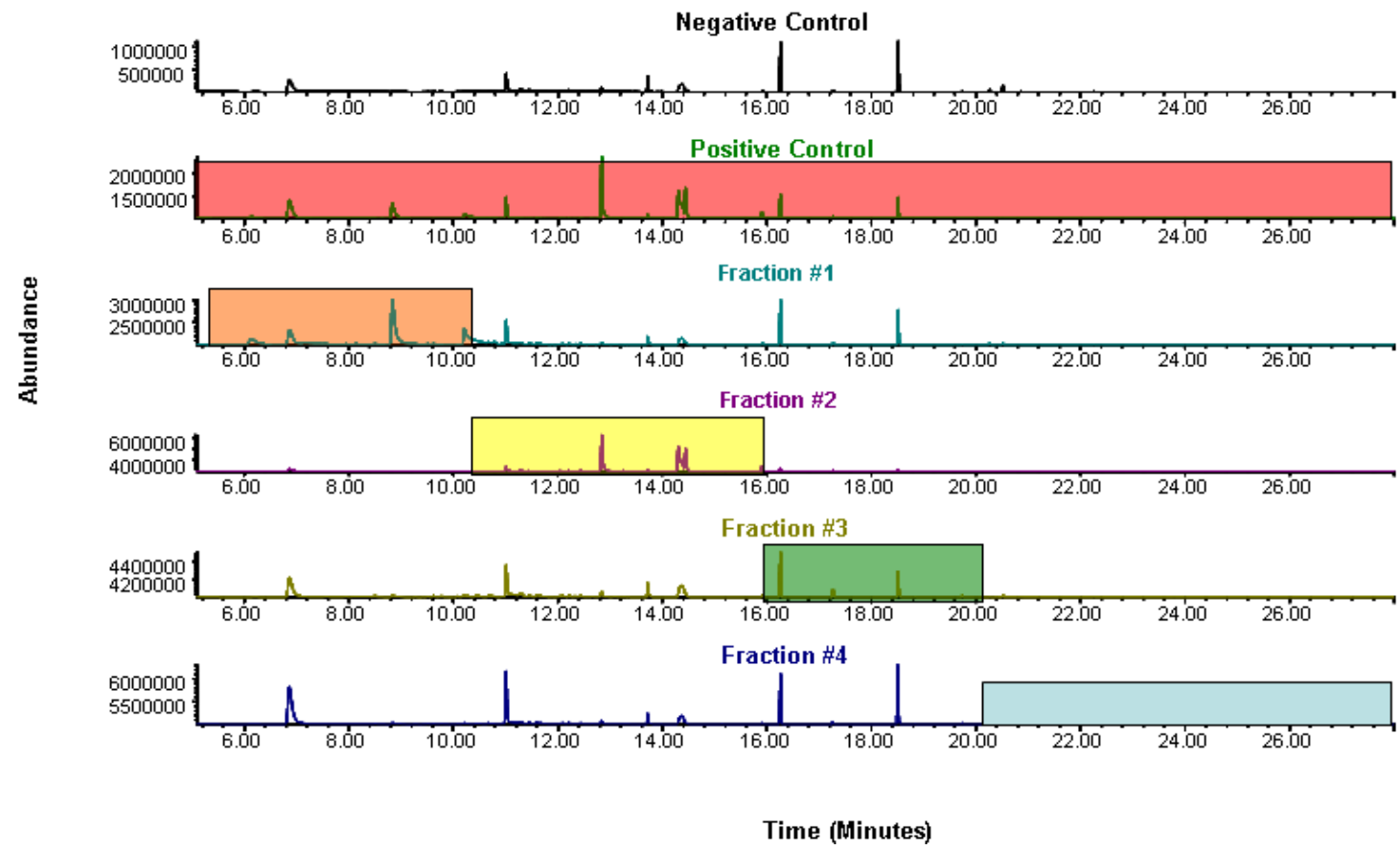

Figure 105: Hand odor sample collected from a female subject, fractioned using GC/FID and collected on Dukal brand gauze followed by SPME-GC/MS analysis

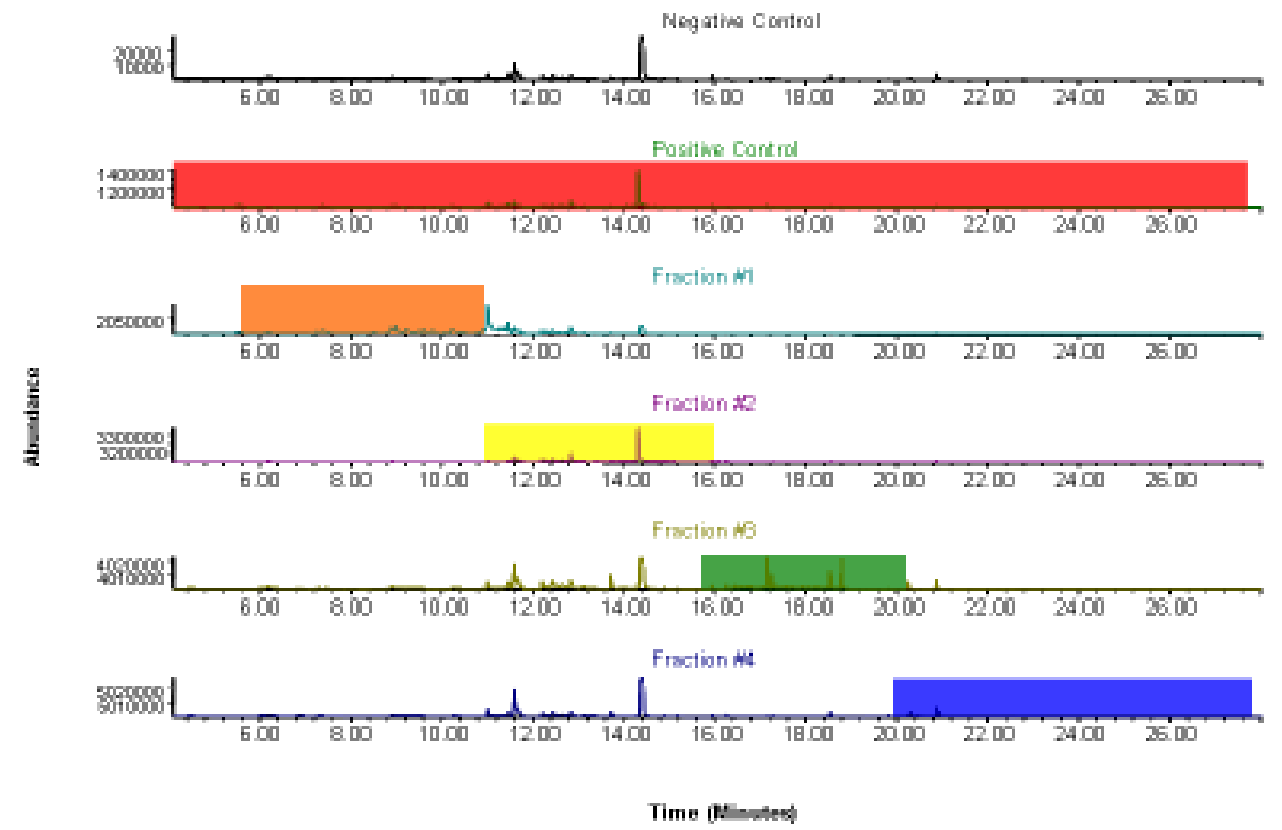


Figure 106: Hand odor sample collected from a male subject, fractioned using GC/FID and collected on Johnson and Johnson brand gauze followed by SPME-GC/MS analysis

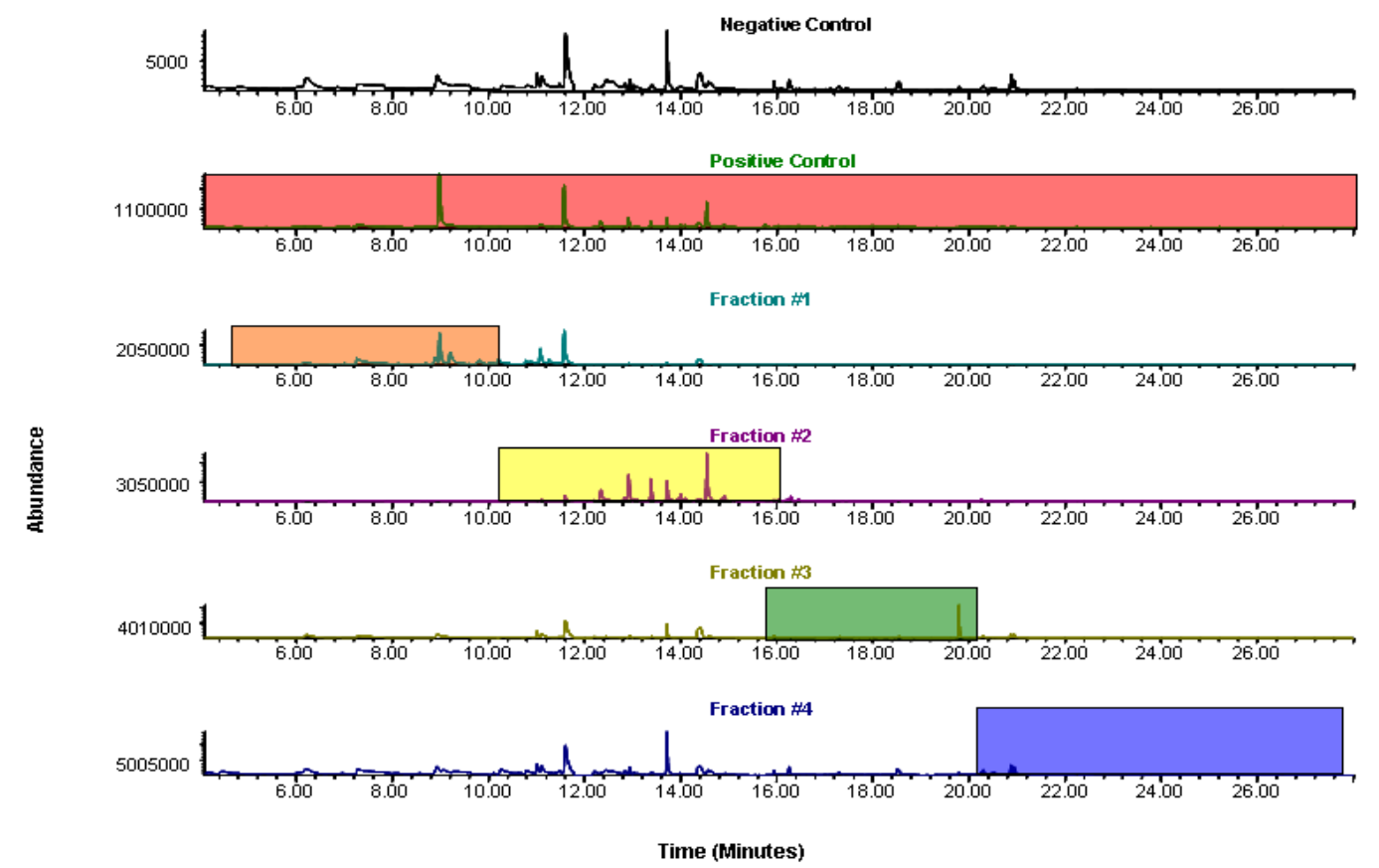

Figure 107: Hand odor sample collected from a female subject, fractioned using GC/FID and collected on Johnson and Johnson brand gauze followed by SPME-GC/MS analysis

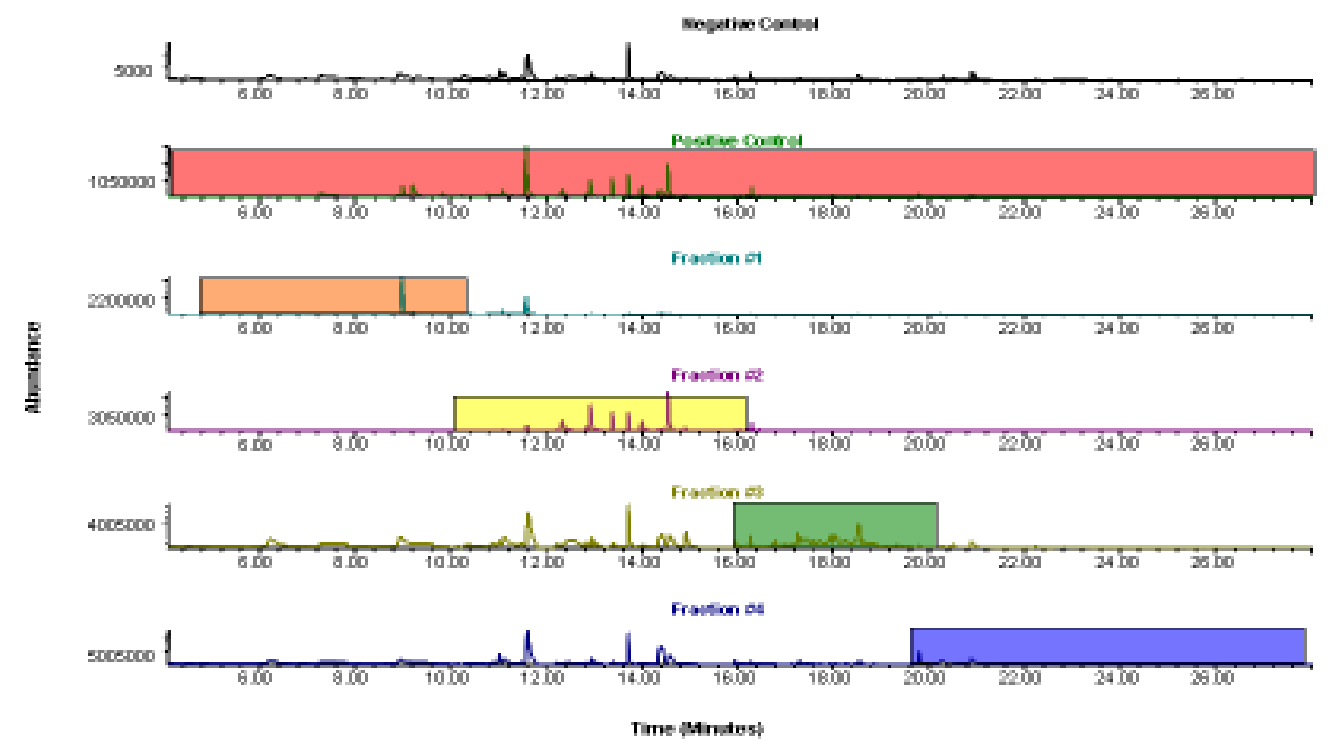


4.7. Discriminating between the hand odor of monozygotic and dizygotic twins using SPME-GC/MS

Studies have demonstrated that specially trained canines can identify persons by the chemical components of his or her unique odor. In the case of twins, however, studies have shown that while canines can readily discriminate between dizygotic (DZ) twins they have difficulty discriminating between monozygotic (MZ) twins. In this experiment, scent from three sets of co-habitating DZ twins and three sets of co-habitating MZ twins were tested using Solid Phase Micro Extraction Gas Chromatography Mass Spectrometry (SPME-GCMS) to determine if twins could be discriminated based on their scent.

Comparisons which were made between the hand odor profiles of the DZ twin sets and the MZ twin sets showed that the there were greater differences in the VOCs of the hand odor profiles of the DZ twin sets than the MZ twin sets. The data were analyzed using Bray-Curtis similarity which showed greater similarity between the VOCs of MZ twins than the VOCs of DZ twins. The greatest similarity seen between a set of the DZ twins was 67 percent while between a set of MZ twins, the similarity was as great as 86 percent (Figure 108 - Figure 119).

Researchers have theorized that odor similarities in twins could be attributed to shared environmental factors rather than direct genetic effect (43). This study was conducted with twin sets that were all cohabiting resulting in their environmental influences such as diet and social status being extremely similar. Despite these environmental similarities, differences between hand odor samples collected from the twin sets were determined. As greater differences were observed between the $\mathrm{DZ}$ twins than the $\mathrm{MZ}$ twins, these results are suggesting that odor could be more influenced by genes rather than environmental 
factors. Since no two individuals are identical in their MHC genes except for identical twins, if VOCs comprising odor is indeed controlled by these genes, it is expected that greater differences should be seen in the $\mathrm{DZ}$ twins as compared to MZ twins.

Figure 108: VOCs present in hand odor samples collected from a DZ boy and girl twin

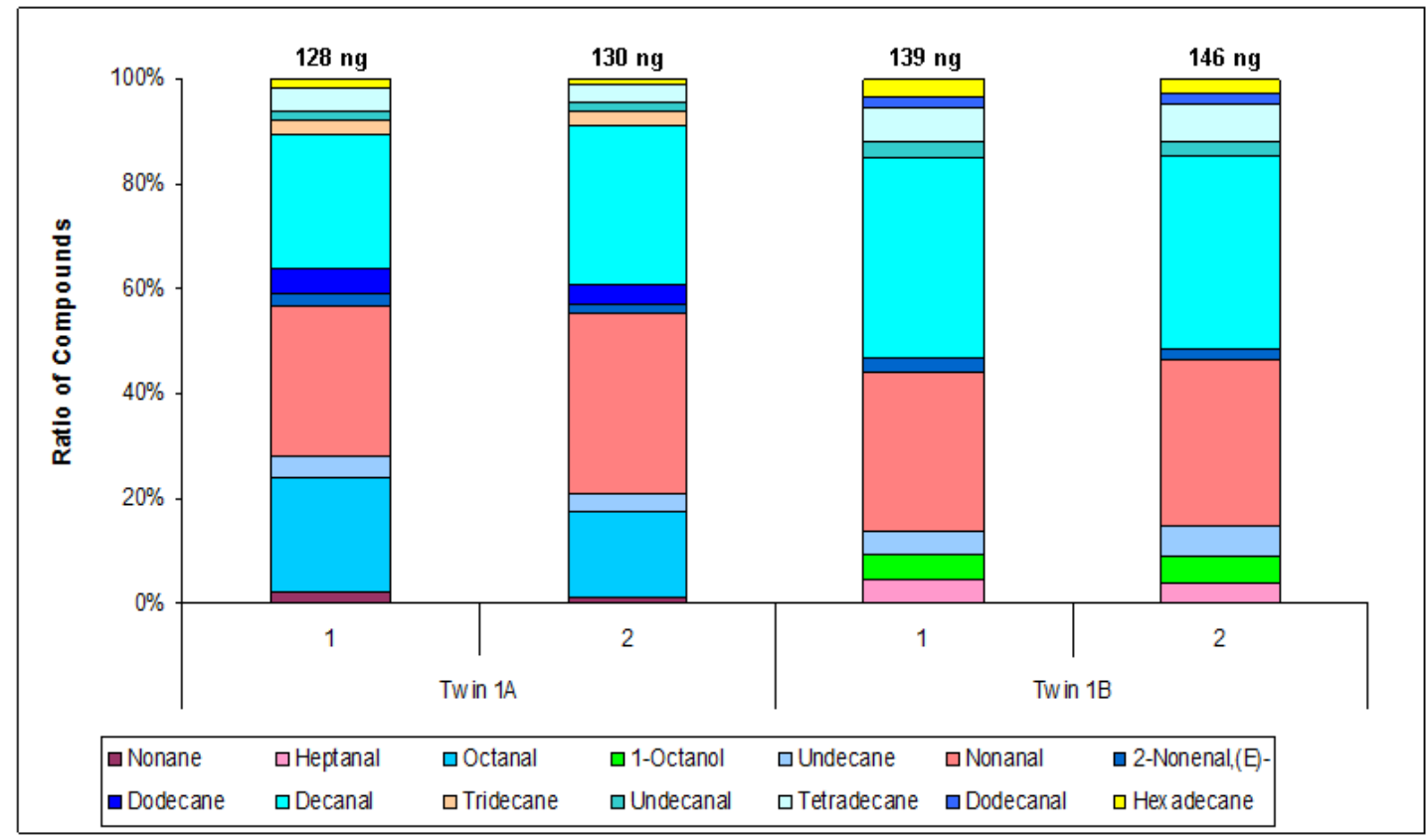

Figure 109: Dendrogram showing Bray Curtis Similarity between VOCs present in hand odor samples collected from a DZ boy and girl twin

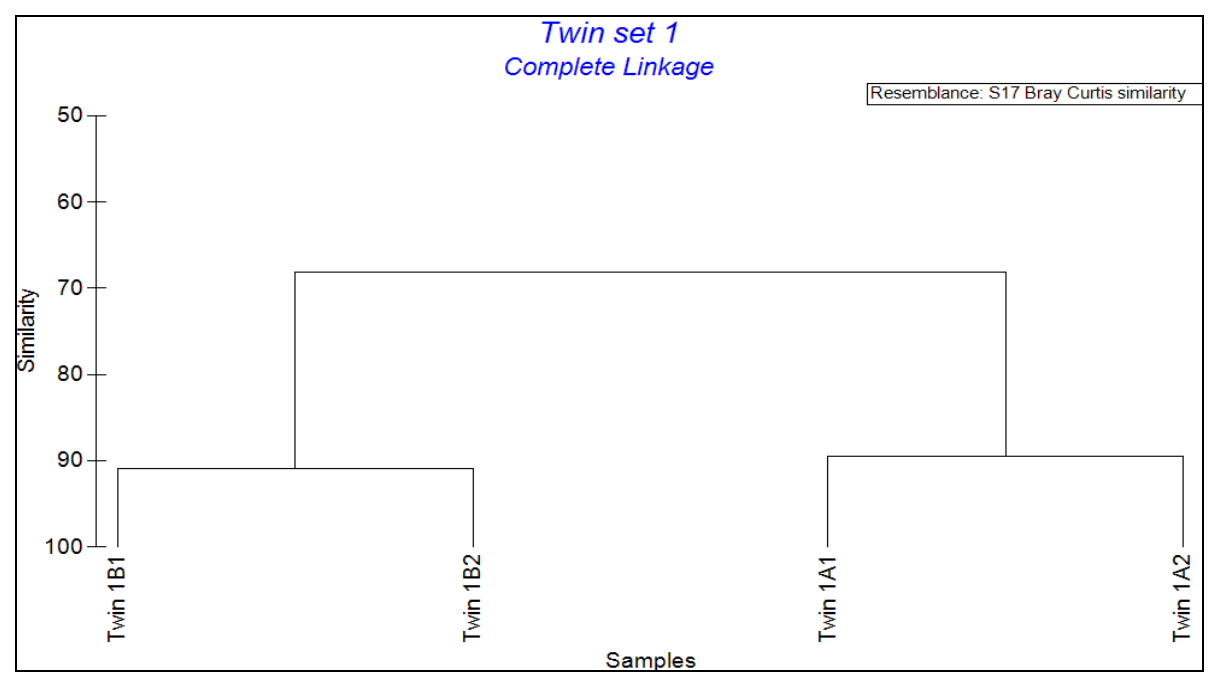


Figure 110: VOCs present in hand odor samples collected from DZ twin girls

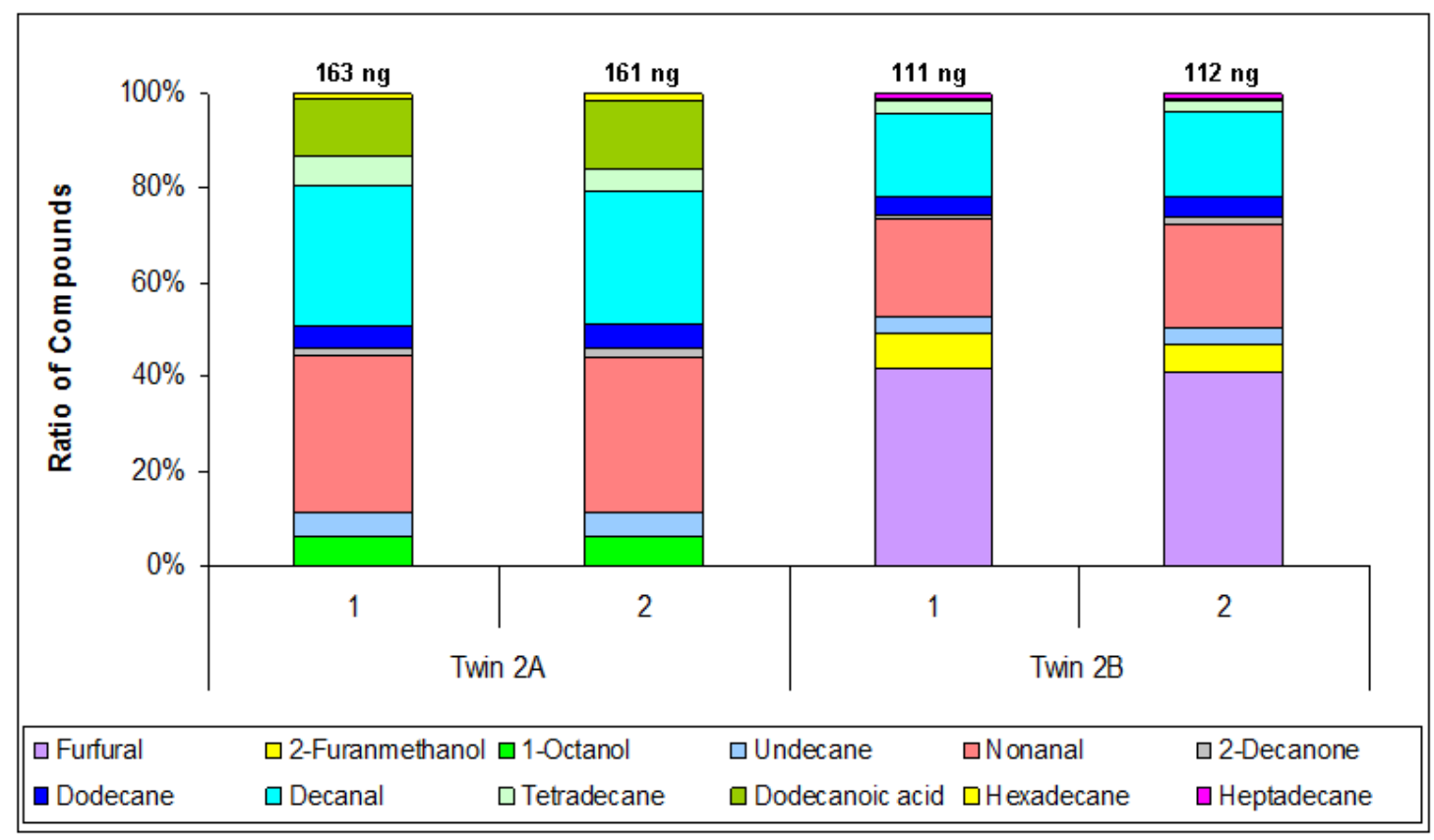

Figure 111: Dendrogram showing Bray Curtis Similarity between VOCs present in hand odor samples collected from $\mathrm{DZ}$ twin girls

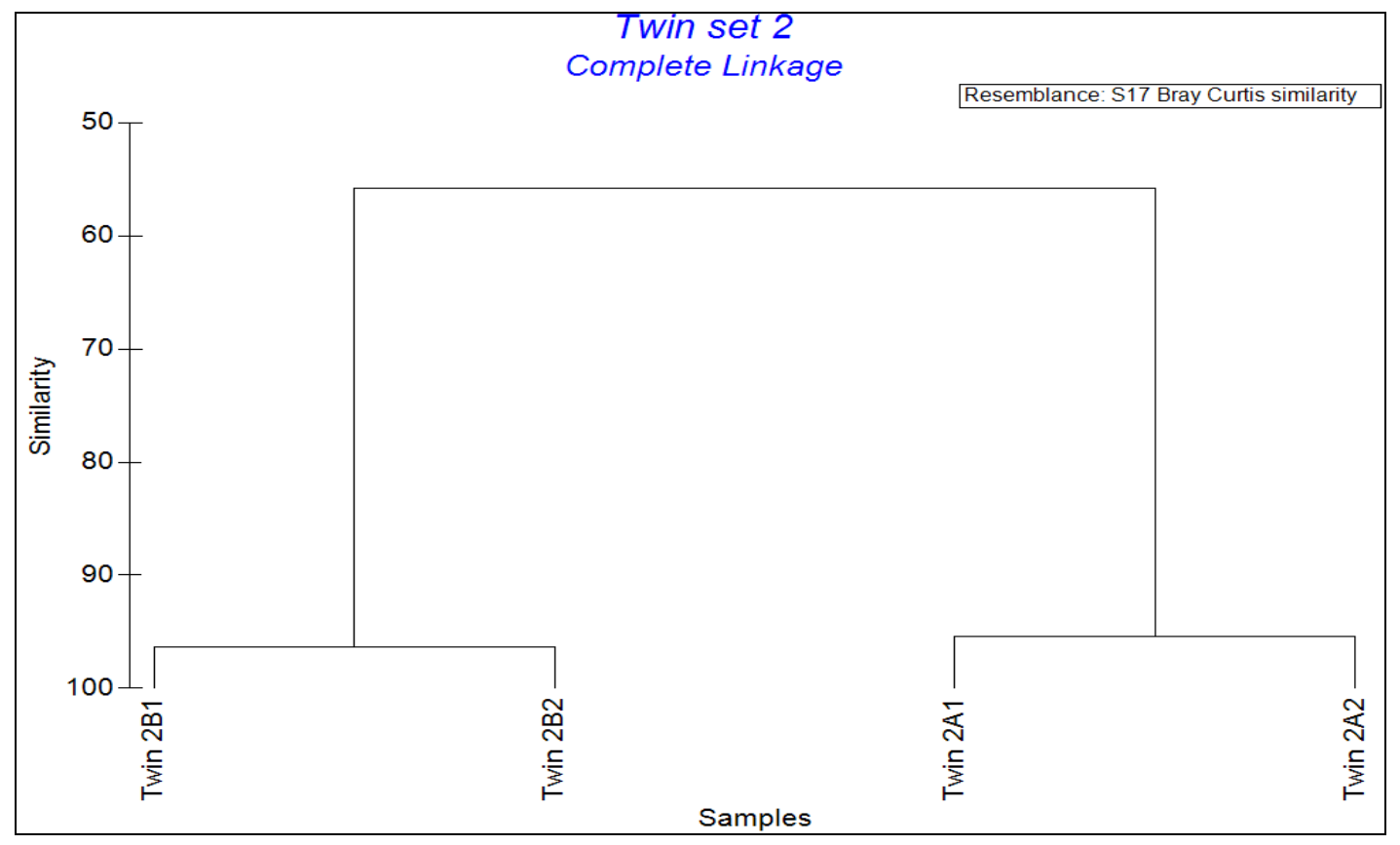


Figure 112: VOCs present in hand odor samples collected from DZ twin boys

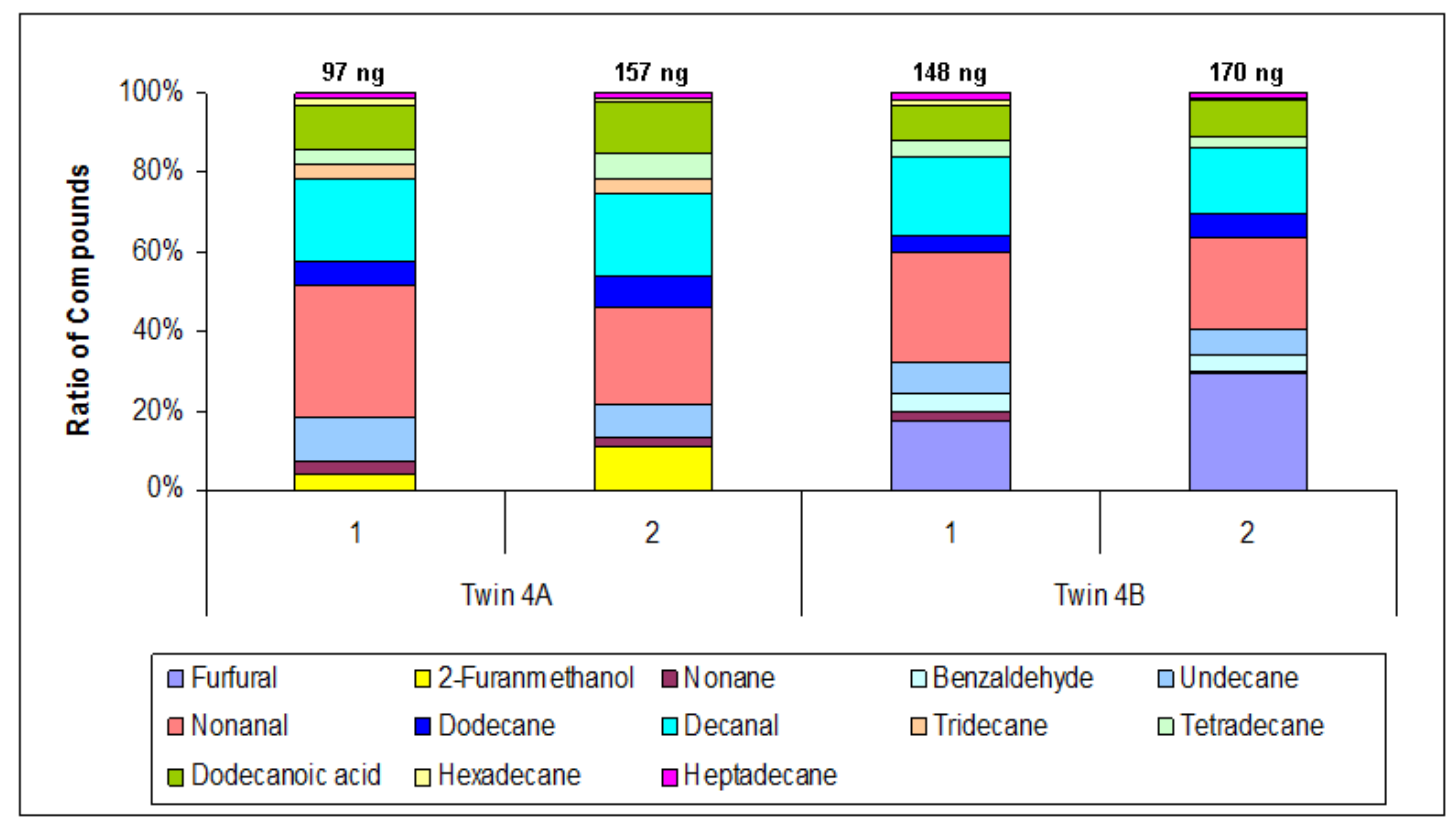

Figure 113: Dendrogram showing Bray Curtis Similarity between VOCs present in hand odor samples collected from DZ twin boys

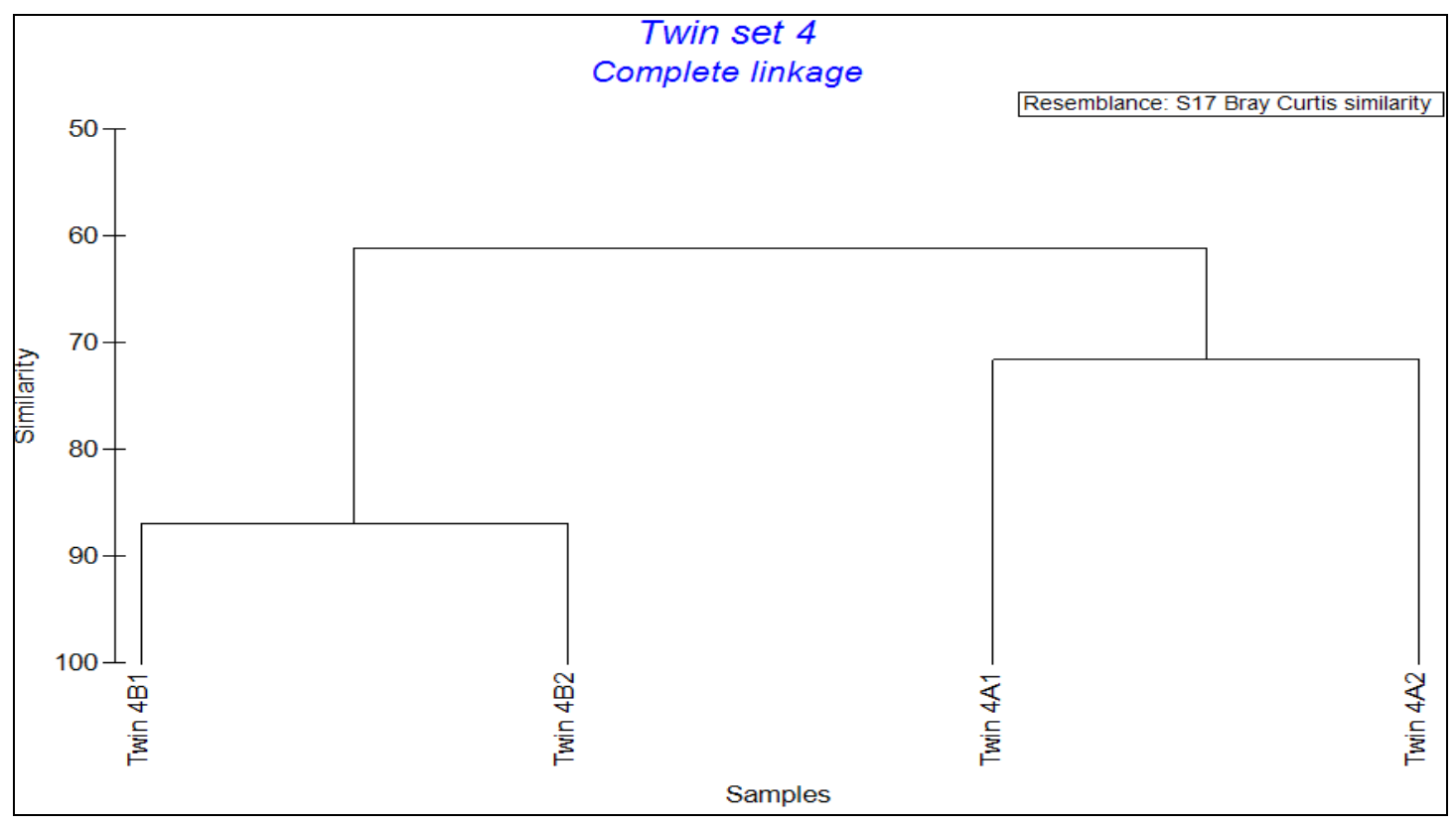


Figure 114: VOCs present in hand odor samples collected from MZ twin girls

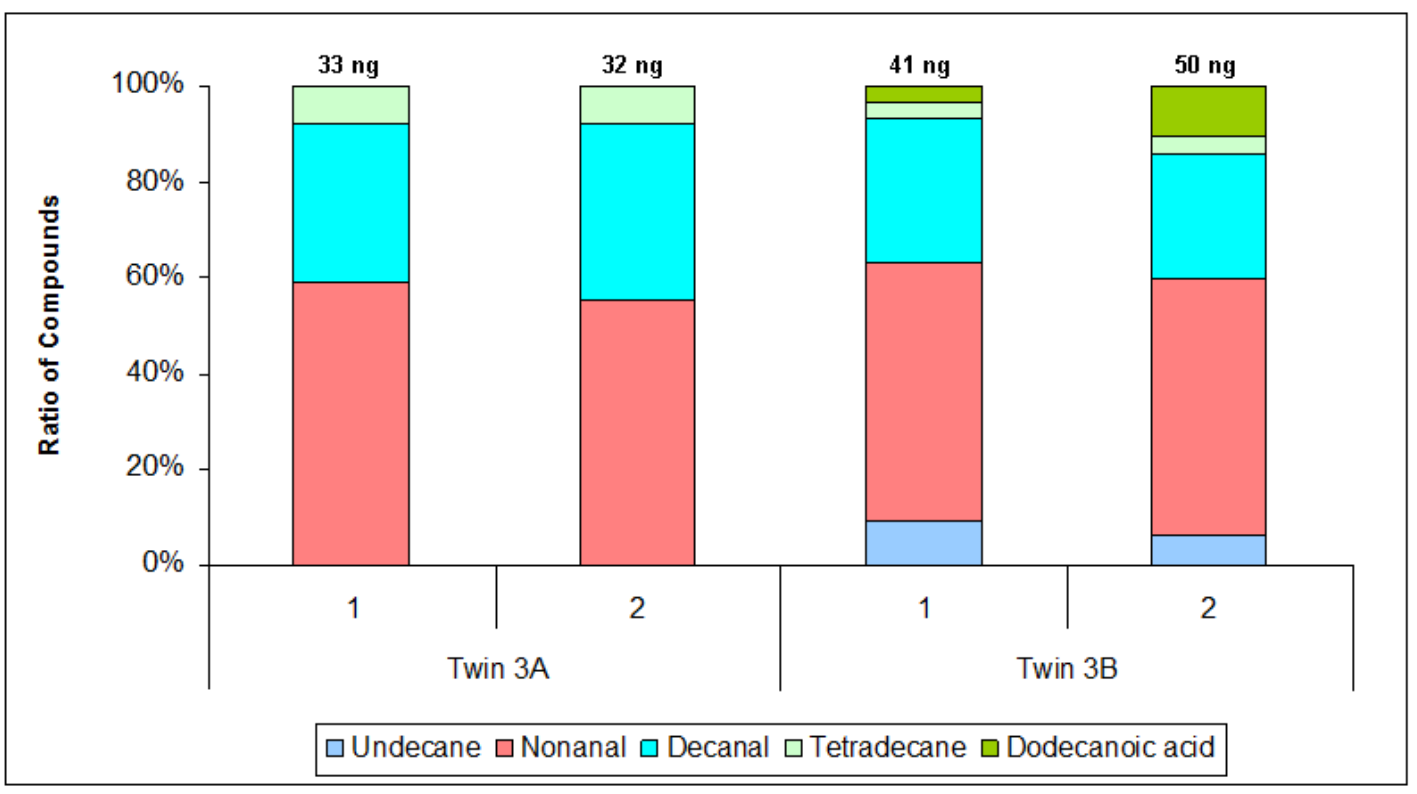

Figure 115: Dendrogram showing Bray Curtis Similarity between VOCs present in hand odor samples collected from $\mathrm{MZ}$ twin girls

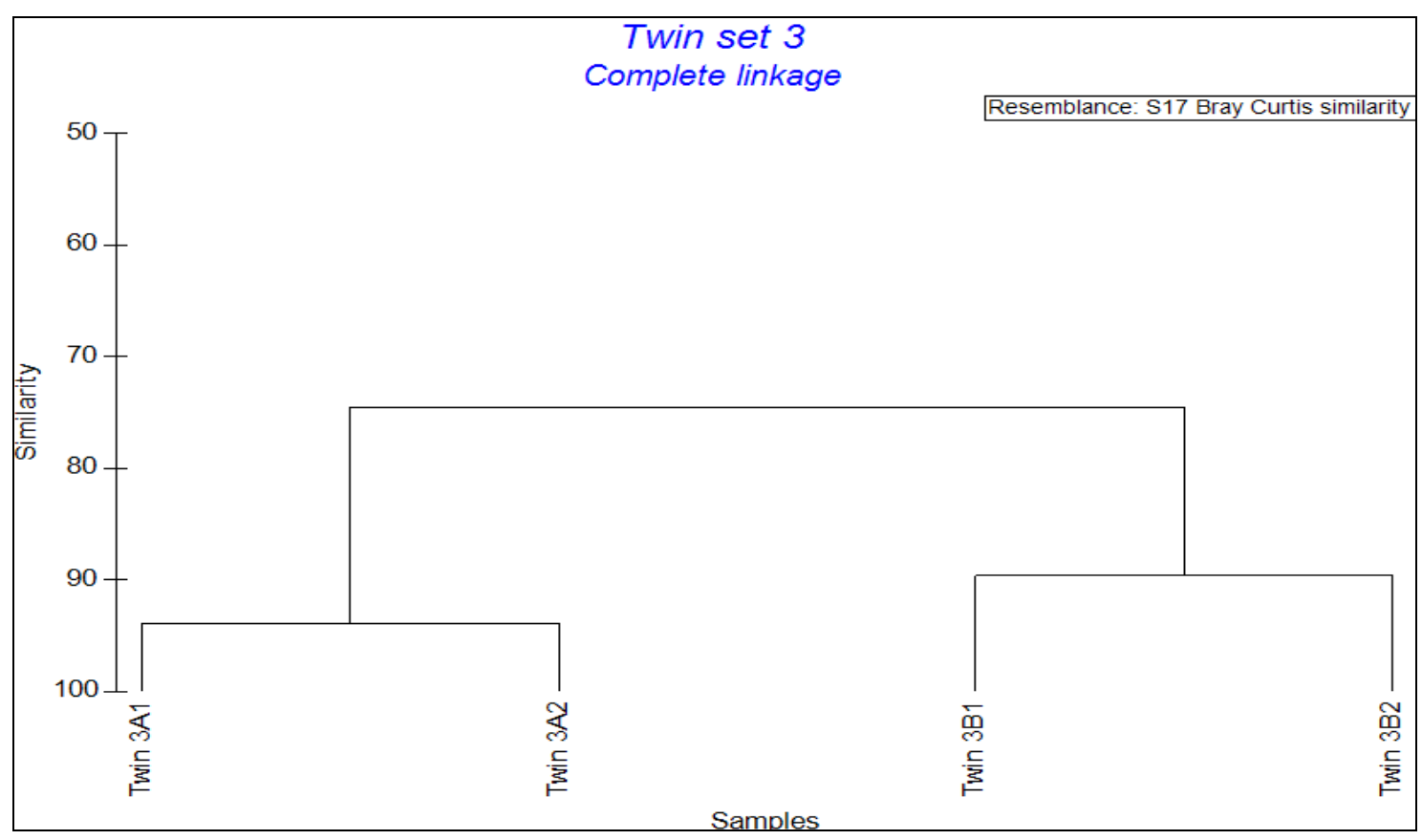


Figure 116: VOCs present in hand odor samples collected from MZ twin boys

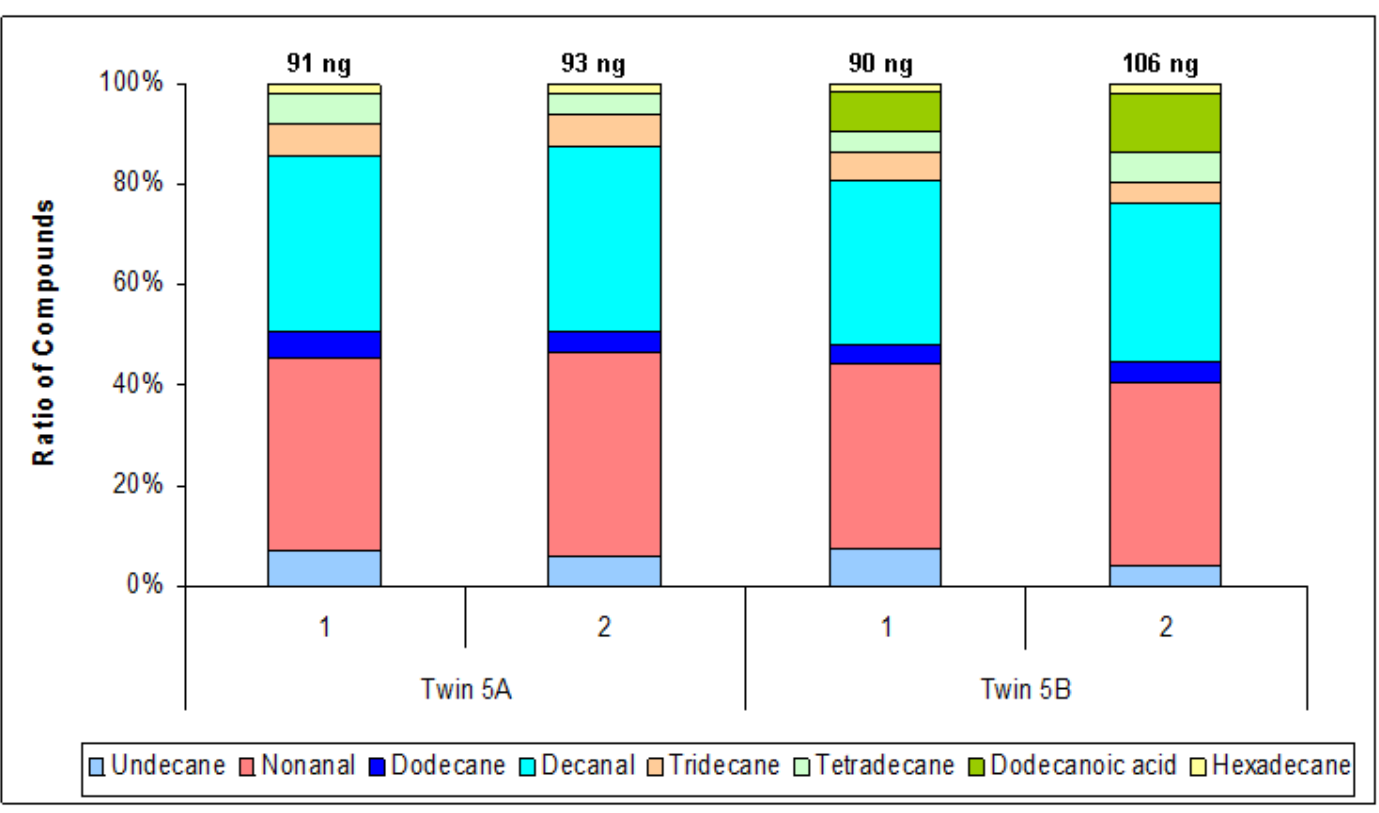

Figure 117: Dendrogram showing Bray Curtis Similarity between VOCs present in hand odor samples collected from MZ twin boys

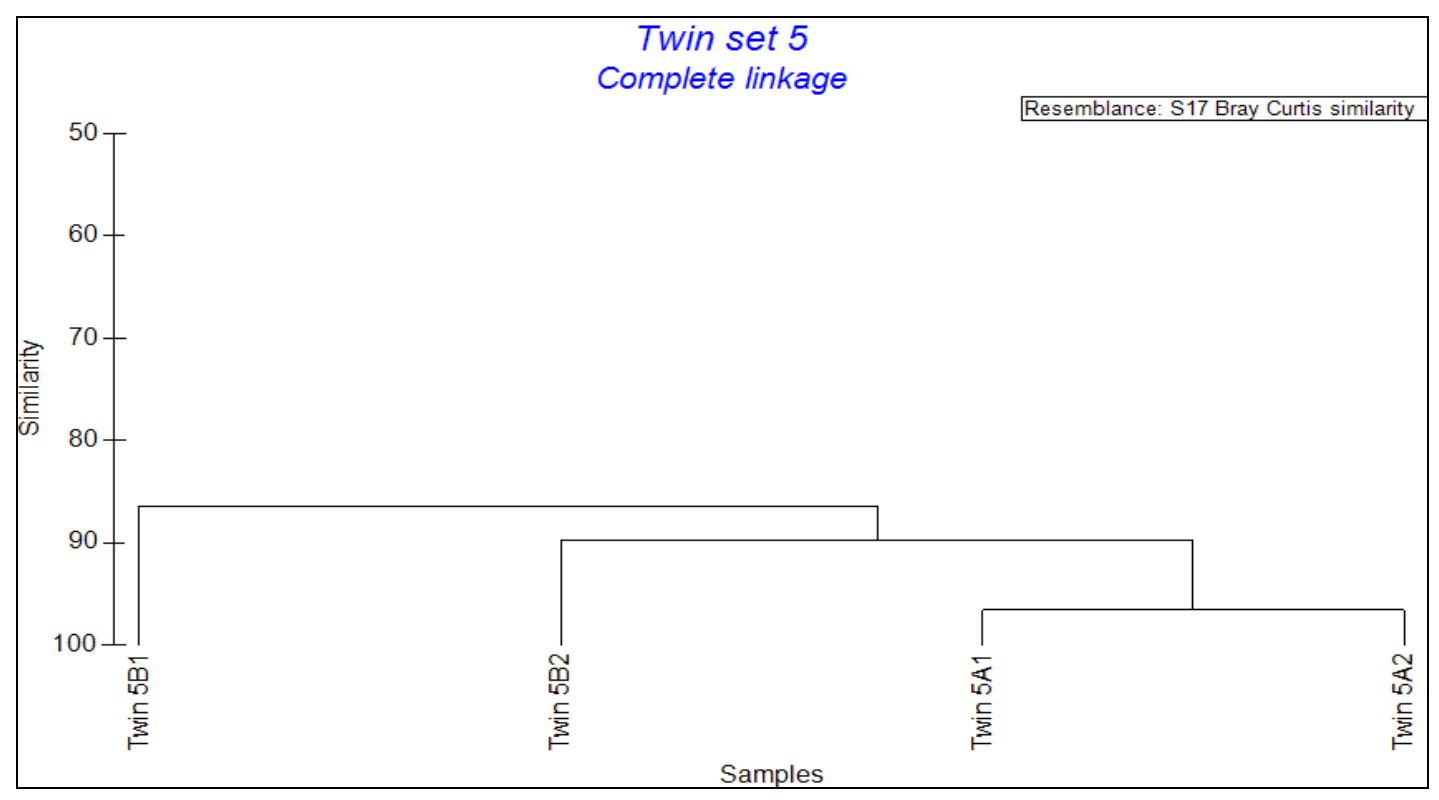


Figure 118: VOCs present in hand odor samples collected from MZ twin boys

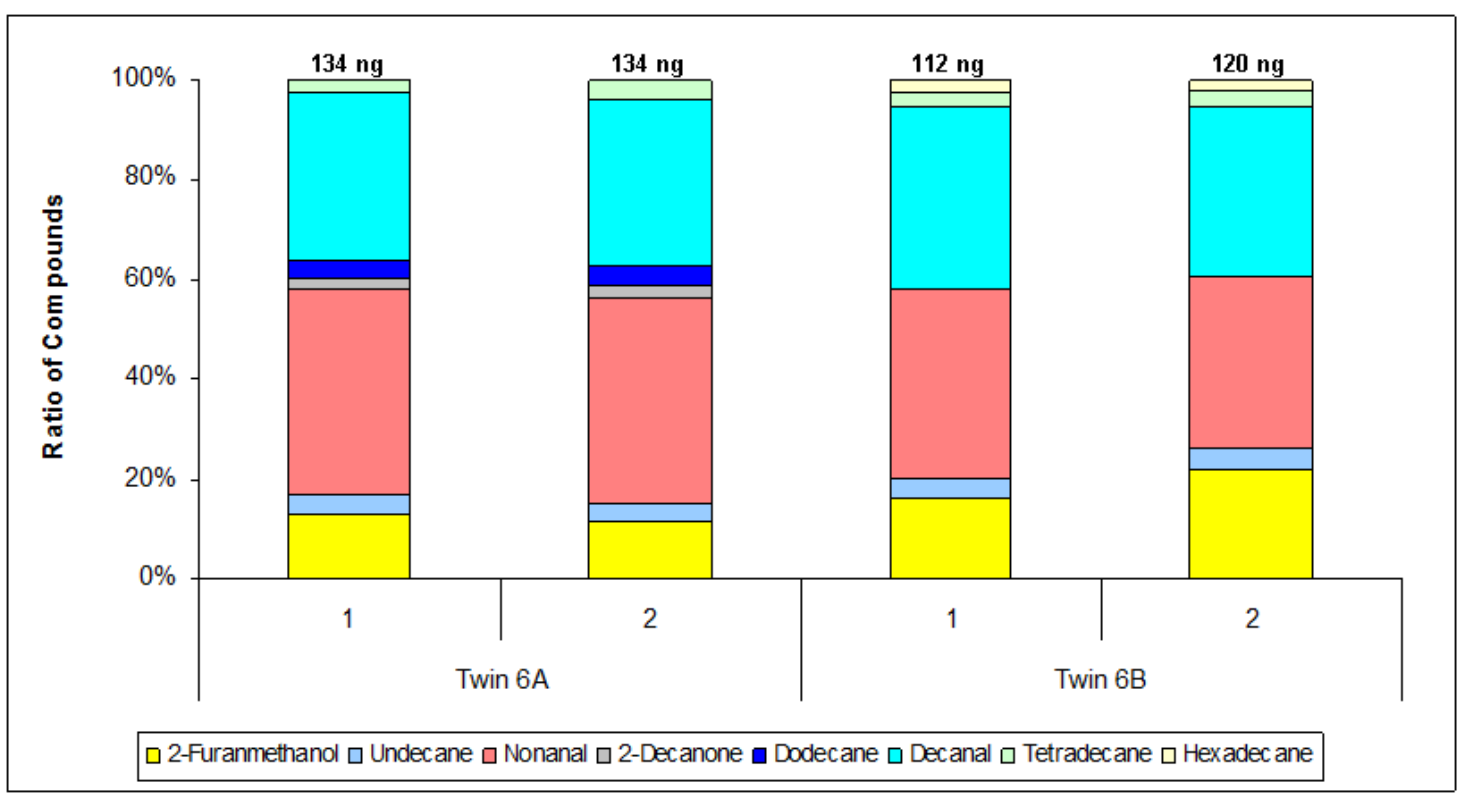

Figure 119: Dendrogram showing Bray Curtis Similarity between VOCs present in hand odor samples collected from $\mathrm{MZ}$ twin boys

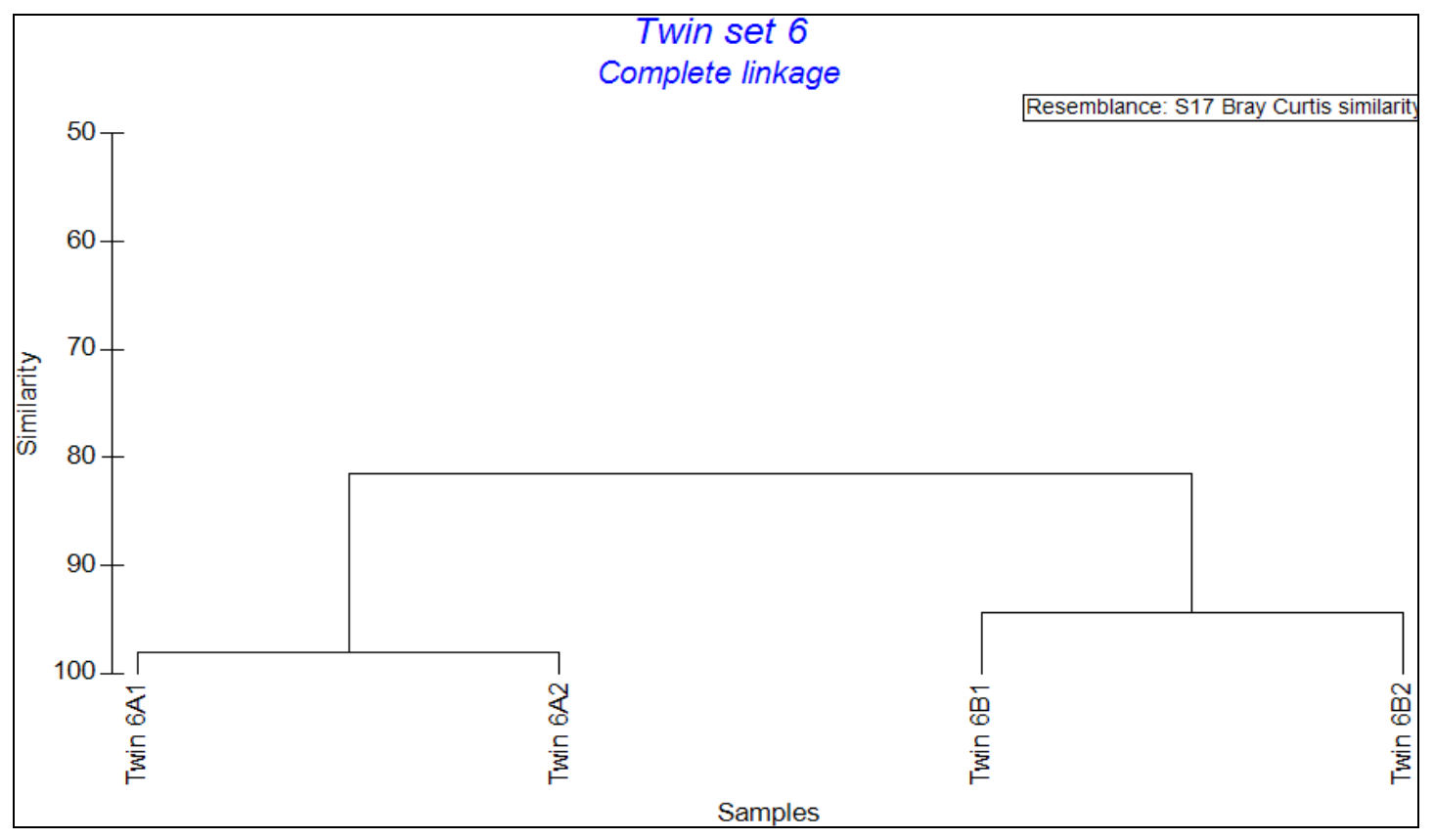




\section{CONCLUSION}

This study was successful in using SPME-GC/MS to show that individuals including twins possess distinctive scent profiles which can be statistically differentiated. Subjecting collected human scent samples to various environmental conditions demonstrated that scent samples should be stored with minimal exposure to light to prevent changes in the overall scent profile of the sample. As was observed with three dimensional covariance mapping, the greatest changes were observed within the first three weeks of storage with minimal changes seen thereafter. It was also determined that even though overall scent profiles change over time, the primary odor constituents remain stable.

The storage study also revealed differences in the odor profiles that can be obtained from a single individual on different materials. This study was conducted with three different materials, Dukal brand gauze, Kings Cotton and Johnson and Johnson brand gauze. It was determined that the Dukal brand gauze and the Kings Cotton which are 100 percent cotton did not release polar compounds such as alcohols as readily as the Johnson and Johnson brand gauze which is a cotton blend material. This shows the importance of collection material selection in the human scent community especially since numerous research groups are undertaking instrumental evaluation of human scent samples.

Various sampling collection protocols such as contact/non-contact and passive/active collection protocols used for the recovery of human scent from objects were investigated. Differences in these collection methods were determined through the use of standard compounds previously reported as human scent compounds spiked onto stainless steel metal bars. The results showed that passive collection methods produce ten times more 
VOCs by mass than active collection methods. Application of both passive and active collection methods to hand odor samples have shown that they provide inadequate VOCs for instrumental analysis. In the United States, active collection methods have traditionally been used for collection of human scent evidence while in Europe; passive collection methods have traditionally been used and both methods have proven to be adequate for discrimination purposes using canines. For instrumental analyses however, the collection technique has to be maximized to allow reliable detection and identification of human scent compounds. Despite these indirect collection techniques being adequate for canine use, instrumental analyses require techniques which trap more VOCs resulting in better instrumental detection and identification.

Polymerase chain reactions were used to determine if there was a correlation between the amount of DNA that was deposited on an object after contact and the alerts that were produced by human scent identification canines. The results showed no correlation between the two variables. It was also determined that it was difficult to characterize individuals as shedders or non-shedders based on the amount of DNA that was deposited by individuals after they had been in contact with objects. This study did reinforce that individuals do possess distinctive odor profiles and it appeared that the canine alerts were more dependent on the VOCs present in the hand odor samples than the amount of DNA deposited by each individual.

Since the results of the previous task showed that the canines appeared to be more dependent on the VOCs that were present rather than the amount of DNA, the next phase of the research involved preparing fractions of human scent samples and presenting them to the canines to determine if canines were using specific VOCs as queues for a particular 
persons odor profile or if the entire VOC profile was being used to identify an individual. Through the use of analytical instruments such as GC/FID and GC/MS, hand odor samples were successfully separated into fractions. The field trials with the canines were not conducted as there are very few human scent identification canines available and so police agencies that possess these canines are more amenable to case work rather than research.

With this knowledge and ability to create fractions, fractioned hand odor samples can be presented to the canines to determine if the canines are alerting to specific VOCs or if the entire VOC profile is required for the canines to distinguish between individuals. Based on the results of these field trials, a prototype pseudo scent could be created which could be used for training purposes in order to provide more consistent training regiments for law enforcement thereby reducing possible challenges currently being faced in courts of law. 


\section{LIST OF REFERENCES}

1. Syrotuck W. Scent and the scenting dog. $1^{\text {st }}$ ed. Pennsylvania: 2000.

2. Lorenzo $\mathrm{N}$ et al. Laboratory and field experiments to identify Canis lupus var. familiaris active odor signature chemicals from drugs, explosives, and humans. Anal Bioanal Chem 2003; 376: 1212-1224.

3. Wolff K, Goldsmith LA, Katz SI, Gilchrest B, Paller AS, Leffell DJ. Fitzpatrick's Dermatology in General Medicine. Chapter 7, 7th ed., McGraw-Hill, 2007.

4. Desmond TJ. Biochemistry of the human skin - our brain on the outside. Chemical Society Reviews 2006; 35: 52-6.

5. Brooks G, Idson B. Skin lipids. International Journal of Cosmetic Science 1991; 13: 103-113.

6. Nicolaides N. Skin lipids: Their biochemical uniqueness. Science 1974; 186 (4158): 19-26.

7. Gallagher M, Wysocki CJ, Leyden JJ, Spielman AI, Sun X, Preti G. Analyses of volatile organic compounds from human skin. British Journal of Dermatology 2008; 159(4): 780-791.

8. Schoon A, Haak R. K 9 Suspect Discrimination Training and Practicing Scent Identification Line-ups. $1^{\text {st }}$ ed., Detselig Enterprises Ltd, Canada, 2002.

9. http://www.textbookofbacteriology.net

10. $108^{\text {th }}$ General Meeting, American Society for Microbiology, Scientists study bacterial communities inside us to better understand health and disease. June 2008. Boston, (Ma).

11. Taylor D, Daulby A, Grimshaw S, James G, Mercer J, Vaziri S. Characterization of the microflora of the human axilla. International Journal of Cosmetics Science 2003; 25: $137-145$.

12. Shelley WB, Hurley HJ, Nichols AC. Axillary Odor. AMA Archives of Dermatology and Syphiology. 1953; 68 (4): 430-446.

13. Trocax M, Starkenmann C, Niclass Y, Van de Waal M, Clark AJ. 3-methyl-3sulfanylhexan-1-ol as a major descriptor for the human axilla sweat profile. Chemistry and Biodiversity 2004; 1: 1022-1035. 
14. James AG, Hyliands D, Johnston $\mathrm{H}$. Generation of volatile fatty acids by axillary bacteria. International Journal of Cosmetic Science 2004; 26: 149-156.

15. Natsch A, Schmid J, Flachsmann F. Identification of odoriferous sulfanylalkanols in human axilla secretions and their formation through cleavage of cysteine precursors by a COS lyase isolated from axilla bacteria. Chemistry and biodiversity 2004; 1 : $1058-1072$.

16. Leyden JJ, McGinley KJ, Holze E, Labows JN, Kligman AM. The microbiology of the human axilla and its relationship to axillary odor. The Journal of Investigative Dermatology 1981; 77 (5): 413-416.

17. McBride ME, Duncan C, Knox JM. The environment and the microbial ecology of human skin. Applied and Environmental Microbiology 1977; 33(3): 603-608.

18. Bernier UR, Kline DL, Barnard DR, Schreck CE, Yost RA. Analysis of human skin emanations by gas chromatography mass spectrometry. 1. Thermal desorption of attractants for the yellow fever mosquito (Aedes aegypti) from handled glass beads. Anal Chem 1999; 71: 1-7.

19. Bernier UR, Kline DL, Barnard DR, Schreck CE, Yost RA. Analysis of human skin emanations by gas chromatography mass spectrometry. 2. Identification of volatile compounds that are candidate attractants for the yellow fever mosquito (Aedes aegypti) from handled glass beads. Anal Chem 1999; 72 (4): 747-756.

20. Asano KG, Bayne CK, Horsman KM, Buchanan MV. Chemical composition of fingerprints for gender determination. Journal of Forensic Science 2002; 47(4): 805807.

21. Zeng XN, Leyden JJ, Lawley HJ, Sawano K, Nohara I, Preti G. Analysis of characteristic odors from human male axillae. Journal of Chemical Ecology 1991; 17(7): 1469-1492.

22. Zeng XN, Leyden JJ, Spielman AI, Preti G. Analysis of characteristic human female axillary odors: qualitative comparison to males. Journal of Chemical Ecology 1996; 22(2): 237-257.

23. Ostrovskya A, Landa P, Sokolinsky M, Rosalia AD, Maes D. Study and identification of volatile compounds form human skin. Annual Scientific Meeting. Estee Lauder Inc. 2001.

24. Curran AM. The analytical determination of the uniqueness and persistence of the volatile components of human scent using optimized collection methods [Dissertation]. Miami (Fl): Florida International University, 2005. 
25. Zhang ZM, Cai JJ, Ruan GH, Li GK. The study of fingerprint characteristics of the emanations from human arm skin using the original sampling system by SPMEGC/MS. Institute of Analytical Sciences. China. 2005.

26. Penn DJ. Individual and gender fingerprints in human body odor. Journal of the Royal Society Interface 2007; 4: 331-340.

27. Curran AM, Ramirez CF, Schoon AA, Furton KG. The frequency of occurrence and discriminatory power of compounds found in human scent across a population determined by SPME-GC/MS. Journal of Chormatography B 2007; 846: 86-97.

28. Sommerville BA, McCormick JP, Broom DM. Analysis of human sweat volatiles: an example of pattern recognition in the analysis and interpretation of gas chromatograms. Pesticide Science 1994; 41: 365-368.

29. Brown JL, Eklund A. Kin recognition and the major histocompatibility complex: An integrative review. The American Naturalist 1994; 143(3): 435-444.

30. Thornhill R, Gangestad SW, Miller R, Scheyd G, McCollough K, Franklin M. Major histocompatibility complex genes, symmetry, and body scent attractiveness in men and women. Behavioral Ecology 2003; 14(5): 668-678.

31. Penn D, Potts W. How do major histocompatibility complex genes influence odor and mating preferences? Advances in Immunology 1998; 69: 411-429.

32. Wadekind C, Penn D. MHC genes, body odours and odour preferences. Nephron Dial Transplant. 2000; 15: 1269-1271.

33. Savelev SU et al. Individual variation in 3-Methylbutanal: A putative link between human leukocyte antigen and skin microflora. Journal of Chemical Ecology 2008; 34: 1253-1257.

34. Hepper PG, Wells DL. How many footsteps do dogs need to determine the direction of an odour trail. Chemical Senses 2005; 30: 291-298.

35. Harvey LM, Harvey SJ, Hom M, Perna A, Salib J. The use of bloodhounds in determining the impact of genetics and the environment on the expression of human odortype. Journal of Forensic Science 2006; 51(5): 1109-1114.

36. Beauchamp GK, Kunio Y. Individual differences and the chemical senses. Chemical Senses 2005; 30: i6-i9.

37. Brown RE. What is the role of the immune system in determining individually distinct body odours? International Journal of Immunopharmacology 1995; 17 (8): 655-661. 
38. Wedekind C, Seebeck T, Bettens F, Paepke AJ. The intensity of human body odors and the MHC: Should we expect a link? Evolutionary Psychology 2006; 4: 85-94.

39. McClintock MK, Bullivant S, Jacob S, Spencer N, Zelano B, Ober C. Human body scents: Conscious perceptions and biological effects. Chemical Senses 2005; 30(1): i135-i137.

40. Lanyon CV, Rushton SP, O’Donnell AG, Goodfellow M, Ward A, Petrie M, et al. Murine scent mark microbial communities are genetically determined. FEMS Microbiol Ecol. 2007; 59: 576-583.

41. Schaefer ML, Young DA, Restrepo D. Olfactory fingerprints for major histocompatibility complex determined body odors. The Journal of Neurosciences 2001; 21(7): 2481-2487.

42. Hurst JL, Thom MD, Nevison CM, Humphries RE, Beynon RJ. MHC odours are not required or sufficient for recognition of individual scent owners. Proceedings of the Royal Society 2005; 272: 715-724.

43. Roberts SC, Gosling LM, Spector TD, Miller P, Penn DJ, Petrie M. Body odor similarity in noncohabiting twins. Chemical Senses 2005; 30:651-656.

44. Olson SB, Barnard J, Turri L. Olfaction and identification of unrelated individuals: examination of the mysteries of human odor recognition. Journal of Chemical Ecology 2006; 32: 1635-1645.

45. Porter RH. Olfaction and human kin recognition. Genetica 1999; 104: 259-263.

46. Stockholm RA, Slavin DL, Kift W. Specialized use of human scent in criminal investigations. Forensic Science Communications 2004; 6 (3).

47. Russel RA. Odour detection by mobile robots. Volume 22. Australia: 1999.

48. Mesloh, C. Scent as Forensic Evidence and its Relationship to the Law Enforcement Canine [Thesis]. Orlando, (Fl): University of Central Florida, (2000).

49. Wickenheiser RA. Trace DNA: A review, discussion of theory, and application of the transfer of trace quantities of DNA through skin contact. Journal of Forensic Science $2001 ; 442-450$.

50. Lowe A, Murray C, Whitaker J, Tully G, Gill P. The propensity of individuals to deposit DNA and secondary transfer of low level DNA from individuals to inert surfaces. Forensic Science International 2002; 129: 25-34. 
51. Phipps M, Petricevic S. The tendency of individuals to transfer DNA to handled items. Forensic Science International. 2007; 168: 162-168.

52. Alessandrini F, Cecati M, Pesaresi M, Turchi C, Carle F, Tagliabracci A. Fingerprints as evidence for a genetic profile: morphological study on fingerprints and analysis of exogenous and individual factors affecting DNA typing. Journal of Forensic Sciences 2003; 48(3): 1-7.

53. Bright J, Petricevic SF. Recovery of trace DNA and its application to DNA profiling of shoe insoles. Forensic Science International 2004; 145:7-12.

54. Asano KG, Eckenrode BA, Ramsey SA, Stockham RA, Van Berkel GJ, Wolf DA. Performance evaluation of the scent transfer unit ${ }^{\mathrm{TM}}$ (STU-100) for organic compound collection and release. Journal of Forensic science 2006; 51 (4): 780-789.

55. Carter ME. Essential Fiber Chemistry. $1^{\text {st }}$ ed. New York: 1971.

56. Cook JG. Handbook of Textile Fibres. $5^{\text {th }}$ ed. Britain: 1984.

57. Peters RH. Textile Chemistry, the Chemistry of Fibers, Volume 1. Netherlands: 1963.

58. Peters RH. Textile Chemistry, Impurities in Fibers, Purification of Fibers Volume 11. Netherlands: 1967.

59. Bendak A, El-Marsafi SM. Effects of chemical modifications on polyester fibers. Journal of Islamic Academy of Sciences 1991; 4(4): 275-284.

60. http://www.english.peopledaily.com.cn/200603/21/eng20060321 252270.html Accessed September 13, 2007.

61. http://www.news.xinhuanet.com/english/2006-03/15/content_4307207.html Accessed September 13, 2007.

62. Saferstein R. Forensic Science Handbook Volume I. $2^{\text {nd }}$ ed. New Jersey: 2002.

63. Taslitz AE. Does the cold nose know? The unscientific myth of the dog scent lineup. Hastings Law Journal 1990 November; 42(17): 1-179.

64. People of the State of California v. Jeffrey Dewyane Mitchell. Court of Appeal of California, Second Appellate District, Division One (2003)

65. People of the State of California v. Ryan Willis. Court of Appeal of California, Second Appellate District, Division One (2004). 
66. People of the State of California V. Benigno Salcido, Los Angeles Superior Court (2005).

67. Scheppers S. Solid Phase Microextraction A Practical Guide. New York: 1999.

68. Niessen WMA. Current practice of gas chromatography-mass spectrometry, Volume 86. Switzerland: 2001.

69. Robards K, Haddad PR, Jackson PE. Principles and practices of modern chromatographic methods. London: 2004.

70. Skoog DA, Holler FJ, Neiman TA. Principles of Instrumental Analysis. $5^{\text {th }}$ ed. USA: 1998.

71. Sigman ME, Williams MR. Covariance mapping in the analysis of ignitable liquids by gas chromatography mass spectrometry. Analytical Chemistry 2006 March; 78(5): 1713-18.

72. Miller JN, Miller JC. Statistics and Chemometrics for Analytical Chemistry. $1^{\text {st }}$ ed. England: 2000.

73. Schoon GAA. The effect of the ageing of crime scene objects on the results of scent identification line-ups using trained dogs. Forensic Science International 2005; 147(1): 43-47.

74. Quignon P, Kirk E, Cadieu E, Touleimat N, Guyon R, Hitte C, et al. Comparison of the canine olfactory and human receptor gene repertoires. Genome Biology 2003; 4:R80.

75. Flether KS. Optimization and development of a human scent collection method [Thesis]. Bethsada, Maryland: Uniformed Services University of the Health Sciences, 2007. 


\section{APPENDICES}

\section{Appendix A}

Calibration Curves for human scent compounds

Figure 120: Calibration curve for Octane

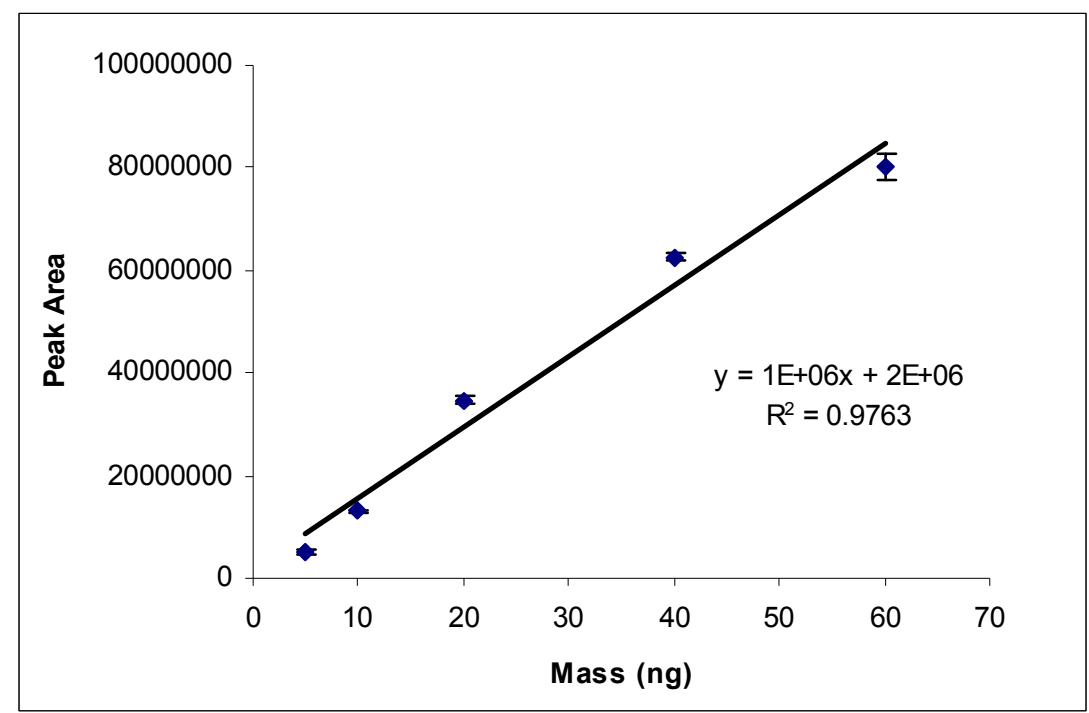

Figure 121: Calibration curve for Furfural

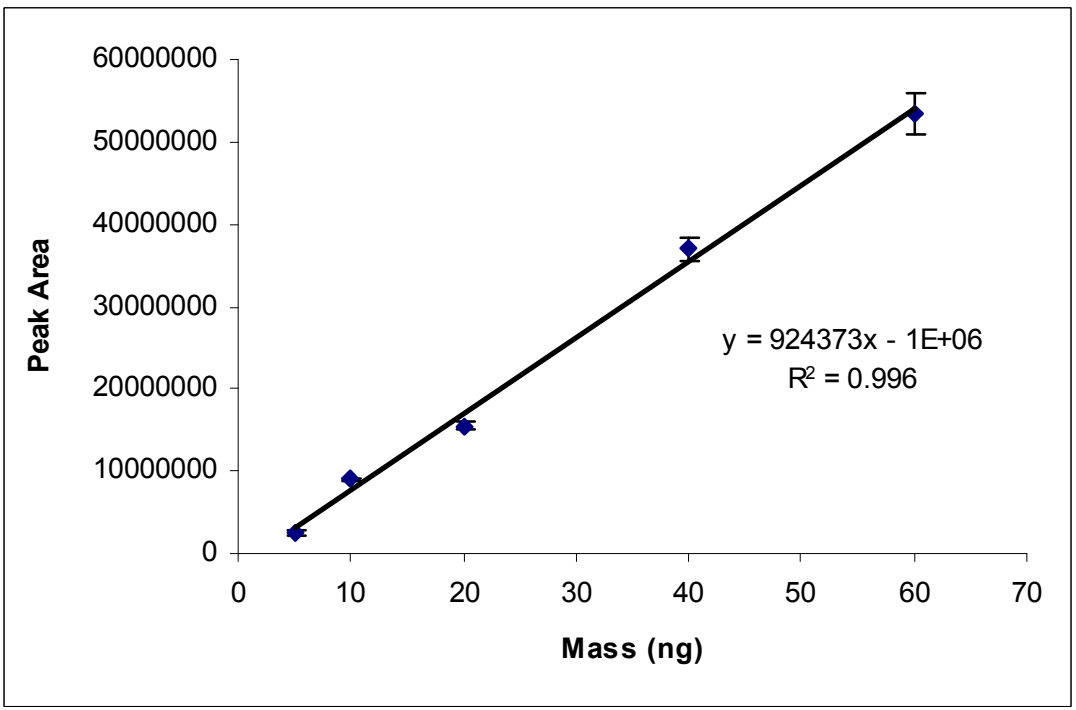


Figure 122: Calibration curve for 2-Furanmethanol

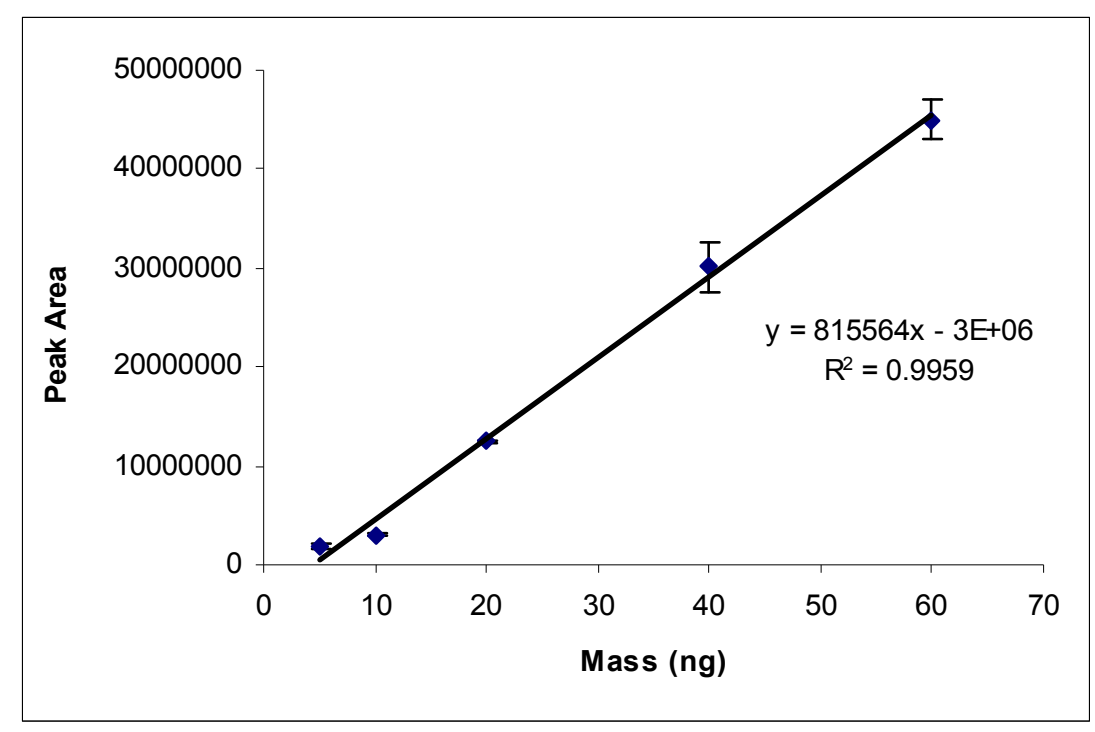

Figure 123: Calibration curve for Nonane

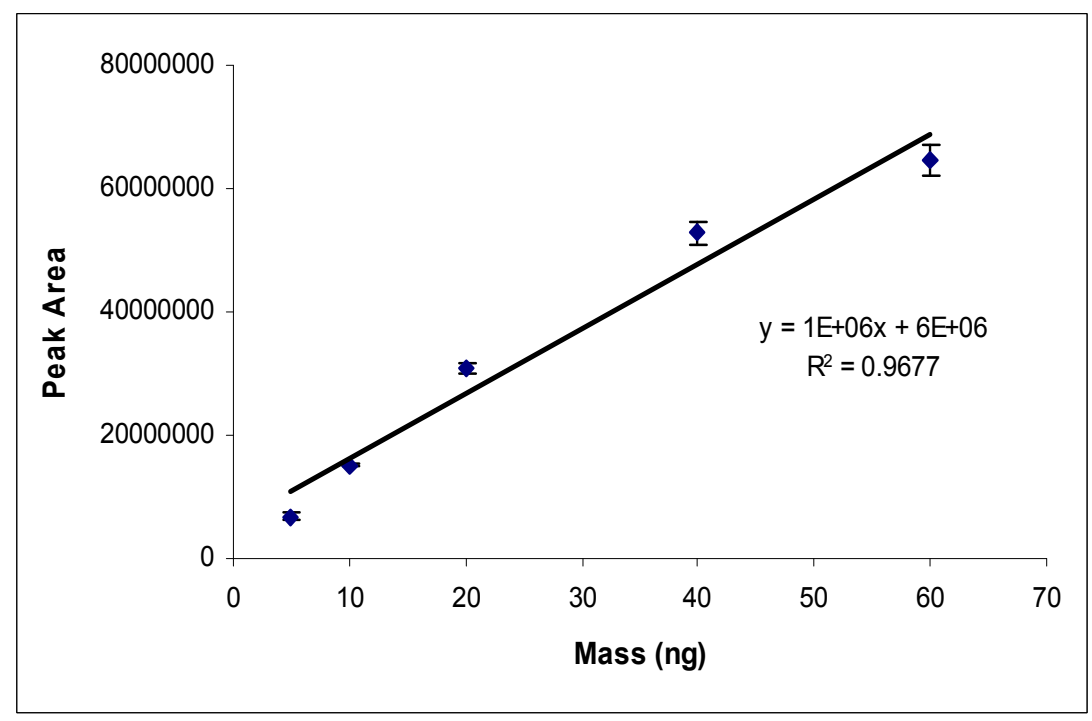


Figure 124: Calibration curve for Heptanal

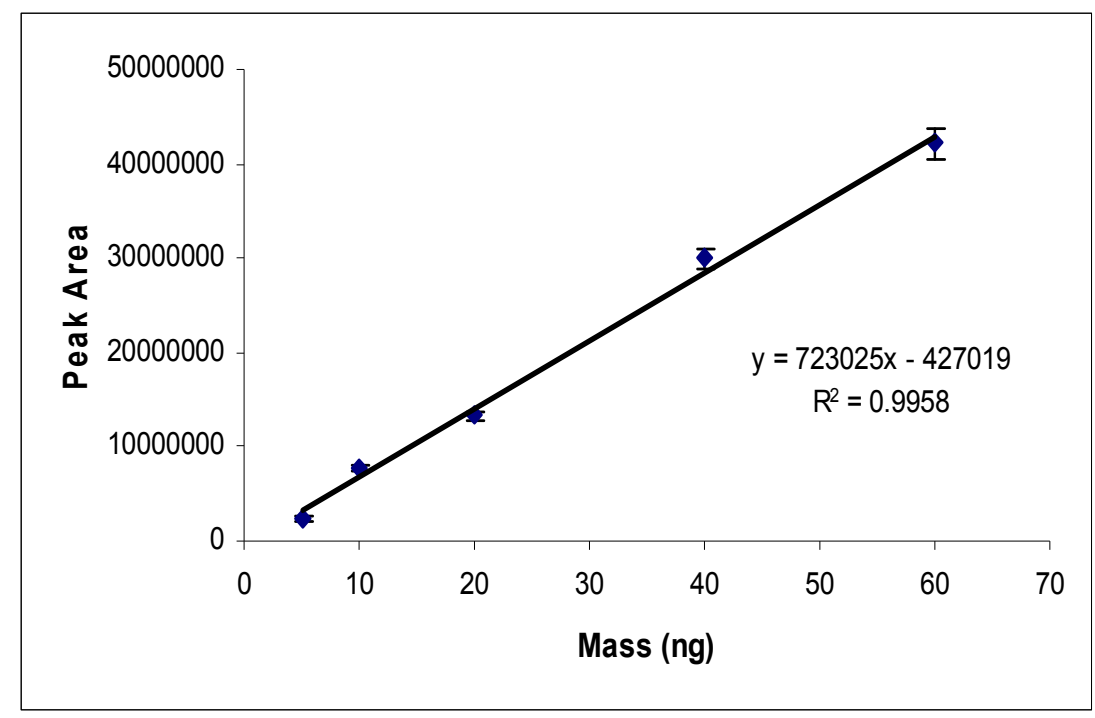

Figure 125: Calibration curve for Propanedioic acid dimethyl ester

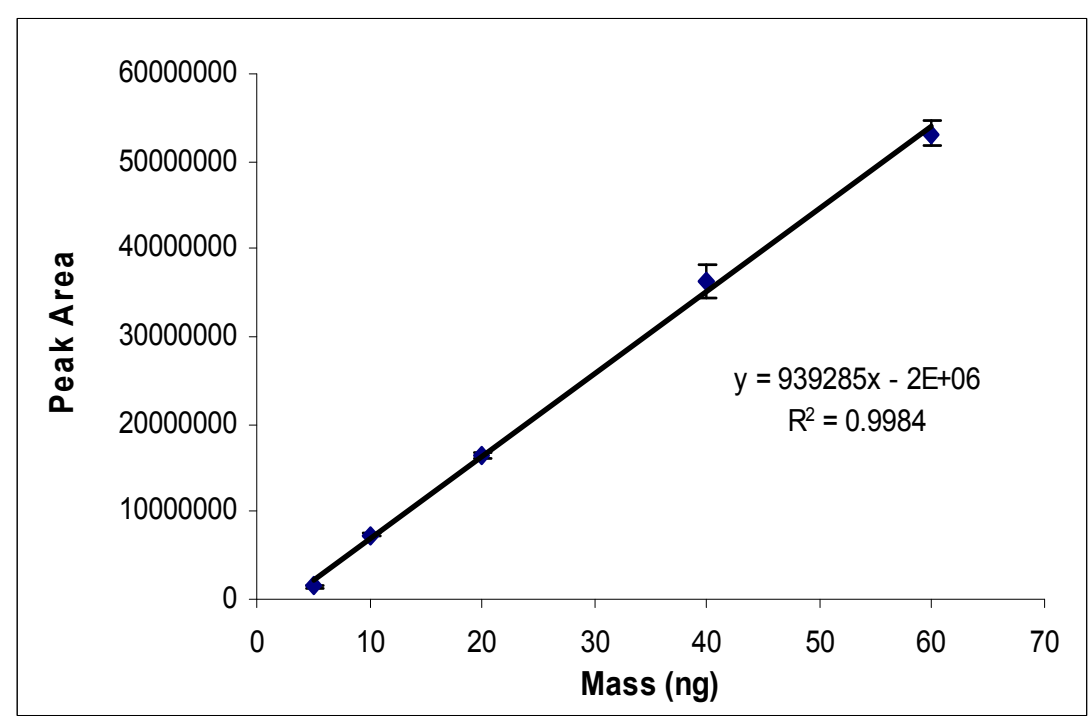


Figure 126: Calibration curve for Benzaldehyde

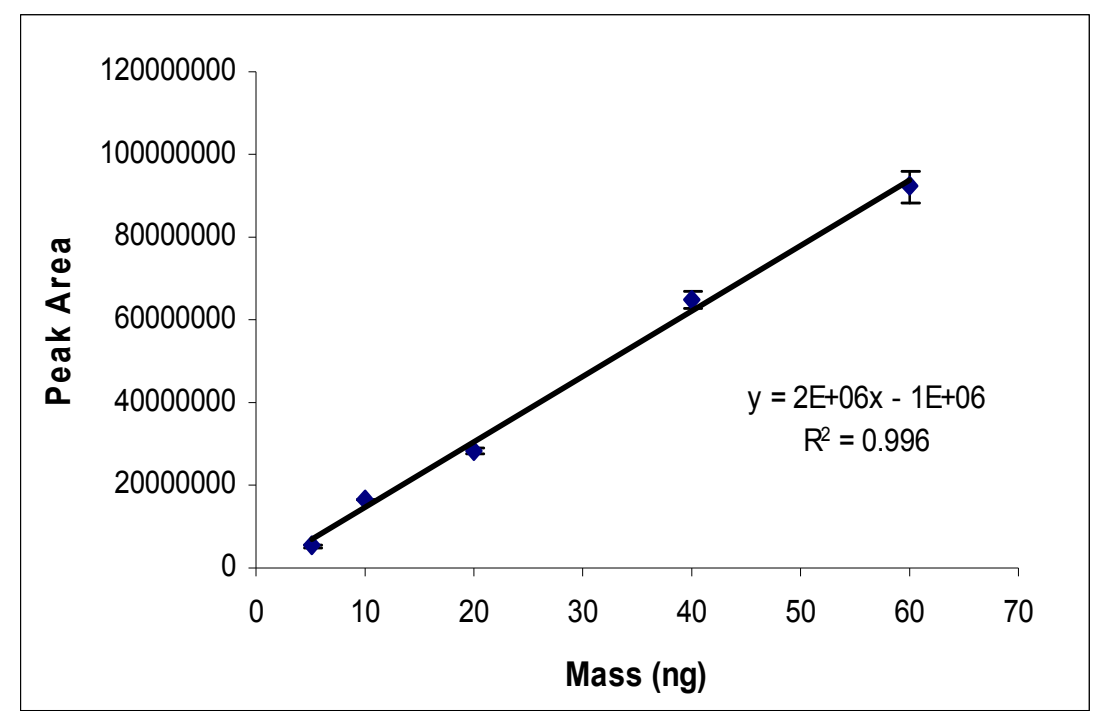

Figure 127: Calibration curve for Phenol

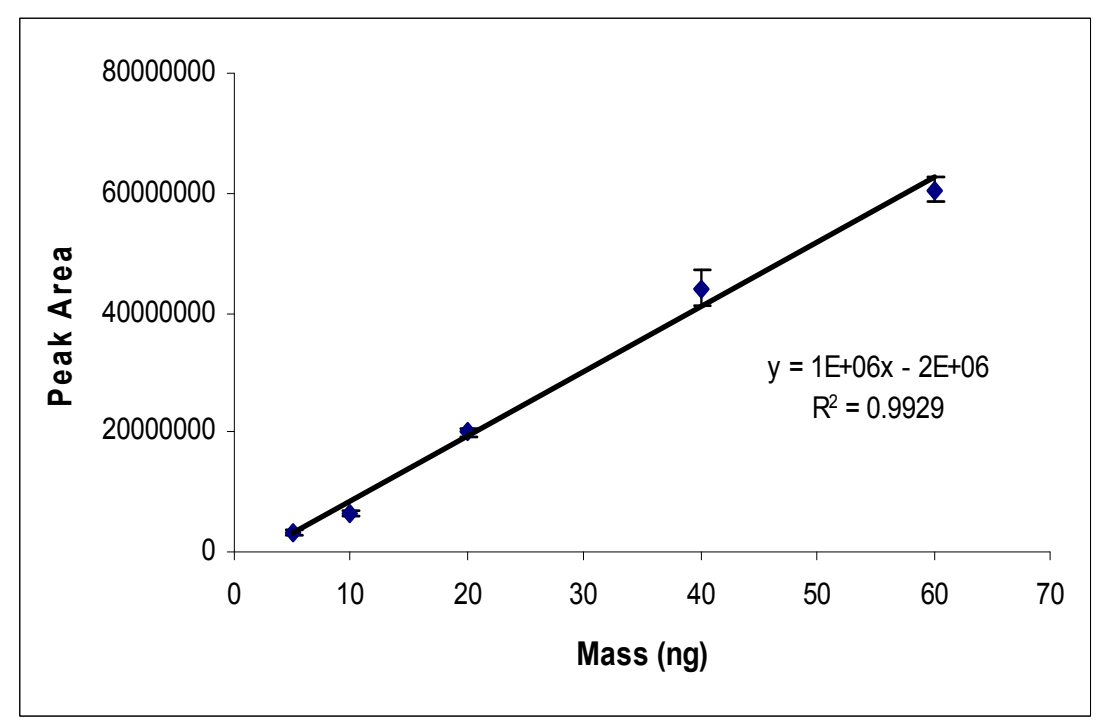


Figure 128: Calibration curve for 6-Methyl-5-hepten-2-one

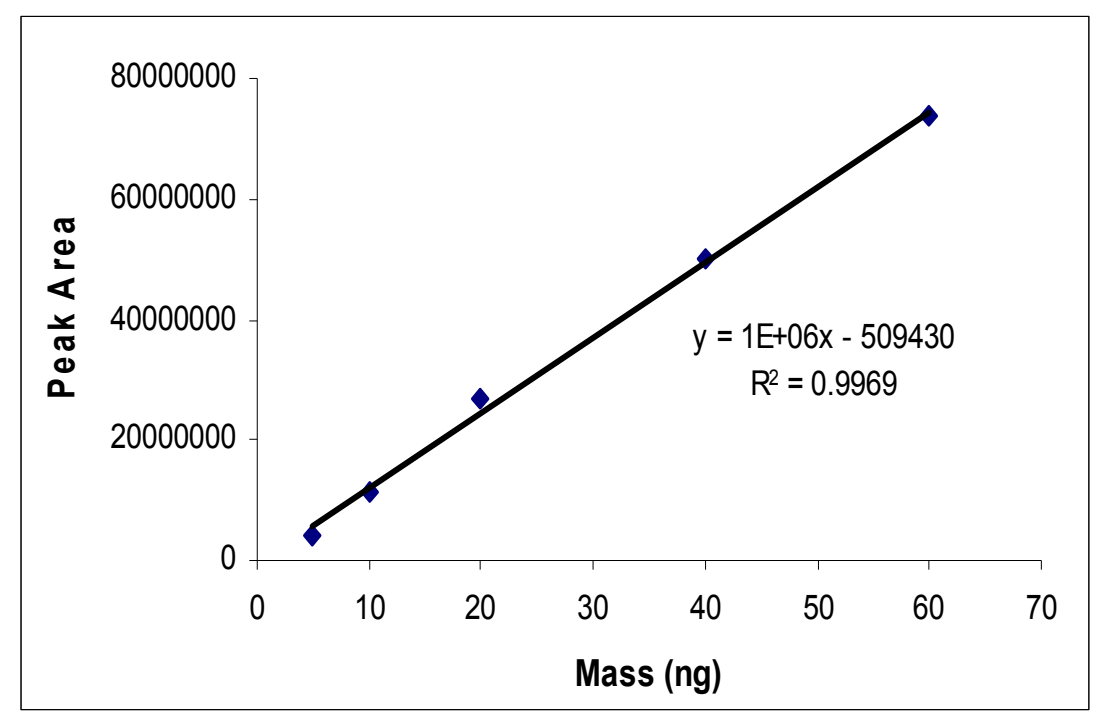

Figure 129: Calibration curve for Octanal

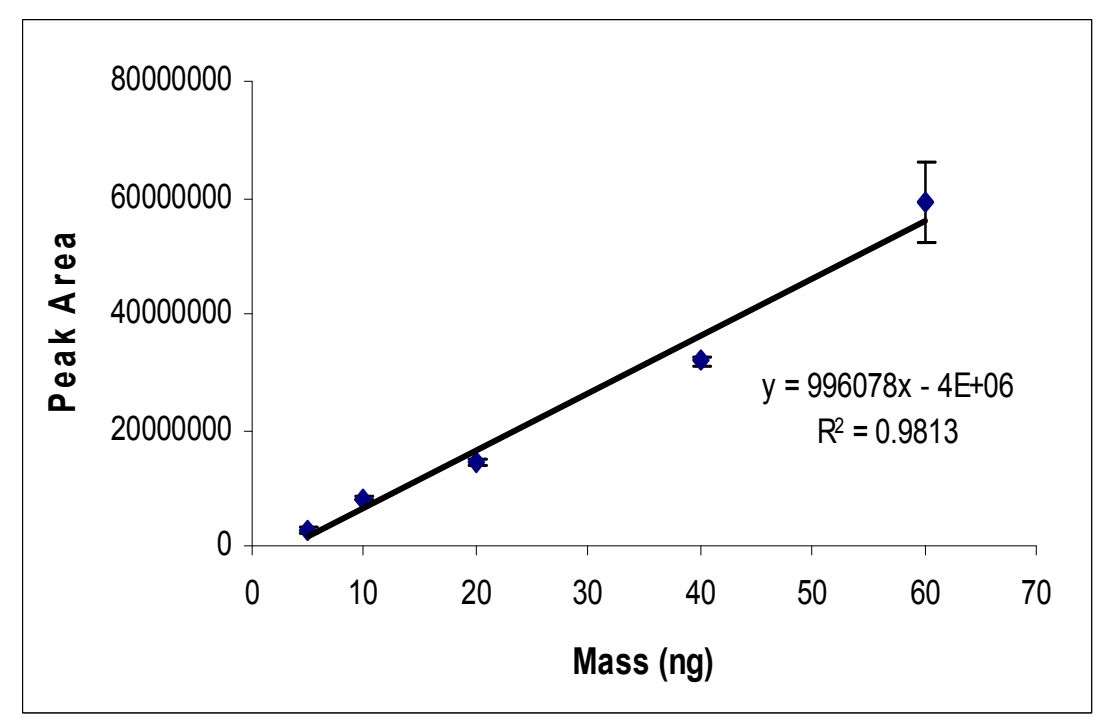


Figure 130: Calibration curve for Benzyl alcohol

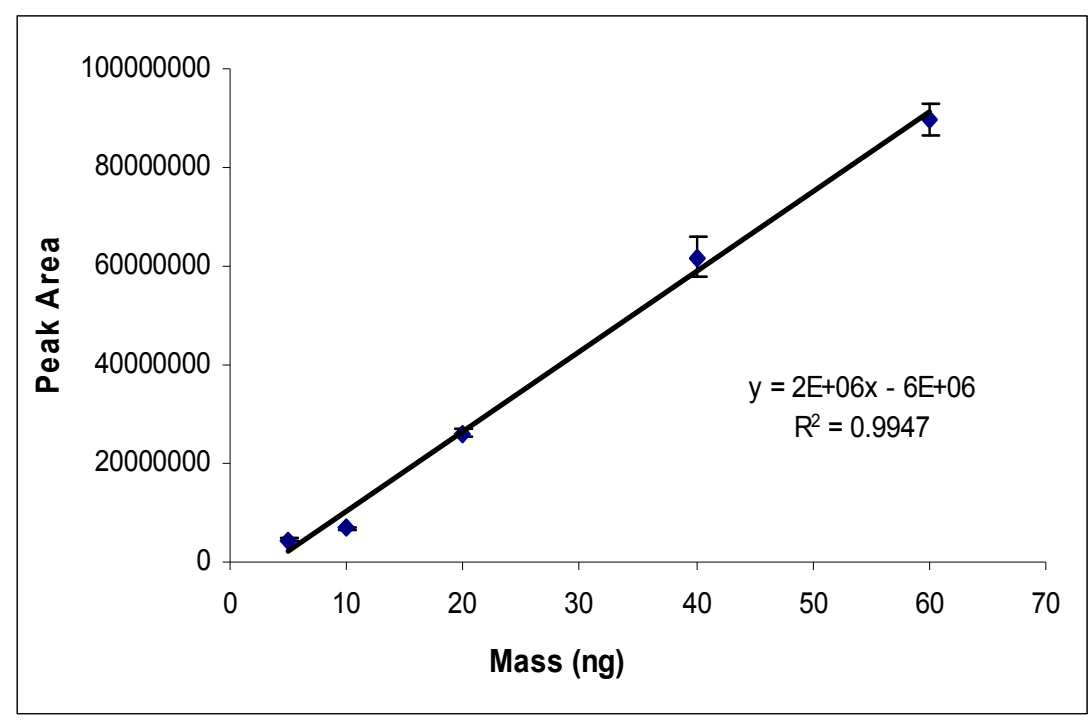

Figure 131: Calibration curve for 2-Octenal (E)

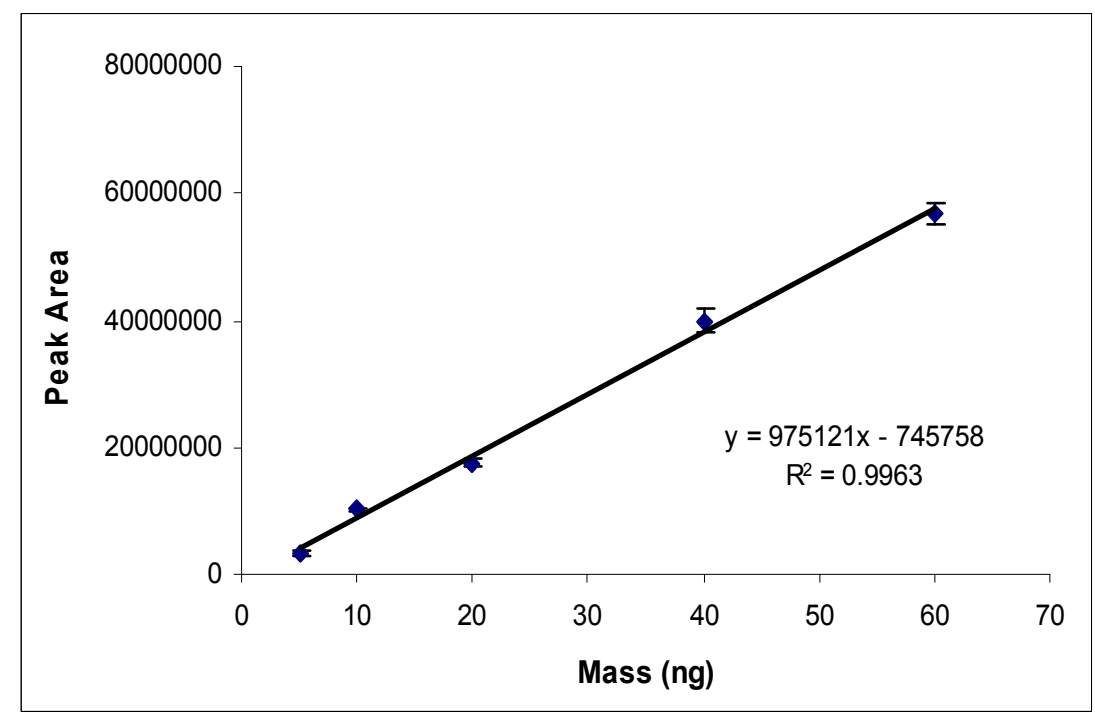


Figure 132: Calibration curve for 1-Octanol

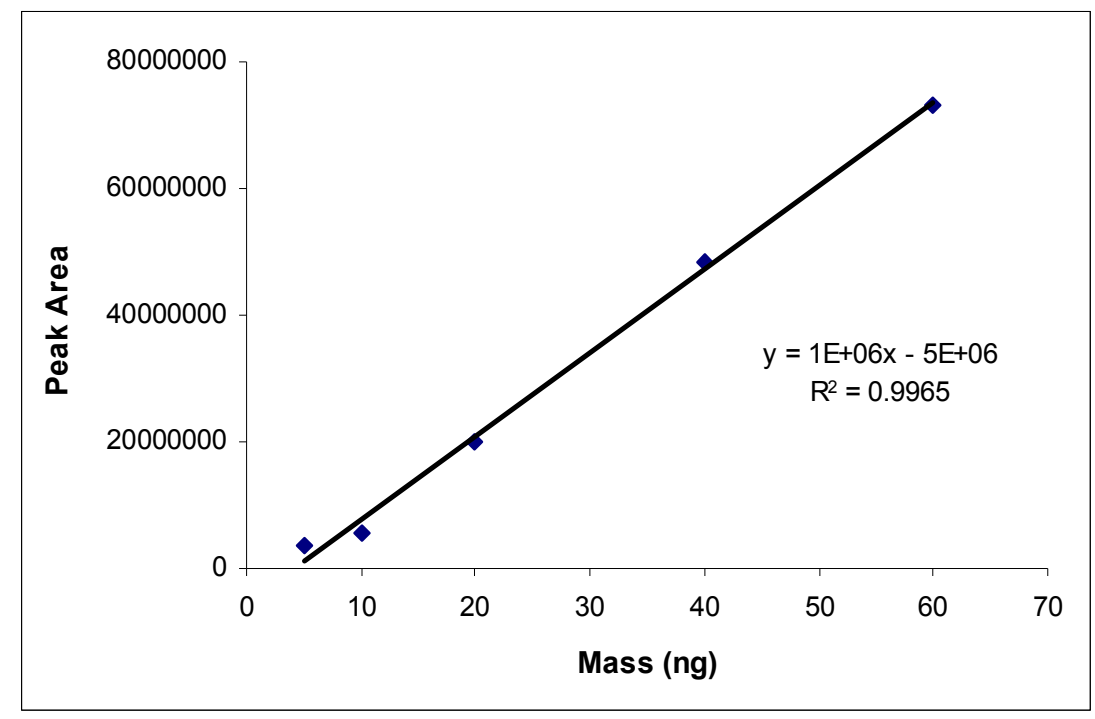

Figure 133: Calibration curve for Nonanal

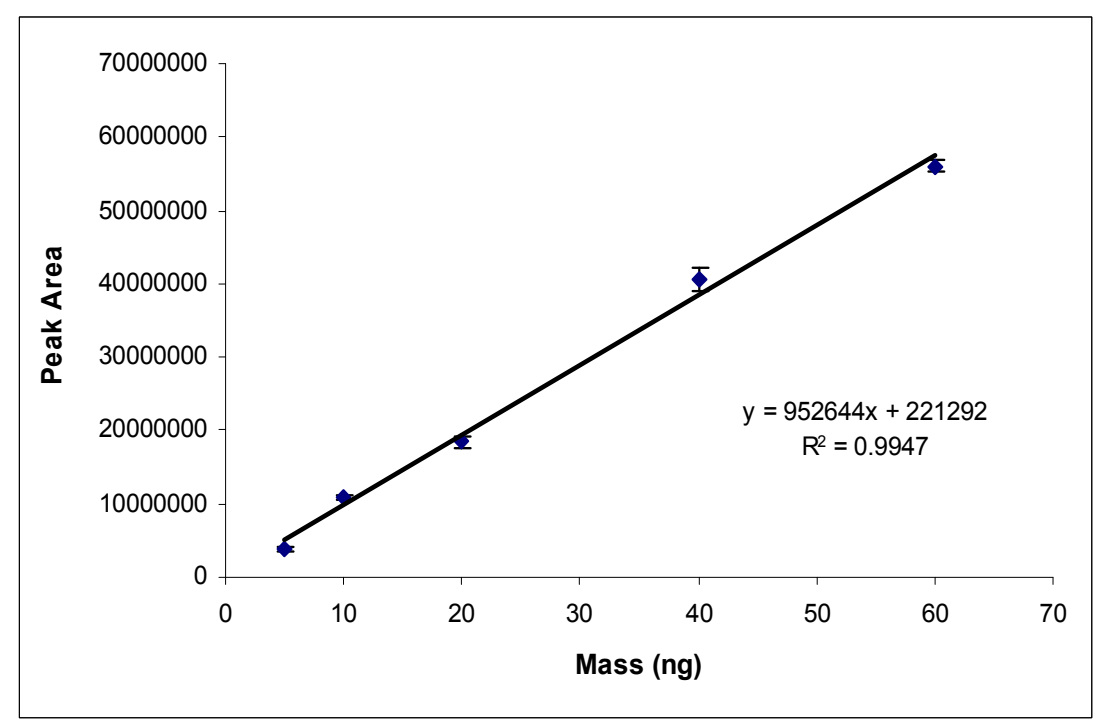


Figure 134: Calibration curve for Phenylethyl alcohol

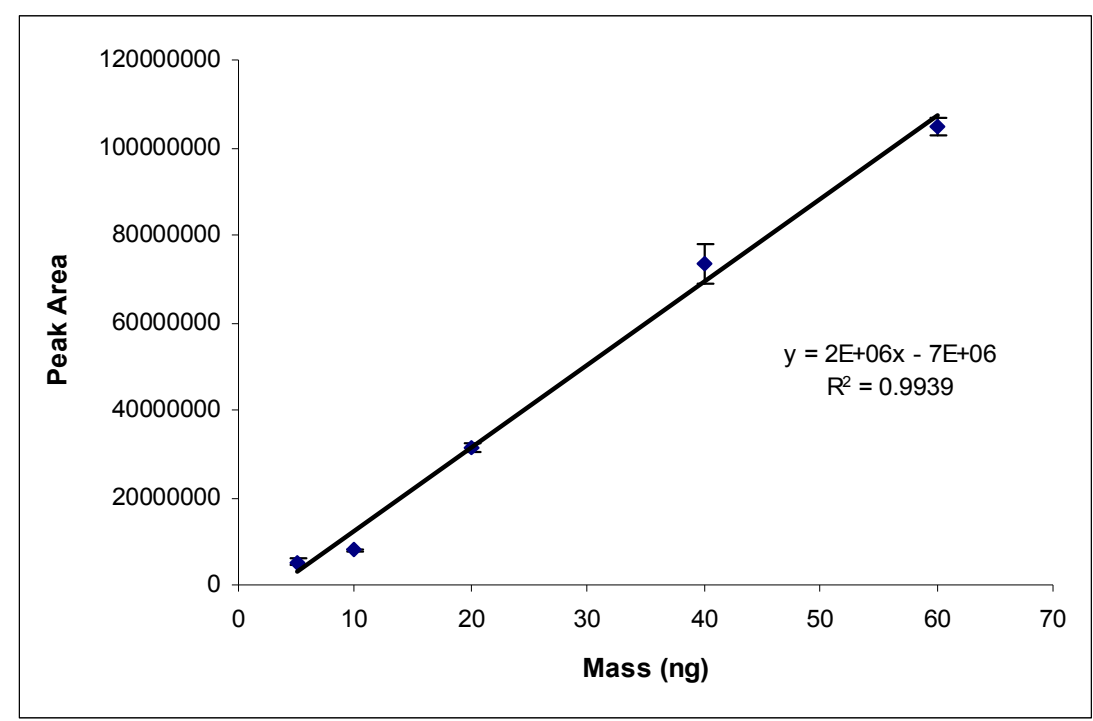

Figure 135: Calibration curve for Octanoic acid methyl ester

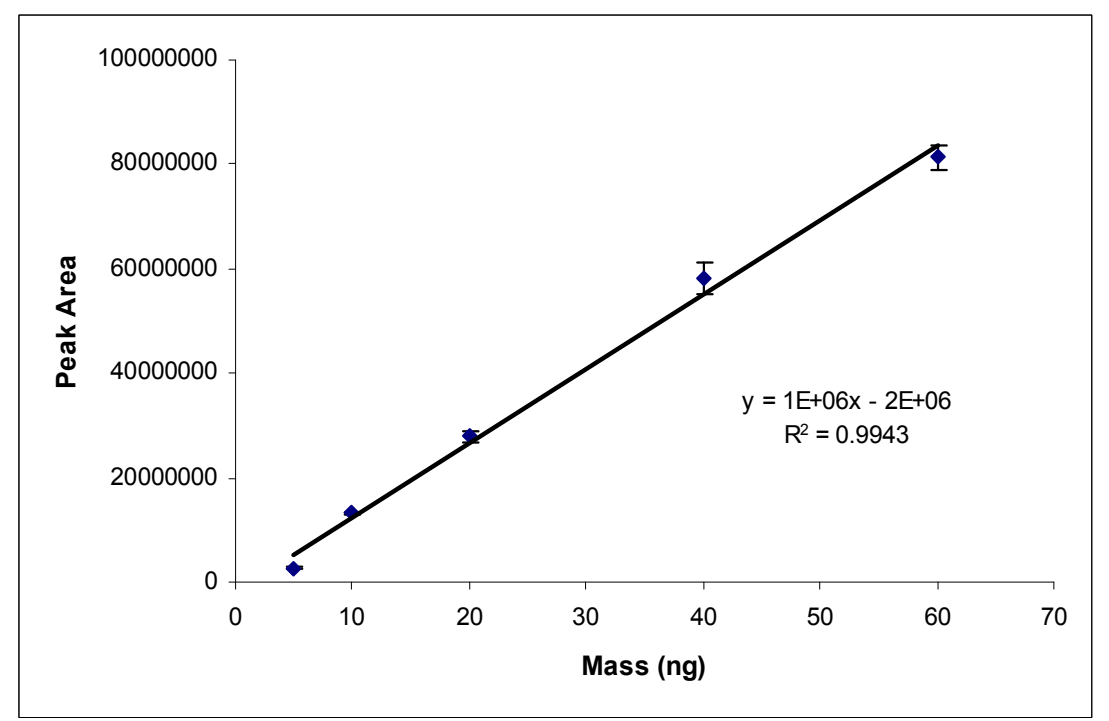


Figure 136: Calibration curve for 1-Nonanol

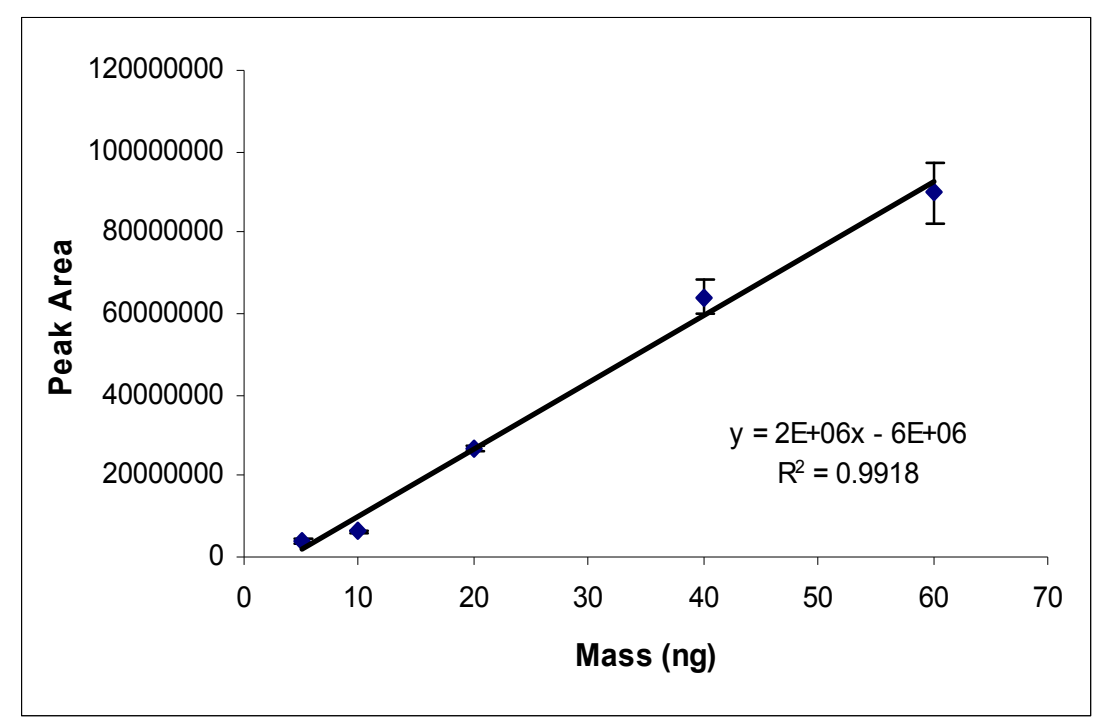

Figure 137: Calibration curve for Naphthalene

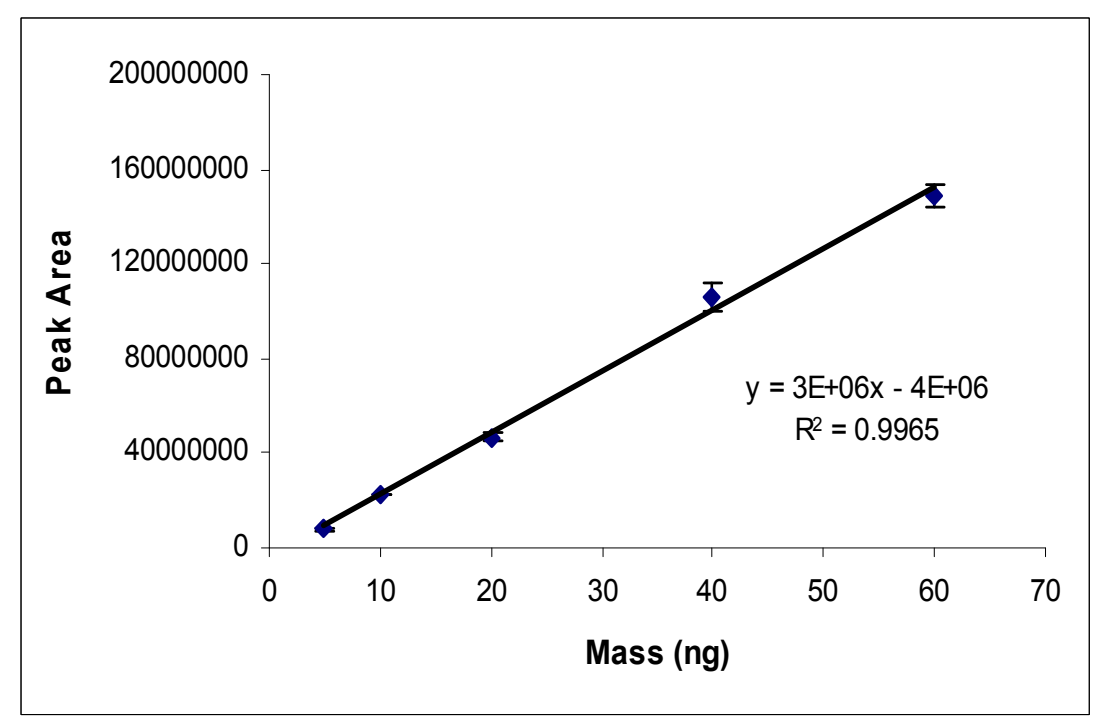


Figure 138: Calibration curve for 2-Decanone

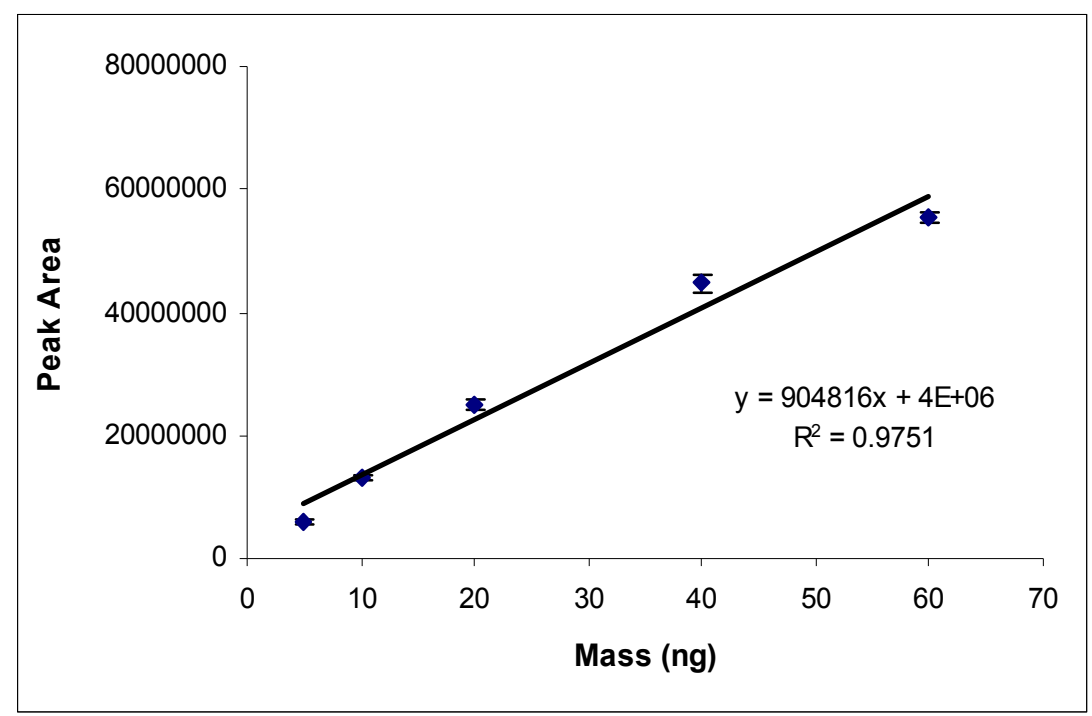

Figure 139: Calibration curve for Dodecane

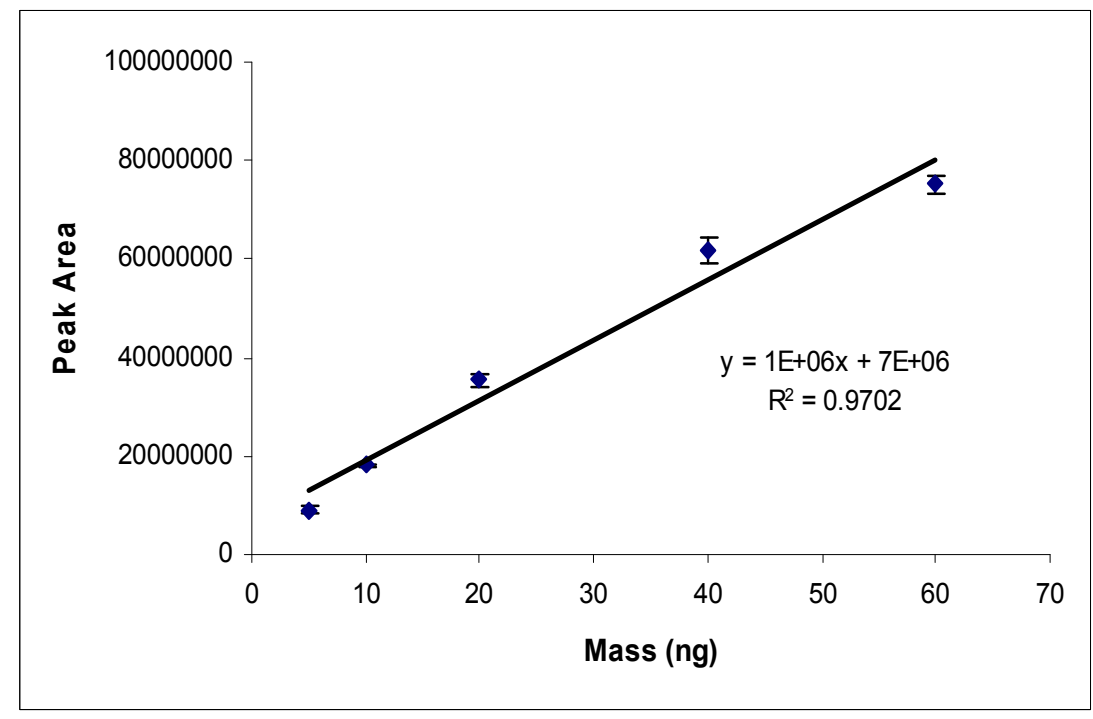


Figure 140: Calibration curve for Decanal

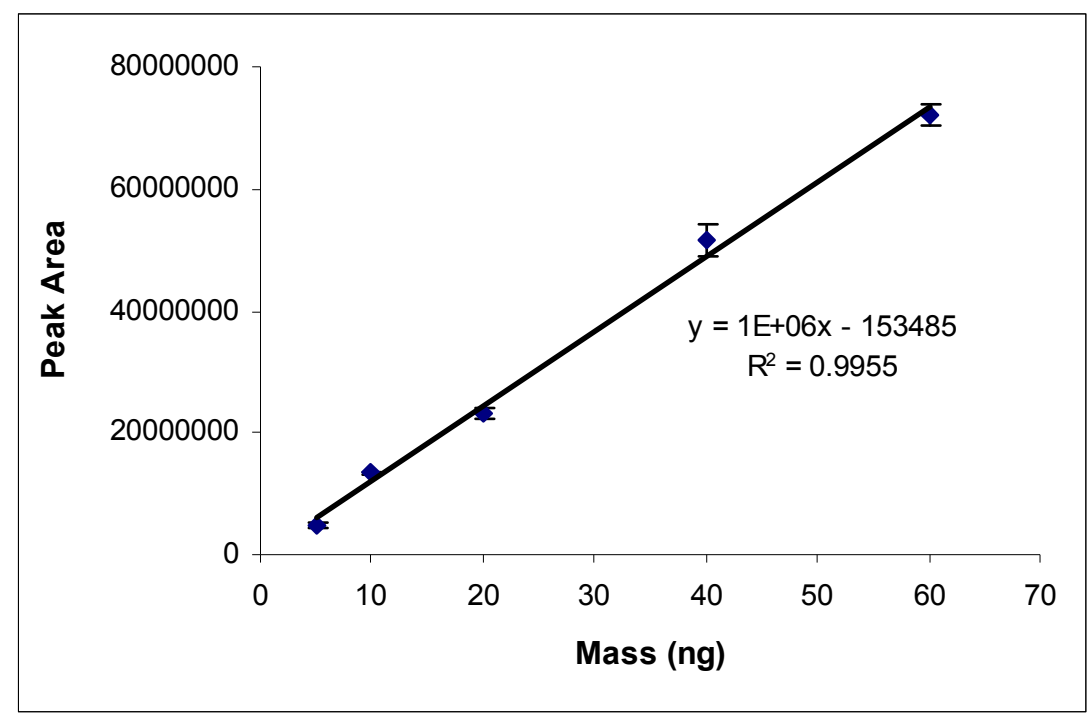

Figure 141: Calibration curve for Hexanedioic acid dimethy ester

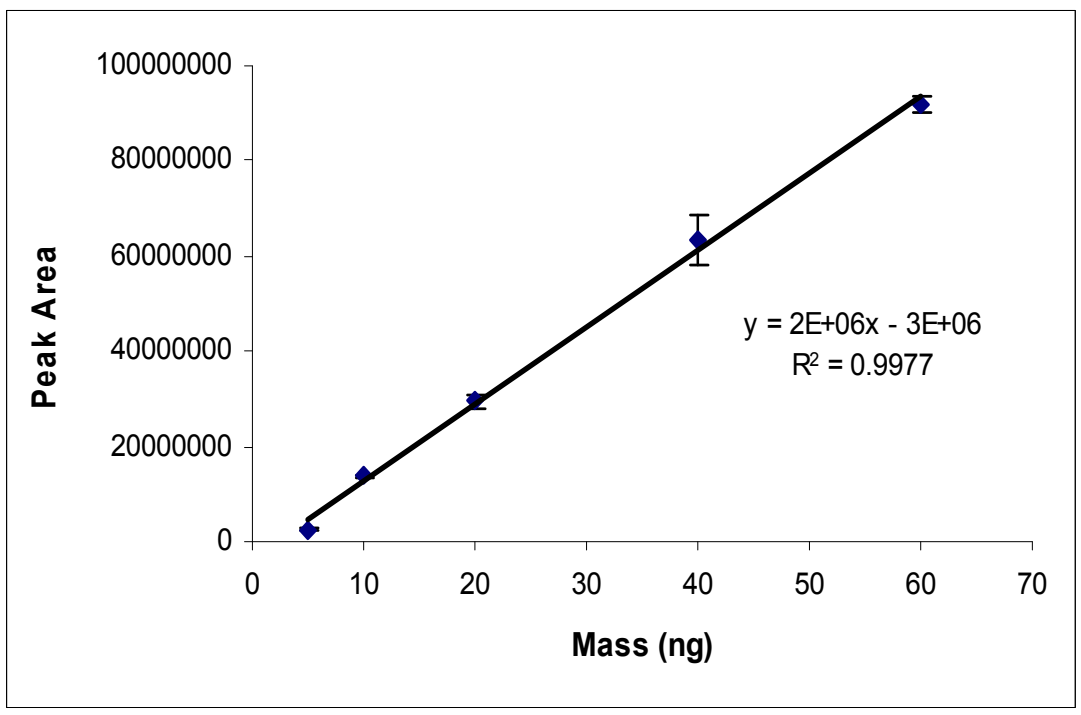


Figure 142: Calibration curve for Tridecane

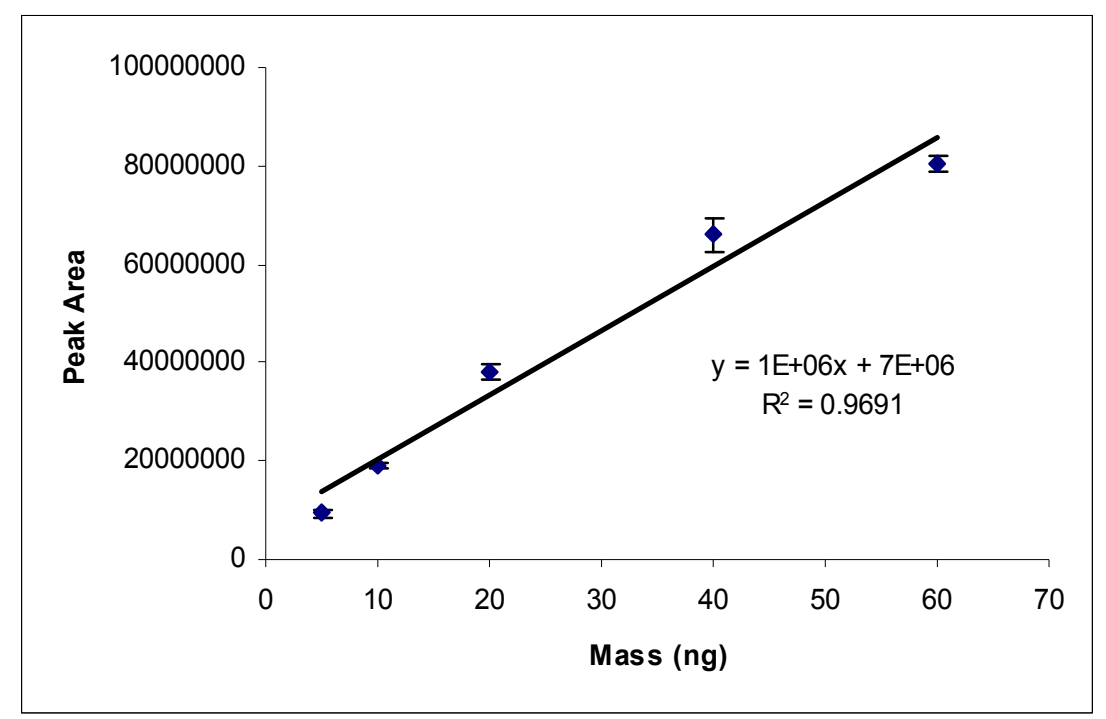

Figure 143: Calibration curve for Undecanal

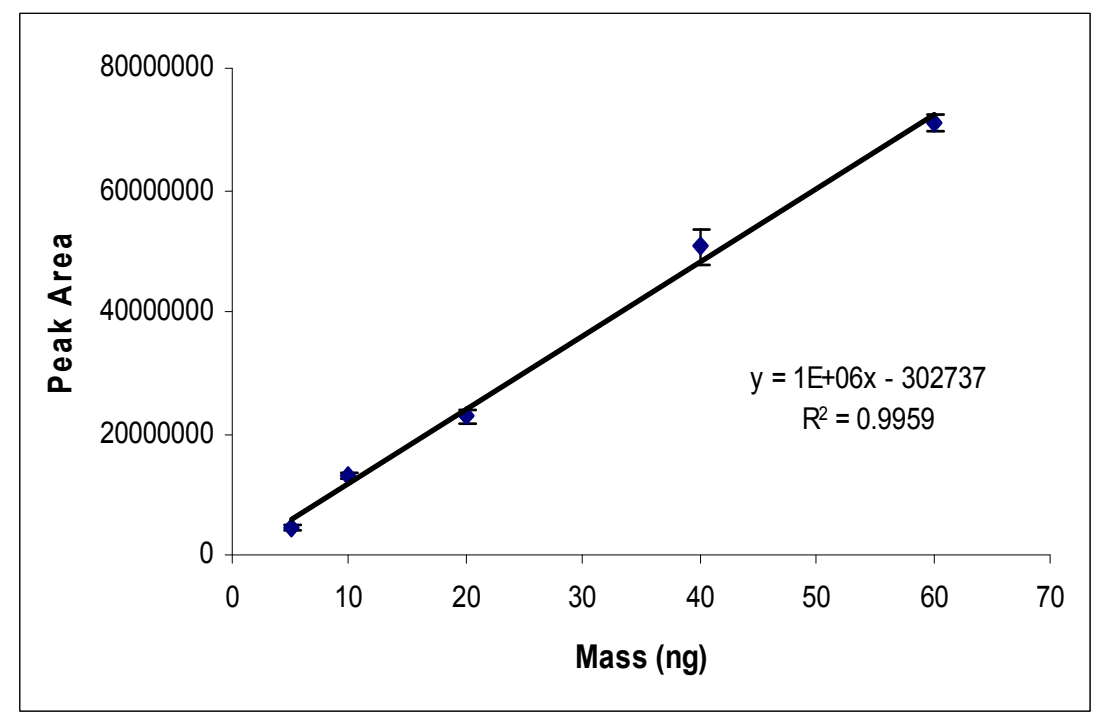


Figure 144: Calibration curve for n-Decanoic acid

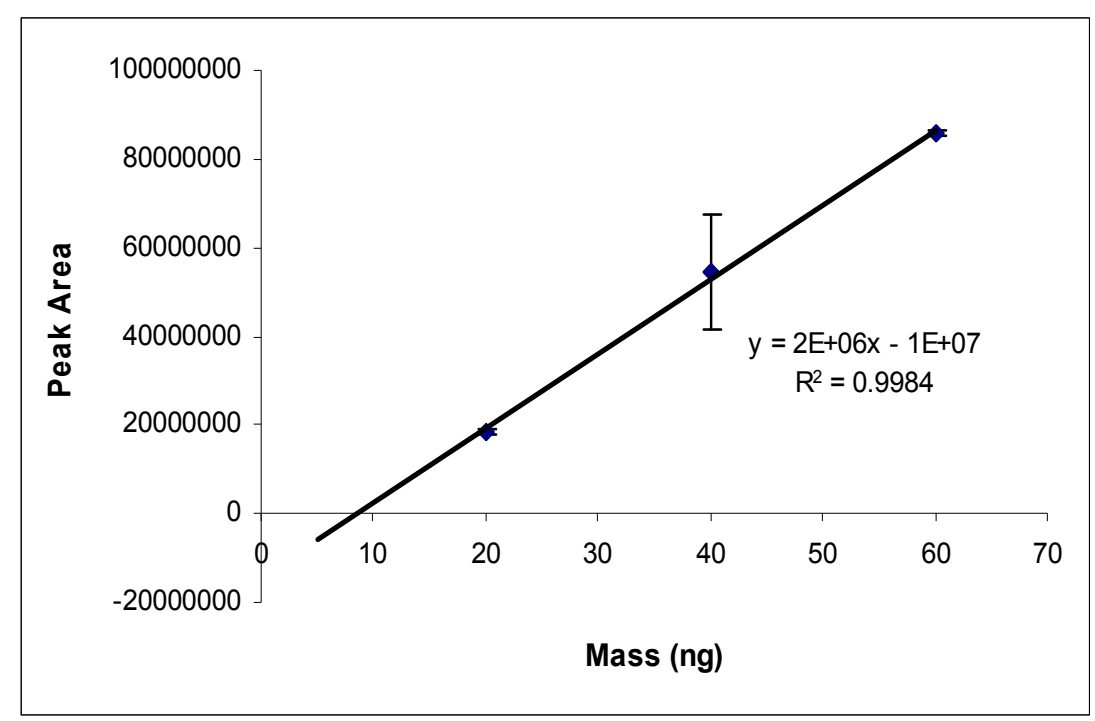

Figure 145: Calibration curve for Tetradecane

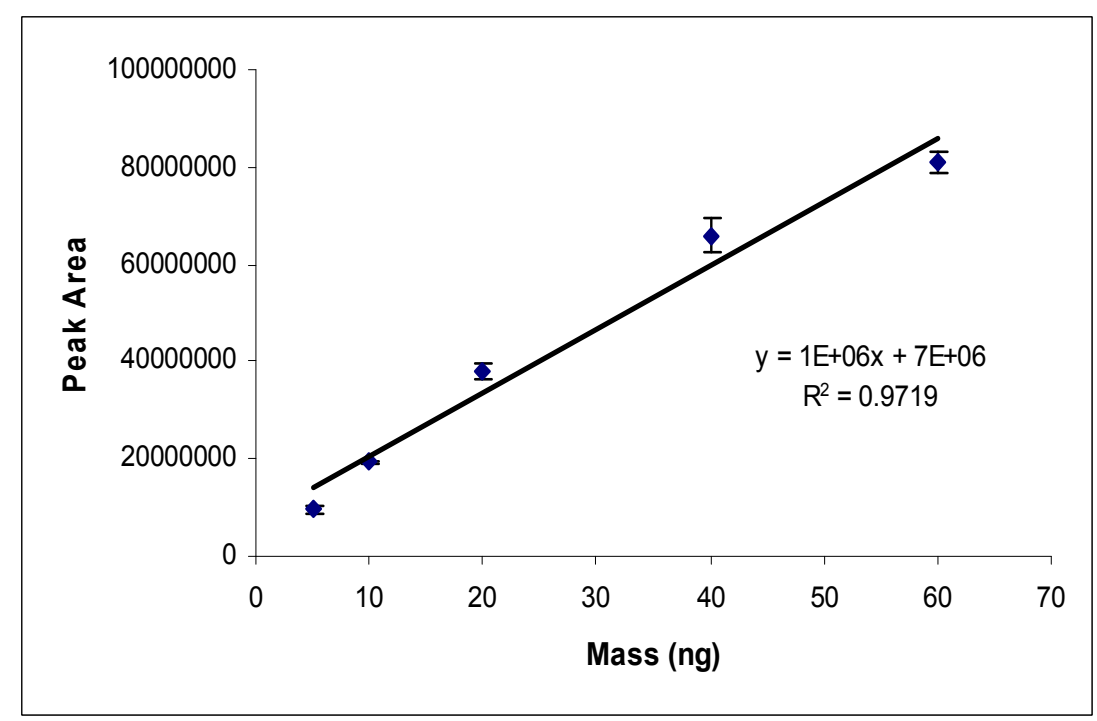


Figure 146: Calibration curve for Dodecanal

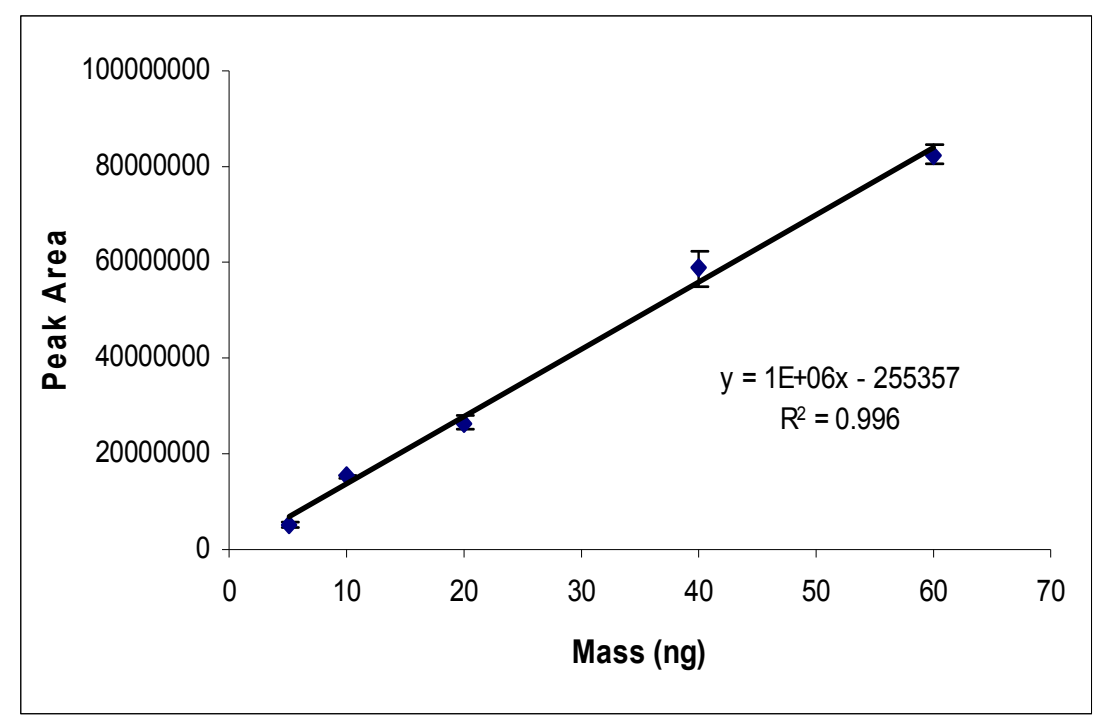

Figure 147: Calibration curve for 6, 10-Dimethyl-5, 9-undecadien-2-one

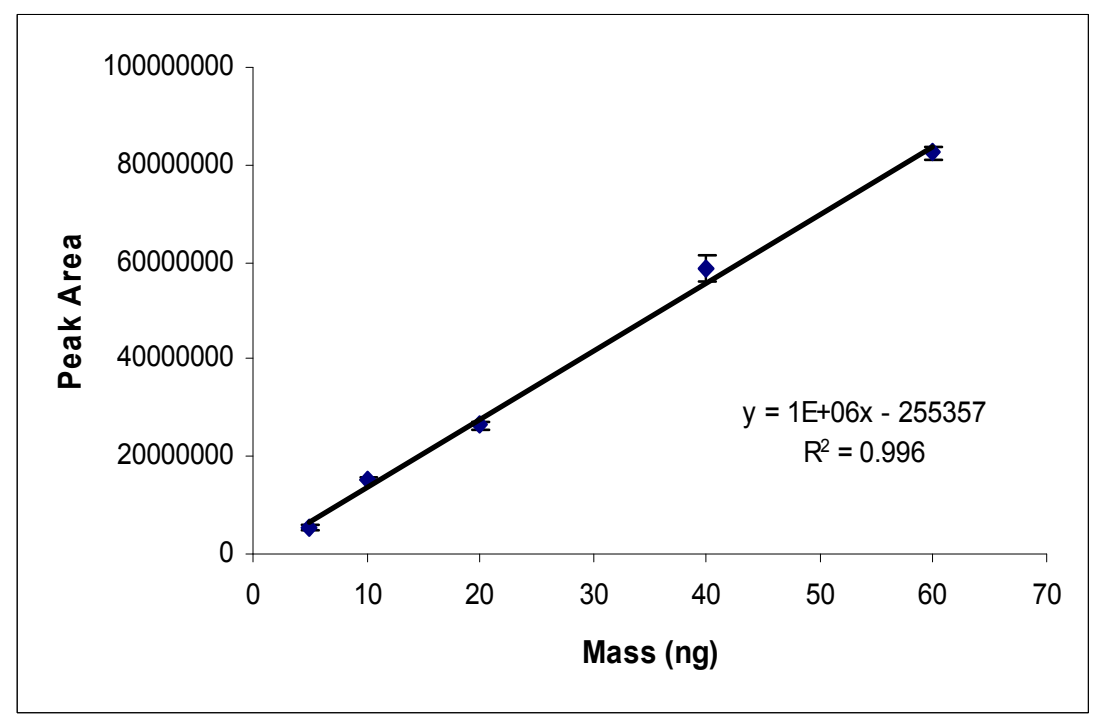


Figure 148: Calibration curve for Pentadecane

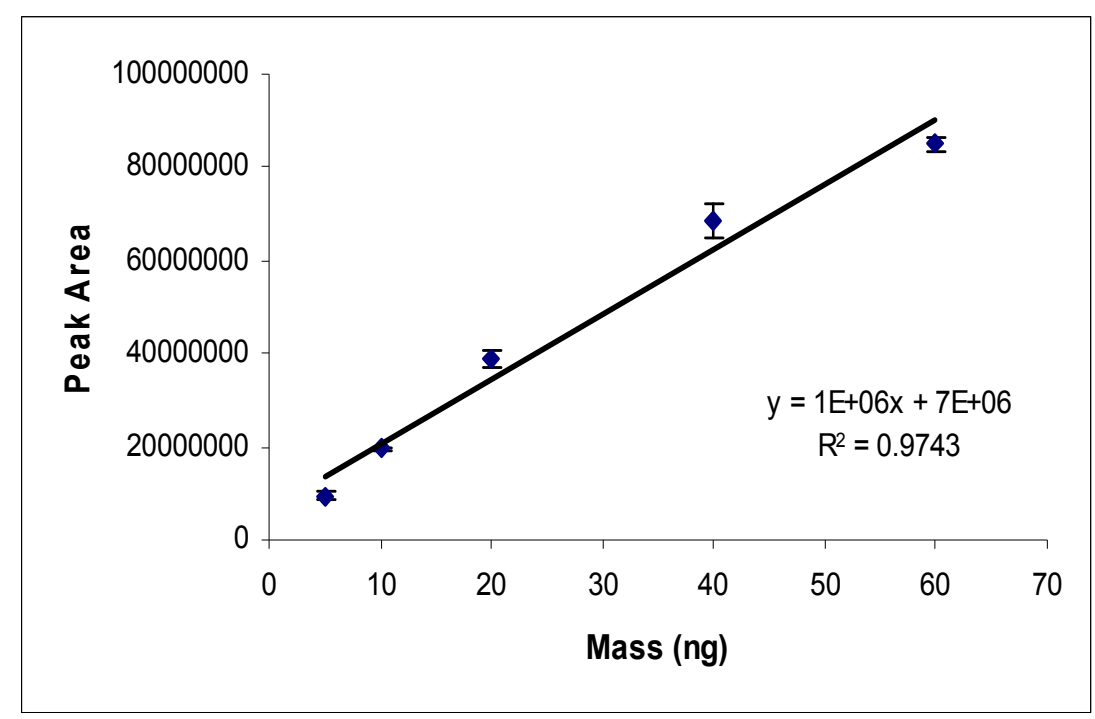

Figure 149: Calibration curve for Tridecanal

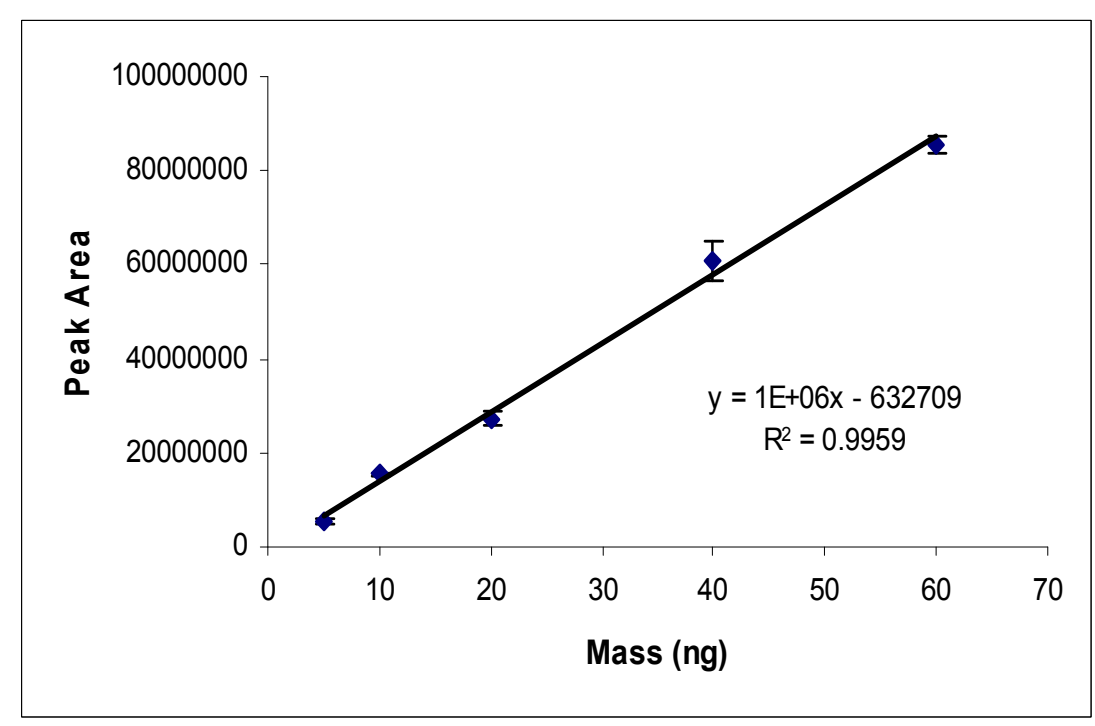


Figure 150: Calibration curve for Dodecanoic acid methyl ester

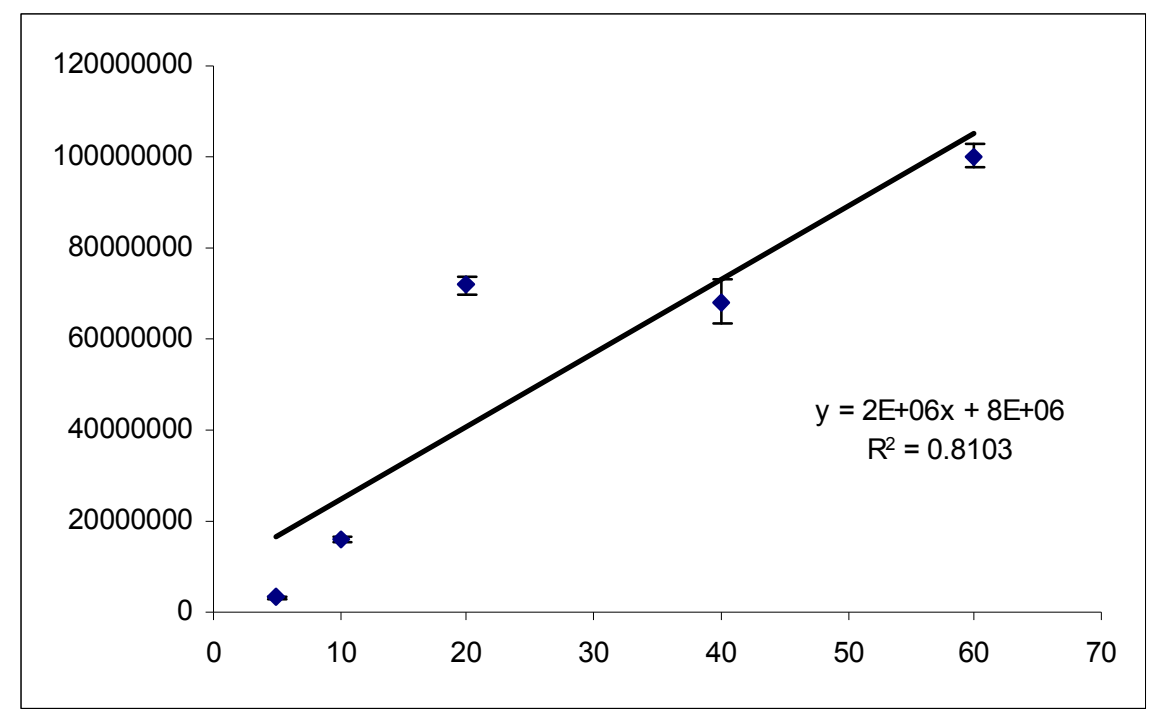

Figure 151: Calibration curve for Dodecanoic acid

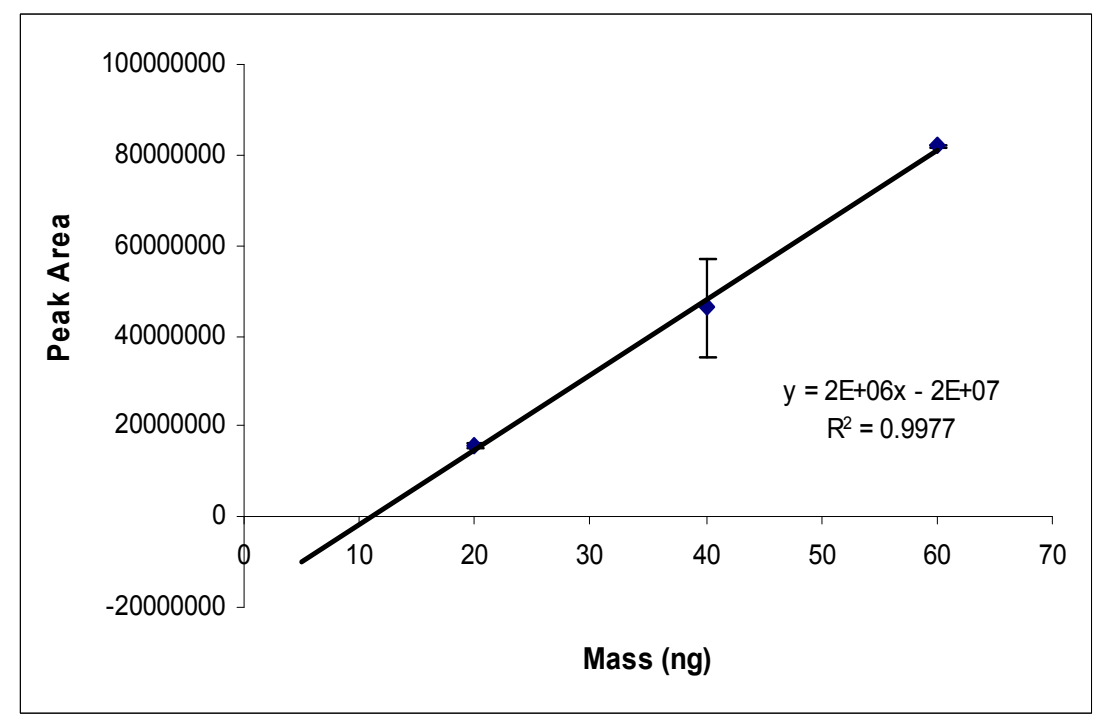


Figure 152: Calibration curve for Hexadecane

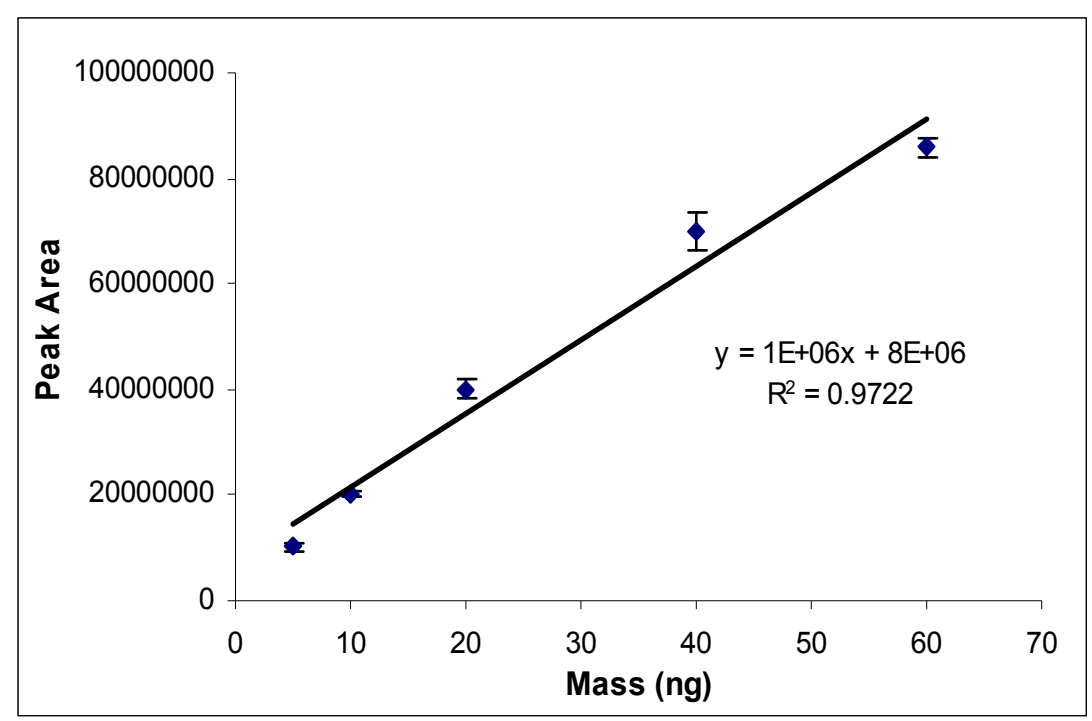

Figure 153: Calibration curve for Heptadecane

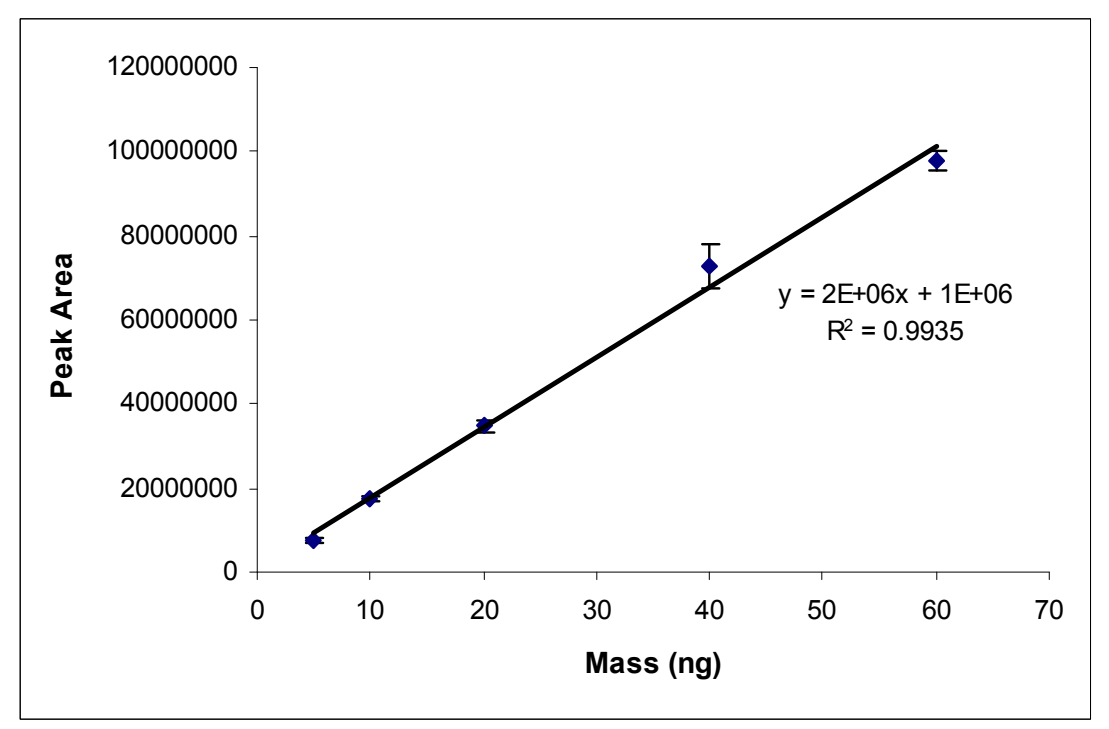


Figure 154: Calibration curve for Methyl tetradecanoate

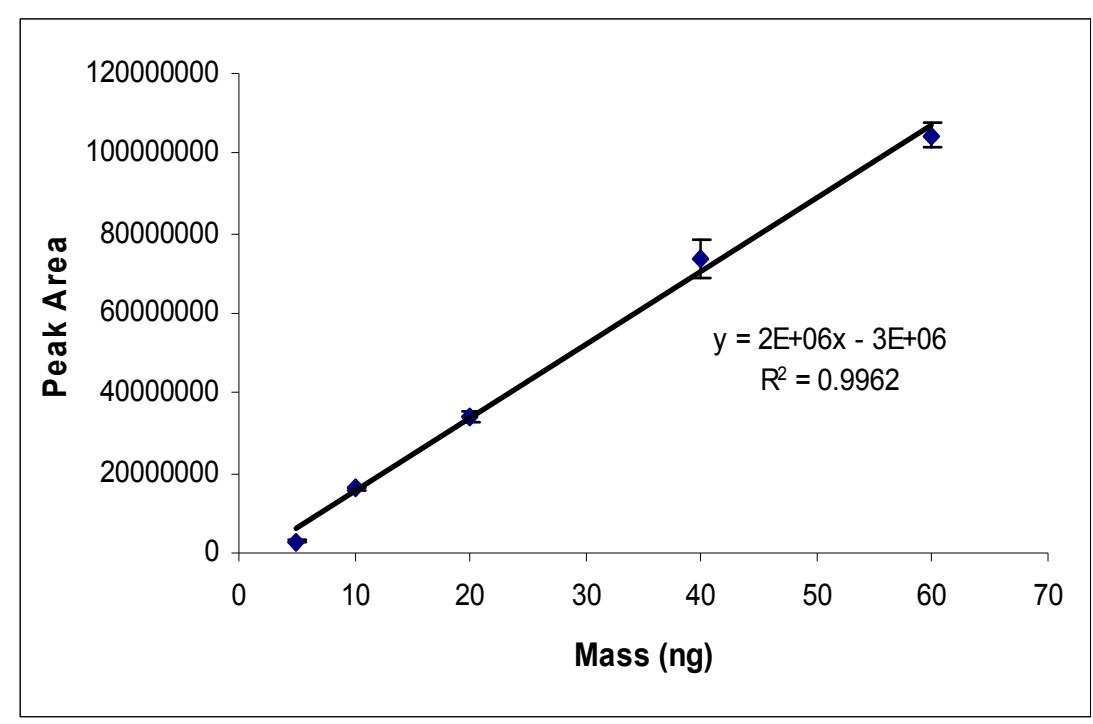

Figure 155: Calibration curve for Pentadecanoic acid

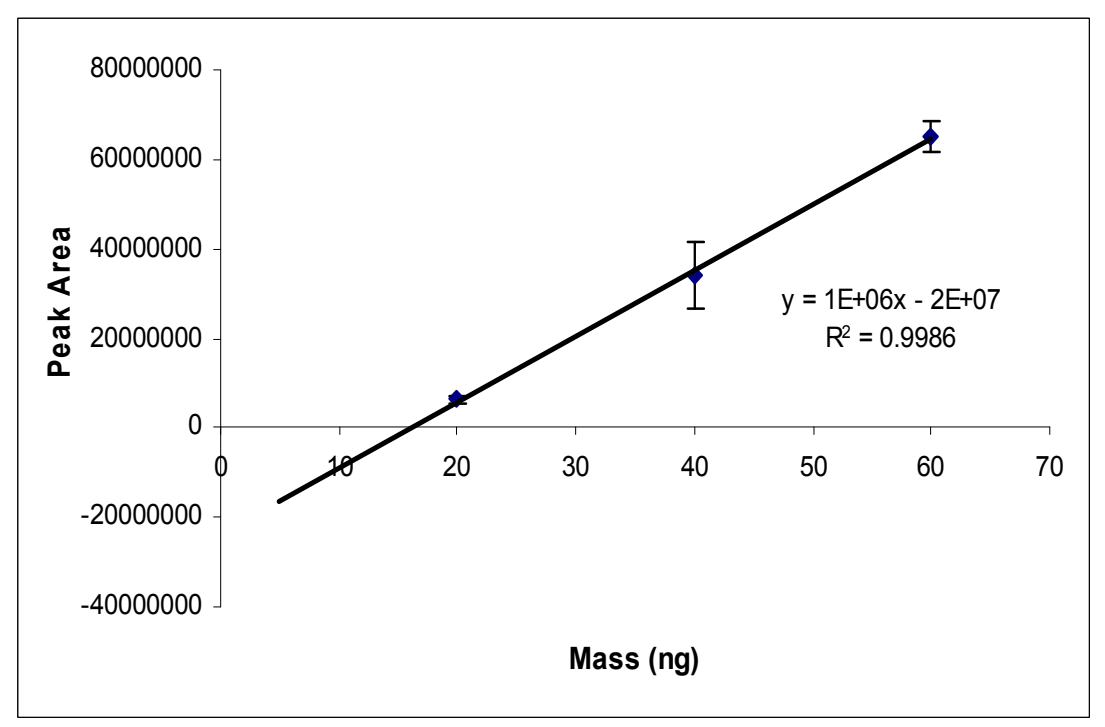


Figure 156: Calibration curve for Hexadecanoic acid methyl ester

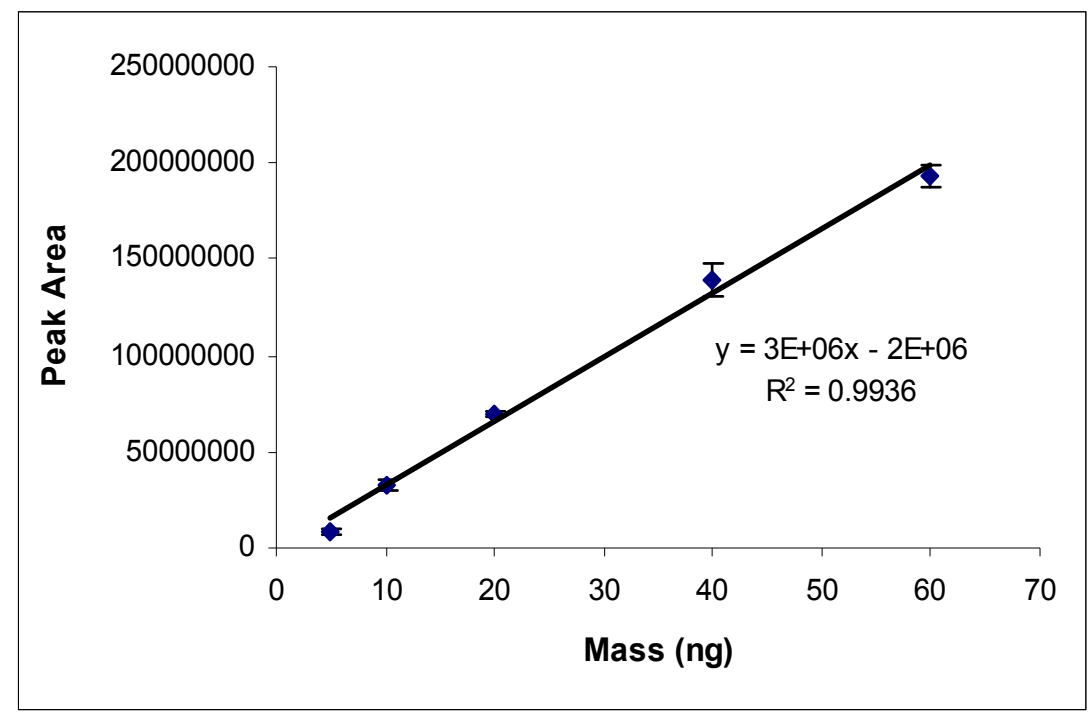


Appendix B

Protocol for DNA extraction and PCR analysis for DNA present in hand odor samples collected on pre-cleaned Solon cotton tipped swabs

\section{Principle}

To extract HMW DNA from swabs obtained individuals after holding pre-cleaned Solon cotton tipped swabs for 10 minutes between the palms of their hands. The procedure will be based on the Qiagen QIAamp ${ }^{\circledR}$ DNA Micro Kit and the recovered DNA will be used for microbial DNA profiling.

\section{General Safety Requirements}

1. Always wear lab coat and gloves.

2. Do not pipette by mouth.

\section{Essentials}

(A) Reagents (QIAamp ${ }^{\circledR}$ DNA Micro Kit)

Proteinase $\mathrm{K}$

Buffer ATL

Buffer AL

$(96-100 \%)$ ethanol

Buffer AW1

Buffer AW2

Buffer AE

(B) Supplies

QIAamp ${ }^{\circledR}$ DNA MicroElute columns

Pipettes and tips $(2 \mu \mathrm{l}, 10 \mu \mathrm{l}, 20 \mu \mathrm{l}, 200 \mu \mathrm{l}, 1000 \mu \mathrm{l})$ (calibrated/certified

Rainin pipettes dedicated to casework)

Sterile microcentrifuge tubes $(1.5$ and $2 \mu 1)$

(C) Equipment

Tweezers

Centrifuge (Eppendorf, 5415D) 
Thermomixer (Eppendorf, AG)

Vortex (Daigger, Vortex Genie 2)

\section{Procedure}

\section{Preparation of work bench and supplies}

1.1. Turn on laboratory UV light for 1 hour prior to procedure.

1.2. Turn off UV light.

1.3. Turn on visible light.

1.4. Clean bench space with 5\% hypochlorite, water and ethanol.

1.5. Cut enough VersiDry (Fisher Scientific) to cover the area that will be used for the extraction.

1.6. Set thermomixer to $56{ }^{\circ} \mathrm{C}$.

\section{Sample preparation}

2.1. Use tweezers to transfer one (already pre-cut swab) from the sample container to a $2 \mathrm{ml}$ micro centrifuge tube.

NOTE: Tweezers should be decontaminated between samples in 95-100\% ethanol and allowed to dry before transferring the next sample swab.

\section{Extraction}

3.1. Add $20 \mu 1$ Proteinase $\mathrm{K}$ to the sample.

3.2. Add $400 \mu \mathrm{l}$ Buffer ATL to the sample. Mix by pulse vortexing for $10 \mathrm{~s}$.

\subsubsection{NOTE: DO NOT add Proteinase K directly to Buffer ATL.}

3.3. Incubate sample at $56{ }^{\circ} \mathrm{C}$ with shaking for at least 1 hour.

3.4. Briefly centrifuge samples to remove drops from inside the lid.

3.5. Add $400 \mu 1$ Buffer AL to the sample, close the lid and mix by vortexing

$$
\text { 3.5.1.1.for } 15 \mathrm{~s} \text {. }
$$

3.6. Incubate tubes at $70{ }^{\circ} \mathrm{C}$ with shaking at $900 \mathrm{rpm}$ for $10 \mathrm{~min}$.

3.7. Briefly centrifuge the tube to remove drops from inside the lid. 
3.8. Add $200 \mu 1$ ethanol (96-100\%) and mix by vortexing for $15 \mathrm{~s}$.

3.9. Briefly centrifuge to remove drops from inside the lid.

3.10. Carefully transfer the entire lysate to a QIAamp MiniElute Column without wetting the rim.

3.11. Close the lid and centrifuge at $6000 \mathrm{xg}$ for $1 \mathrm{~min}$.

3.12. Place the QIAamp MiniElute Column in a clean $2 \mathrm{ml}$ collection tube and discard the tube containing the filtrate.

3.13. Carefully open the QIAamp MiniElute Column and add $500 \mu 1$ Buffer

3.14. AW1 without wetting the rim.

3.15. Close the lid and centrifuge at $6000 \mathrm{x} \mathrm{g}$ for 1 minute. Place the column in a new $2 \mathrm{ml}$ collection tube and discard the tube containing the filtrate.

3.16. Carefully open the QIAamp MiniElute Column and add $500 \mu 1$ Buffer

3.17. AW2 without wetting the rim. Close the lid and centrifuge at $6000 \mathrm{x} g$ for 1 minute

3.18. Place the QIAamp MiniElute Column in a new $2 \mathrm{ml}$ collection tube and discard the tube containing the filtrate.

3.19. Centrifuge at $20,000 \mathrm{x}$ g for 3 minutes.

3.20. Place the QIAamp MiniElute Column in a sterile $1.5 \mathrm{ml}$ microcentrifuge tube and discard the tube containing the filtrate.

3.21. Carefully open the QIAamp MiniElute Column and add $30 \mu 1$ Buffer AE.

3.22. Incubate at room temperature for 1 minute, and then centrifuge at $20,000 \mathrm{x}$ $\mathrm{g}$ for 1 minute.

3.23. Label and store at $4{ }^{\circ} \mathrm{C}$ until ready to dilute. 
Appendix C

Protocol for DNA extraction and quantitation from telogen shed hair

\section{Purpose}

To extract and purify human DNA from telogen (shed) hairs

\section{Safety}

All laboratory safety procedures will be complied with during this procedure.

\section{Reagents, Supplies, and Equipment}

Reagents:

Differential extraction buffer (DEB)

Proteinase K

Hair Extraction Buffer (HEB)

DTT

$0.9 \% \mathrm{NaCl}$ solution

Absolute ethanol

$70 \%$ Phenol/Chloroform/Water $\left(\mathrm{PCH}_{2} \mathrm{O}\right)$

PCR dd $\mathrm{d}_{2} \mathrm{O}$

Supplies:

$600 \mu \mathrm{L}$ flat cap tubes

100-1000 $\mu \mathrm{L}$ pipettor

100-1000 $\mu \mathrm{L}$ barrier pipet tips

10-100 $\mu \mathrm{L}$ pipettor

10-100 $\mu \mathrm{L}$ barrier pipet tips 
$0.5-10 \mu \mathrm{L}$ pipettor

10XL $\mu \mathrm{L}$ barrier pipet tips

Microcon YM-30 Filtration columns

Gloves

Tweezers

Kim Wipes

$15 \mathrm{~mL}$ centrifuge tubes

Equipment:

Shaking water bath

Tube racks

Waterproof container

Analytical Balance

Microcentrifuges

\section{General}

a. Procedure will be used for extracting and purifying human DNA from telogen hairs

b. Procedure will be used as necessary for research

c. Gloves should be worn at all times

d. Phenol chloroform should be used in the hood

\section{Procedure}

a. Add $300 \mu \mathrm{L}$ of $\mathrm{DEB}$ to tubes containing hair samples

b. Add $2 \mu \mathrm{L}$ of Proteinase $\mathrm{K}$ to each tube, and use pipet tip to push hair down into the solution. 
c. Place capped tubes 1 half of tube rack, and place tube rack in waterproof container.

d. Place container in shaking water bath that has been preheated to $56^{\circ} \mathrm{C}$ and shake for 2 hours.

e. Remove tubes from bath, and spin down in centrifuges. Remove buffer from tubes without removing hair using the $100-1000 \mu \mathrm{L}$ pipettor and barrier tips. Change tips between samples. If extraction is to be done on differential buffer, transfer to a new $600 \mu \mathrm{L}$ tube and label and set aside.

f. Add $500 \mu \mathrm{L}$ of the $0.9 \% \mathrm{NaCl}$ to each tube. Remove $\mathrm{NaCl}$ solution without removing hair.

g. Add $500 \mu \mathrm{L}$ of absolute ethanol to each tube.

h. Label new $600 \mu \mathrm{L}$ tubes for each sample. Remove hairs from ethanol and transfer to appropriate new tube with tweezers. Clean and dry tweezers between samples.

i. Weight out $15 \mathrm{mg}$ of DTT, and add to $15 \mathrm{~mL}$ of HEB in $15 \mathrm{~mL}$ tubes. Shake to dissolve DTT.

j. Add $300 \mu \mathrm{L}$ of HEB with DTT to each new sample tube.

k. Add $4 \mu \mathrm{L}$ of Proteinase $\mathrm{K}$ to each tube, and use pipet tip to push hair down into the solution.

1. Place capped tubes 1 half of tube rack, and place tube rack in waterproof container.

$\mathrm{m}$. Place container in shaking water bath that has been preheated to $56^{\circ} \mathrm{C}$ and shake for 2 hours. 
n. Remove tubes from bath, and spin down in centrifuges.

o. Add $300 \mu \mathrm{L}$ of $\mathrm{PCH}_{2} \mathrm{O}$ to each sample tube. Work in the fume hood.

Shake tube until solution is milky. (Add to differential buffers at this time if extracting from those buffers).

p. Centrifuge tubes at $5000 \mathrm{rpm}$ for 2 minutes.

q. Assemble Microcon filters and label for each sample.

r. Remove aqueous (top) layer and transfer to filter cup of Microcons. Use the $10-100 \mu \mathrm{L}$ pipettor and tips, and be careful not to remove any of the organic (bottom) layer.

s. Spin tubes at 13,000 rpm for 12 minutes. Discard filtrate.

t. Add $200 \mu \mathrm{L}$ PCR $\mathrm{ddH}_{2} \mathrm{O}$ to filter cup.

u. Spin tubes at 13,000 rpm for 12 minutes.

v. Remove caps from Microcon tubes and label for each sample.

w. Add $60 \mu \mathrm{L}$ of PCR ddH $\mathrm{H}_{2} \mathrm{O}$ directly to filter in filter cup. Invert cup into capless tubes.

$\mathrm{x}$. Spin at $5000 \mathrm{rpm}$ for 2 minutes.

y. Discard filter cup and cap tubes. Store at $4^{\circ} \mathrm{C}$ overnight before quantification. 


\section{Alu-based Real-Time PCR Quantitation Method for telogen shed hairs}

\section{Purpose}

To quantify human DNA using Real Time PCR, Alu primers, and SYBR Green I dye.

\section{Safety}

All laboratory safety procedures will be complied with during this procedure. SYBR Green Dye is a mutagen/carcinogen. Appropriate handling procedures should be followed.

\section{Reagents, Supplies, and Equipment}

$\underline{\text { Reagents }}$

SYBR Green I dye

DMSO

PCR dd $\mathrm{H}_{2} \mathrm{O}$

10* ABI Buffer I

$\mathrm{MgCl}_{2}(25 \mathrm{mM})$

dNTPs $(2.5 \mathrm{mM})$

Amplitaq Gold or RampTaq hot start Taq polymerase $(5 \mathrm{U} / \mu \mathrm{L})$

Triton X 100 (10\% solution)

Nonacetylated BSA $(20 \mathrm{mg} / \mathrm{mL})$

Alu primers, numbers 1 and 2 for large fragments, 1 and 60 for small fragments (100 $\mathrm{pmol} / \mu \mathrm{L})$ 
9948 DNA standard

Supplies

$0.2 \mathrm{~mL}$ flat cap PCR tubes

$2 \mathrm{~mL}$ flat cap micro centrifuge tubes

Rainin $0.5-10 \mu \mathrm{L}$ pipet tips

10-100 $\mu \mathrm{L}$ pipet tips

Rainin electronic pipettor (multichannel, 0.5-10 $\mu \mathrm{L}$ )

10-100 $\mu \mathrm{L}$ pipettor

Gloves

Bench paper

\section{$\underline{\text { Equipment }}$}

Rainin electronic pipettor (multichannel, 0.5-10 $\mu \mathrm{L}$ )

10-100 $\mu \mathrm{L}$ pipettor

Corbett Rotor Gene 3000 Real Time PCR

36 sample rotor

\section{General}

1. Procedure will be used for preparing and quantifying extracted human genomic DNA samples

2. Procedure will be used as necessary for research.

3. Gloves should be worn at all times. 


\section{Procedure}

1. Preparation of $0.5 \%$ working solution of SYBR Green I (Molecular Probes, Eugene, OR)

a. Take $1 \mu \mathrm{L}$ of $10,000 \mathrm{X}$ concentrated Sybr Green I and add $199 \mu \mathrm{L}$ of DMSO. Prepare aliquots for future use.

2. Prepare DNA standards.

a. Use 9948 DNA standard, dilute to $1,0.1$ and $0.05 \mathrm{ng} / \mu \mathrm{L}$ for $\mathrm{LCN}$, or

b. Use 9948 as $10 \mathrm{ng} / \mu \mathrm{L}$ and dilute to $1 \mathrm{ng} / \mu \mathrm{L}$ and $0.1 \mathrm{ng} / \mu \mathrm{L}$ for buccal swab samples

3. Prepare DNA samples to be quantified: spin down before opening tubes.

4. Prepare 36 flat-top tubes, label them on the cap. Of the 36 , label 2 sets of standards and 1 NTC (no template control).

5. Prepare and vortex Alu Mix for 36 samples:

a. Mix $542.0 \mu \mathrm{L}$ PCR $\mathrm{H}_{2} 0,84.0 \mu \mathrm{L} 10^{*}$ ABI Buffer I, $67.0 \mu \mathrm{L}$ dNTPs, $50.0 \mu \mathrm{L} \mathrm{MgCl}_{2}, 14 \mu \mathrm{L}$ Taq polymerase, $8.4 \mu \mathrm{L}$ Alu Primer 1 (forward), $8.4 \mu \mathrm{L}$ Alu Primer 2 (large) or 60 (small) (reverse), $8.4 \mu \mathrm{L}$ TritonX $10 \%, 8.4 \mu \mathrm{L}$ SYBR green solution, $8.4 \mu 1 \mathrm{BSA}$ in $2 \mathrm{ml}$ tube.

b. Spin down before opening tube.

6. Pipet $19 \mu \mathrm{L}$ of Alu Mix into labeled PCR microtubes.

7. Add DNA
a. Add $1 \mu \mathrm{L}$ of standard or DNA sample to each tube.
b. Add $1 \mu 1 \mathrm{ddH}_{2} 0$ to NTC tube.
c. Vortex and mix. 
d. Remove bubbles and spin down.

8. Turn on PC and turn on the Rotor Gene instrument

9. Clean accessible optics with cotton Q-tip and ethanol.

10. Place tubes on the appropriate wells of the carousel and place ring on top.

Align carousel in the chamber. Screw in the cap with the red dot on top. Close cover.

11. Select SYBR Green program and click "New"

12. Edit profile (if needed)

$\begin{array}{ll}\text { Denature } & 95{ }^{0} \mathrm{C} 10 \text { minutes } \\ \text { Denature } & 96{ }^{0} \mathrm{C} 10 \text { seconds } \\ \text { Cycles } & 45 \\ \text { Cycling } & 95{ }^{0} \mathrm{C} 15 \mathrm{~s}, 55{ }^{0} \mathrm{C} 20 \mathrm{~s}, 72{ }^{0} \mathrm{C} 20 \mathrm{~s} \\ \text { Melt: Ramp from } & \text { acquiring to cycling onSybr Green } \\ \text { Rising by } 1{ }^{\circ} \mathrm{C} \text { each step } & 12{ }^{0} \mathrm{C} \text { to } 99{ }^{0} \mathrm{C}\end{array}$

14. Start run, go to correct folder to name an experiment with "dateName samples".

15. During run, fill the sample table: distinguish between DNA samples, no template control (NTC), and standards. Fill in the given concentrations in the "given concentration" column for standards and sample names for other sample tubes. 
16. When experiment is completed, click Analysis-Quantitation-Show. New windows will appear and a box in the middle - click Cancel.

17. Fill:

Slope correct
$\begin{aligned} & \text { Eliminate cycles before } \\ & \text { Threshold }\end{aligned}$
When the box comes up, click OK

18. The standard curve, fluorescence threshold cycle $(\mathrm{Ct})$ and concentrations of samples will be calculated. The standard curve should have an efficiency and $r$ value close to 1.00. You can choose to exclude those standard samples that cause give errors.

19. If raw data is good but not quantitated, click on the "quantitative settings" and decrease the threshold to $2 \%(1 \%)$.

20. Click "reports" in the upper left of the Quantitation window - Full Report Send to Word and save.

21. Click Analysis-Melt.

22. Check if melting curve has two peaks (first is smaller). 


\section{Appendix D}

Glossary of Terms

\section{Headspace Sampling}

The protective sheath of the SPME fiber pierces the septum of the vial containing the sample. The plunger is lowered to immerse the SPME fiber to the space above the sample. The SPME fiber does not come into contact with the sample.

\section{Flame ionization detector (FID)}

Flame ionization detector is one of the most widely used detectors for gas chromatography. It possesses a burner in which the effluent from the GC column is mixed with air and hydrogen and then ignited electrically. Most organic compounds can be pyrolyzed in the hydrogen/air flame, producing ions and electrons that can conduct electricity. A collector is present which can measure the electricity produced which is proportional to the amount of sample which was burnt.

\section{$\underline{\text { Limit of Detection (LOD) }}$}

This can be defined as the lowest quantity of a substance that can be distinguished from the absence of that substance (a blank value) within a stated confidence limit.

\section{Covariance Matrix}

A matrix in which the rows and columns are variables and the entries are covariances.

\section{$\underline{\text { STU }-100^{\mathrm{TM}}-\text { Scent Transfer Unit }}$}

This is a portable vacuum that uses airflow to capture volatiles from an article of evidence onto a sorbent material.

$\underline{\operatorname{Lux}}$

This is a measurement of light intensity. E.g. a brightly lit office would be 400 lux. 


\section{$\underline{\text { UVA/UVB Light - Ultra violet light }}$}

Ultra violet light is electromagnetic radiation which is found as part of the radiation received by the earth from the sun.

$\underline{D N A}$

DNA stands for deoxyribonucleic acid and it is the genetic material which is found in the nucleus of cells.

$\underline{P C R}$ - Polymerase Chain Reaction

This is a technique used in molecular biology to amplify small quantities of DNA. It consists of three steps; (1) denaturation, (2) annealing and (3) extension/elongation. $\underline{\text { RFLP - Restriction length polymorphism }}$

This is the variation in the DNA sequence of a genome. It can be detected by breaking the DNA into pieces using restriction enzymes and analyzing the size of the resulting fragments using gel electrophoresis.

\section{$\underline{S T R}-$ Short tandem repeat}

In DNA, this is a type of polymorphism that occurs when a pattern of two or more nucleotides are repeated with the repeated sequences next to each other.

\section{Thermochron I-Buttons}

This is a programmable device that contains a temperature sensor, a real time clock and memory for data storage.

\section{Passive Collection}

This is the collection of volatiles without the use of airflow.

\section{Dynamic/Active Collection}

This is the collection of volatiles with the use of airflow from the STU- $100^{\mathrm{TM}}$. 


\section{Monozygotic Twin}

Monozygotic twins are also known as identical twins and originate from the same fertilized ovum and sperm.

Dizygotic Twin

Dizygotic twins are known as fraternal twins are produced from two eggs separately fertilized by two sperms resulting in the twins not possessing identical DNA. 
VITA

\section{DAVIA HUDSON}

August 25, 1981

$1999-2002$

$2003-2004$

$2005-2008$

$2008-2009$
Born, Clarendon, Jamaica

B.Sc. Chemistry (Honors)

University of the West Indies

Jamaica, West Indies

Laboratory Technologist

Sugar Industry Research Institute

Jamaica, West Indies

Research Assistant

Florida International University

Miami, Florida

Teaching Assistant

Florida International University

Miami, Florida

$2^{\text {nd }}$ Place Graduate Student's Association

Scholarly Forum

Florida International University

Miami, Florida

\section{PUBLICATIONS AND PRESENTATIONS}

Hudson DH, Curran AM, Furton KG. The stability of collected human scent under various environmental conditions. Journal of Forensic Science. In Press, September 2009.

Hudson DH, Curran AM, Schoon GAA, Furton KG. The Effects of Storage Conditions on Human Scent by SPME-GC/MS. Presented at the $58^{\text {th }}$ Annual American Academy of Forensic Science, Seattle, Washington, February 2006.

Hudson DH, Curran AM, Schoon GAA, and Furton KG. Storage Conditions and Human Scent Evidence. Presented at the $4^{\text {th }}$ European Academy of Forensic Science Helsinki, Finland, June 2006.

Hudson DH, Schoon GAA and Furton KG. Biological and Chemical Influences on a Canine's Ability to Differentiate Hand Odor Samples. Presented at $59^{\text {th }}$ Annual American Academy of Forensic Science. San Antonio, Texas, February 2007. 
Hudson DH, Schoon GAA and Furton KG. Variables Affecting Alerts Produced by Human Scent Identification Canines. Presented at the 3rd National Detector Dog Conference, UK LEADS. Scotland, UK, June 2007

Hudson DH, Furton KG. Variables Influencing the Ease with Which Canines Match Hand Odor Samples from Individuals. Presented at the 60th Annual American Academy of Forensic Science, Washington DC. February 2008. 